\title{
Simulation of the global coupled climate/ice sheet system over millennial timescales
}

\author{
by \\ Jeremy Fyke
}

A thesis

submitted to the Victoria University of Wellington

in fulfilment of the

requirements for the degree of

Doctor of Philosophy in Geology.

Victoria University of Wellington

2011 



\section{Abstract}

Ice sheets are important components of the Earth system that are expected to respond strongly to anthropogenic forcing of climate. The aim of this work is to use numerical climate and ice sheet modelling to identify and understand the millennial-scale interaction between the Antarctic and Greenland Ice Sheets (AIS and GIS) and global climate.

An initial modelling effort evaluated the response of ice shelves and ice sheets to future $\mathrm{CO}_{2}$ emission scenarios by quantifying the duration and magnitude of summer melt periods. A temperature threshold based on positive degree days was applied to bias-corrected University of Victoria Earth System Climate Model (UVic ESCM) output spanning 1000 years into the future. The simulations indicated that an increase in summer melting over most of the GIS, the Ross and Ronne-Filchner ice shelves, and large sections of the West Antarctic Ice Sheet (where little present-day ablation occurs) could occur if future emissions are not curtailed.

This initial work highlighted the need to assess the dynamic response of ice sheets to climate change. I therefore developed an ice sheet/climate model comprised of the UVic ESCM and the Pennsylvania State University Ice Sheet Model. Coupling these models required development of new techniques, including subgrid-scale energy balance calculations that incorporate a surface air temperature (SAT) model bias correction procedure. In testing the model, I found that climate model SAT bias, melt water refreezing and albedo variations play an important role in simulated ice sheet evolution, particularly as more of the ice surface experiences melting conditions. The model realistically reproduced the AIS and GIS, and 
captured the surface mass balance (SMB) distributions for both ice sheets well for the present day, including narrow GIS ablation zones.

The newly developed model was used to carry out a suite of experiments designed to assess the behavior of the GIS under elevated- $\mathrm{CO}_{2}$ conditions. A deglacial SMB-based GIS stability threshold was identified between 3-4x preindustrial atmospheric levels (PAL) of $\mathrm{CO}_{2}$. Below the threshold, GIS retreat still occurred but the ice ultimately stabilized in a 'reduced ice sheet' configuration, while at $\mathrm{CO}_{2}>=4 \times \mathrm{PAL} \mathrm{CO}_{2}$, ice retreated to mountain ice caps. Ice sheet inception simulations indicated that above $4 \times \mathrm{PAL} \mathrm{CO}_{2}$, ice growth was limited, while at $4 \times \mathrm{PAL} \mathrm{CO}_{2}$ ice was able to reach the eastern Greenland coastline. Between 2-3x PAL $\mathrm{CO}_{2}$, separate ice caps in the southern and eastern mountains coalesced and exported ice onto the lowland plains. Large-scale ice sheet growth was limited until 1-2x PAL CO 2 . GIS ice loss increased with greater cumulative $\mathrm{CO}_{2}$ emissions in transient simulations. However, the ice sheet was able to briefly overshoot the $\mathrm{CO}_{2}$ stability threshold without experiencing drastic ice retreat due to the long response time of the simulated GIS relative to the rate of deep ocean carbon uptake.

Finally, several model experiments were carried out using the coupled model to examine the impact of ocean melt-driven AIS retreat on the oceanic circulation and structure. This retreat produced freshwater fluxes to the Southern Ocean that were of the same magnitude (and initially greater) than the background continental flux, and continued for 3000 years after the initial shift to high-melt conditions. The Ross and Weddell Seas became productive sea ice export regions, which resulted in higher salinities in these seas and very low ocean temperatures. Enhanced sea ice export and melt in the open Southern Ocean contributed to a slight shallowing and weakening of the North Atlantic Deepwater circulation cell, that would reinforce predicted trends expected as a result of future anthropogenic $\mathrm{CO}_{2}$ emissions. 


\section{Acknowledgments}

I would first like to sincerely thank my wife Sara and son Nico for their endless patience, and acknowledge the excellent and endless technical, logistical, financial, field and moral support provided by my supervisors Lionel Carter, Andrew Mackintosh and Andrew Weaver.

I would also like to thank Michael Eby for being a source of climate modelling and Earth system knowledge; Edward Wiebe for managing the UVic climate lab computer systems; Brian Anderson for introducing me to the Franz Josef and being a generous host at Mikonui; David Pollard for generously hosting me at Penn State University and allowing open access to his model; and my fellow students at both VUW and UVic, with whom I shared many great discussions and good times. 


\section{Contents}

1 Introduction $\quad 1$

1.1 Ice sheets in the climate system ........... 3

1.1.1 Climate modification of ice sheets . . . . . . . . 4

1.1.2 Ice sheet modification of climate . . . . . . . 7

1.1.3 Ice sheet/climate feedbacks . . . . . . . . . . . . 10

1.2 Ice sheets on Earth: a geologic perspective . . . . . . . . . . 14

1.2.1 Archaean and Proterozoic glaciations . . . . . . . . 14

1.2.2 Phanerozoic glaciations ............ 15

1.2.3 Present and future glaciation ........... 23

1.2.4 Outstanding questions in ice sheet-climate research . 24

1.3 Ice sheet-climate modelling . . . . . . . . . . 26

1.3.1 Stand-alone modelling . . . . . . . . . . . 27

1.3.2 Coupled modelling . . . . . . . . . . . . . 29

1.3.3 Outstanding issues in ice sheet-climate modelling . . 32

1.4 Objectives of this thesis . . . . . . . . . . 33 
2 Surface Melting over Ice Shelves and Ice Sheets as Assessed from Modelled Surface Air Temperatures 35

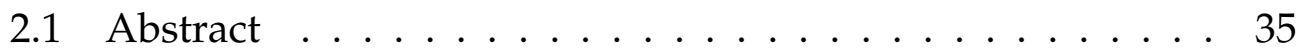

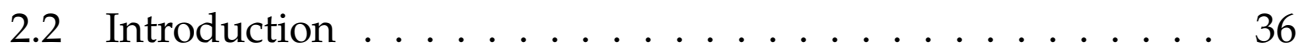

2.3 Model and Methods . . . . . . . . . . . . . . . . . . . 38

2.4 Results . . . . . . . . . . . . . . . . 41

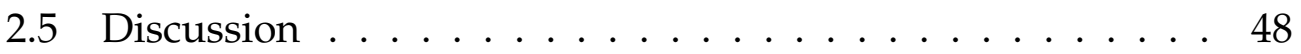

3 A new coupled ice sheet/climate model: description and sensitivity to model physics under Eemian, Last Glacial Maximum, late Holocene and modern climate conditions 51

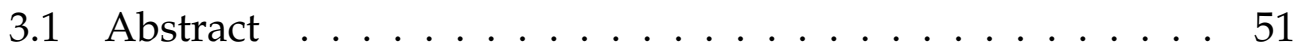

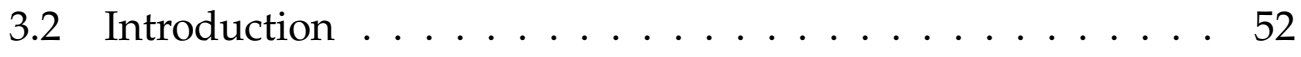

3.3 Model description . . . . . . . . . . . . . . . . . . . 54

$3.3 .1 \quad$ UVic ESCM . . . . . . . . . . . . . . . . . . 54

3.3 .2 PSUI $\ldots \ldots \ldots \ldots \ldots \ldots \ldots \ldots \ldots$

3.3.3 Ice-atmosphere coupling . . . . . . . . . . . 56

3.3 .4 Ice-land coupling . . . . . . . . . . . . . 63

3.3.5 Ice-ocean coupling . . . . . . . . . . . . . . 65

3.3.6 Multiple ice sheet capability, initialization, ice acceleration and I/O . . . . . . . . . . . . . . 67

3.4 Results and discussion $\ldots \ldots \ldots 9$

3.4.1 Control simulations $\ldots \ldots \ldots \ldots \ldots$ 
3.4.2 Ice sheet evolution sensitivity to climate model surface air temperature bias . . . . . . . . . . . 77

3.4.3 Ice sheet evolution sensitivity to meltwater retention and refreezing . . . . . . . . . . . 82

3.4.4 Ice sheet evolution sensitivity to surface albedo . . . 84

3.4.5 Modern transient simulation . . . . . . . . . . 86

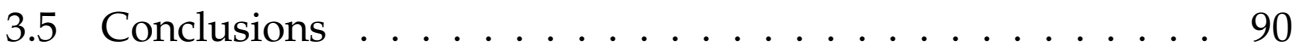

4 Greenland in a high- $\mathrm{CO}_{2}$ world 93

4.1 Introduction $\ldots \ldots \ldots \ldots \ldots \ldots \ldots \ldots$

4.2 Methods . . . . . . . . . . . . . . . . . . 94

4.2 .1 Model Design . . . . . . . . . . . . . . . . . . . 94

4.2.2 Boundary Conditions . . . . . . . . . . 96

4.3 Results and Discussion . . . . . . . . . . . . . . 97

4.3.1 Equilibrium Deglacial Simulations . . . . . . . . . . 97

4.3.2 Transient Deglacial Simulations . . . . . . . . . . . . 100

4.3.3 Inception Simulations . . . . . . . . . . . . . . . 101

4.3 .4 Hysteresis . . . . . . . . . . . . . . . . 102

4.3.5 Discussion and Conclusions . . . . . . . . . . . . . . 103

5 The oceanographic response to Antarctic ice loss: preliminary re$\begin{array}{ll}\text { sults } & 107\end{array}$

5.1 Introduction . . . . . . . . . . . . . . 107

5.2 Methods . . . . . . . . . . . . . . . . 110 
5.3 Preliminary results . . . . . . . . . . . . . . . . 111

5.3.1 Ice sheet response to increased basal melting . . . . . 111

5.3.2 Sea ice and surface ocean response to ice discharge . 112

5.3.3 Deep ocean response to ice discharge . . . . . . . . 113

5.3.4 Ice sheet-climate feedbacks . . . . . . . . . . . . . 115

5.4 Summary . . . . . . . . . . . . . . . . 115

6 Conclusions 125

6.1 Summary . . . . . . . . . . . . . . . . . . 125

6.2 Concluding Perspectives . . . . . . . . . . . . . . . 132

6.3 Proposed future work . . . . . . . . . . . . . . 133

6.3.1 Development and model analysis . . . . . . . . 133

6.3 .2 Science . . . . . . . . . . . . . . . . 136

Appendices

A A simple 1D glacier model 139

B Statement of author contributions 143

C Journal of Climate article: Surface melting over ice shelves and ice sheets as assessed from modelled surface air temperatures

D Geoscientific Model Development article: A new coupled ice sheet/climate model: description and sensitivity to model physics under Eemian, Last Glacial Maximum, late Holocene and modern climate conditions 


\section{Chapter 1}

\section{Introduction}

Ice sheets remain one of the least understood components of the surface Earth, despite their integral role in the evolution of the exogenic Earth system. This thesis describes model-based investigations into the sensitivity of the coupled global ice sheet-climate system to different forcings and perturbations, using a numerical modelling approach.

Glacier ice on the surface of the Earth, ranging in scale from glaciers to globe-spanning ice sheets, has formed an integral component of the climate system for much of the Earth's history. Ice sheets (Molnia, 2007) are of particular importance to global climate. These large ice masses act as capacitors of fresh water, reflectors of incoming solar radiation, and imposers of elevation upon the land surface. Movement of ice sheets controls many erosional and sedimentary processes at mid-to-high latitudes (e.g. Agassiz, 1840). Long term crustal flexure due to ice loading and unloading (Peltier, 2004) generates vertical land surface movements that rival tectonic rates of uplift and subsidence. Variation in the geometry of ice sheets can significantly alter regional climate (Manabe and Broccoli, 1985) and global sea level (Daly, 1910). In the extreme case, runaway ice sheets may even grow to encompass the planet (Budyko, 1969), causing drastic 
changes to environments and their associated biology and biogeochemistry.

Despite their continental scale, ice sheets can be very sensitive to externally forced changes in climate, and have been widely implicated in causing regional and global-scale climate events (e.g. Broecker, 1994). Ice sheet response to climate change is modulated by climate-ice feedbacks, internal ice dynamics, solid earth deformation and basal conditions. The complex interaction of these processes with each other and the external environment can generate a range of mechanisms by which ice sheets can respond in an extremely nonlinear manner and/or chaotically to linear forcings (Oerlemans, 1981; Huybers, 2009) and potentially decouple completely from the climatic state (MacAyeal, 1993).

The ability of large ice sheets to respond dramatically to past climate variations is concerning, given projected anthropogenically driven trends in climate over the coming centuries and millennia. Economically viable emissions of fossil fuel result in atmospheric $\mathrm{CO}_{2}$ concentrations approaching those experienced during the Eocene (Eby et al., 2009; Pagani et al., 2005), a time when the planet was largely free of continental ice sheets. This empirical relation immediately suggests that a return to these $\mathrm{CO}_{2}$ levels could ultimately destabilize the existing Antarctic and Greenland ice sheets and move the Earth system from the dominant glacial-interglacial regime of the last $3 \mathrm{Ma} \mathrm{BP}$ to a reduced-ice state (Berger and Loutre, 2002; Archer and Ganopolski, 2005). This pressing concern, along with a recognized lack of understanding of ice sheet behaviour (Lemke et al., 2007), has driven recent large-scale modelling and observational efforts over both ice sheets, and has also motivated efforts to better constrain past ice sheet behaviour through collection and interpretation of paleoclimatic records.

Numerical climate and ice sheet modelling work presented in this thesis is intended to contribute to these ongoing efforts. Chapter 2 describes 
an initial model-based exploration of the ice sheet-climate system based on surface melting. This discussion is followed by description and initial results of a new coupled ice sheet-climate model (Chapter 3), which explore the impact of elevated $\mathrm{CO}_{2}$ on the simulated Greenland Ice Sheet (GIS, Chapter 4). Chapter 5 presents initial research results into the oceanographic effect of Antarctic ice shelf loss and subsequent ice dynamic response.

The foundation of this thesis is three papers written in a science journal format. Chapters 2, 3 and 4 each consist of discrete scientific manuscripts. As such, each of these chapters contains separate Abstract, Methods, etc... For this reason some repetition of content occurs.

The remainder of Chapter 1 presents a broad overview of the ice sheetclimate system, focused on: 1) the means by which ice sheets and climate interact with each other; 2) the history of ice sheets on Earth and 3) previous and ongoing ice sheet/climate computer modelling efforts. In the context of this thesis, I believe these are important topics to review. A broad understanding of the mechanics of ice sheet-climate behaviour is an essential first step towards modelling the ice sheet-climate system, while exploring the past history of ice sheet behaviour allows potential future behaviour to be placed in context. Finally, a review of previous modelling efforts allows the results presented here to be compared against the spectrum of existing studies.

\subsection{Ice sheets in the climate system}

Ice sheets are unique components of the climate system. Because they can potentially extend to the ocean, they interact simultaneously with all other major components of the climate - atmosphere, hydrosphere and geosphere (Lemke et al., 2007). By virtue of their sheer size, they have the 
ability to alter important aspects of the global climate, while at the same time being fundamentally controlled by climatic changes. As a result of this closely coupled behaviour, the system exhibits feedbacks that enhance or dampen coupled ice sheet-climate evolution. Before exploring these ice sheet-climate feedbacks it is useful to first consider the ways by which climate can modify ice sheets, and vice versa.

\subsubsection{Climate modification of ice sheets}

Ice sheet inception is fundamentally dependent on a climate that allows initial ice growth, epitomized by the consistent presence of an end-of-summer snowpack. To generate end-of-summer snowpack, cumulative annual snowfall plus hoar deposition (together termed "accumulation") must outweigh cumulative annual melt-derived runoff and sublimation (together termed "ablation") (Paterson, 1994). Given enough driving stress, the initial snowfield will begin to deform down gradient, exporting ice to lower elevations. Because temperatures increase with decreasing elevation in the troposphere, exported ice will experience greater ablation. When net ablation fully balances net accumulation, the ice mass is in mass equilibrium. If accumulation continually exceeds ablation, the ice will continue to advance until the sea is reached and dynamic calving of ice closes the net mass budget. In this case, contact with the ocean allows oceanic processes to influence ice volume by under-ice melting and warming the local atmosphere.

Ablation is controlled by the net balance of energy fluxes at the surface (Fanning and Weaver, 1996). Incoming energy fluxes include absorbed downward shortwave, downward longwave and sensible heat fluxes, and the latent heat flux associated with surface hoar deposition. Outgoing energy fluxes include outgoing longwave radiative fluxes, sensible heat fluxes, the latent heat flux associated with sublimation, and 
conductive/advective fluxes of heat into the subsurface. If the ice surface temperature reaches the melting point and excess energy is still available, this energy is utilized to melt ice and close the surface energy budget.

Conditions that directly affect the surface energy balance include surface air temperature, surface relative humidity, windspeed, downward longwave/shortwave radiation fluxes, and factors which affect surface albedo. Changes to these variables can be caused by changes to largescale atmospheric circulation patterns (e.g. Mosley-Thompson et al., 2005) that advect air masses with different temperatures over the ice sheets, and local radiative processes (Oerlemans, 1991) that alter the surface energy balance and potential ablation rate.

The atmosphere is responsible for transporting moisture from source regions to the ice sheet and depositing this moisture in solid form on the ice sheet surface if the air temperature is sufficiently low and relative humidity sufficiently high. The requirement that air temperature be near or below the freezing point for accumulation to occur has a profound influence on ice sheet evolution and stability, because a consistent increase in annual temperature not only generates more melt during the summer, but also decreased precipitation as snow during the shoulder seasons (e.g. Huybers and Tziperman, 2008).

The total amount of accumulation on an ice sheet depends on the proximity of the ice sheet to upwind evaporative moisture sources, the nature of the prevailing winds, the characteristic shape of ice sheets, and atmospheric temperature. Orographic precipitation decreases with distance from the primary moisture source, due to the progressive depletion of moisture in air masses crossing the ice sheet and the blocking effects of characteristic high pressure centers over large ice masses (Section 1.1.2). This pattern is clearly seen over present-day ice sheets (Figure 1.1).

Ocean-ice interaction plays a large role in marine-terminating ice sheet evolution (Rignot et al., 2008). While the ocean can influence ice 


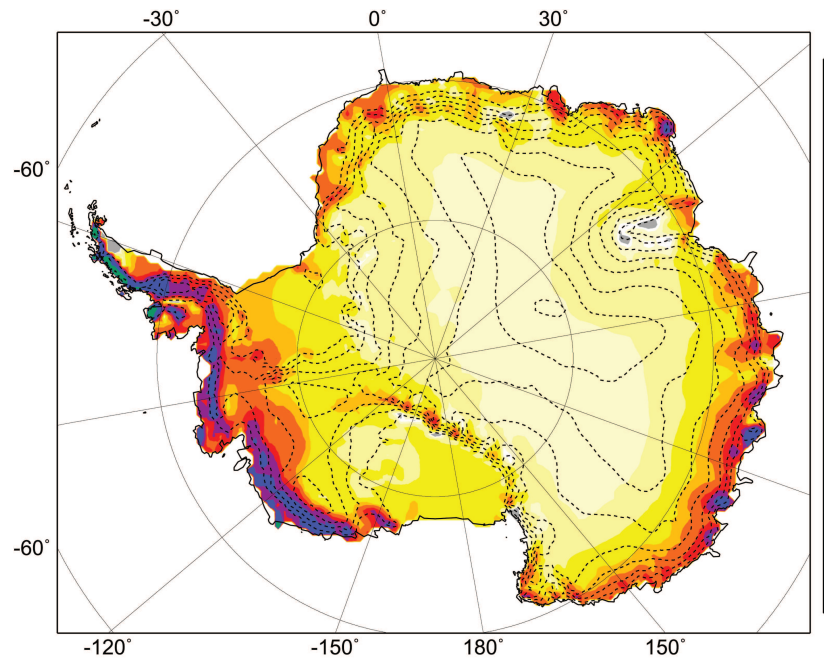

(a) AIS SMB

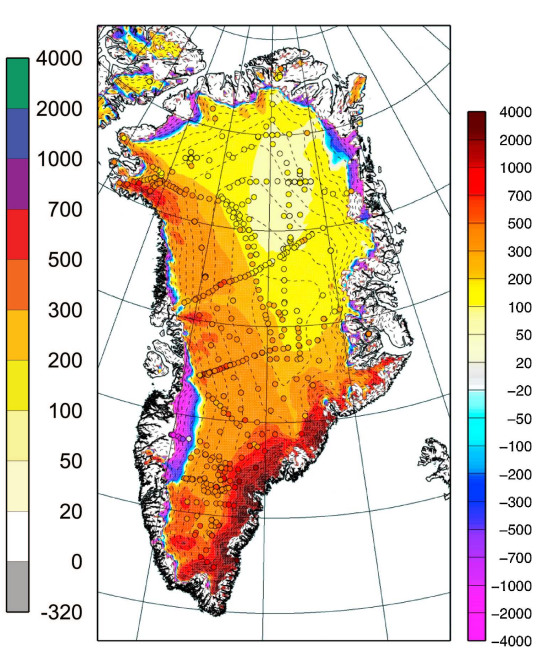

(b) GIS SMB

Figure 1.1: AIS and GIS surface mass balance fields, obtained with regional models (van de Berg et al., 2006; Ettema et al., 2009). Units are mm water equivalent (w.e.) per year.

shelf calving rates directly by providing wave-generated stresses to ice shelves (MacAyeal et al., 2006), over longer timescales the thermal effect of oceans likely plays a greater role in ice sheet evolution. Higher dimensional modelling of ocean circulation within sub-ice-shelf cavities (Holland et al., 2008b) suggests that the shelf-average rate of ice melt is quadratically related to the change in proximal ocean temperature. This high sensitivity is supported by recent observations of high rates of ice loss in conjuction with warm ocean waters (Payne et al., 2004; Holland et al., 2008a; Jenkins et al., 2010), and model simulations of the West Antarctic Ice Sheet (WAIS), which can only match observations of ice retreat if sub-shelf melting is increased (Pollard and DeConto, 2009). 


\subsubsection{Ice sheet modification of climate}

The global climate system, including the geosphere, hydrosphere and atmosphere, fundamentally determines where ice sheets can develop and how large they can grow. However, once established, ice sheets can subsequently exert a significant influence on the climate system through regulation of sea level, generation of large freshwater fluxes, albedo change, and atmospheric circulation steering.

Changes to the volume of ice stored on land have the ability to change eustatic sea level by tens of meters (e.g. Daly, 1910). Global average, icesheet-sourced, sea level change depends on the amount of ice volume lost or gained, global hypsometry/bathymetry, and the initial sea level. This global sea level change signal is overprinted with regional variability resulting from effect of changing ice/water load on the flexure of the Earth surface and the changing geoid (Kendall et al., 2005). Hypsometry and bathymetry also determine the areal extent of land uncovered or flooded during sea level change (Figure 1.2). For example, during glacial periods most continental shelves were exposed to the atmosphere. This likely had important consequences for the terrestrial carbon reservoir (Montenegro et al., 2006), coastal ocean carbon sequestration (Rippeth et al., 2008), sediment delivery to the deep ocean (Carter et al., 2004), and human migration (Mandryk et al., 2001). Another important physical effect of sea level change is the opening and closing of 'marginal' ocean gateways. A contemporary example is the Bering Strait, which has alternately allowed and prohibited fresh Pacific water from entering the Arctic Ocean as a function of rising and falling sea level, with consequences for the Arctic and North Atlantic oceanography (Hu et al., 2010).

In certain climate states the global thermohaline circulation system is prone to large-scale reorganization when a large surface freshwater flux is applied to high northern or southern latitudes which are important production factories of deep and bottom waters (e.g. Weaver et al., 2003; 


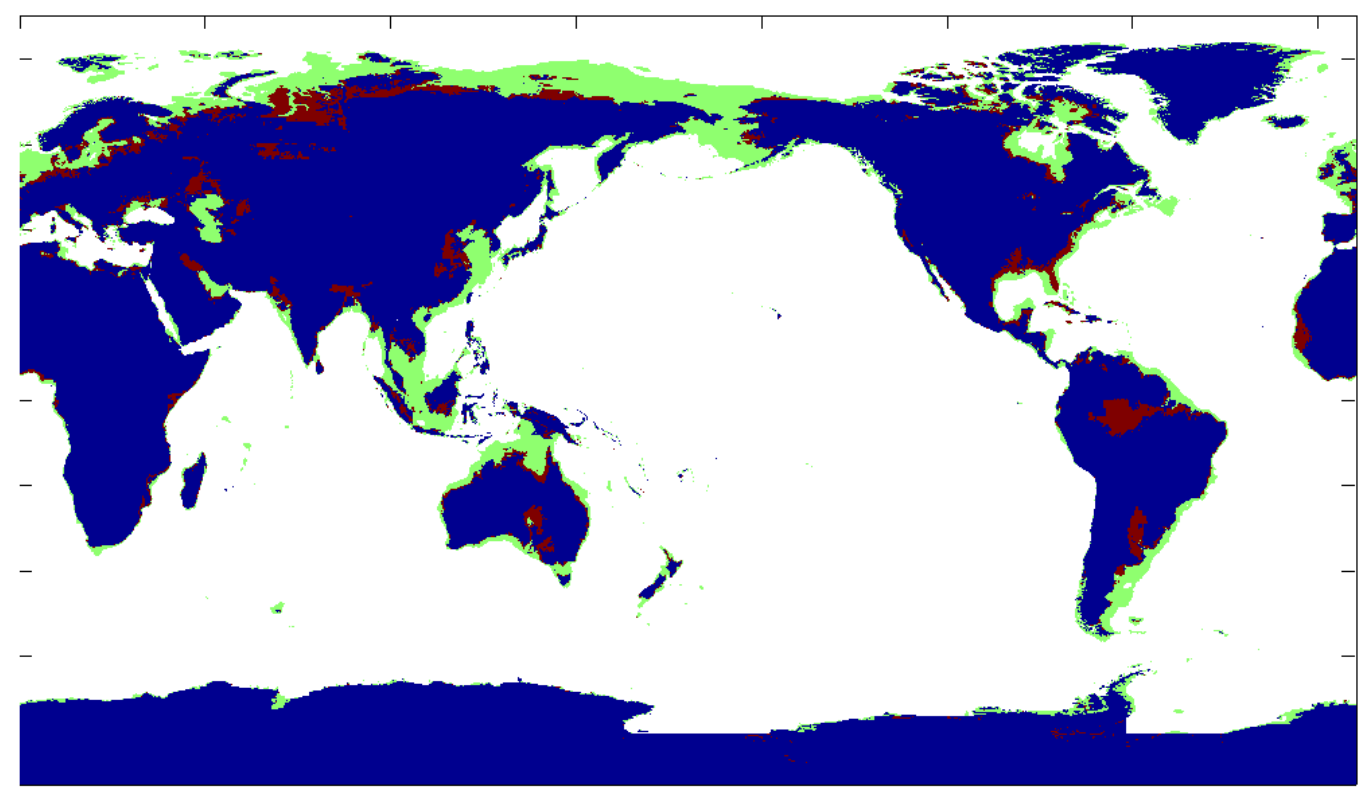

Figure 1.2: Global map of areal flooding or exposure caused by sea level change, relative to the present-day. Blue: present-day continents; green: approximate sea level during the Last Glacial Ma BPximum; red: approximate sea level if both the AIS and GIS were to melt completely. Data: ETOPO5 bathymetric/topographic dataset. Note the poor representation of Antarctic ice sheets and ice-free Antarctic topography/bathymetry in this dataset (NOAA, 1988).

Saenko et al., 2007). In ocean models, fluxes of ice sheet-derived fresh water cause increased water column stratification, which weakens deepwater formation and in turn drives hemispheric-scale changes to ocean circulation and global heat and freshwater transport patterns (Figure 1.3). Large fluxes of freshwater can potentially be sourced from ice sheets in a number of ways. Internal ice dynamics and basal conditions associated with grounded ice sheets can generate periodic episodes of ice discharge (MacAyeal, 1993), while the marine ice sheet instability mechanism (Section 1.1.3) (Weertman, 1974; Mercer, 1978) is another means by which ice sheets can generate large iceberg fluxes. Lastly, catastrophic release of 
glacially dammed lakes during deglaciations also produce large fluxes, for example periodic floods from Lake Agassiz, a massive freshwater body dammed by the Laurentide Ice Sheet (LIS) (Teller et al., 2002).
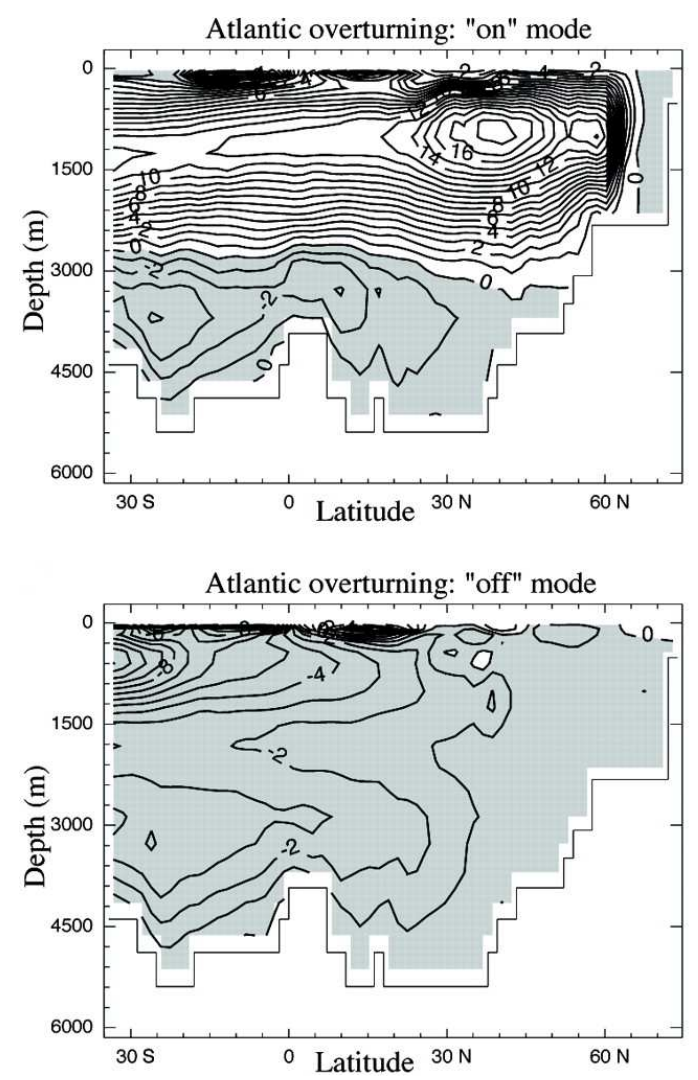

Figure 1.3: Difference in the North Atlantic overturning stream function when a freshwater flux equivalent to $22 \mathrm{~m}$ of sea level rise over 500 years is applied to the University of Victoria Earth System Climate Model (UVic ESCM) in North Atlantic Deep Water (NADW)-off mode, meant to simulate an Antarctic MWP1A source (Weaver et al., 2003).

Ice sheets are capable of altering large-scale atmospheric flow through both topographic and energy balance processes. The high elevation of ice sheets creates an effective mechanical barrier to flow patterns and can significantly alter atmospheric circulation (Scorer, 1988; Bromwich et al., 
2004). Additionally, persistent near-surface temperature inversions over ice sheets caused by radiant heat transfer from ice to atmosphere generate downslope density driven flows which can be locally topographically steered, forming katabatic winds. Due to Coriolis forcing the large-scale divergent wind pattern is deflected and form large-scale anticyclonic circulation cells around ice sheets, which in turn promotes downwelling of upper level air in the ice sheet interior. The resulting high pressure pattern over ice sheets and the near-surface pattern of anticyclonic flow is clearly displayed by the polar easterlies around the Greenland and Antarctic ice sheets, and in simulations of the Laurentide Ice Sheet (LIS) during the LGM (Guo et al., 2003; Cassano et al., 2001; Bromwich et al., 2004), and plays a large role in determining surrounding oceanic and atmospheric conditions.

\subsubsection{Ice sheet/climate feedbacks}

A critical aspect of the interaction between ice sheets and the surrounding climate is the presence of strong feedback loops that modify initial externally forced perturbations to ice sheet volume. Feedbacks are processes that amplify or dampen initial perturbations to ice volume, and can be quantified by:

$$
g=V_{f b} / V_{n f b}
$$

where $V_{f b}$ is the final (equilibrium) change in ice volume with the feedback operating, $V_{n f b}$ is the change in ice volume without the feedback process, and $g$ is the gain factor. If $g$ is greater than 1 , the feedback is positive (i.e. an initial perturbation to ice volume is enhanced by the feedback), while a value of less than 1 implies a dampening effect. Observation-based quantification of feedback factors related to ice sheet volume is difficult, so the task of defining $g$ typically falls to models, which can arbitrarily 'turn off' feedback mechanisms and thereby isolate individual feedback effects (e.g. 
Kageyama et al., 2004). Important feedbacks within the ice-climate system that are discussed below include the elevation-mass balance, ice albedo, and 'marine ice sheet instability' feedbacks. Each of these processes depend on particular geometrical or climatic conditions, without which $g$ reverts to 1 . Under the right conditions, these feedbacks can generate potentially nonlinear, path dependent ice sheet changes in response to small climate forcings.

A strong positive feedback on ice growth/loss occurs in response to ice sheet elevation change (Figure 1.4). As the average ice sheet elevation increases, the ice area above the equilibrium line altitude increases, simultaneously decreasing ablation (if the total ice area remains constant) and increasing accumulation. As a result, the net surface mass balance increases, enhancing initial growth. This feedback can generate strong hysteresis behaviour (Oerlemans, 1981; Pollard and DeConto, 2005) and is bi-directional; the effect enhances ice retreat as well as ice growth. Given typical ice sheet thicknesses and atmospheric lapse rates, this feedback has the ability to change near-surface air temperature by as much as $10-15^{\circ} \mathrm{C}$ in the most extreme ice loss scenarios. Importantly, this feedback only works if a significant ablation zone exists.

Another positive ice sheet-climate feedback occurs when reflective ice expands to cover darker bare land or ocean. The resulting drop in absorbed shortwave radiation decreases the temperature of the surface and subsequently the regional atmospheric temperature (a result of the StefanBoltzmann Law that relates blackbody temperature to emitted radiation). The presence of this feedback depends on new ice coverage of previously bare land: this can occur either through dynamic ice expansion or in-situ ice accumulation. In the former case the feedback does not rely on the local energy balance while in the latter case in-situ ice growth implies cold surface temperatures. A strong seasonal ice-albedo feedback can also occur over the ice sheet interior when reflective snow is removed, exposing darker glacial ice and any dust or debris at the ice surface (Konzle- 


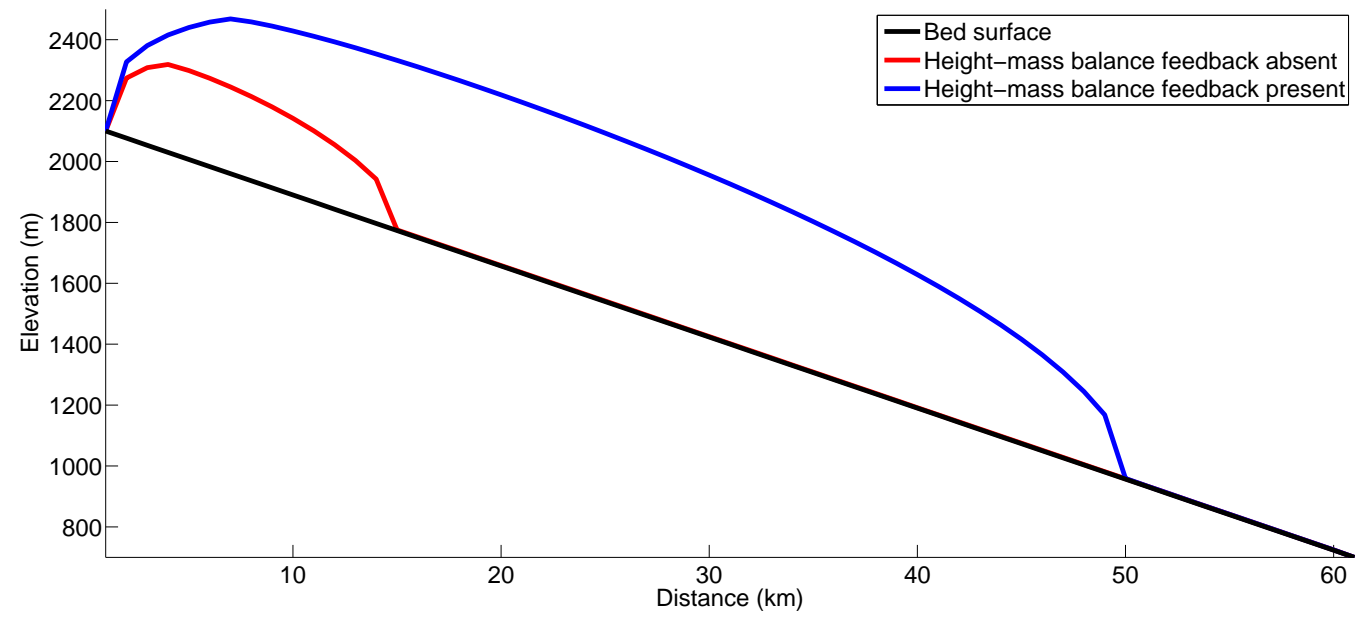

Figure 1.4: Simple positive degree day (PDD)-driven glacier flow model (Appendix A) demonstration of the elevation-mass balance feedback. In these simulations, a simple 1D glacier is grown over an initially ice-free surface. Boundary surface mass balance conditions are determined by a sea level temperature of $10^{\circ} \mathrm{C}$, a lapse rate of $6^{\circ} \mathrm{C} / \mathrm{km}$, and an annual snow accumulation of $3 \mathrm{~m} / \mathrm{yr}$. The red and blue lines show the equilibrium position of simulations without/with elevation-mass balance feedback, respectively. In the red simulation, the PDD model only sees the elevated bed elevation (black line), regardless of the overlying ice thickness. The PDD in the blue simulation is allowed to 'sense' the effect of ice sheet thickness on surface temperature. Given these final ice 'volumes', $g$ could be easily calculated using Equation 1.1. 
mann and Braithwaite, 1995). In this case, the ice-albedo feedback depends on the presence/absence of melting conditions. More generally, the ice-albedo feedback depends on the presence of incoming shortwave radiation, which is entirely lacking during polar winters.

Ice shelves are floating portions of ice sheets that are in contact with both the atmosphere and ocean, and as such are sensitive to changes in both components of the climate system. While the strong link between ocean temperatures and ice shelf melting clearly plays an important role in marine-terminating ice sheet evolution, the difficulty of explicitly modelling and/or observing sub-ice-shelf environments has limited understanding of feedbacks that operate there. It might be expected that the extraction of heat from ocean water would generally act to cool the surrounding ocean and inhibit ice shelf melt; this would represent a negative feedback. However, complex density driven under-shelf flow patterns may negate this effect, and in any case, local flow is strongly dependent on local oceanographic and bathymetric conditions. In general, the role of feedbacks in ice-ocean interaction remains an important area of research.

An additional ice shelf positive feedback mechanism occurs because of the near frictionless interface between liquid ocean water and basal ice. Significant surface melt water penetration into crevasses existing in floating ice is capable of dynamically fracturing pre-weakened ice shelves via hydrostatic pressure, resulting in sudden ice shelf disintegration after successive high melt years (Scambos et al., 2009).

Marine based ice sheets have the potential to display nonlinear behaviour (Weertman, 1974; Mercer, 1978) due to the proposed dependence of ice velocity at the grounding line on ice thickness (Schoof, 2007). Because of this dependence, the slope of the bed inland from the grounding-line plays an important role in regulating ice discharge into the ocean. If the bed slopes upward away from the grounding line, an initial grounding-line retreat will quickly self-stabilize. However, if the 
bed deepens inland of the grounding line, an initial grounding line retreat will generate a thicker ice column at the grounding line, and a correspondingly increased ice velocity there. The resulting flux anomaly will draw down the ice surface, thinning the ice near the grounding line and driving further retreat. This process is a powerful means for initial grounding-line perturbations driven by changes in sea level or sub-ice-shelf melting to drive large-scale ice sheet retreat.

\subsection{Ice sheets on Earth: a geologic perspective}

In order to put potential future trends in ice sheet evolution into perspective, it is instructive to first explore records of ice sheets from the last $\sim 3$ Ma BP Pliocene-Pleistocene glacial/interglacial cycles, as well as ice sheet behavior from much earlier periods in Earth's history. Studies of the past $\sim 3$ Ma BP provide insight into the natural behaviour of ice sheets in a climate and tectonic configuration similar to the present-day, while the distribution of land ice in drastically different climatic regimes of the past may shed light on future changes to the glacial inventory of the planet under anthropogenic forcing. Study of past ice sheet-climate interactions also highlights the profound role ice sheets play in the global Earth system, both as regulators and bellwethers of fundamental trends in climate. Below I summarize important global glaciation events, from deep time to present.

\subsubsection{Archaean and Proterozoic glaciations}

Tentative records of glaciation from the Archaean Eon (3500-2800 Ma BP) are scarce and controversial, and based on the relative dominance of nonglacial Archaean deposits, it is generally assumed that this period had 
little or no large-scale glaciation (Eyles, 1993). This conclusion is difficult to reconcile with solar models, which suggest that the early Sun was up to $40 \%$ less luminous than the present-day. To explain this discrepancy, the planet would presumably have required substantially higher greenhouse gas concentrations (particularly $\mathrm{CH}_{4}$ in the absence of significant $\mathrm{O}_{2}$ ) and / or a decrease in global albedo. However, to date a robust observation-backed explanation of the 'faint-sun paradox' remains elusive (Kasting, 2010).

The Proterozoic Era (2500-542 Ma BP) was the first period in the geologic record to host unambiguous evidence of large-scale glaciation. Glacial conditions during the Paleoproterozoic Huronian glacial period appears to coincide with increased atmospheric oxygen concentrations (implying oxidation of $\mathrm{CH}_{4}$ ), continental rifting, and weathering-induced drawdown of atmospheric $\mathrm{CO}_{2}$ (Eyles, 1993). Neoproterozoic glacial deposits formed between 750 and 580 Ma BP exist on all continents and are clustered into two glacial periods, the Sturtian and Marinoan. The inferred low paleolatitude and paleoaltitude of many glacial deposits from these periods, along with the presence of large carbon isotopic excursions and associated massive carbonate deposits, have driven speculation that Earth was at times completely encased in ice (Hoffman et al., 1998; Fairchild and Kennedy, 2007). Several model studies have explored the causes and implications of such a global glaciation (e.g. Hyde et al., 2000; Lewis et al., 2003; Pierrehumbert, 2005) and have highlighted the importance of orbital configurations, paleogeography, ocean dynamics, albedo, and low greenhouse gas levels in instigating global icehouses.

\subsubsection{Phanerozoic glaciations}

The Phanerozoic Eon (540 Ma BP-present) has been marked by four general episodes of glaciation during the Ordovician-Silurian, Carboniferous- 
Permian, Jurassic-Cretaceous, and Eocene-Holocene Periods, with each episode of glaciation generally corresponding to estimated $\mathrm{CO}_{2}$ concentrations of less than 1000 ppmv (Vaughan, 2007). The fourth Phanerozoic glacial episode marks the last $\sim 55$ million years of Earth's history and encompasses the majority of the Cenozoic Era. Improved preservation of sedimentary, tectonic, and isotopic records have allowed better identification of global controls on this glacial period. In addition, the relative similarity between present-day and earlier Cenozoic climatic boundary conditions (compared to earlier Phanerozoic glacial periods) suggests that the Cenozoic provides the best analogies for future climate states. For these reasons, I focus exclusively on the history of Cenozoic glaciations.

\section{Cenozoic Antarctic glaciations}

Available paleorecords indicate transient glaciations began in Antarctica after $\sim 42 \mathrm{Ma} \mathrm{BP}$, with large shifts in the benthic oxygen isotope signal record at least three distinct episodes of near-complete East Antarctic Ice Sheet (EAIS) growth and subsequent loss between 42 and 34 Ma BP (Tripati et al., 2005). One of these isotopic excursions, at $36 \mathrm{Ma} \mathrm{BP}$, is also clearly reflected by a $\sim 100 \mathrm{kyr}$ period of ice rafted debris (IRD) deposition over Kerguelen Plateau in the Southern Ocean (Zachos et al., 1992) and by far-field geological evidence of a transient $\sim 40 \mathrm{~m}$ drop in sea level (Peters et al., 2010). These large-scale transient glaciations were followed by an abrupt increase in ice volume at $34 \mathrm{Ma}$ BP Eocene-Oligocene (EO) boundary (Zachos et al., 2001) that marked the clear transition to near-permanent East Antarctic ice coverage and was accompanied by a large, rapid and permanent drop in atmospheric $\mathrm{CO}_{2}$ (Figure 1.5) (Pagani et al., 2005; DeConto, 2010). Paleo-topography imaged during radar surveys of the Gamburtsev Mountains, under the central EAIS, suggest that the penultimate $34 \mathrm{Ma}$ BP transition to full ice coverage there was rapid and permanent (Bo et al., 2009). Numerical modelling (DeConto and Pollard, 2003; Pol- 
lard and DeConto, 2005) qualitatively recreated the multi-stage behaviour of Antarctic glaciation by forcing a coupled terrestrial ice sheet/climate model with slowly decreasing $\mathrm{CO}_{2}$ and synthetic orbital variations; this behaviour can also be reproduced in a much simpler 1D model (Figure 1.6).

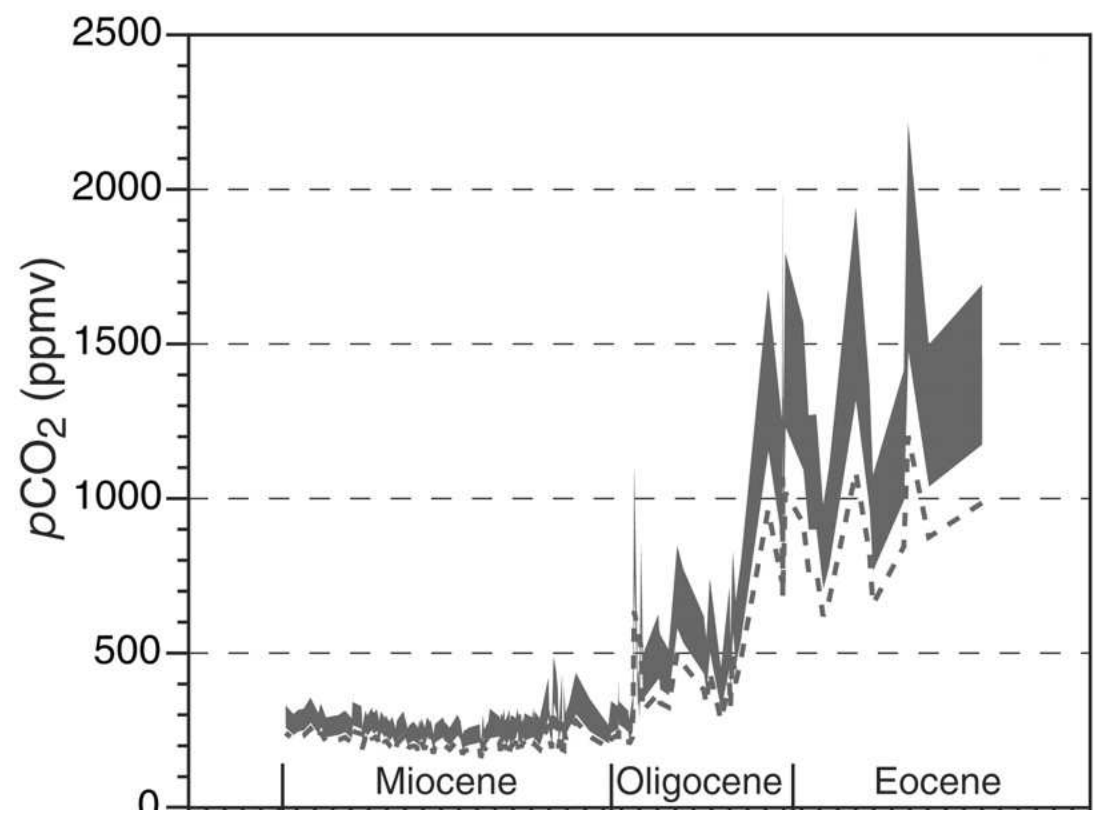

Figure 1.5: Timeseries of Paleogene-Neogene $\mathrm{CO}_{2}$ reconstructed from alkenones derived from deep-sea sediments (Pagani et al., 2005)

In addition to a large $\mathrm{CO}_{2}$ decrease, the $\mathrm{EO}$ transition was bracketed by gradual deepening of the Drake and Tasman passages (Kennett, 1977; Scher and Martin, 2006). The weak dependence of modelled AIS surface mass balance on simulated Drake Passage opening in the study of Pollard and DeConto (2003) is surprising; deepening of this gateway and the Tasman gateway is thought to have greatly reduced meridional heat transfer to high southern latitudes through reorganization of global ocean circulation (Toggweiler and Samuels, 1995; Sijp and England, 2004). However, even if the direct surface effect of Drake/Tasman Passage deepenings 


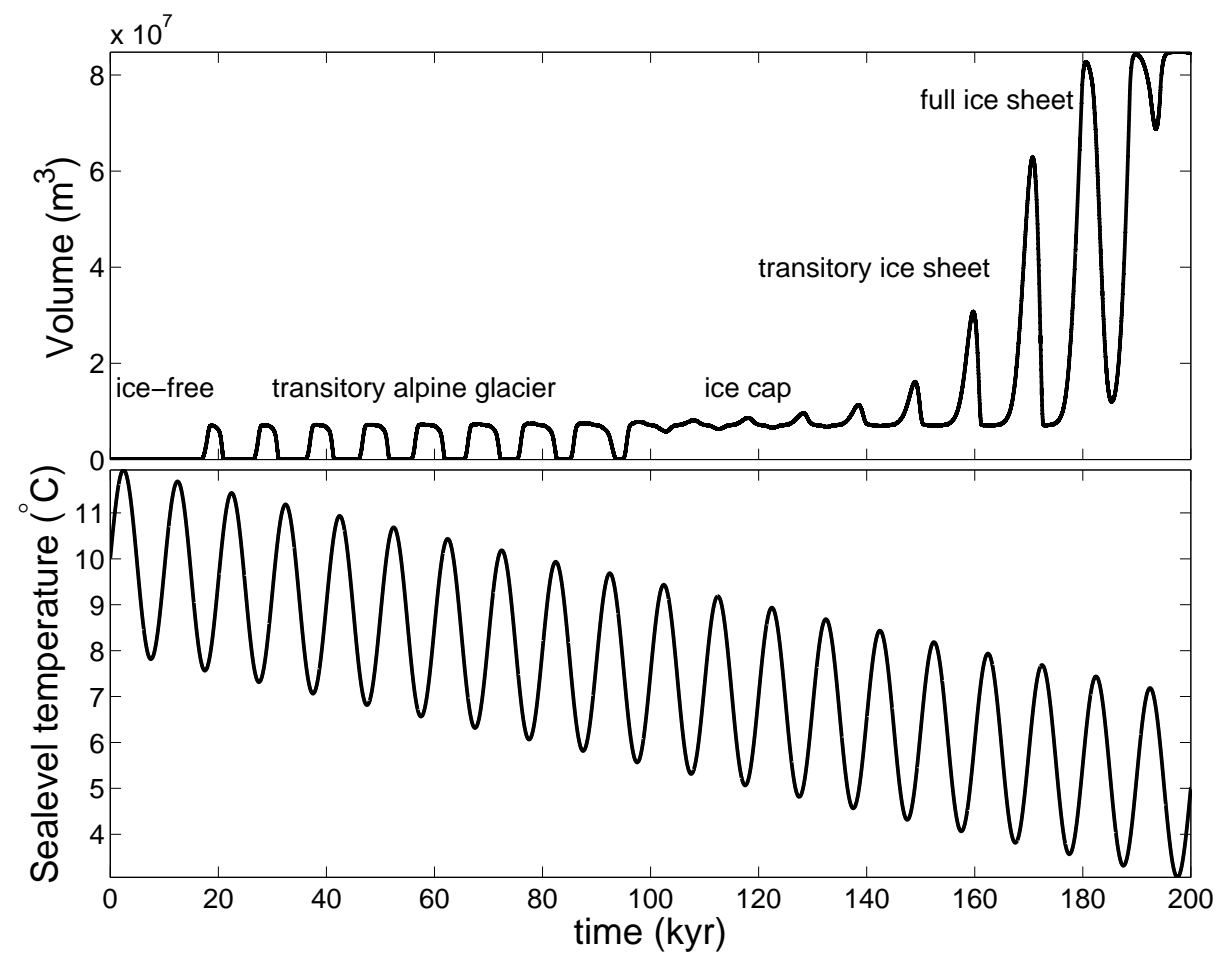

Figure 1.6: Simple 1D ice flow-positive degree day model (Appendix A) forced by a Milankovitch-like sinusoidal $2^{\circ} \mathrm{C}$ forcing superimposed on a $5^{\circ} \mathrm{C}$ decrease in ambient temperature over $200 \mathrm{ka}$. Note the stepwise transitions through glacial regimes, and temporary ice sheet coverage prior to permanent ice sheet establishment. The specific model response to the forcing signal relies in part on the presence of a small elevated plateau (i.e. the Gamburtsev or Transantarctic Mountains) in the model domain. Given the 1D nature of the model, the simulated ice volume (y-axis) is not meant to quantitatively capture realistic ice volumes and is in fact a measure of ice cross-sectional area (or alternatively, unit volume). 
were small, they may have played a critical, indirect role in Antarctic Ice Sheet (AIS) inception via the global carbon cycle. Observations indicate a stepwise decrease of the calcite compensation depth (CCD) across the EO boundary (Tripati et al., 2005) and Scher and Martin (2006) speculated that this decrease reflects a large-scale redistribution of global carbon reservoirs, including a drawdown of atmospheric $\mathrm{CO}_{2}$, driven by inception of the full Antarctic Circumpolar Current and associated meridional overturning cells (Toggweiler and Samuels, 1995; Kennett and Exon, 2004).

Following initial East Antarctic glaciation partial retreat occurred, culminating in the Mid-Miocene Climatic Optimum at 17 Ma BP (Zachos et al., 2001) that Lagabrielle et al. (2009) associated with a temporary shoaling of Drake Passage and increased North Atlantic volcanism. By $10 \mathrm{Ma}$ $\mathrm{BP}$, the EAIS was again completely glaciated, and widespread erosion in the deep ocean, consistent with invigoration of the supply of deep and bottom water and climatic forcing of the Antarctic Circumpolar Current was established. By $\sim 6$ Ma BP periodic growth of the WAIS had begun. Early Pliocene sedimentary records indicate that the early WAIS was highly variable (Naish et al., 2009), with prolonged periods of open ocean in the Ross Sea despite global average temperatures of only $3-4^{\circ} \mathrm{C}$ warmer than present and $\mathrm{CO}_{2}$ levels of 400 ppmv (Pagani et al., 2010). From 3.3 to 2.5 Ma BP Antarctic climate began to cool and the presence of the WAIS became more common, resulting in total Antarctic ice sheet volume oscillations that typically varied between present-day volumes, and larger volumes associated with modern glacial maxima. AIS volumes between 5-1.3 Ma BP cycled with a 40 kyr periodicity. Between 1.3-0.8 Ma BP the cyclicity drifted to $\sim 100 \mathrm{kyr}$ periods, and this period has remained dominant since then. Modelling of Pliocene-Pleistocene Antarctic evolution (Pollard and DeConto, 2009) highlighted the importance of ocean temperatures in shifting from a modern day to collapsed WAIS state, and the combined effect of ocean temperatures and sea level in moving from a modern to glacial maximum state. This indicates that orbital variations effectively regulated 
Southern Ocean temperature and/or eustatic sea level changes, which in turn regulated WAIS ice volume.

\section{Cenozoic Northern Hemisphere glaciations}

While there is broad agreement that Northern Hemisphere continental glaciations lagged Southern Hemisphere ice growth, several lines of evidence point to the existence of sizeable ice volumes in Greenland at the same time that the early EAIS was forming. Eldrett et al. (2007) reported the presence of East Greenland-sourced glacial dropstones in 38-30 Ma BP Eocene-Oligocene sediments at Ocean Drilling Project Site 913, while Tripati et al. (2008) presented evidence of glacier-sourced IRD from 44$30 \mathrm{Ma} \mathrm{BP}$ at the same location. A single, in-situ $1 \mathrm{~cm}$ gneissic dropstone (Moran et al., 2006) in 45 Ma BP sediments on the Lomonosov Ridge suggests that land ice was calving into the Arctic Ocean during the Eocene. In support these early indications of Greenland ice at sea level, Tripati et al. (2005) indicated that a large oxygen isotope excursion at 42 Ma BP could only be accommodated by significant Northern Hemisphere ice growth. It is noteworthy that all evidence of ice at sea level prior to $34 \mathrm{Ma}$ BP implies (at least) regional ice caps in Greenland under 500-1500 ppmv $\mathrm{CO}_{2}$ (Pagani et al., 2005).

At $16 \mathrm{Ma} \mathrm{BP}$, after $28 \mathrm{Ma} \mathrm{BP}$ of poor sedimentary preservation, records of IRD resumed, with increased ice discharge evident at $14 \mathrm{Ma}$ BP and 3.2 Ma BP (Alley et al., 2010) indicating a shift to persistent ice sheet conditions over Greenland by 3.2 Ma BP. Direct records of the last million years of Greenland history indicate that the ice sheet retreated significantly during interglacials. Of particular relevance is Marine Isotope Stage 11 (MIS 11, 428 to $397 \mathrm{kyr} \mathrm{BP}$ ), during which orbital geometry was similar to the present-day MIS 1 (Berger and Loutre, 1991). MIS 11 sea level records indicate that MIS 11 sea level was higher than present, and GIS ice volume was much reduced (Alley et al., 2010). Given that MIS $11 \mathrm{CO}_{2}$ con- 
centrations derived from Antarctic ice cores were equal or less than late Holocene preindustrial values (Lüthi et al., 2008), this appears difficult to reconcile with the apparent relative stability of the GIS in the Holocene climate, let alone evidence of Greenland ice during the high $\mathrm{CO}_{2}$ Oligocene. MIS 5e ( $130 \mathrm{kyr} B P$, the Eemian) is another period characterized by GIS retreat, evinced by basal ice of MIS 5e age obtained in ice cores around the southern, northwest, and east Greenland. However, in this case, preMIS 5e ice, obtained in central Greenland ice cores, clearly indicates only partial ice loss (Willerslev et al., 2007).

The largest changes to the global cyrosphere since the inception of Antarctica involved the periodic Quaternary growth and decay of large Northern Hemisphere continental ice sheets, with the signature of these glaciations reflected in the marked variability in deep sea oxygen isotope record from the Pliocene onwards (Figure 1.7) (Lisiecki and Raymo, 2005). The continental Northern Hemisphere ice sheets differed from the the present-day Greenland and Antarctic ice masses in that they were not bounded on all sides by water, and could advance until the development of extremely large ablation zones provided enough melt to counterbalance accumulation (Thompson and Pollard, 1997). The presence of large ablation-defined boundaries meant that the equilibrium ice sheet volumes were highly susceptible to small changes in temperature. Partly for this reason, the ice sheets at equilibrium were extremely sensitive to climate, and gradual buildups were typically terminated by abrupt, rapid loss of ice (Clark et al., 2009).

Northern Hemisphere ice volume oscillations followed a primary 41 kyr obliquity periodicity from $\sim 3-0.8 \mathrm{Ma} B \mathrm{BP}$ then switched to $100 \mathrm{kyr}$ from 0.8-0 Ma BP (Figure 1.7). Huybers and Tziperman (2008) used a seasonally enabled energy balance coupled to an ice sheet model to recreate the observed $41 \mathrm{kyr}$ obliquity glacial cyclicity, and concluded that integrated summer energy available for melt was the primary regulator of Northern Hemisphere continental glaciation. The mechanism that shifted 


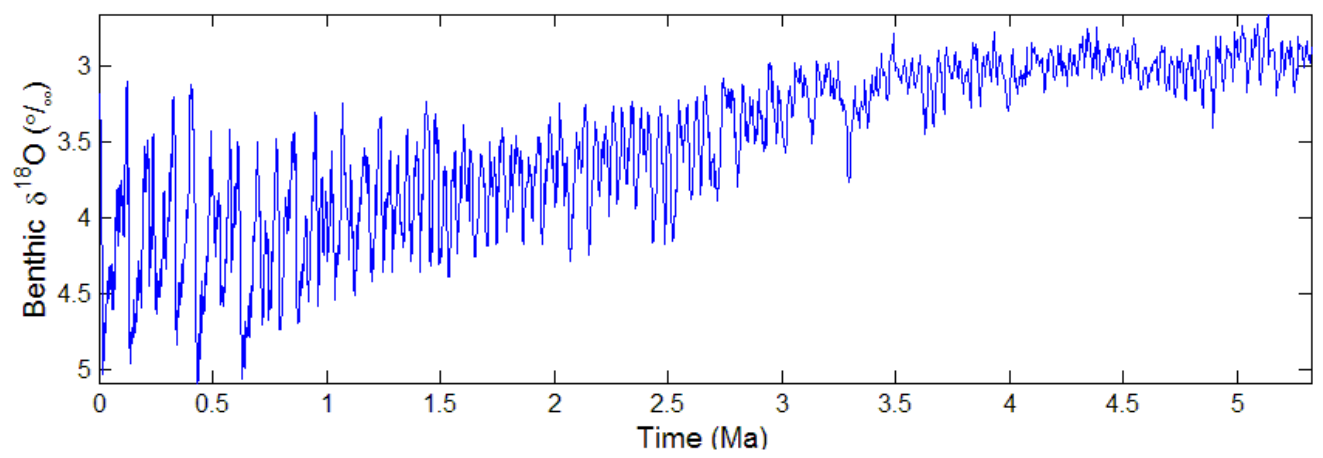

Figure 1.7: A $\sim 5$ Ma BP composite benthic oxygen isotope stack, from Lisiecki and Raymo (2005).

glacial periodicity to $100 \mathrm{kyr}$ - the Mid-Pleistocene Transition - has been a long standing scientific mystery, particularly given a lack variation to orbital parameters at these time scales. It has been tentatively associated with, among other things, a threshold response to long term decline in $\mathrm{CO}_{2}$ and/or scouring of Northern Hemisphere regolith (Clark et al., 1999). However, using a simple model that leveraged the observed lagged relationship between the ice volume rate of change and ice volume, Huybers (2009) managed to recreate chaotic transitions between 40-100 kyr periodicities, including random sequences that reproduced observed 3-0 Ma BP Northern Hemisphere glacial variability well. Huybers (2009) suggested that bed mechanics and internal ice dynamics could be responsible for the lag between volume and rate of change of volume; these processes have also been implicated by others (e.g. MacAyeal, 1993) in causing causing millennial frequency surges of ice, which deposited ubiquitous IRD layers in the North Atlantic (Heinrich, 1988). Clearly, the complex role of internal ice dynamics in continental Northern Hemisphere glaciations was large. 


\subsubsection{Present and future glaciation}

"The climate of the Holocene is not well-suited to be the baseline climate of the planet." Hay et al. (1997)

The Holocene (12 kyr-present-day) represents the latest warm interglacial phase of the Quaternary, and is the period in which modern humans developed. It also represents the starting point from which future climate change will proceed. Given the broad review of glaciation on the planet in Sections 1.2.1-1.2.2, it is possible to place the present global inventory of land ice and future changes to this inventory in the context of past glacial states.

Prior to human additions to the atmospheric $\mathrm{CO}_{2}$ burden, Holocene $\mathrm{CO}_{2}$ concentrations were near their maximum glacial-interglacial values ( 280 ppmv). Under this radiative forcing and near-modern orbital parameters, the AIS (including the WAIS) and the GIS persisted for $10 \mathrm{kyr}$. Greenland appears to have fully stabilized during this time, while Antarctica is likely still undergoing residual adjustment to deglaciation (Huybrechts and de Wolde, 1999). Notably, a significant fraction of ice loss for both ice sheets during the Holocene was through calving. This suggests that both preindustrial ice sheets were not in imminent danger of crossing surface melt-derived thresholds on ice sheet stability.

Within the previous two centuries, atmospheric $\mathrm{CO}_{2}$ concentrations have risen by approximately 100 ppmv to 390 ppmv due to human emissions and land use change. This represents an increase of $40 \%$ over Holocene levels, a $110 \%$ increase from LGM levels, and a multifold increase in the rate of change of $\mathrm{CO}_{2}$ concentrations, compared to the maximum rate recorded in ice cores over the last 0.2 Ma BP (Petit et al., 1999) (Figure 1.8). Projected future $\mathrm{CO}_{2}$ concentrations are highly dependent on the emission pathway taken by future society (Meehl et al., 2007); plausible cumulative emissions of the presently economically 
available coal, oil, and gas result in $\mathrm{CO}_{2}$ concentrations of over 2000 ppmv (Rogner, 1997; Eby et al., 2009). Warming associated with these $\mathrm{CO}_{2}$ concentrations will occur on top of an already-warm natural state, so it is clear that that stadials associated with Pliocene-Pliestocene glacial cycles will not provide an accurate analog for future trends (Hay et al., 1997; Archer and Ganopolski, 2005). Imminent future warming may have analogs in recent MIS 5e, MIS 11, and/or MIS 31. These climates were characterized by a diminished GIS, and periodic WAIS retreat. Longer-term warming may be reflective of early Oligocene conditions, when Greenland ice was limited to high elevation regions and the WAIS was largely absent. Yet more warming would require a late Eocene analog, with permanent WAIS loss and a highly dynamic EAIS. Extreme warming would return the climate to a near ice free Paleocene-Eocene Thermal Maximum (PETM)-like state, during which glaciation was absent or limited to high elevation Antarctic plateaux. Which climate to use as an analogy for the future is highly dependent on the magnitude of anthropogenic forcing (which is predicted to increasingly dominate the integrated climate forcing signal (Meehl et al., 2007)) and the contemporary ice sheet-climate response.

The presence of bifurcations in the global climate-ice sheet system (Oerlemans, 1981; North et al., 1981; Crowley and Hyde, 2008) suggests that future changes to the global ice inventory may be nonlinear and occur suddenly as climatic thresholds are crossed. Such thresholds are presumably important parameters of the Earth System to constrain, if society wishes to develop plans to avoid large, difficult-to-reverse climatic changes.

\subsubsection{Outstanding questions in ice sheet-climate research}

While the existing knowledge of ice sheet-climate interactions, gained from both observational and modelling studies, is substantial, a large 


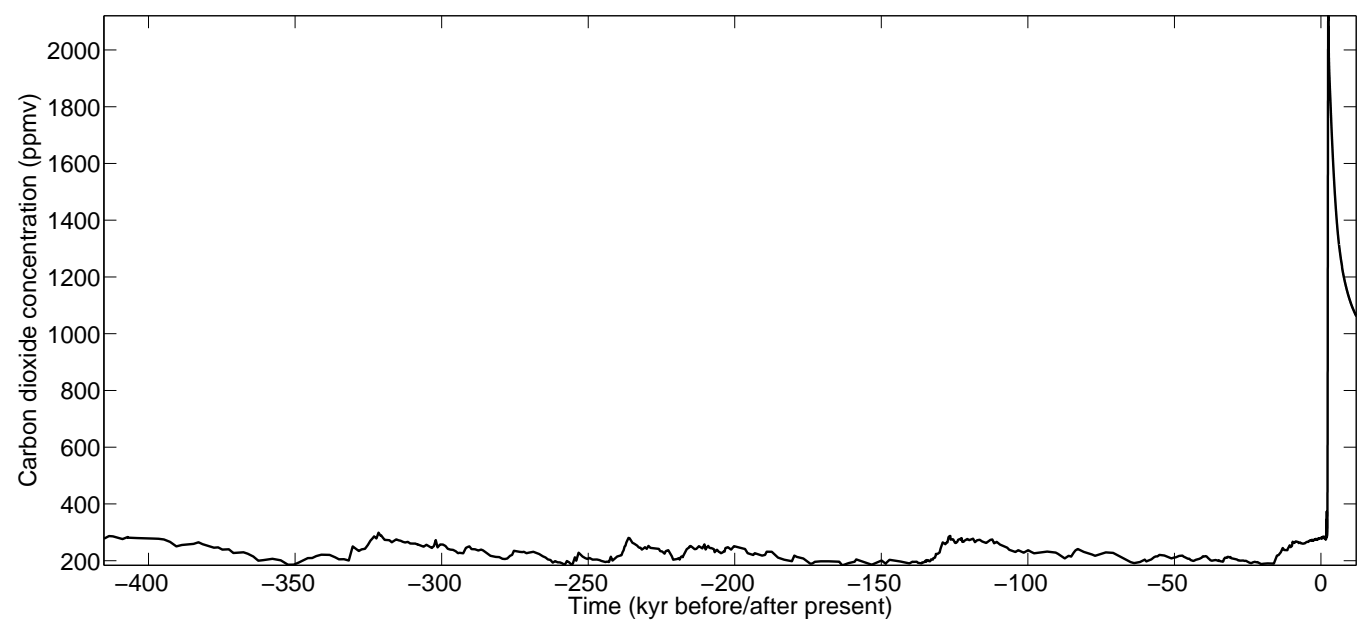

Figure 1.8: A composite $\mathrm{CO}_{2}$ stack, consisting of the Vostok $\mathrm{CO}_{2}$ record (Petit et al., 1999), direct observations of $\mathrm{CO}_{2}$ to present, and a $\mathrm{CO}_{2}$ concentration profile derived from emissions of $5120 \mathrm{Gt} C$ carbon from 2100-2300 (Eby et al., 2009).

number of critical questions remain unresolved. A small sample of these include:

1. Past observations of ice sheet-climate evolution: where was Meltwater Pulse 1A sourced from? What caused the Mid-Pleistocene transition? What caused $\mathrm{CO}_{2}$ to drop, instigating AIS inception?

2. The dynamic behaviour and mass balance of the contemporary AIS and GIS: is current observed mass loss attributable to anthropogenic forcing? Why is the GIS stable in the Holocene? Is the WAIS currently undergoing unstable retreat?

3. The future response of the AIS and GIS to predicted anthropogenically forced climate change: at what $\mathrm{CO}_{2}$ concentrations do the AIS and GIS become unstable? What will the role of the ocean be in future ice sheet evolution? Is potential future ice sheet loss effectively permanent? 
In order to resolve these questions (among many others), current research is focussing on:

1. Identifying major atmospheric and oceanic controls on ice sheets over millennial timescales.

2. Quantifying thresholds in the climate system, including those associated both with glacial/interglacial cycles and the more fundamental presence/absence of ice sheets.

3. Assessing the role of ice dynamics in ice sheet response to climate perturbations, and ice sheet triggering of climate change.

Whilst observations play a fundamental role in understanding the ice sheet-climate system, numerical modelling is becoming increasingly important to modern ice-climate science, by allowing a thorough processbased understanding of the climate and the ice sheets and their interaction with climate. It is this approach that is taken in the present thesis, to contribute to understanding of the ice sheet-climate system.

\subsection{Ice sheet-climate modelling}

Computer models are excellent 'numerical laboratories' for identifying and understanding complex processes within the Earth system, testing hypotheses about how the system operates, and generating projections of future change (Kiehl, 2006). Based on these criteria, the ice sheet-climate system represents an ideal candidate for modelling studies. Ice sheet and climate behaviour, while extremely complex, relies fundamentally on basic physical principles that can in theory be represented by computer code. The surface/interior of ice sheets are difficult/near-impossible to observe robustly. Perhaps most importantly, ice sheets are expected to change significantly in response to future climatic changes, but the nature and rate of 
the change is not yet clear. For this reason, studies of ice sheet-climate interactions have increasingly relied on modelling to support foundational observational and theoretical research.

This section provides a general review of ice sheet-climate modelling efforts to date. Previous modelling studies can be broadly separated into studies that only send information from the ice sheet to the climate or vice versa (stand-alone modelling), and studies in which information is passed both ways as simulations proceed (coupled modelling). I briefly discuss stand-alone modelling efforts but focus mostly on coupled modelling, because this is the primary approach taken in this thesis.

\subsubsection{Stand-alone modelling}

Stand-alone modelling of ice sheets typically involves forcing the ice sheet with some form of prescribed climate data. This method neglects any effects that a changing ice sheet may have on the climate. Climatic fields (particularly precipitation and surface temperature) are generated in a range of ways. Early models (e.g. Weertman, 1976; Oerlemans, 1981, 1982) generated a mass balance as a function of sea level temperature, elevation, distance inland and/or insolation, and applied this mass balance to idealized 2-D or relatively coarsely gridded 3-D ice sheets. Such models were (and still are, e.g. Huybers and Tziperman (2008)) instrumental in understanding fundamental ice sheet behaviour, particularly over long timescales. The correlation between benthic

oxygen isotopes and ice ages (Hays et al., 1976) has motivated the use of oxygen isotope stacks (e.g. Lisiecki and Raymo, 2005) to control parameterizations of climate over modelled ice sheets. Typically, present-day precipitation and temperature fields are perturbed by an amount proportional to isotopic deviation from a baseline value. Alternatively, empirical relationships between representative isotope and 
precipitation/temperature timeseries are extrapolated to generate time-varying surface mass balance fields. However, reliance on oxygen isotope stacks for driving climate models is somewhat ambiguous, because although it accurately represents the global average temporal evolution of glacial periods, the magnitude of the oscillation is itself partially dependent on ice volume. In practice model tuning is required to arrive at a reasonable relations between local variations of mass balance and isotopic change. Nonetheless, important results of such models include estimates of the extent of GIS ice loss during the last interglacial (Cuffey and Marshall, 2000), long term simulations of the AIS (Pollard and DeConto, 2009), and explorations of factors responsible for the evolution of the GIS and AIS (Huybrechts and de Wolde, 1999; Huybrechts, 2002)

The use of model-derived climate fields to generate surface mass balance for ice sheet studies has become increasingly popular. Three general levels of complexity are associated with these types of experiments. In the first, mass balance fields are computed from climatic fields, but not sent to a dynamic ice model. These experiments have been used to determine limits on glacial inception and deglaciation (e.g. Otieno and Bromwich, 2009) and generate high resolution, modern day, mass balance fields (e.g. Ettema et al., 2009). While useful, this approach is ultimately limited to short term simulations due to their static representation of ice sheets.

The next level of sophistication involves driving a dynamic ice sheet model with output from climate models. By directly simulating mass balance trends within global models, or more commonly extracting temperature and precipitation fields for downscaling to the ice sheet grid, ice sheet models are endowed with signals of global climate change. A challenge arises in downscaling coarse climate model output to fine scale ice sheet grids, and these types of experiments are also limited by the static nature of the climate input. Regardless, such models have been used successfully to explore issues such as GIS inception (Lunt et al., 2008), the extent of GIS 
retreat during MIS 5 (Otto-Bliesner et al., 2006), and the effect of model parameters and input data on model output (Stone et al., 2010).

The third level of sophistication involves full coupled modelling of the coupled ice sheet-climate system, and is described in more detail in the following section.

\subsubsection{Coupled modelling}

Two-way coupling involves the simultaneous evolution of both the ice sheet and climate, as in the real world. This coupling involves the transfer of climate fields (either temperature and precipitation, or pre-computed mass balance) to the ice sheet. In return, the ice sheet model provides updated elevation, albedo, meltwater, calving and ice area fields to the climate model. Such an approach explicitly resolves feedbacks that are not captured in one-way coupled experiments. As with standalone ice sheet models driven by climate model output, an accurate means of downscaling the climate model-derived mass balance to the ice sheet grid can be a challenge. In addition, the climate model in two-way-coupled experiments must update land, ocean and atmosphere boundary conditions to reflect changing ice sheet geometry, and ideally conserve mass and energy throughout the entire system. The timescale of ice evolution places limits on which climate models can be practically used to simulate ice sheetclimate evolution. Full, high resolution atmosphere-ocean general circulation models (AOGCMs) are computationally expensive, and are therefore generally limited to multi-century synchronous ice sheet/climate simulations. Because of this, simplified models such as Earth system models of intermediate complexity (EMICs) or atmosphere-only general circulation models (AGCMs) coupled to slab ocean models are often utilized as the climate-side model.

Three-dimensional, two-way-coupled ice sheet-climate models have a 
relatively short history. Yoshimori et al. (2001) and Schmittner et al. (2002a) utilized an early version of the University of Victoria Earth System Climate Model (UVic ESCM), asynchronously coupled to a non-interpolated, coarse isothermal ice sheet to investigate feedbacks between LGM ice sheets and the surrounding climate. Their use of an energy-moisture-balance model (EMBM) to calculate the surface mass balance of the ice sheet avoided any dependence on empirical melt constants and flux adjustments.

A lineage of ice sheet-climate model simulations of the Cenozoic AIS evolution have been presented by Robert DeConto and David Pollard in a variety of publications (e.g. DeConto and Pollard, 2003; Pollard and DeConto, 2005). They performed Myr-scale integrations using an atmospheric general circulation model (AGCM), a land surface model, and a simple but efficient slab ocean/sea ice model, all coupled asynchronously to a 3D thermomechanical ice sheet.

Ridley et al. (2005) used a 3D thermomechanical grounded-ice sheet model (Huybrechts and de Wolde, 1999) coupled to the HadCM3 climate model to investigate the effect of increasing $\mathrm{CO}_{2}$ on the melting of the GIS. A PDD model, driven by monthly temperature and precipitation anomalies generated by HadCM3 (and lapse-rate adjusted to the ice sheet grid), generated a mass balance. Their simulations highlighted the multi-phase progression of projected GIS deglaciation due to marginal melting, increased interior accumulation and subsequent ice dynamic effects. Subsequent work (Ridley et al., 2010) explored the ability of the GIS to regrow, given partial or complete ice loss. Driesschaert et al. (2007) coupled the ice sheet model of Huybrechts and de Wolde (1999) into an intermediatecomplexity climate model, using a PDD-anomaly model to calculate mass balance. The resulting system was used to investigate future melting of the GIS, and the effect of melting on the Atlantic meridional overturning circulation. The SICOPOLIS ice sheet model (Greve, 1997), unique for its ability to account for both cold and temperate ice, has been coupled to a 
variety of climate models. Winguth et al. (2005) used SICOPOLIS coupled to a coarse ocean/atmosphere/land surface model to explore the effect of the melting GIS on ocean circulation and carbon uptake by land and ocean.

Mikolajewicz et al. (2007b) and Vizcaíno (2006) utilized SICOPOLIS on a relatively coarse $80 \mathrm{~km}^{2}$ grid with ECHAM5/MPIOM, a coarse resolution AOGCM. Unique in this experimental setup was the use of an energy balance model, employed on the ice sheet grid, to determine melting. Distribution of surface mass loss under future warming scenarios was investigated. Vizcaíno et al. (2010) again used SICOPOLIS, coupled to a coarse atmosphere-ocean, long-timescale-capable AOGCM.

Several studies have utilized the CLIMBER climate model coupled with the GREMLINS/GRISLI ice sheet model. CLIMBER is a simplified model consisting of a $10^{\circ} \times 51^{\circ}$ atmosphere, three $2 \mathrm{D}$ ocean basins and a land surface scheme. GREMLIN/GRISLI (described in Ritz et al. (2001)) is a 3D thermomechanical ice sheet model that resolves both ice sheets and ice shelves with simple coupling at the grounding line. Melting of Antarctic ice shelves is parameterized according to Beckmann and Goosse (2003). Temperature and precipitation fields are calculated at several atmospheric levels, trilinearly interpolated and lapse-rate-corrected to the ice sheet grid, where a PDD model calculates the mass balance. Charbit et al. (2005) and Philippon et al. (2006) utilized the CLIMBER/GREMLIN architecture to study the last deglaciation. They concluded that orbital and $\mathrm{CO}_{2}$ forcing, along with basal melting and sea level (for the AIS) were important influences and suggested that melting of the Northern Hemisphere ice sheets caused AIS retreat through imposed sea level rise. Charbit et al. (2008) utilized the same CLIMBER-GRISLI/GREMLIN configuration to explore the response of the GIS to anthropogenic emissions of $\mathrm{CO}_{2}$. Using a highly parameterized expression for carbon uptake, they found that above $3000 \mathrm{Gt} C$ emitted, the GIS melts completely, regardless of the shape of the emission profile. 
Finally, Pritchard et al. (2008a) coupled the thermomechanical ice sheet model of Marshall and Clarke (1997) to the AGCM component of the Community Climate System Model (CAM3, Collins et al. (2006)) and used a PDD parameterization to determine surface melt. The system explored ice-atmosphere interactions during the deglaciation of the LIS, especially those caused by the utilization of a variable albedo surface parameterization.

\subsubsection{Outstanding issues in ice sheet-climate modelling}

Recent rapid development of stand-alone ice sheet models and coupled ice sheet-climate models has occurred in the interval since publication of the IPCC AR4 (Lemke et al., 2007), which highlighted the large uncertainty associated with the land-ice contribution to future sea level rise. Progress has been generally focussed on several topics:

1. Development of ice sheet model physics that can resolve ice streams, ice shelves, and dynamic grounding lines.

2. Understanding basal dynamics.

3. Understanding of ice-ocean interactions.

4. Creation of high resolution regional model-driven estimates of surface mass balance.

5. Development of robust coupling between ice sheet models and climate models for future predictions.

The latter point is particularly relevant to the current thesis, the majority of which details construction and preliminary use of a new coupled ice sheet-climate model as described in Section 1.4. Numerous studies 
have highlighted the need for a new generation of fully coupled ice sheetclimate models that can dynamically and explicitly translate regional and global climate changes (e.g. sea ice advance/retreat) to ice sheet boundary conditions (e.g. surface mass balance). It is this deficiency that provided motivation for investing significant effort in constructing the new coupled model.

\subsection{Objectives of this thesis}

Motivated by recognition that predictions of AIS and GIS evolution under expected future anthropogenic climate change are poorly constrained (Meehl et al., 2007), I set out to to assess the potential behaviour of these ice sheets in the future using a numerical coupled climate model approach. This broad goal was addressed by defining a narrower set of objectives, which were chosen to maximize the increase in understanding of ice sheet/climate interactions within the constraints of a $\mathrm{PhD}$ project.

- Exploration of ice sheet-relevant climate diagnostics: how will surface melting conditions over ice sheets and ice shelves evolve under climate warming? An initial assessment of surface melting conditions over ice sheets and ice shelves, described in Chapter 2, was motivated by previous work that recognized the correlation between surface air temperatures and ice shelf stability (Mercer, 1978; Scambos et al., 2003; Copland et al., 2007). The experimental design was relatively straightforward to implement given previous experience with the UVic ESCM (Fyke and Weaver, 2006), and results provided an initial indication of the potential response of the AIS and GIS to future climate change. This project was also an introduction to the effects of climate model bias and the potential role of the ocean in controlling ice shelf behaviour. Importantly, this work used the default UVic ESCM, and had no dynamic ice sheet component. 
- Coupled ice sheet/climate evolution: how will the GIS respond to future climate change, over millennial timescales? Generation of a full model-based assessment of the response of the GIS to future climate change was deemed an important thesis objective, given the few existing coupled simulations of GIS evolution under high- $\mathrm{CO}_{2}$ environments. The first step towards achieving this objective involved integration of a dynamic land ice component into the UVic ESCM in order to facilitate coupled simulations of the ice sheet-climate system. While the aim of development was to simulate GIS-climate behaviour, the model was generalized to simulate an arbitrary number of ice sheets, including marine-based ice sheets, within the global simulation. This work represents a major technical component of the thesis, and involved code development, design of original coupling techniques, and an extensive initial round of model testing, all described in Chapter 3. Chapter 4 details the initial round of simulations with the coupled model meant to explore GIS behaviour in the future.

- Coupled ice sheet/climate evolution: how will the ocean respond to freshwater fluxes derived from dynamic marine ice sheet retreat? The AIS has been shown to be susceptible to sub-shelf-melt-derived retreat. Conversely, the global ocean is potentially sensitive to AIS-derived freshwater fluxes. Capturing a modern oceanic response to realistic timedependent retreat of the AIS driven by imposed sub-ice-shelf melting rates was thus recognized as a pertinent objective, in order to give an indication of potential future effects of AIS retreat on Southern Ocean sea ice and global ocean circulation, and provide an initial exploration of ocean-ice sheet feedbacks within the coupled model framework. Chapter 5 describes initial results stemming from model investigations of the oceanic response to AIS retreat. 


\section{Chapter 2}

\section{Surface Melting over Ice Shelves and Ice Sheets as Assessed from Modelled Surface Air Temperatures}

\subsection{Abstract}

Summer surface melting plays an important role in the evolution of ice shelves and their progenitor ice sheets. In order to explore the magnitude of surface melt occurring over modern ice shelves and ice sheets in a climate scenario forced by anthropogenic emissions of carbon dioxide, a coupled climate model was used to simulate the distribution of summer melt at high latitudes and project the future evolution of high melt regions in both hemispheres. Forcing of the climate model with $\mathrm{CO}_{2}$ emissions resulting from combustion of the present-day fossil fuel resource base resulted in expansion of high-melt regions, defined by the 200 positive degree days (PDD) per year contour, in the Northern Hemisphere 
and the Antarctic Peninsula, and the introduction of high summer melt over the Ross, Ronne-Filchner and Amery ice shelves as well as a large portion of the West Antarctic Ice Sheet (WAIS) and most of the Greenland Ice Sheet (GIS) by year 2500. Capping $\mathrm{CO}_{2}$ concentrations at present day levels avoided significant summer melt over the large Antarctic shelves, the WAIS and much of the GIS.

\subsection{Introduction}

Ice shelves and ice sheets evolve in response to changes in oceanic and atmospheric boundary conditions. Recent dramatic losses of long-lived ice shelves in both hemispheres highlight the uniqueness of recent climate change and have focussed attention on causal factors that promote ice shelf retreat. Ice shelves respond dynamically and thermodynamically to changes in underlying ocean temperature (Holland et al., 2008a) and surface air temperature (SAT). Several authors (e.g. Mercer (1978); Vaughan and Doake (1996)) have linked the observed poleward migration of annual or monthly SAT isotherms to episodes of ice shelf retreat, indicating a strong correlation between SAT and the sudden break-up of existing ice shelves. While the Larsen B Ice Shelf was pre-weakened by at least a decade of thinning due largely to ocean-induced basal melting (Shepherd et al., 2003) prior to the final collapse (an event that Domack et al. (2005) suggested was unprecedented for Larsen $B$ during the Holocene), the final sudden disintegration event (along with that of Larsen A) has been attributed to warming SAT, which led to development of surface melt ponds and ice fracturing of existing crevasses (van den Broeke, 2005; Scambos et al., 2000, 2003). The Wilkins Ice Shelf, which currently undergoes extensive summer melting, also experienced a break-up event associated with the 2008 melt season that Scambos et al. (2009) suggested was triggered by melt-water induced crevasse deepening. This break-up differs from 
large winter-time break-up loss events over the Wilkins Ice Shelf which Braun et al. (2009) attributed to basal melt-induced bending stresses. In the northern hemisphere, ice shelf break-up events associated with the generation of significant summer surface melt have been observed on northern Ellesmere Island, where the Ward Hunt and Ayles Ice Shelves retreated (2002-2009 and 2005, respectively) (Mueller et al., 2003; Copland et al., 2007). These examples indicate that increased SAT over an ice shelf that is structurally vulnerable due to internal glacial discontinuities provides one important mechanism for rapid ice shelf retreat or loss.

The stability of remaining Antarctic ice shelves has implications for West Antarctic Ice Sheet (WAIS) stability, sea level rise and bottom water production. The loss of the Larsen B Ice Shelf resulted in an increased flow velocity of several grounded inland source glaciers (Scambos et al., 2004). Similarly, present-day thinning of the grounded Pine Island Glacier has been attributed to changes in the rate of ice shelf basal melting (Payne et al., 2004). It has been suggested that loss of the Ross and/or RonneFilchner ice shelves would also accelerate flow of the marine-based WAIS (Mercer, 1978), potentially resulting in large-scale WAIS retreat. Naish et al. (2009) and Pollard and DeConto (2009) interpreted sediment core results and an associated ice sheet modelling simulation to suggest that periodic loss of the Ross Ice Shelf occurred during the warm, early Pliocene 5-3 Ma BP, indicating that it is sensitive to changes in environmental conditions similar to those projected for the coming centuries. Arctic ice shelves, in contrast to their southern counterparts, do not buttress significant grounded ice.

Recent Arctic and Antarctic air temperature changes have been attributed directly to human influence (Gillett et al., 2008). Continuing evolution of high latitude climate in response to anthropogenic forcing may significantly affect the stability of remaining ice shelves in both hemispheres. We utilized a climate model forced by anthropogenic emissions of carbon dioxide to simulate large-scale surface warming 
trends. Model output was analysed for periods of extended summer warmth to infer the potential for melting of the magnitude that is currently associated with observed ice shelf retreat. While we focussed on regions of the Earth where ice shelves occur, the global model domain also allowed us to analyze melting trends over present-day grounded ice sheets.

The model output was first compared against observed SAT, an ensemble of atmosphere-ocean general circulation model (AOGCM) simulations of the $21^{\text {st }}$ century and the timing of major ice shelf retreats, then integrated for several hundred years into the future to explore the potential for increased melting over ice surfaces in both hemispheres.

\subsection{Model and Methods}

Version 2.8 of the University of Victoria Earth System Climate Model (UVic ESCM) was used. This intermediate complexity climate model couples atmospheric, oceanic and land surface components, a thermodynamic/dynamic sea ice model and a closed and coupled carbon cycle that includes carbon transfer between inorganic and organic carbon reservoirs. The ocean component is a full 3D ocean general circulation model (MOM2 (Pacanowski, 1995)). The atmospheric component consists of a vertically integrated energy-moisture balance model in which the radiative forcing associated with atmospheric $\mathrm{CO}_{2}$ is applied through a decrease in outgoing long wave radiation, parameterized as

$$
F=F_{0} \ln \left(\frac{C(t)}{350}\right)
$$

where $C(t)$ is the atmospheric $\mathrm{CO}_{2}$ concentration (ppmv) at time $t$ and $\mathrm{F}_{0}$ $=5.35 \mathrm{~W} / \mathrm{m}^{2}$ corresponds to a specified radiative forcing of $3.7 \mathrm{~W} / \mathrm{m}^{2}$ for a doubling of atmospheric $\mathrm{CO}_{2}$ (Houghton et al., 2001). Surface air temperature is prognostically calculated as a function of the surface energy 
balance and elevation (via a constant lapse rate). Ice sheets are static, noninteractive components of the model and are reflected in global elevation and albedo fields. Surface albedo fields are a function of surface type such as plant functional type, ice and snow cover. While potential melt ponding plays an important role in the energy balance over ice (via a lowered surface albedo), we could not resolve this effect due to a lack of a detailed surface hydrological scheme. This made our subsequent determination of SAT change conservative by removing a positive feedback on SAT.

Heat and moisture fluxes between the ice shelves and the ocean were neglected in this version of the model. Heat flux from the ocean to ice shelves is proportional to the temperature difference between the pressure-dependent melt temperature of ice and the in-situ temperature of seawater at the ice-ocean interface and is expected to increase in a quadratic fashion as the ocean warms (Holland et al., 2008b). However, UVic ESCM simulations indicated that the contribution of this flux to the total Southern Ocean heat budget is still small compared to heat fluxes to/from the ocean resulting from sea ice formation/melting, and open ocean heat exchange with the atmosphere. We therefore assume that ice shelf-to-ocean heat flux plays a small role in the large-scale SAT, which is the field we are primarily interested in. The resolution of all components within the model is $3.6^{\circ}$ in longitude by $1.8^{\circ}$ in latitude.

The UVic ESCM reproduces the observed climate, including the zonal mean amplitude of seasonal SAT change (Randall et al., 2007), and falls within the mid-range of IPCC AR4 model ensemble predictions of the 21st century (Meehl et al., 2007). Due to computational efficiency, the model is able to simulate climate over millennial time scales, making it ideal for exploring long-term effects of anthropogenic emissions that cannot be addressed using full AOGCMs. A detailed description of the model and its validation is described in Weaver et al. (2001).

Two simulations were carried out. Both were initialized from a prein- 
dustrial equilibrium at year 1850 in which atmospheric $\mathrm{CO}_{2}$ was stable at approximately $280 \mathrm{ppmv}$. They were then integrated forward for 1000 years until year 2850. In the first simulation, termed the 'high emission scenario', observed emissions were applied until year 2000 (Marland et al., 2008). From 2000-2100, emissions followed the IPCC A2 scenario (Meehl et al., 2007). From 2100-2300, emissions decreased linearly back to zero. This emission profile added $5134 \mathrm{Gt}$ of carbon (C) to the climate system and corresponds closely to combustion of all of the present day oil, natural gas and coal resource base (including nonconventional sources such as tar sands, Rogner (1997)). The second simulation in which $\mathrm{CO}_{2}$ was capped at $390 \mathrm{ppmv}$ from 2010 onwards was undertaken to simulate warming to which the climate system is already committed, as Weaver et al. (2008) found that reduction below present-day $\mathrm{CO}_{2}$ concentrations within the next millenia is unrealistic if emissions are reduced by anything less than $90 \%$ of present-day levels by 2050 . This simulation is termed the 'commitment scenario'.

An anomaly approach was used to obtain SAT fields. This method superimposed the temperature trend simulated by the UVic model on the National Centers for Environmental Prediction (NCEP) climatology (Kalnay et al., 1996). This removed potential systematic SAT biases within the raw simulated UVic ESCM SAT field. Daily average SAT for the period 1970-2001 was generated for NCEP data and the UVic ESCM simulation. The final SAT was then calculated as:

$$
S A T=S A T_{\text {raw }}-S A T_{U V i c}+S A T_{N C E P}
$$

where $\mathrm{SAT}_{\text {raw }}$ is the raw simulated time-dependent SAT and $\mathrm{SAT}_{U V i c}$ and SAT $_{N C E P}$ are the 1970-2001 daily average UVic and NCEP SAT fields, respectively. The 30 year average period removed high frequency variability from the NCEP and UVic ESCM climate, which would otherwise obscure the long term evolution of SAT trends. Bromwich et al. (2007) analysed NCEP data over high latitude locations. They found large biases in pre- 
satellite NCEP data over the winter periods at high latitudes, particularly over Antarctica. However, biases were much reduced during the summer when melting occurs.

In order to infer regions that experience summer melt periods of the same magnitude as those observed in conjunction with observed ice shelf retreat the annual sum of positive degree days (PDD), which is assumed proportional to the annual melt, was recorded throughout the simulation for each grid cell following the method of Vaughan (2006). Based on observations, Copland et al. (2007) estimated that the $200 \mathrm{PDD} \mathrm{yr}^{-1}$ contour defines the limit of ice shelf stability for the northern Ellesmere Island ice shelves. Vaughan (2006) analysed the distribution of PDDs over the Antarctic Peninsula. Interestingly, the $200 \mathrm{PDD} \mathrm{yr}^{-1}$ contour of his analysis lies across the Larsen A/B ice shelves in 2000, which approximates the period when both shelves underwent persistent large-scale surface melt and retreat. A $200 \mathrm{PDD} \mathrm{yr}^{-1}$ limit was therefore utilized as the primary threshold, with a reasonable range of values explored to determine the sensitivity of the ice shelf stability zone to this value.

\subsection{Results}

The simulated preindustrial steady state climate exhibited two broad re-

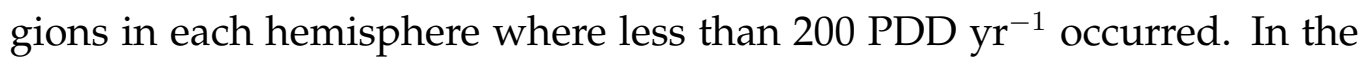
Arctic, this zone encompassed northern Ellesmere Island (location of the Ward Hunt and Ayles ice shelves), the Greenland Ice Sheet (GIS) and a region of the offshore Arctic Ocean (Figure 2.1)). In the Antarctic, the entire continent and nearby Southern Ocean fell within the low summer melt zone. This agrees with established ice shelves here prior to significant human-derived emissions.

In the Arctic, by 2011-2021, the $200 \mathrm{PDD} / \mathrm{yr}$ criterion was surpassed in the ocean off Ellesmere Island (Figure 2.2). When the threshhold was 

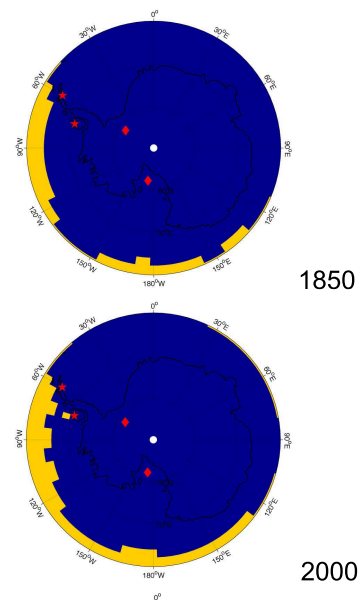

1850
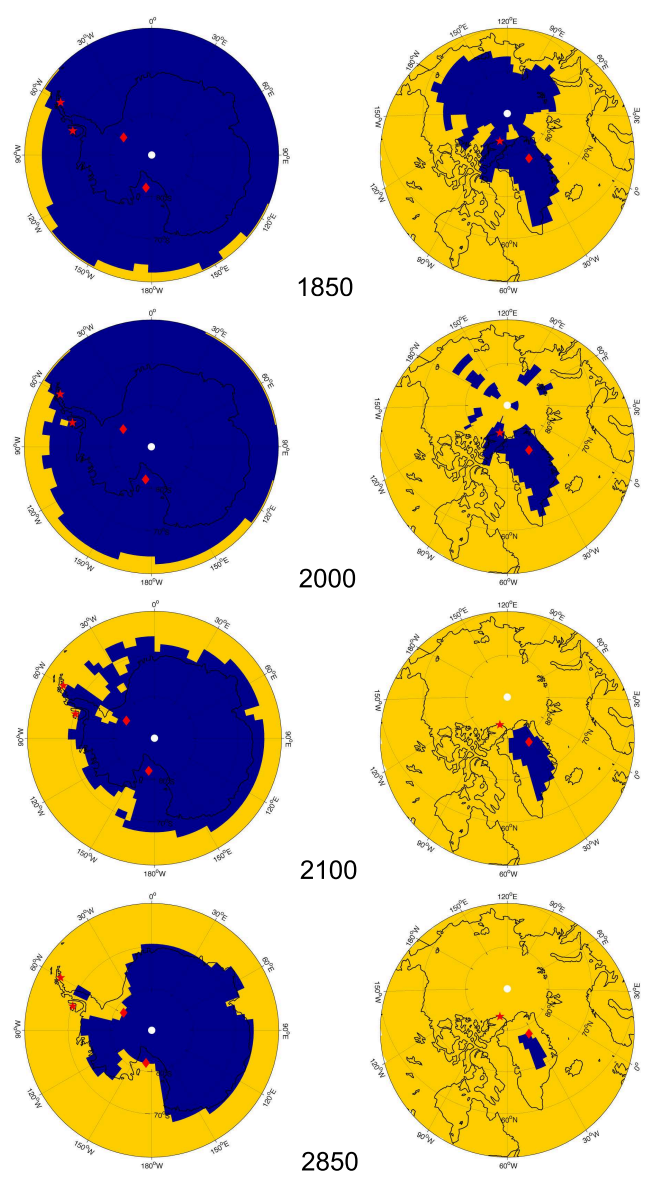

Figure 2.1: Simulated evolution of Antarctic (left column) and Greenland (right column) summer melting caused by combustion of the entire present-day fossil fuel resource base. Yellow: Regions that experience more than $200 \mathrm{PDD} \mathrm{yr}^{-1}$. Blue: Regions that experience less than 200 PDD $\mathrm{yr}^{-1}$. Red stars in Antarctic plots: locations of Larsen A/B and Wilkins Ice Shelf PDD time series. Red diamonds in Antarctic plots: locations of Ross and Ronne-Filchner Ice Shelf PDD evolution time series. Red star in Greenland plots: location of Ward Hunt/Ayles PDD time series. Red diamond in Greenland plots: location of GIS PDD evolution time series (Figs. 2.2 and 2.3). 


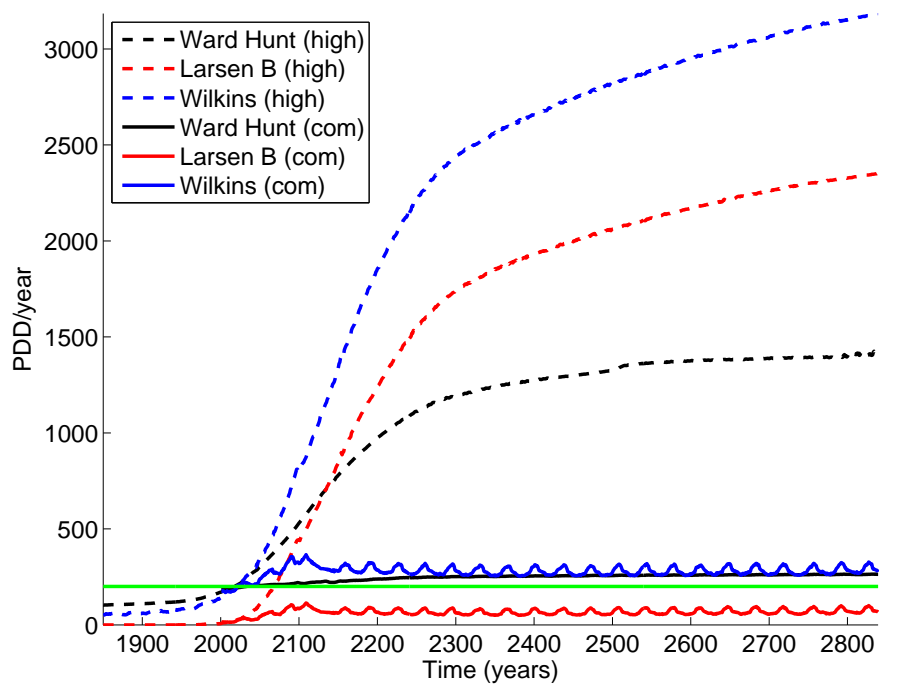

Figure 2.2: Simulated PDD evolution timeseries of Larsen B, Wilkins, and Ayles/Ward Hunt ice shelves (Figure 2.1). Dashed lines: high emission scenario ('high'), solid lines: commitment scenario ('com'). Green line:

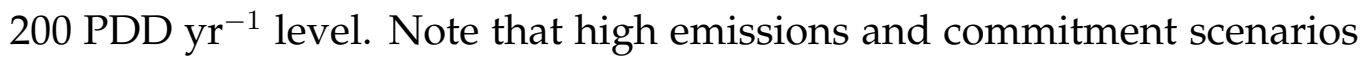
begin to diverge from each other after year 2010 due to a change in $\mathrm{CO}_{2}$ concentrations after this time. The oscillations in the Larsen B and Wilkins ice shelf PDD timeseries are mirrored in small interannual fluctuations in simulated southern hemisphere sea ice distribution and are prominent in the PDD timeseries because these locations lie near to the $0^{\circ} \mathrm{C}$ annual isotherm in this simulation.

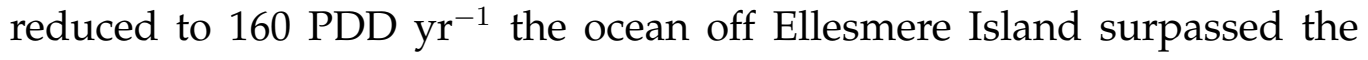
threshold in 2001-2011. This result bracketed the timing of ongoing ice shelf loss in this region remarkably well within the framework of a 1000year simulation, and reinforced the 200 PDD limit estimate of Copland et al. (2007).

On the Antarctic Peninsula, high summer melting (based on the 200 PDD $\mathrm{yr}^{-1}$ criterion) migrated over Larsen A/B Ice Shelf region in the 20612071 period in the high emission scenario. This lies in contrast to observa- 


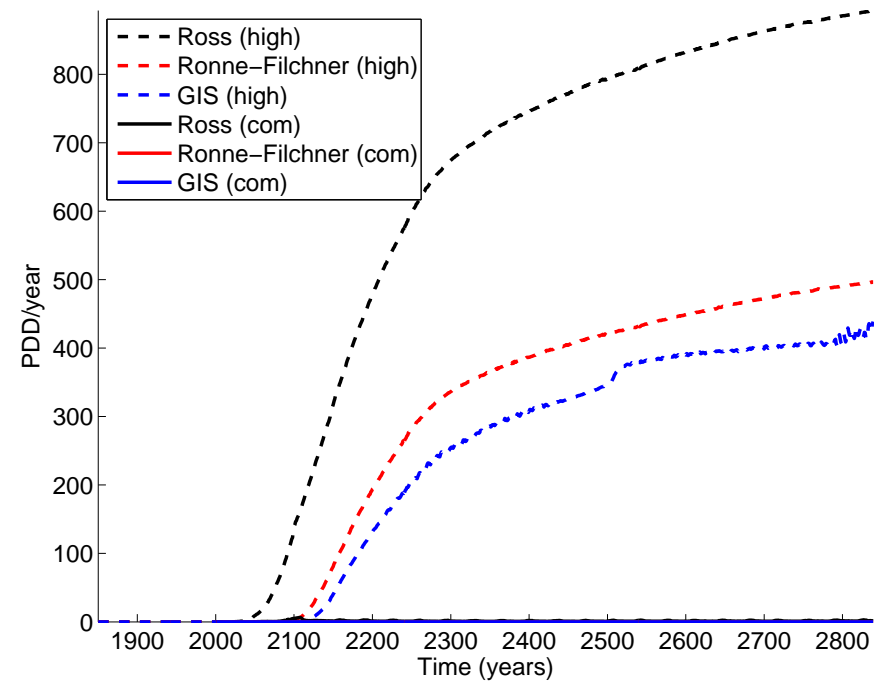

Figure 2.3: Simulated PDD evolution timeseries of representative Ross and Ronne Ice Shelf and GIS locations (Figure 2.1) that transit from low to high

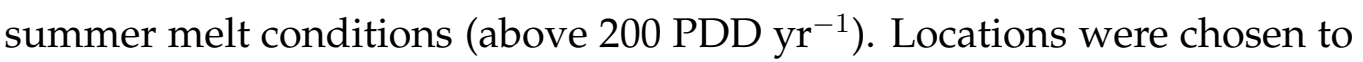

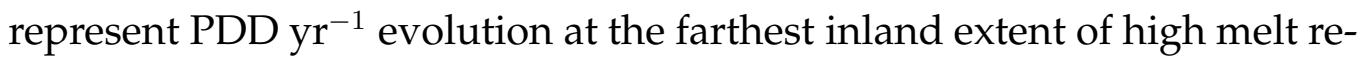
gions by 2850. Dashed lines: high emission scenario ('high'), solid lines: commitment scenario ('com'). Note that since all locations exhibit negligible PDD $\mathrm{yr}^{-1}$ count in the commitment scenario simulation, all the solid lines lie along the x-axis.

tions, which indicate an excess of $200 \mathrm{PDD} \mathrm{yr}^{-1}$ on the Antarctic Peninsula next to the Larsen A/B shelves by year 2000. This discrepancy was due to an underestimation of the observed northern Antarctic Peninsula warming trend in 1960-2000 (Chapman and Walsh, 2007) by the UVic ESCM. Elsewhere, the PDD trend bias was smaller. Grid cells immediately next to the Wilkins Ice Shelf experienced warmth in excess of $200 \mathrm{PDD} \mathrm{yr}^{-1}$ in 2011-2021. Tedesco (2008) determined an average annual Antarctic melt extent of $8.6 \times 10^{5} \mathrm{~km}^{2}$ for 1987-2008. This melt extent was not surpassed in the high emission scenario simulation until 2063 (although by 1997, the simulated melt extent, $3.0 \times 10^{5} \mathrm{~km}^{2}$, was within the measured range of melt 
extents). This delay was largely attributable to the underestimated warming over the Antarctic Peninsula, although an additional important cause of the low simulated melt extent was the coarseness of the UVic ESCM grid, which simply did not resolve narrow coastal regions of melt that contributed to the melt extent of Tedesco (2008). A comparison of simulated rates of PDD increase to observed rates is given on Table 2.1.

Table 2.1: Comparison of available observed PDD $\mathrm{yr}^{-1}$ trends to UVic ESCM simulated trends. Also shown for comparison: simulated 2006-2046 PDD $\mathrm{yr}^{-1}$ trends. In all cases the PDD $\mathrm{yr}^{-1}$ trend accelerates compared to the observational period. Observed PDD $\mathrm{yr}^{-1}$ trend sources: 1, Vaughan (2006); 2, Copland et al. (2007).

\begin{tabular}{|c|c|c|c|}
\hline $\begin{array}{l}\text { PDD trend ob- } \\
\text { servation loca- } \\
\text { tion }\end{array}$ & $\begin{array}{l}\text { Average observed } \\
\text { PDD } \mathrm{yr}^{-1} \text { trend } \\
\text { (timeseries length) }\end{array}$ & $\begin{array}{l}\text { Simulated } \\
{\text { PDD } \mathrm{yr}^{-1} \text { trend }} \\
\text { 1970-2001 }\end{array}$ & $\begin{array}{l}\text { Simulated } \\
{\text { PDD } \mathrm{yr}^{-1} \text { trend }} \\
2006-2046\end{array}$ \\
\hline Faraday & $1.4 \pm 0.7(1947-2005)^{1}$ & 0.8 & 3.2 \\
\hline Bellingshausen & $2.7 \pm 1.3(1967-2005)^{1}$ & 1.9 & 4.6 \\
\hline Rothera & $1.8 \pm 1.7(1979-2005)^{1}$ & 0.00 & 0.1 \\
\hline Ayles & $\begin{array}{l}2.6(1965-2005) \\
0.18(1947-2005)^{2}\end{array}$ & 1.4 & 2.8 \\
\hline
\end{tabular}

To further gauge the accuracy of high-latitude warming simulated by the UVic ESCM in the near-future, the rate of warming for 2000-2100 under the high emission scenario was compared to a five-model ensemble of AOGCMs (CGCM3, GDFL CM2, ECHAM5-MPIOM, CCSM3, HadCM3) also forced with the A2 scenario for the 2000-2100 period (Meehl et al., 2007). The UVic ESCM rate of warming over the Antarctic Peninsula and the Antarctic coastal warming trend corresponded well to the ensemble average but the rate of warming over the interior of Antarctica (including the WAIS $)$ and the GIS was slightly lower $\left(\sim 0.1^{\circ} \mathrm{C} /\right.$ decade $)$ than the en- 
semble average. This indicated that polar amplification of warming in the UVic ESCM, while present, was less pronounced than in the IPCC ensemble.

Overall, the simulations captured both preindustrial regions of ice shelf stability and the introduction of significant summer melting over regions characterized by recent ice shelf losses (with a particular delay in southwards migration of the high melt zone based on the 200 PDD/day criterion across the western Antarctic Peninsula). The underestimated rate of warming over the Antarctic Peninsula, combined with the slightly lower average rate of warming at each pole (compared to the IPCC ensemble), suggested that melt extent and PDD $\mathrm{yr}^{-1}$ values obtained by the UVic ESCM simulations represented lower bounds on the rate of poleward migration of high melt zones over the coming centuries.

Further integration of the high emission scenario to 2850 resulted in a global annual average SAT increase of $\sim 7^{\circ} \mathrm{C}$. Temperatures were still slowly increasing at the end of the simulation, despite a total cessation of emissions at 2300. Polar amplification of SAT changes resulted in Arctic temperature increases of up to $12^{\circ} \mathrm{C}$, while in the Antarctic several coastal regions warmed by up to $10^{\circ} \mathrm{C}$. In the Arctic, warming occurred rapidly, while in the Antarctic major warming was delayed until approximately 2100-2300.

In the Arctic, by 2100, widespread surface melting was simulated over all regions that presently contain ice shelves (Figure 2.1). Further expansion of the high melting zone resulted in marked summer melt over most of the GIS by 2850 with only a small central core remaining below the 200 PDD/day threshold. In Antarctica, by 2100, several isolated regions of the Antarctic Peninsula began to experience summer melting above the $200 \mathrm{PDD} /$ day criterion while the WAIS and EAIS remained below the 200 PDD $\mathrm{yr}^{-1}$ threshold. However, between $\sim 2050$ and $\sim 2500$, regions encompassing the Ronne-Filchner, Ross and Amery ice shelves experienced 
a rise in PDDs, such that large portions of these regions surpassed the 200 $\mathrm{PDD} \mathrm{yr}^{-1}$ threshold by year 2500 (for representative example locations, see Figure 2.3). By year 2850 the entire Ronne-Filchner and Ross ice shelves and the northern Amery Ice Shelf were all well above the 200 PDD/day threshold (Figure 2.1). In addition, significant parts of the WAIS poleward of the Ronne-Filchner and Ross ice shelves and the Antarctic Peninsula moved into the high-melt region (Figure 2.1). In contrast, the EAIS did not experience significant summer melting of the ice sheet interior, with the exception of sporadic coastal cells and a small area around Prydz Bay. The total simulated extent of Antarctic melt had expanded by roughly a factor of 10 from the simulated and observed present-day extent, to $3.6 \times 10^{6} \mathrm{~km}^{2}$.

In contrast to the high emission scenario, the commitment scenario simulation exhibited less encroachment of melting at high latitudes. By 2500, global average SAT had equilibrated at $\sim 0.6^{\circ} \mathrm{C}$ above 2010 levels. While the Arctic Ocean and surrounding regions still migrated almost completely into the high summer melt zone for all criteria, the major Antarctic ice shelves and the WAIS, all of which experienced melting in excess of $200 \mathrm{PDD} \mathrm{yr}^{-1}$ in the high emission scenario, now remained well below the $200 \mathrm{PDD} \mathrm{yr}^{-1}$ criteria (Figs. 2.2, 2.3, 2.4) for the commitment scenario. Although the Wilkins region experienced melting slightly in

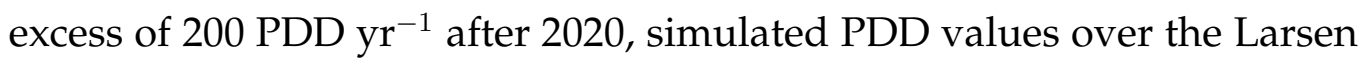
region remained low. This indicated that warming in this region was too modest for the commitment scenario simulation and was consistent with the anomalously late warming experienced in the high emission scenario: under modest $\mathrm{CO}_{2}$ increases, the UVic ESCM (along with the IPCC ensemble) underestimated the warming over the western Antarctic Peninsula. 

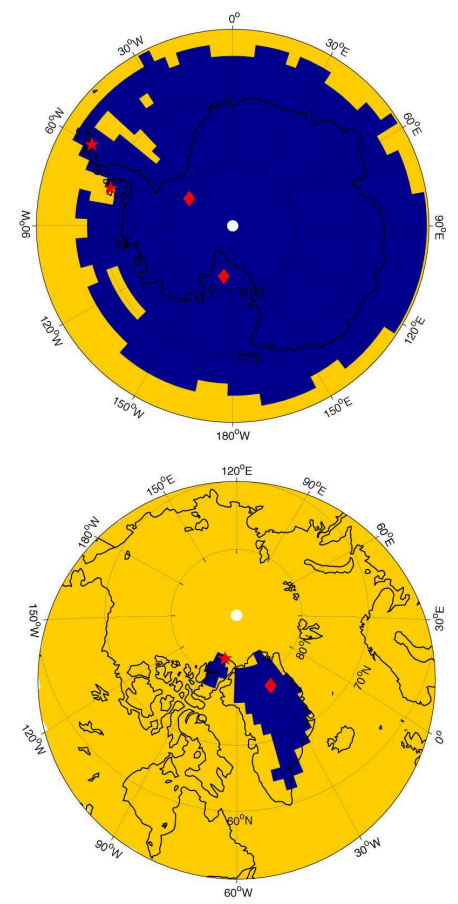

Figure 2.4: Final equilibrium state (year 2850) of Antarctica (top) and Greenland (bottom) summer melting extent as a result of a $\mathrm{CO}_{2}$ concentration cap at year 2010 levels. Colors as for previous figures.

\subsection{Discussion}

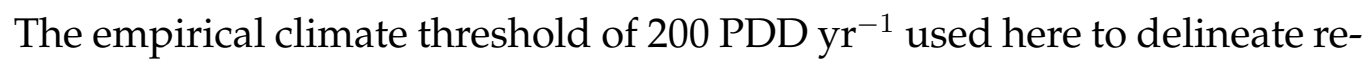
gions of high summer melting was chosen to reflect SAT conditions closely associated with observed melt-induced fracturing of ice shelves and was meant to extrapolate the SAT/ice shelf loss correlation of Vaughan and Doake (1996) into the future using climate model output instead of observations. However, it is important to note that oceanic heat flux is an alternate or additional thermodynamic mechanism for driving ice shelf loss (Holland et al., 2008b). Several ice shelf retreats have been attributed at least in part to sub-shelf melting. Furthermore, future Antarctic ice shelf 
loss due to under-shelf warming and/or increased injection of warm Circumpolar Deep Water could result in ice shelf loss that was not captured by the SAT-derived ice shelf stability inference used here.

Several first order trends in the simulated future evolution of summer melt zones at each pole, as represented by the $200 \mathrm{PDD} \mathrm{yr}^{-1}$ threshold, were notable. Warming trends resulted in high summer melt periods over the entire Arctic Ocean by 2100, even if $\mathrm{CO}_{2}$ concentrations were capped at 2010 levels. Additionally, when the model was forced by emissions equivalent to all the present day fossil fuel resource base, most of the GIS experienced periods of extended summer surface melting by 2500, in agreement with other modelling studies (Ridley et al., 2005; Charbit et al., 2008). Ongoing work incorporating an integrated mass balance/dynamic ice sheet model into the coupled climate model indicates that this intensity of melting results in annually-averaged net ice loss from the GIS. Increased flow of meltwater into the GIS via moulins would warm interior ice through both advection of heat and latent heat release during refreezing, and contribute towards lubrication of the ice sheet bed. However, explicit analysis of this effect was beyond the scope of this study.

The high-emission scenario resulted in extended summer surface melt periods over the Ross, Ronne-Filchner and Amery ice shelves and lowerelevation portions of the WAIS by year 2850 with extensive summer melt beginning at $\sim 2100-2300$. This result suggested that in the absence of a mechanism that reinforces ice shelf stability (i.e. reduced sub-shelf melting) summer melting could begin to degrade the integrity of these large shelves where zones of existing surface glacial discontinuities exist. It is unlikely that ocean temperatures under the ice shelves will decrease, thereby counteracting the potential effect of melt-induced weakening. On the contrary, the simulated ocean immediately offshore of the Ross and Ronne-Filchner ice shelves between 300-1400 m water depth warmed by $2.2^{\circ}$ and $2.6^{\circ} \mathrm{C}$ respectively over the course of the high emission scenario simulation, providing an additional source of heat for basal shelf melt- 
ing. Introduction of significant simulated summer melting over the WAIS implied that in the future the WAIS surface may resemble that of the GIS, with similar accumulation of summer melt ponds, moulins and associated meltwater transfer to the ice sheet bed.

Recent analysis of sediment cores obtained from beneath the Ross Ice Shelf combined with ice sheet modelling (Pollard and DeConto, 2009) revealed cyclical retreats or even collapses of the Ross Ice Shelf and the WAIS during the warm early Pliocene, resulting in an open Ross Sea (Naish et al., 2009), despite $\mathrm{CO}_{2}$ concentrations of only $\sim 400$ ppmv. This implies that the WAIS was sensitive to retreat under climatic conditions that are expected to occur in coming decades. Vaughan and Doake (1996) suggested that a SAT warming of $10^{\circ} \mathrm{C}$ above present-day temperatures could threaten the Ross and Ronne-Filchner ice shelves. This magnitude of warming was simulated in response to combustion of all the present day fossil fuel resource base, but was notably absent over the large Antarctic ice shelves and the WAIS if $\mathrm{CO}_{2}$ was capped at 2010 concentrations. This indicates that at least two important climatic thresholds, that of largescale Antarctic ice shelf degradation and significant WAIS surface melting, could be crossed if human-derived $\mathrm{CO}_{2}$ emissions are not reduced. 


\section{Chapter 3}

\section{A new coupled ice sheet/climate model: description and sensitivity to model physics under Eemian, Last Glacial Maximum, late Holocene and modern climate conditions}

\subsection{Abstract}

The need to better understand long-term climate/ice sheet feedback loops is motivating efforts to couple ice sheet models into Earth System models which are capable of long-timescale simulations. In this paper we describe a coupled model that consists of the University of Victoria Earth System Climate Model (UVic ESCM) and the Pennsylvania State University Ice model (PSUI). The climate model generates a surface mass balance (SMB) 
field via a sub-gridded surface energy/moisture balance model that resolves narrow ice sheet ablation zones. The ice model returns revised elevation, surface albedo and ice area fields, plus coastal fluxes of heat and moisture. An arbitrary number of ice sheets can be simulated, each on their own high-resolution grid and each capable of synchronous or asynchronous coupling with the overlying climate model. The model is designed to conserve global heat and moisture. In the process of improving model performance we developed a procedure to account for modelled surface air temperature (SAT) biases within the energy / moisture balance surface model and improved the UVic ESCM snow surface scheme through addition of variable albedos and refreezing over the ice sheet.

A number of simulations for late Holocene, Last Glacial Maximum (LGM), and Eemian climate boundary conditions were carried out to explore the sensitivity of the coupled model and identify model configurations that best represented these climate states. The modelled SAT bias was found to play a significant role in long-term ice sheet evolution, as was the effect of refreezing meltwater and surface albedo. The bias-corrected model was able to reasonably capture important aspects of the Antarctic and Greenland ice sheets, including modern SMB and ice distribution. The simulated northern Greenland ice sheet was found to be prone to ice margin retreat at radiative forcings corresponding closely to those of the Eemian or the present-day.

\subsection{Introduction}

Ice sheets are important components of the climate system, but are among the least understood (Lemke et al., 2007). Dramatic changes to the global climate in the past are likely due in part to the evolution of large ice sheets in response to changing external forcing and internal ice sheet dynamics. Ice sheets may also exert a large influence on the climate system in the 
coming millennia, a time when large changes to the planet are expected in response to human forcing of climate. Recent research indicates that present and projected anthropogenic carbon emissions and corresponding temperature will be retained by the surface-Earth carbon system over millennial timescales (Montenegro et al., 2007; Eby et al., 2009). Such timescales are relevant to ice sheet dynamics and evolution. It is therefore important that the effect of such emissions on the cryosphere be explored, before thresholds on ice sheet stability, based on increases to atmospheric or ocean temperatures, are surpassed and the Earth becomes irreversibly committed to near-permanent ice sheet decay or loss and associated sea level rise (Ridley et al., 2010).

A coupled Earth system modelling approach is a powerful way to explore interactions between ice sheets and climate. Coupled Earth system models incorporate realistic subcomponent models (e.g., atmosphere, ocean, or land surface) and interactive communication of fluxes between subcomponents in such a way that allows feedbacks within the climate system to be resolved. To date only a few fully coupled Earth system models with the ability to realistically simulate climate change over millennial timescales have been synchronously coupled to high resolution, dynamic ice sheets (e.g., Kageyama et al., 2004; Ridley et al., 2005; Driesschaert et al., 2007; Vizcaíno et al., 2008; Charbit et al., 2008; Vizcaíno et al., 2010; Pritchard et al., 2008a). Furthermore, to date no coupled ice-climate models have explicitly represented the large Antarctic ice shelves.

A new ice-sheet/ice-shelf/climate model consisting of the University of Victoria Earth System Climate Model (UVic ESCM) and the Pennsylvania State University ice sheet model (PSUI) is presented here. It is designed to efficiently simulate the ice sheet/climate system over 1-10 kyr timescales. First, the model and its components are described. Then, the performance of the model under equilibrium Eemian (c. $129 \mathrm{kyr}$ BP), LGM (c. 21 kyr BP), late Holocene (c. $0.2 \mathrm{kyr} \mathrm{BP}$ ), and transient modern climate conditions is evaluated in response to simple perturbations to model 
physics, including the treatment of climate model surface air temperature (SAT) bias, surface albedo, and refreezing. Finally, a transient simulation that models present-day SMB conditions is described.

\subsection{Model description}

Several major design requirements dictated the choice of both climate and ice sheet models, as well as the design of the coupling software, and motivated the choice of the UVic ESCM, version 2.9 and PSUI as suitable candidates for coupling. An earlier version of the UVic model had previously been coupled to an ice sheet model (Marshall and Clarke, 1997) and used to study the role of ice sheets during deglacial periods (Yoshimori et al., 2001; Schmittner et al., 2002b). However, the representation of ice in these studies was simplified, in part due to very low ice sheet resolution, isothermal ice and an inability to resolve floating ice shelves. Given the recent advances in ice sheet modeling we felt it prudent to update the ice sheet component of the UVic ESCM to the full PSUI model.

\subsubsection{UVic ESCM}

UVic ESCM is an Earth System model of intermediate complexity that includes fully coupled atmospheric, oceanic and land surface components, a thermodynamic/dynamic sea ice model and a closed and coupled complex carbon cycle model. The ocean component is the full 3-D ocean general circulation model MOM2 (Pacanowski, 1995). The atmospheric component consists of a vertically integrated energy-moisture balance model in which the radiative forcing associated with an increase in atmospheric $\mathrm{CO}_{2}$ is applied as a decrease in outgoing long wave radiation. Heat and moisture are diffused and advected throughout the atmosphere, with winds being provided by present-day 
NCEP climatological long-term monthly means (Kalnay et al., 1996). Dynamic modification to the prescribed wind fields is obtained by a routine which generates anomalies to the monthly mean winds as a function of surface air temperature (Weaver et al., 2001). The land surface component of the model includes the MOSES-TRIFFID global vegetation model (Meissner et al., 2003). The model has been extensively used for a large number of studies of paleoclimate and future climate projections and is currently under active development and use. The UVic ESCM was recently run at ocean eddy-resolving resolution (Spence et al., 2008). While regional differences exist between this version of the UVic ESCM and the standard lower resolution version, the overall response is similar between the two. We therefore retain the standard UVic ESCM resolution of $3.6^{\circ}$ in longitude by $1.8^{\circ}$, as this allows millennial-scale simulations to be performed on existing computers.

\subsubsection{PSUI}

PSUI is a hybrid ice-sheet/ice-shelf model that simulates grounded and floating ice. Over inland ice on stiff bedrock, the shallow-ice approximation applies. Over ice with reduced basal traction (for example, ice shelves and regions of the West Antarctic Ice Sheet), the shallow shelf equations are employed. The transition between the two is dealt with heuristically by iteratively blending the velocities of both

solutions. Additionally, a grounding-line ice velocity is imposed, and shelf back-stress is included, based on the analytic treatment of Schoof (2007). Three-dimensional advection and vertical diffusion of heat, and lithospheric flexure/local bedrock isostasy are calculated. Detailed descriptions of the model are in the Supplementary Material of Pollard and DeConto (2009), and Pollard and DeConto (2007). 


\subsubsection{Ice-atmosphere coupling}

\section{Energy-moisture balance model (EMBM)}

The ice sheet surface mass balance (SMB), consisting of melt, runoff, sublimation and accumulation, is calculated using a modified version of the existing UVic ESCM vertically integrated energy-moisture balance atmosphere model (EMBM) and simple snow model. We were motivated to use the existing EMBM, instead of a positive-degree-day (PDD) model, to calculate the SMB for reasons that have been recently described (e.g., Bougamont et al., 2005). PDD approaches rely solely on surface air temperature (SAT) to derive snow or ice melt rates. The PDD factor must therefore be tuned to capture the effect of changing albedo and related non-sensible surface energy fluxes. However, this implicit adjustment may break down in scenarios where, for example, insolation remains constant but SAT increases due to higher concentrations of atmospheric greenhouse gases, or ice sheet elevation changes dramatically.

Inputs to the energy balance calculation are incoming shortwave radiation, specific humidity, wind speed, surface skin temperature, albedo and roughness, and surface air temperature (elevated from sea level using a constant lapse rate, nominally $5.0^{\circ} \mathrm{C} / \mathrm{km}$ ). This lapse rate is comparable to the summer lapse rate over the Greenland Ice Sheet (GIS) (Fausto et al., 2009), and like Stone et al. (2010) we suggest that this low lapse rate is a reasonable choice, as it reproduces summer ablation reasonably without significantly affecting wintertime accumulation. The snow temperature is found by solving the energy balance equation:

$$
Q_{\mathrm{dswr}}+Q_{\mathrm{dlwr}}=Q_{\mathrm{lt}}(T)+Q_{\mathrm{s}}(T)+Q_{\mathrm{ulwr}}(T)
$$

for temperature, using Newton's method. $T$ is temperature, and $Q_{\mathrm{dswr}}$, $Q_{\mathrm{dlwr}}, Q_{\mathrm{lt}}, Q_{\mathrm{s}}$ and $Q_{\mathrm{ulwr}}$ are incoming shortwave, incoming longwave (both supplied by the UVic ESCM), outgoing latent, outgoing sensible and outgoing longwave heat fluxes, respectively. Snow and ice emissivity is set 
to 0.94 . During the iteration, the surface equilibrium vapor pressure is determined and compared to the ambient specific humidity. If the equilibrium specific humidity is greater, solid-to-vapor wind-enhanced sublimation occurs to equalize vapor pressures and the outgoing latent heat and moisture fluxes are determined. If the surface temperature is at the melting point after the iteration and a net flux of energy into the surface exists, it is entirely used to melt snow /ice. Sublimation of scoured, airborne snow (Box et al., 2006; Lenaerts et al., 2010) is not explicitly modelled, although wind speed is used in the calculation of the sublimation-derived moisture flux and therefore has a direct effect on surface sublimation rates.

Representation of snow and runoff used here is relatively simple, in line with the intermediate-complexity character of the UVic ESCM. An arbitrary maximum snow thickness of $10 \mathrm{~m}$ is prescribed, above which any additional accumulation is added to the ice sheet as a positive SMB. Conversely, the entire $10 \mathrm{~m}$ snowpack must melt before ice ablation can occur. The snow model is greatly simplified by assuming that snow/ice heat capacity $c_{p}=0$ (i.e., the snowpack temperature is always equal to the surface temperature) for the sake of energy balance calculations. This assumption leverages the fact that heat fluxes used to change snow and ice temperatures are an order of magnitude less than the the heat fluxes required for phase changes and can be neglected. This simplification is mirrored in the approach of Robinson et al. (2009).

Pfeffer et al. (1991), Bougamont et al. (2007) and others have recognized the importance of refreezing in limiting runoff from ice sheets. In order to capture the effect of refreezing within the relatively simple snow model, the parameterization described in Pfeffer et al. (1991) for representing refreezing of meltwater is adopted. An annual snow thickness (i.e., between last fall melt and first spring melt) is first accumulated. When melt is first detected, the thickness of meltwater that is stored in the snowpack is calculated based on the requirements that the annual snowpack average temperature be raised to freezing point and all the available pore space within 
the snowpack be filled. The scheme effectively assumes that an impermeable layer exists between annual layers in the snowpack and that the annual snow layer has a constant density (set to $330 \mathrm{~kg} / \mathrm{m}^{3}$ ).

Over ice sheets, surface albedo varies as a function of snow/ice thickness and snow/ice temperature. Default albedo values for cold/melting snow albedo are 0.8/0.6, with a linear interpolation between cold and warm snow values occurring between $-5^{\circ} \mathrm{C}$ and $0^{\circ} \mathrm{C}$. Glacial ice albedo is set to 0.45 . At snow thicknesses below $10 \mathrm{~cm}$, snow and ice albedos are linearly blended. These values are very similar to those of Robinson et al. (2009), though they were obtained independently by setting albedo values to approximate the glacier zone-specific values of Nolin and Payne (2007). The current model does not yet account for age-related changes in snow albedo (e.g., van de Wal and Oerlemans, 1994).

Moisture is delivered to the ice sheets via advective/diffusive transport within the atmospheric model. Precipitation occurs when the relative humidity at the surface surpasses 0.85 . This relative humidity is calculated as a function of the subgridded elevation-dependent SAT and the specific humidity of the overlying atmospheric grid cell. Precipitation falls as rain/snow when the sub-gridded temperature is above/below a threshold temperature, set over ice sheets to $-2^{\circ} \mathrm{C}$ which is approximately the midrange of the observationally-derived snow-to-rain temperature parameterization of Robinson et al. (2009).

\section{Subgridded elevation-binned mass balance calculations}

Realistic transfer of climate-model-derived SMB to high resolution ice sheet grids is a non-trivial exercise due to spatial and temporal differences in scale between ice sheet and climate models (Pollard, 2010). Ice sheet models require grids on the order of $10^{0}-10^{1} \mathrm{~km}$ to 
appropriately resolve ice flow and gradients in SMB (particularly ablation). However, due to the slow flow of ice, time steps can be long, on the order of months to years. Climate models, on the other hand, typically operate on grids with spatial scales on the order $10^{2} \mathrm{~km}$ and temporal scales of minutes to days. In order to accommodate the variation in scales while maintaining computational efficiency and conservation of mass and energy, a routine was developed to calculate SMB based on the distribution of elevation within each climate grid cell. Instead of one EMBM calculation per climate grid cell, the scheme allocates $N$ EMBM calculations:

$$
N=\operatorname{int}(R / D)+1
$$

where $R$ is the total relief (defined as the difference between the maximum and minimum ice sheet surface elevations falling within the larger UVic ESCM grid cell, Figure 3.1) and $D$ is the binning threshold of the elevations bins, set to $100 \mathrm{~m}$. Within each bin, the elevation is set to the average area-weighted elevation of the ice sheet grid cells that fall within the bin elevation range, and for each bin the EMBM algorithm evolves independent albedos, $Q_{\mathrm{lt}}(T), Q_{\mathrm{s}}(T), Q_{\mathrm{ulwr}}(T)$, snow thicknesses, and SMB values. When remapped back onto the ice sheet grid, the resolution of ablation zones and accumulation over short-wavelength, high-relief topography is greatly improved, in agreement with the similar approach and results of Wild et al. (2003). Over topography with wavelengths greater than the overlying climate model grid resolution (e.g., the continental East Antarctic Ice Sheet, EAIS) the subgrid scheme-derived accumulation field rapidly approaches the equivalent non-subgridded distribution.

Prior to each atmospheric time step, fluxes from all subgrid ice sheet bins within a climate model cell are accumulated, after area-weighting, and passed to the atmospheric model. This implies that the atmosphere is well mixed within each climate model cell, which was the implicit assumption before subgrid binning was introduced. At initialization and 


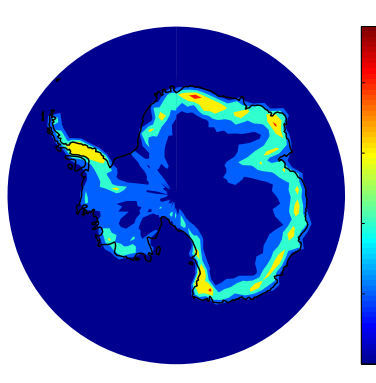

(a) AIS relief

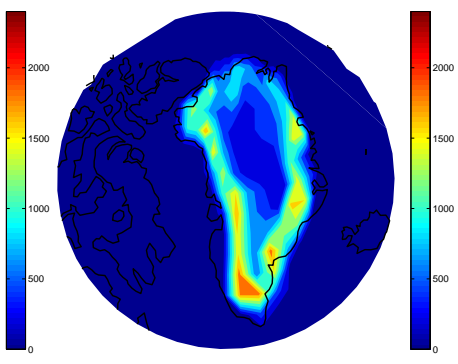

(b) GIS relief

Figure 3.1: Total relief used to determine number of elevation bins in each climate model grid cell (m) for the Antarctic Ice Sheet (AIS) and Greenland Ice Sheet (GIS), where total relief is the maximum elevation minus the minimum elevation existing in the ice sheet grid cells contained within the boundaries of a UVic ESCM grid cell.

after each ice sheet timestep, the elevation bins are re-calculated according to the updated ice sheet geometry and the existing snowpack is redistributed into the new elevation bins. Where the ice dynamically retreats or melts over land or ocean any residual snow, if it exists, is sent to the ocean. Where the ice sheet dynamically expands, snow from the overridden bare land is transferred to the ice sheet surface. Finally, the updated fractional ice coverage is relayed to the overlying climate model grid. Model simulations with and without the sub-gridded elevation binning scheme indicate that the subgrid-enabled scheme is much better suited to resolve narrow ablation zones (limited in width only by the underlying ice sheet grid resolution) and orographically driven precipitation over short wavelength topography than interpolation-based SMB downscaling procedures. Furthermore, it retains computational efficiency by automatically focussing computing resources over high-relief regions, not unlike the manual procedure of van de Wal and Oerlemans (1994). For the modern ice sheet distribution, the number of EMBM calculations is reduced by a factor of 14, compared to the same number of equivalent calculations over each 
high-resolution ice sheet grid-point. The resulting system is designed to conserve mass and energy to within machine precision, in accordance with the rest of the UVic ESCM.

\section{SAT bias correction}

Surface mass balance and evolution of ice sheet geometry are highly sensitive to variations in SAT that are of the same magnitude as SAT biases in present-generation climate models (van de Wal and Oerlemans, 1994; Pollard, 2000). For this reason, previous coupled ice sheet-climate model studies (e.g., Ridley et al., 2005, 2010) have utilized approaches in which modelled temperature anomalies, obtained by subtracting a perturbed model state from the control value, are added to observational climatologies prior to processing by PDD models. This method reduces spurious $\mathrm{SMB}$ values resulting from persistent and intrinsic modelled temperature biases but is handicapped by drawbacks of the PDD model approach (Sect. 3.3.3). Other studies (Bonelli et al., 2009; Pritchard et al., 2008a; Charbit et al., 2008) also utilized the PDD approach, but with "uncorrected" climate model SAT that still retained a climate model SAT bias. Recently, Calov et al. (2009) and Vizcaíno et al. (2010) employed surface energy balance models to calculate SMB over the Northern Hemisphere and Greenland, respectively, without SAT corrections. They suggested that their annual present-day modelled climatology was sufficiently similar to observations to justify use of raw model output to supply their SMB model. However, visual inspection of Figure 1 in Vizcaíno et al. (2010) suggests that differences of $\sim 5-10^{\circ} \mathrm{C}$ still exist in their annually averaged surface air temperature and Calov et al. (2009) do not provide an analagous difference figure of SAT.

In order to use a surface energy balance model to generate $\mathrm{SMB}$, but also analyze and optionally correct the effect of climate model-derived SAT biases on ice sheet evolution, all without losing global conservation of 
energy, the following bias correction procedure for use in the EMBM was developed.

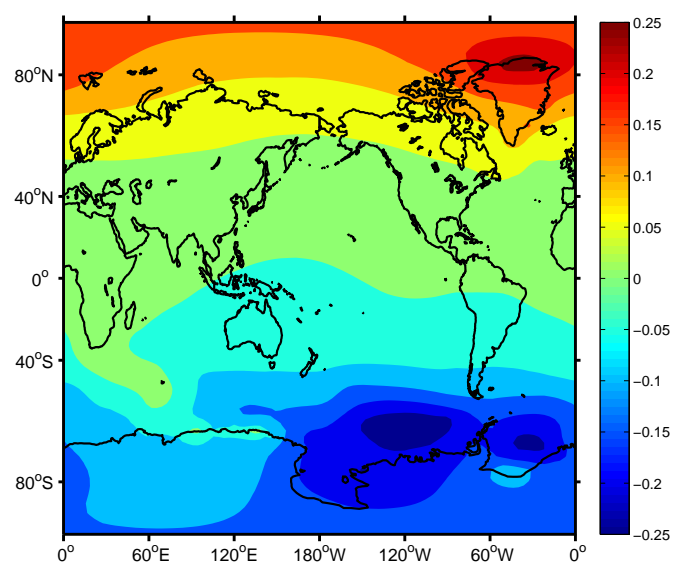

Figure 3.2: The difference $\left({ }^{\circ} \mathrm{C}\right)$ between annual mean UVic ESCM atmospheric SAT fields of late Holocene simulations with/without the bias correction applied over the ice sheets. The effect of the bias correction procedure is largest over the AIS and GIS and diminishes with distance from the correction regions. The global affect of the bias correction over both ice sheets is to redistribute heat from the Southern Hemisphere to the Northern Hemisphere. However, the resulting temperature change is less than $0.25^{\circ} \mathrm{C}$ everywhere and does not significantly affect the non-ice-sheet components of the system.

1. A UVic ESCM simulation forced with late Holocene orbital and $\mathrm{CO}_{2}$ conditions was run to equilibrium. Ice sheet model elevations were held constant at present-day values. Equilibrium late Holocene monthly-mean raw model SAT fields were extracted.

2. The model was then forced with transient $\mathrm{CO}_{2}$ concentrations to year 2000, and the monthly-mean temperature difference between year 2000 and the late Holocene steady state was obtained. 
3. This difference was subtracted from the 1971-2000 ERA40 (Uppala et al., 2006) monthly-mean SAT to derive an observed SAT, extrapolated to late Holocene conditions.

4. Another late Holocene UVic ESCM simulation was carried out, in which the model-derived SAT values were replaced with the late Holocene "observed" SAT values used in the EMBM calculations over the ice sheets (the SAT used in non-ice-sheet EMBM calculations remained the value provided by the atmospheric component of the UVic ESCM). This procedure effectively forced the energy balance model over ice sheet domains to respond to SAT anomalies and generated a regionally altered pattern of atmospheric heat transport. This altered transport field perturbed the global modelled SAT field in bias-corrected simulations, but the magnitude of the perturbation was less than $0.25^{\circ} \mathrm{C}$ anywhere (Figure 3.2) and lessened with distance from the ice sheets.

5. The monthly-mean SAT difference between the two simulations was obtained. These monthly-mean bias maps were added as a correction factor to the UVic ESCM atmospheric temperature used in the calculation of the surface energy balance and the rain/snow decision.

Results of the bias-corrected models are described in Sect. 3.4.2.

\subsubsection{Ice-land coupling}

As the simulated grounded ice sheets advance or retreat they cover or expose bare land. The dynamic vegetation model MOSES-TRIFFID is currently excluded from any potential ice sheet region (i.e., the island of Greenland and the Antarctic continent) in the present version of the model. Instead, the albedo and roughness lengths of bare land areas in 
Greenland and Antarctica are set to values typical of tundra (when free of snow). For GIS and AIS simulations initialized with existing ice that do not undergo drastic retreat this is likely a reasonable approach.

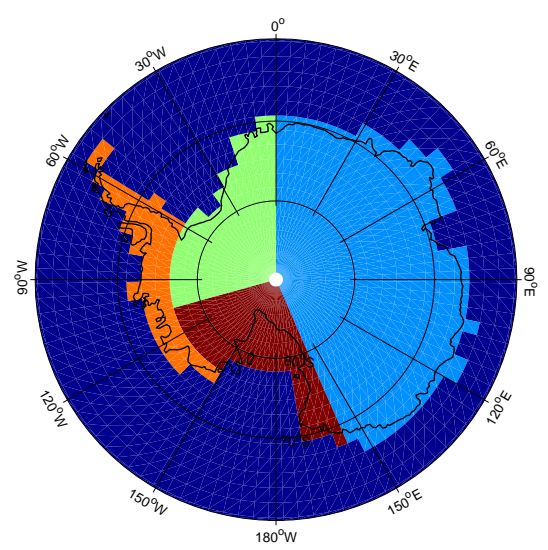

Figure 3.3: Antarctic drainage basins. Moisture and heat fluxes associated with ice discharge are evenly distributed to coastlines within each drainage basin.

Surface meltwater is routed instantaneously via large-scale drainage basins to the ocean model. The AIS drainage basin distribution (Figure 3.3) is based roughly on present-day ice surface topography and would become unrealistic only under a drastic change to ice geometry or significant continental-scale deviation in subglacial drainage from the surface topography. The GIS was assigned one drainage basin, resulting in an even distribution of meltwater flux around the GIS coast.

The elevation field of climate model grid cells that overlay ice sheet model instances evolve according to the grid-averaged ice sheet or exposed bedrock elevations calculated by the ice sheet lithosphere model. Elevations remain static over climate grid cells that do not overlay ice sheet grids. 


\subsubsection{Ice-ocean coupling}

PSUI explicitly simulates ice shelves and a dynamic grounding line. Ice shelves are represented in the UVic ESCM by fractional surface coverage of ocean grid cells. Increasing fractional ice shelf coverage progressively "shades" underlying ocean and sea ice grid cells from atmospheric heat and moisture fluxes until the climate grid cell is fully covered, at which point the ocean and sea ice models are completely insulated from all atmospheric heat and moisture fluxes. The treatment of momentum fluxes is slightly different. If atmospheric momentum fluxes are simply shaded, calculation of sea ice dynamics within the dynamic/thermodynamic sea ice component of the UVic ESCM results in artificial convergence and divergence of sea ice in partially-covered ocean cells. Therefore, sea ice is allowed to advect freely in partially-covered ocean cells (although the thermodynamically derived rate of change of sea ice thickness is reduced due to decreased heat and moisture fluxes).

Simulated bathymetry in the ocean model MOM2 was improved over the default UVic ESCM bathymetry to better represent modern undershelf conditions (Lythe and Vaughan, 2001). The ocean is therefore free to circulate to the equivalent of the modern-day AIS grounding line. MOM2 is not capable of capturing the effect of a depressed upper boundary geometry. For this reason, as well as the the coarse scale of the ocean model, oceanic effects associated with ice shelf draft are currently neglected.

Modelling and observations indicate that oceanic melting of ice shelves plays an important role in ice sheet evolution (Pollard and DeConto, 2009; Payne et al., 2004). Modelling results that attempt to simulate the interaction between ice shelves and subshelf ocean circulation (Holland et al., 2008b; Olbers and Hellmer, 2009) suggest that an ocean temperature increase of only a few degrees Celcius results in a quadratic increase in ice shelf melt rates. The obvious relationship between ocean temperature and ice shelf melt rates calls for a parameterization that links ice shelf melt 
rates to coarse modelled ocean temperatures. However, this version of the coupled model does not currently include such a parameterization as a default option. Instead, melt rates and calving are prescribed according to the method described in the Methods section of Pollard and DeConto (2009) for either modern or LGM conditions for the AIS. This parameterization, which generates a time-and-space-evolving distribution of subice-shelf melt, is based on a triplet of melt values $\left(\mathrm{M}_{p}<\mathrm{M}_{d}<\mathrm{M}_{e}\right)$ for protected, deep-ocean and exposed-shelf conditions, respectively. This triplet of melt values is combined based on gridpoint-specific bathymetry, access to open ocean, and distance to the current shelf edge, to generate pointspecific sub-shelf melt rates. In lieu of a universal calving law, calving is parameterized as high sub-shelf melt, which increases with decreasing straight-line distance to the shelf edge, as described above. The overall parameterization was tuned by Pollard and DeConto (2009) in order to obtain realistic late Holocene and LGM ice shelf extents when combined with realistic sea level. The associated triplet values are given in Table 3.1. Fluxes of moisture and heat derived from AIS sub-shelf melting are delivered to the ocean along the ice shelf edge. In contrast to the AIS, sub-shelf melt is simply set to high values for the GIS (although the model does not generate spurious GIS shelves in the present-day with the standard Pollard and DeConto (2009) parameterization values).

Table 3.1: Sub-shelf melt triplet values used in the ice shelf melting parameterization that is employed here. $\mathrm{M}_{p}$ =protected shelf melt values, $\mathrm{M}_{d}=$ deepwater shelf melt values, $\mathrm{M}_{e}=$ exposed shelf melt values. For more information, see Pollard and DeConto (2009).

\begin{tabular}{lccc}
\hline Sub-shelf melt triplet values (m/yr ice) & $\mathrm{M}_{p}$ & $\mathrm{M}_{d}$ & $\mathrm{M}_{e}$ \\
\hline late Holocene & 0.1 & 5 & 5 \\
\hline LGM & 0 & 0 & 2 \\
\hline
\end{tabular}

The ice sheet model has the ability to simulate large-scale grounding 
line migration (Pollard and DeConto, 2009) similar to that found in West Antarctic Ice Sheet (WAIS) paleoclimate records (Naish et al., 2009). However, the current UVic ESCM ocean component does not support lower and lateral boundary geometry (i.e., bathymetry and coastline) adjustment. For this reason, any potential climatic effects of large-scale (order $10^{2} \mathrm{~km}$ and above) grounding line migration, such as that implied by the endmember no-WAIS case of Bougamont et al. (2007), are not captured. Here we effectively assume that large-scale oceanographic effects resulting from grounding-line-migration-induced changes to ocean basin geometry are small and recognize that the ability to make ocean boundaries track dynamic grounding lines is an obvious avenue for future ocean model development. In general, we believe the existing model provides an excellent foundation for development of a complete ocean-ice coupling procedure.

\subsubsection{Multiple ice sheet capability, initialization, ice accel- eration and $\mathrm{I} / \mathrm{O}$}

One global, high-resolution ice sheet grid within the global coupled model is not feasible for geometric and computational reasons (Rutt et al., 2009). Therefore, following Rutt et al., the model was designed to accommodate multiple ice sheet "instances", which contain variables describing the entire state of each independent ice sheet in separate derived data type (DDT) variables. The ice sheet instances are accessible via corresponding Fortran 90 pointers (Metcalf and Reid, 1999). This method permits independent regional ice sheet model instances (each with different resolutions, grid sizes, time steps, and ice sheet physics parameters) to exist within a single coupled climate/ice sheet model simulation.

Ice sheets are among the slowest of the exogenic Earth system components to respond to applied climatic forcings. For this reason we have included the ability to accelerate ice sheet evolution relative to the climate. 
For equilibrium simulations, annual SMB is accumulated, and then used to force the ice sheets for multiple years. Resulting moisture and heat fluxes from ice sheets to the surrounding climate are scaled proportionally (Yoshimori et al., 2001) resulting in a loss of global conservation of heat and moisture. Ice acceleration is limited to no more than 20 times (i.e., one year of climate forcing drives no more than 20 years of ice sheet evolution) for equilibrium simulations. Given the efficiency of the UVic ESCM, this still allows $100 \mathrm{kyr}$ simulations to be carried out within a reasonable timeframe. Long-term (i.e., over $10 \mathrm{kyr}$ ) transient simulations can be carried out using a technique in which the orbital and $\mathrm{CO}_{2}$ forcings are accelerated at the same rate as the ice sheet. Following Calov et al. (2009) we limit the acceleration in these cases to no more than 10 times due to the long dynamic and thermal response times of the ice sheet, as well as the abyssal oceans. Interannual variability is not simulated by the UVic ESCM, so we are not concerned with extraction of a longterm climatology for use in forcing the ice sheet model, despite suggestions that millennialscale ice sheet evolution may in fact be sensitive to ENSO-timescale climate variability (Pritchard et al., 2008b).

The current model configuration contains two ice sheet instances that represent the GIS and AIS. Both operate on $20 \mathrm{~km}$ resolution stereographic grids with grid dimensions of 76 by 140 and 282 by 282 grid cells, respectively. At yearly intervals each ice sheet is targeted and run through the ice sheet subroutines for $A_{i} / d t_{\text {ice }}$ timesteps, where $d t_{\text {ice }}$ is the ice sheet timestep (years) and $A_{i}$ is the acceleration factor. In the following experiments each ice sheet utilizes $d t_{\text {ice }}=0.25 \mathrm{yr}$.

Both the ice sheet model and climate model have the capability to initialize from observations or the saved states of previous model simulations. Initial ice sheet observations are obtained from Bamber et al. (2001) for the GIS and Lythe and Vaughan (2001) for the AIS. As the dimension of subgridded elevation bin arrays changes interactively with ice sheet model size and geometry, restarts are checked at initialization to ensure 
they are consistent. If not, new subgridded arrays are constructed and the existing snowpack is redistributed.

\subsection{Results and discussion}

A suite of sensitivity tests was carried out in order to explore the response of the simulated AIS and GIS to model physics, and to approach the model design that produced optimal equilibrium ice sheet states for Eemian, LGM, and late Holocene climate forcings. Equilibrium ice sheet simulations imply non-changing climate forcings, which is not the case in reality. However, since the equilibrium experiments were primarily meant to isolate the effect of model physics on GIS/AIS ice sheet evolution, transient climate forcings (e.g., $\mathrm{CO}_{2}$, orbitally-induced changes to insolation and sea level) were intentionally set to constant values in these equilibrium simulations. To assess the simulated effect of recent climate forcings, we carried out a transient simulation to evaluate simulated SMB trends over modern AIS and GIS geometry and the approximate state of disequilibrium of the present-day ice sheets with respect to anthropogenically-perturbed radiative forcing.

For each equilibrium experiment the model was forced with relevant orbital and $\mathrm{CO}_{2}$ forcings. The paleoclimate equilibrium $\mathrm{CO}_{2}$ concentrations were obtained from a composite of the Vostok (Petit et al., 1999), Taylor Dome (Indermühle et al., 2002), and Law Dome (Meure et al., 2006) ice core records. In all equilibrium simulations the ice sheets were initialized from ice-present conditions (glacial inception was not simulated). The ice sheets were accelerated with respect to the climate by a factor of 20 to hasten the approach to equilibrium. The results described below focus on the effects of climate-model-generated SAT biases, albedo, and parameterized refreezing for each climate state. Simulations with corrected SAT biases, refreezing of meltwater, and variable surface albedo were treated 
as control simulations. The effect of perturbing the model physics was then analysed by comparing runs without SAT bias correction, refreezing, or surface albedo against the control runs. AIS and GIS ice volumes and areas are summarized in Tables 3.2 and 3.3, respectively.

Table 3.2: Final AIS ice volumes $\left(/ 10^{6} \mathrm{~km}^{3}\right)$ and areas $\left(/ 10^{6} \mathrm{~km}^{2}\right)$ for all equilibrium experiments. $N M R R=$ no melting/refreezing; $N B C=$ no bias correction; $\mathrm{CA}=$ constant albedo.

\begin{tabular}{|l|c|c|c|c|}
\hline AIS ice volumes & Control & NMRR & NBC & $C A$ \\
Eemian & 31.2 & 31.2 & 28.1 & 31.3 \\
LGM & 40.4 & 40.1 & 38.1 & 40.5 \\
Late Holocene & 30.9 & 30.9 & 28.2 & 31.2 \\
\hline AIS ice areas & & & & \\
Eemian & 14.2 & 14.1 & 14.2 & 14.2 \\
LGM & 18.7 & 18.7 & 18.5 & 18.7 \\
Late Holocene & 14.1 & 14 & 14.2 & 14.1 \\
\hline
\end{tabular}

Table 3.3: Final GIS ice volumes $\left(/ 10^{6} \mathrm{~km}^{3}\right)$ and areas $\left(/ 10^{6} \mathrm{~km}^{2}\right)$ for all equilibrium experiments. NMRR=no melting/refreezing; $N B C=$ no bias correction; $\mathrm{CA}=$ constant albedo.

\begin{tabular}{|l|c|c|c|c|}
\hline GIS ice volumes & Control & NMRR & NBC & $C A$ \\
Eemian & 2.19 & 1.51 & 3.59 & 3.45 \\
LGM & 3.68 & 3.64 & 3.66 & 3.75 \\
Late Holocene & 3.47 & 3.14 & 3.61 & 3.75 \\
\hline GIS ice areas & & & & \\
Eemian & 1.29 & 1.01 & 2 & 1.92 \\
LGM & 2.12 & 2.07 & 2.14 & 2.22 \\
Late Holocene & 1.91 & 1.76 & 2.04 & 2.14 \\
\hline
\end{tabular}



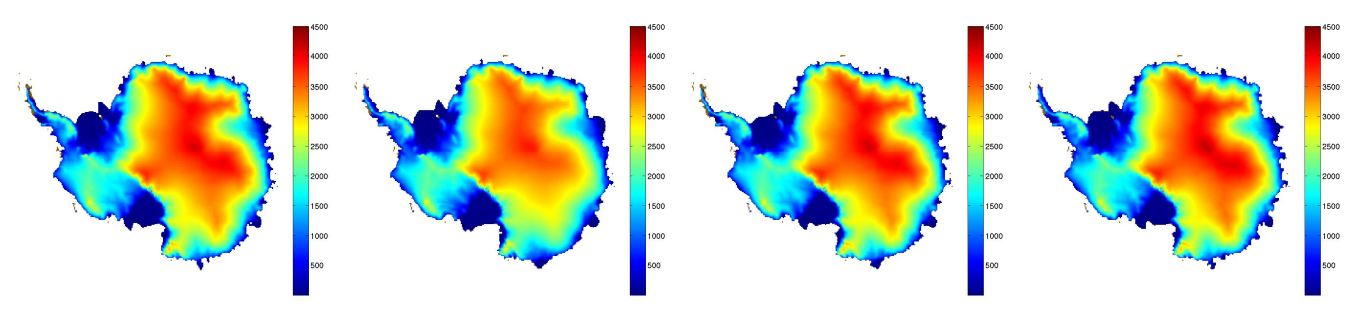

(a) Hol. control

(b) Hol. NBC

(c) Hol. NMRR

(d) Hol. CA
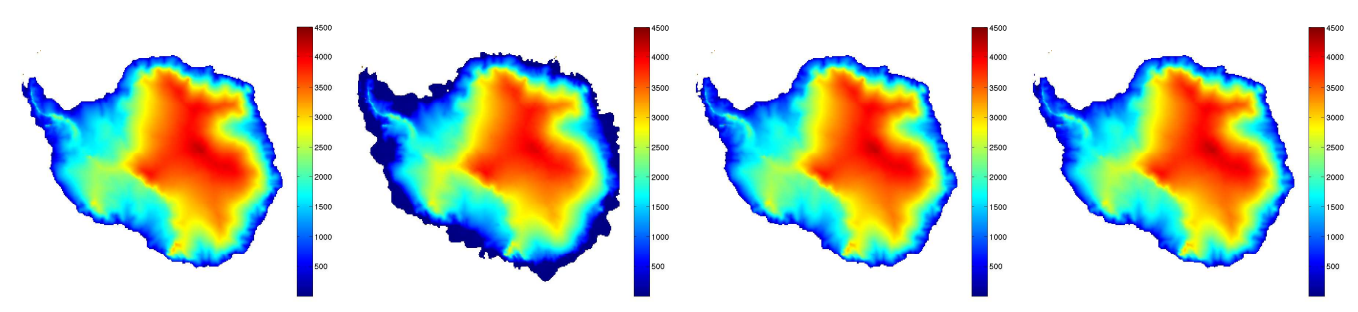

(e) LGM control

(f) LGM NBC

(g) LGM NMRR

(h) LGM CA

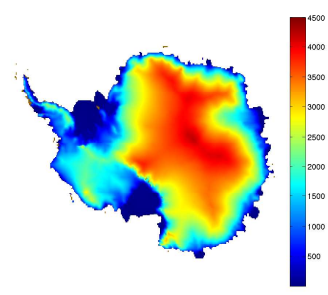

(i) Eem. control

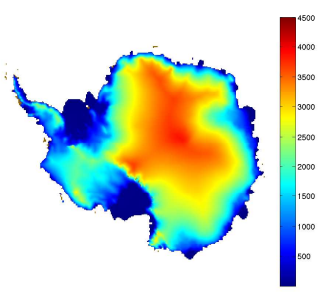

(j) Eem. NBC

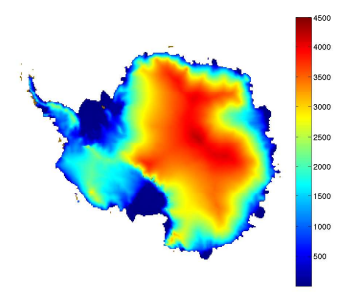

(k) Eem. NMRR

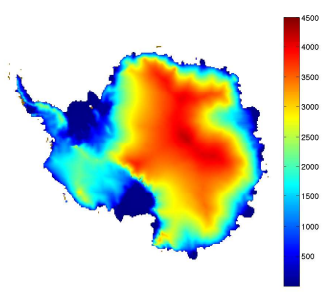

(1) Eem. CA

Figure 3.4: AIS surface ice elevation $(\mathrm{m})$ from control and perturbed physics experiments. NBC=non-bias-corrected, NMRR=non-meltwaterretention or refreezing, $\mathrm{CA}=$ constant albedo. 


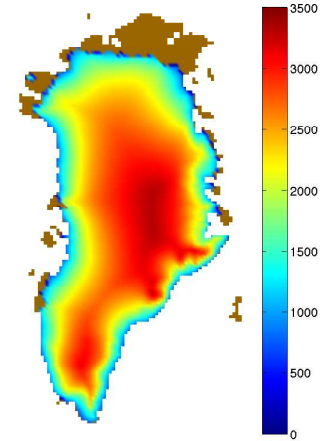

(a) Hol. control

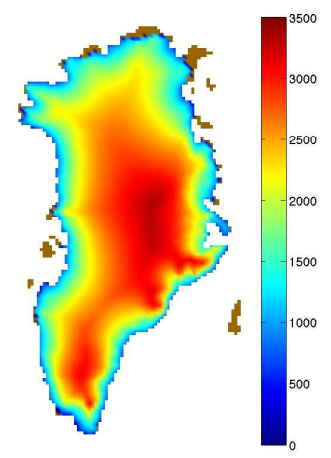

(e) LGM control

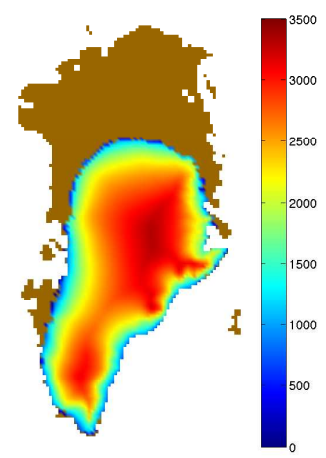

(i) Eem. control

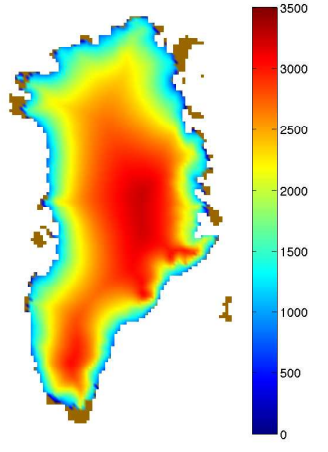

(b) Hol. NBC

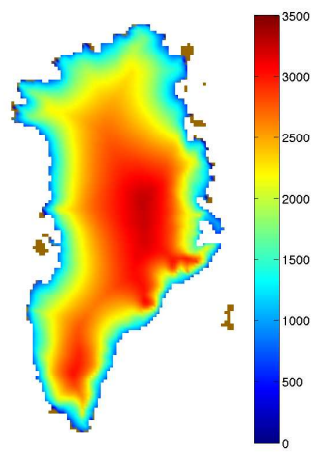

(f) LGM NBC

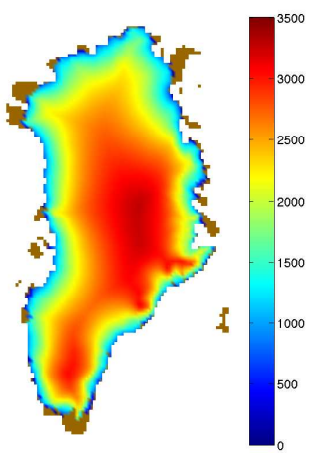

(j) Eem. NBC

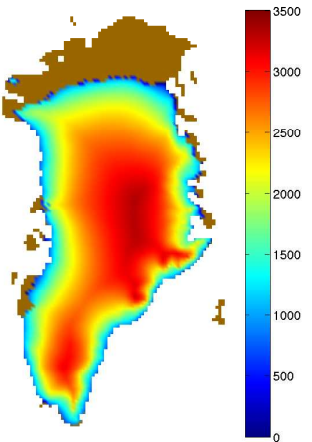

(c) Hol. NMRR

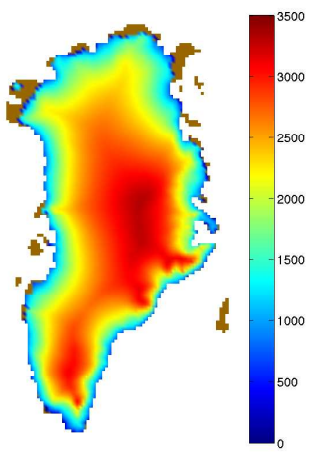

(g) LGM NMRR

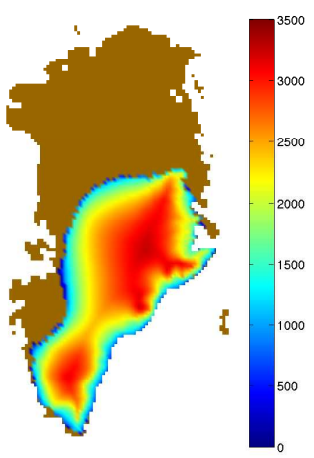

(k) Eem. NMRR

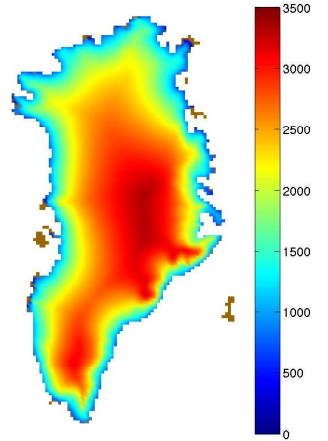

(d) Hol. CA

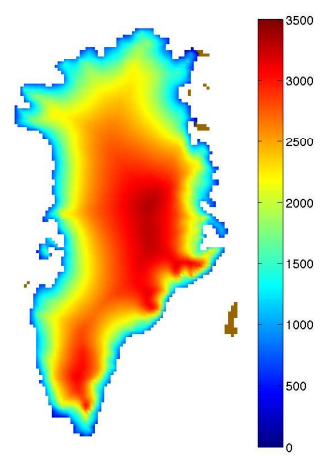

(h) LGM CA

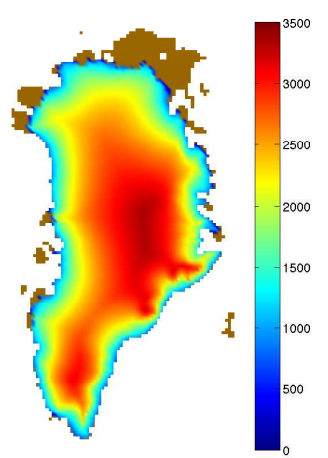

(l) Eem. CA

Figure 3.5: GIS surface ice elevation $(\mathrm{m})$ from control and perturbed physics experiments. NBC=non-bias-corrected, NMRR=non-meltwaterretention or refreezing, $\mathrm{CA}=$ constant albedo. 


\subsubsection{Control simulations}

\section{Late Holocene}

In order to simulate equilibrium ice sheet conditions representative of the late Holocene, orbital and $\mathrm{CO}_{2}$ concentrations were set to $0.2 \mathrm{kyr} \mathrm{BP}$. The control AIS late Holocene volume (Figure 3.4a) grew to $30.9 \times 10^{6} \mathrm{~km}^{3}$, from the initial (present-day observed) volume of approximately $26 \times 10^{6} \mathrm{~km}^{3}$. This overestimation was not due to the neglect of transient forcings or spurious SMB. Rather, since excess ice grew primarily in regions that are presently observed to discharge ice through prominent ice streams (the Ross Sea sector of the WAIS, the Pine Island Glacier ice drainage basin, the Transantarctic Mountains, and the Amery/Prydz Bay region) it is very likely that the overestimation was due to the inability of the model to fully represent ice stream features. This is a common problem among recent modelling studies (Stone et al., 2010; Vizcaíno et al., 2010) that requires a fuller representation of outlet glaciers in whole ice sheet models to alleviate. However, the elevation of the central dome of the EAIS was captured to within $100 \mathrm{~m}$, and the total ice extent, including ice shelves, equilibrated at $14.1 \times 10^{6} \mathrm{~km}^{2}$, close to the initial ice area.

The control GIS late Holocene volume (Figure 3.5a) grew to $3.47 \times 10^{6} \mathrm{~km}^{3}$ from an initial observed volume of approximately $2.9 \times 10^{6} \mathrm{~km}^{3}$. Excess GIS ice formed primarily along the coasts. In particular, ice expanded westwards along the southwest and central eastern margins, covering exposed land surface. Elsewhere around the margins, existing ice thickened. It is likely that here, too, incomplete representation of ice streams allowed the excess ice to build up instead of dynamically discharging. Much of the elevations of the central and eastern interior and the interior of the south dome were within $100 \mathrm{~m}$ of their initial observed elevations. The northern margin retreated slightly 
due to the sensitive balance between low accumulation and summer ablation. The combination of slight northern margin retreat and intermittent central and southern margin expansion resulted in a total areal ice extent of $1.91 \times 10^{6} \mathrm{~km}^{2}$, very similar to the initial observed ice area.

Further detailed discussion of SMB is in Sect. 3.4.5, where we examine the effect of possible anthropogenic influences on recent measured/modelled surface conditions, which have not yet had time to impact large-scale ice geometry.

\section{Last glacial maximum}

In the LGM control simulation, the model was forced with orbital and $\mathrm{CO}_{2}$ conditions corresponding to $21 \mathrm{kyr} \mathrm{BP}$. The control LGM AIS total ice volume (Figure 3.4e) grew significantly to $40.4 \times 10^{6} \mathrm{~km}^{3}$ compared to the late Holocene simulation, largely due to an imposed $125 \mathrm{~m}$ sea level drop, which allowed thick grounded ice to advance into the Ross and FilchnerRonne basins. The prescribed basal melt rates were also reduced, but as found in Pollard and DeConto (2009) sea level was the predominant control on AIS grounding lines, which advanced to the shelf edge. Interior sectors of the WAIS, particularly those that feed the present-day Ross and Filchner-Ronne ice shelves also thickened, by up to $600 \mathrm{~m}$, in response to the increase in seaward ice thickness. The EAIS response was less drastic, with ice thicknesses increasing by 0-200 m over much of the interior of the ice sheet. Slight thinning $(<100 \mathrm{~m})$ occurred along the coastal EAIS. The Lambert Glacier sector also thinned slightly compared to the late Holocene simulation, due to the spurious lack of ice retreat there in the Holocene simulation. The overall difference in ice elevations was in broad agreement with the reconstruction of Denton and Hughes (2002), with the exception of the Lambert Glacier region. 
The control LGM GIS (Figure 3.5e) also grew in comparison to the late Holocene control simulation, to $3.68 \times 10^{6} \mathrm{~km}^{3}$. The area also increased, to $2.12 \times 10^{6} \mathrm{~km}^{2}$, as ablation zones largely vanished and sea level allowed the ice to expand. Despite this growth in ice area, the total SMB decreased slightly as a result of decreased atmospheric moisture transport. The lower $\mathrm{SMB}$ resulted in a slight decrease in the elevation of the central ice sheet.

\section{Eemian}

For the Eemian control simulation, the model was forced with orbital and $\mathrm{CO}_{2}$ conditions corresponding approximately to the midst of the Eemian interglacial, $-129 \mathrm{kyr}$ BP. Middle-Eemian $\mathrm{CO}_{2}$ concentrations were very similar to late Holocene levels, leaving insolation anomalies as the only significant change in forcings between late Holocene and Eemian periods. The Northern Hemisphere experienced a strong positive spring-summer insolation anomaly of up to $80 \mathrm{~W} / \mathrm{m}^{2}$ at $70^{\circ} \mathrm{N}$ compared to the present day, while the Southern Hemisphere insolation remained similar or slightly less than present (Overpeck et al., 2006).

The control Eemian AIS (Figure 3.4i) did not respond strongly to the change in forcing and equilibrated at a volume of $31.2 \times 10^{6} \mathrm{~km}^{3}$, almost identical to the late Holocene control run. This agrees with the modelling results of Overpeck et al. (2006), who found a slight AIS surface cooling under Eemian conditions that would not change the AIS volume significantly.

The control Eemian GIS, in contrast, retreated significantly along the northern margin, and to a lesser extent the western margin, as the increased Northern Hemisphere spring-summer insolation resulted in greater ablation. The final equilibrated GIS ice area (Figure 3.5i) decreased by 32\% compared to the late Holocene control, to $1.29 \times 10^{6} \mathrm{~km}^{2}$. Total simulated GIS ice loss was equivalent to $3.1 \mathrm{~m}$ of sea level rise (compared to the equivalent late Holocene simulation), very 
similar to the mean model-based estimate of Otto-Bliesner et al. (2006) of 1.9-3.0 $\mathrm{m}$ of global mean sea level rise (SLR), but the pattern of ice loss between the two simulations differed noticeably. Otto-Bliesner et al. (2006) lost ice primarily from the south, resulting in an ice-free corridor that developed across the location of the Dye-3 ice core. In support of our modelling result, the validity of an ice-free Eemian Dye-3 location was challenged by recent work (Willerslev et al., 2007) which tentatively limited the age of Dye-3 basal ice to no younger than $450 \mathrm{kyr}$. The sensitivity of the northern margin to retreat is also reflected in other recent GIS simulations (Stone et al., 2010; Greve et al., 2011). However, the extent of northern retreat contradicts evidence of Eemian ice at the base of the Camp Century and NEEM ice cores, suggesting either model overestimation of northern margin retreat or a real GIS that did not reach full equilibration with transient orbital and $\mathrm{CO}_{2}$ forcings during the Eemian. Simulated ice distribution also contradicts evidence of significant vegetation over southern Greenland during the Eemian (de Vernal and Hillaire-Marcel, 2008).

These results warrant further examination that is beyond the scope of this evaluation. However, two points are worth noting: teleconnections that could transport excess heat from north to south (or vice versa) are not significant in the control Eemian simulation, resulting in AIS surface temperatures and SMB that remained relatively unchanged despite the large positive Northern Hemisphere insolation anomaly. An associated simulation in which the Eemian AIS was also forced with the GIS-derived SLR resulted in negligible AIS volume change, ruling out that as a teleconnection, and leaving local oceanic thermal forcing, which was not resolved here as a coupled connection between ice and ocean, as the remaining mechanism available for driving Eemian AIS response. The depth-averaged Southern Ocean water temperature difference (at depths roughly typical of Antarctic ice shelf drafts) between late Holocene and Eemian simulations (Figure 3.6) is not typically large, but does reach $+0.2^{\circ} \mathrm{C}$ in the Ross 
Sea, suggesting that moderate increases in simulated basal melting of the ice shelf could occur there.

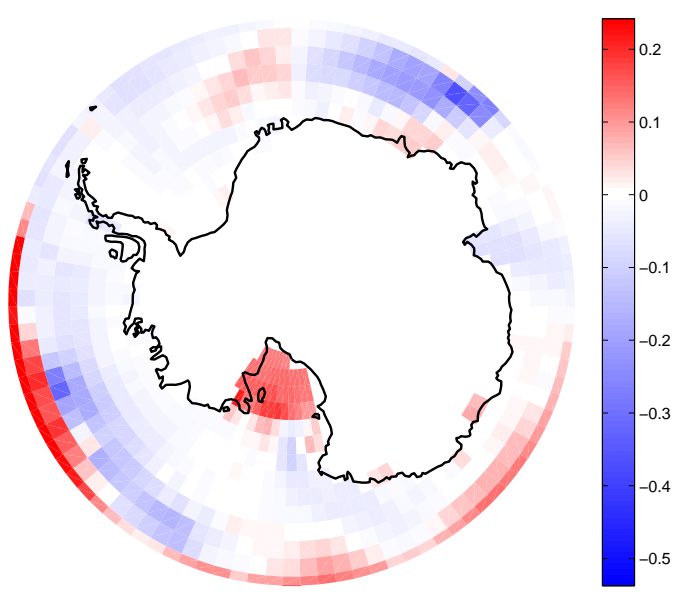

Figure 3.6: Eemian minus late Holocene depth averaged ocean temperatures $\left({ }^{\circ} \mathrm{C}\right)$, from $130 \mathrm{~m}$ to $750 \mathrm{~m}$ depth. Red: warmer Eemian, blue: warmer modern. Note the asymmetry of the color bar towards colder values (white is centered on $0^{\circ} \mathrm{C}$ ).

\subsubsection{Ice sheet evolution sensitivity to climate model sur- face air temperature bias}

To gauge the effect of seasonally-resolved modelled temperature biases on SMB and long term ice sheet evolution in the model, we first compared the 1970-2001 UVic ESCM SAT with the equivalent ERA40 SAT field to determine the extent of the model SAT bias, then compared the Eemian, LGM and late Holocene control (bias-corrected) simulations to similar simulations forced with raw UVic ESCM SAT (here called non-bias-corrected "NBC" simulations). Use of a constant bias corrector field assumes that the modelled SAT bias is independent of the climate or ice sheet state; this is a common assumption among modelling studies but is difficult to con- 
firm given the lack of reliable and comprehensive gridded paleoclimate SAT records.

The simulated 1970-2001 annual average SAT over the ice sheets is compared with ERA40 in Figs. 3.7 and 3.8. The simulated annual average AIS SAT exhibited a warm bias in the cold interior of Wilkes Land and a cold bias over the interior of the WAIS. Around the coast, however, the absolute bias value was typically less than $5^{\circ} \mathrm{C}$. The annual average SAT over the GIS agreed well with ERA40, with absolute values below $6^{\circ} \mathrm{C} \mathrm{ev-}$ erywhere except two local regions in the southeast.

Annual SAT maps do not resolve seasonal SAT biases, which are of greater relevance to ice sheet SMB. Figures 3.7 and 3.8 also show summer and winter SAT compared to equivalent ERA40 values. In winter, locations on the WAIS are up to $15^{\circ} \mathrm{C}$ too cold, while Wilkes Land is up to $15^{\circ} \mathrm{C}$ too warm. The wintertime GIS suffers from much less pronounced SAT biases, but still experiences warm biases of up to $10^{\circ} \mathrm{C}$ locally on the southeast coast. However, despite their magnitude, the wintertime biases over the AIS and GIS are unlikely to play a significant role in the SMB (Stone et al., 2010) as they are not large enough to drive the modelled SAT to the melt point. In contrast, summer-time biases have the ability to affect melt season length, melt magnitude (through both direct sensible heat flux and the impact of SAT on albedo) and the determination of whether precipitation falls as rain or snow. The general distribution of summer biases over the AIS is similar to the winter but with a much reduced range, from $-6^{\circ} \mathrm{C}$ over the WAIS to locally $+8^{\circ}$ in Wilkes Land. SAT biases over the GIS exhibit a general increasing northwest trend with maximum biases of up to $-6^{\circ} \mathrm{C}$ over the central northern ice sheet and along the west coast.

The following sections describe the results of the NBC simulations, in comparison with the control simulations. 


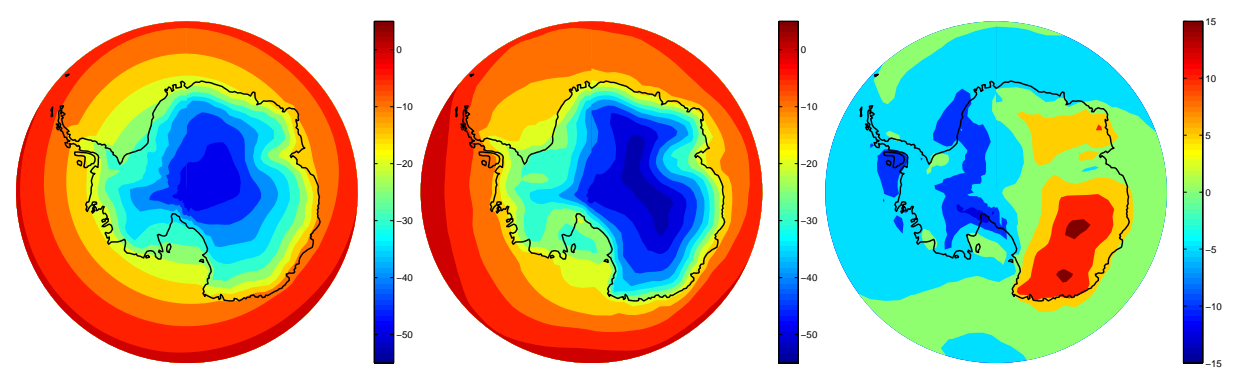

(a) Simulated AIS annual(b) ERA40 AIS annual SAT(c) Model-ERA40 GIS anSAT nual SAT

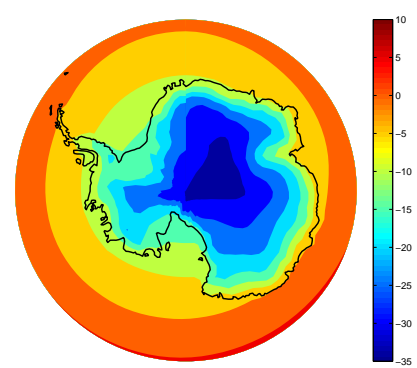

(d) Simulated AIS DJF SAT

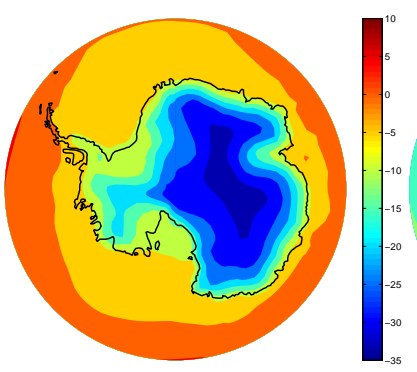

(e) ERA40 AIS DJF SAT

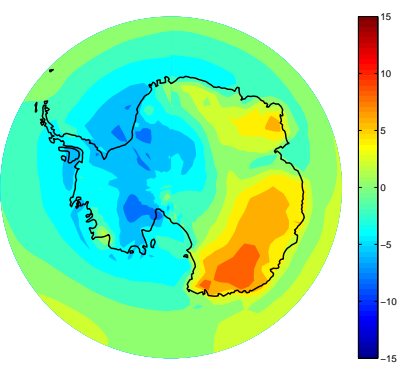

(f) Model-ERA40 AIS DJF SAT

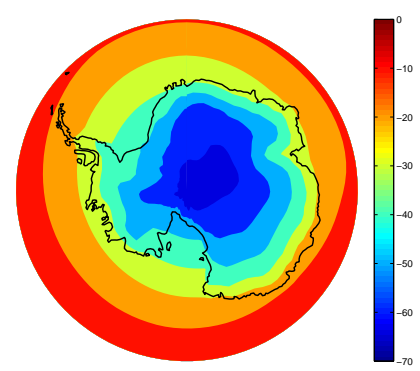

(g) Simulated AIS JJA SAT
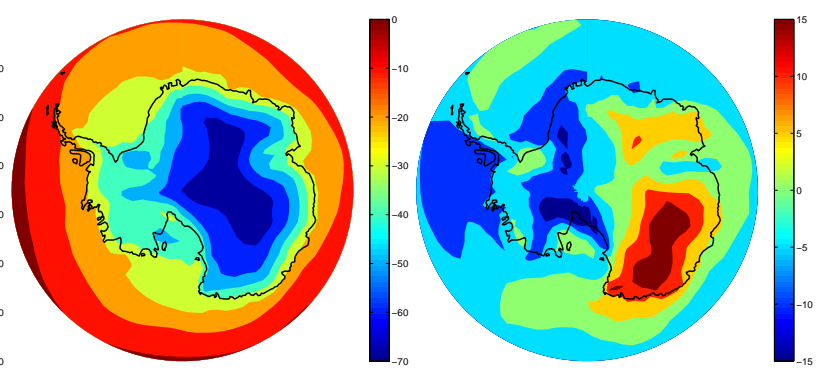

(h) ERA40 AIS JJA SAT

(i) Model-ERA40 AIS JJA SAT

Figure 3.7: Simulated/ERA40 1970-2001 annual, June-July-August (JJA) and December-January-February (DJF) average SAT, and differences between simulated and ERA40 SAT, over the AIS $\left({ }^{\circ} \mathrm{C}\right)$. Note the different color scales for each seasonal average and difference. 


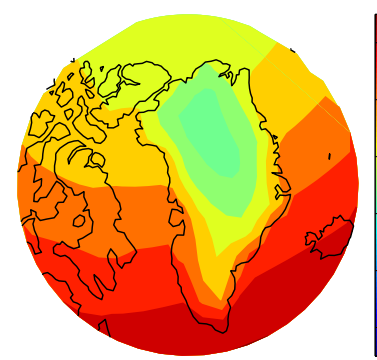

(a) Simulated GIS annual SAT

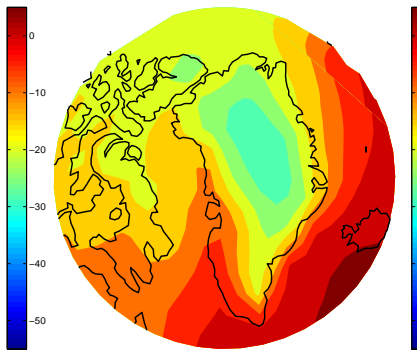

(b) ERA40 GIS SAT

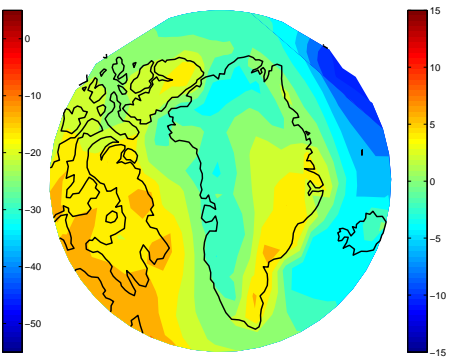

(c) Model-ERA40 GIS annual SAT

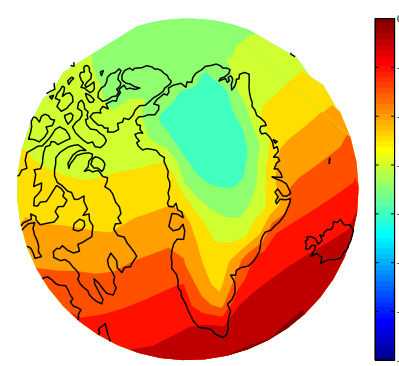

(d) Simulated GIS DJF SAT

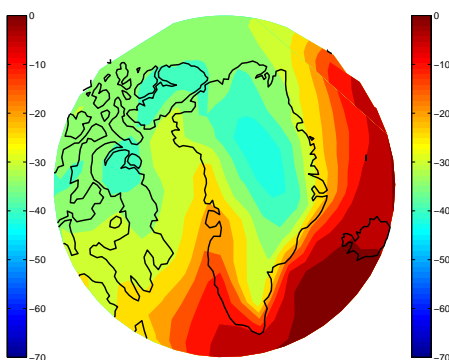

(e) ERA40 GIS DJF SAT

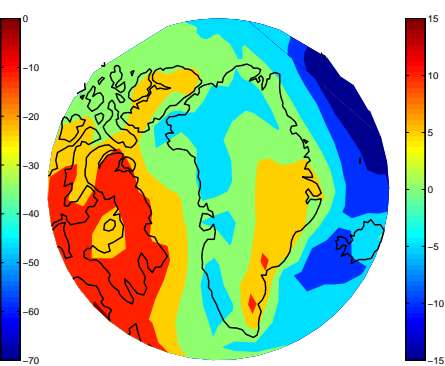

(f) Model-ERA40 GIS DJF SAT

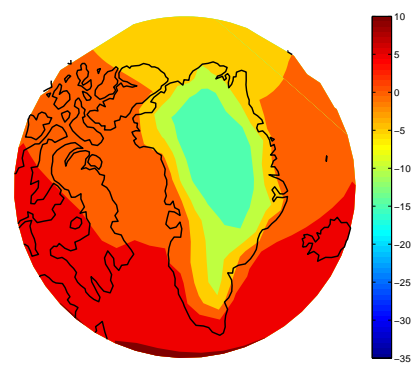

(g) Simulated GIS JJA SAT

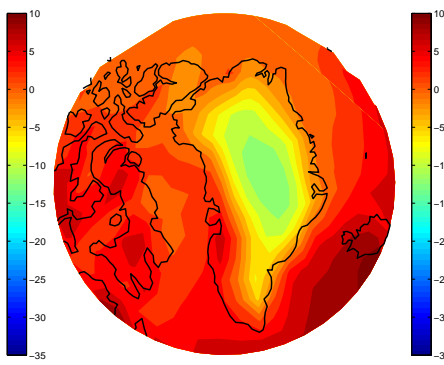

(h) ERA40 GIS JJA SAT

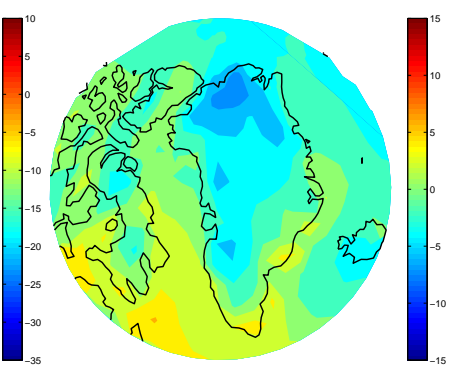

(i) Model-ERA40 GIS JJA SAT

Figure 3.8: Simulated/ERA40 1970-2001 annual, June-July-August (JJA) and December-January-February (DJF) average SAT, and differences between simulated and ERA40 SAT, over the GIS $\left({ }^{\circ} \mathrm{C}\right)$. Note the different color scales for each seasonal average and difference. 


\section{Late Holocene sensitivity to model bias}

The total ice volume of the AIS in the late Holocene NBC simulation (Figure $3.4 \mathrm{~b}$ ) decreased to $28.2 \times 10^{6} \mathrm{~km}^{3}$, closer to the observed AIS volume. Despite lack of a bias correction, no additional ablation zones appeared, as the biases over the AIS were too small to push the SAT over the freezing point in the late Holocene climate. The majority of the ice was lost over the central EAIS, indicating that the large scale atmospheric moisture transport was affected by the temperature-based bias correction over the AIS.

In contrast to the AIS, the total ice volume of the NBC late Holocene GIS increased relative to the control late Holocene ice sheet, stabilizing at $3.59 \times 10^{6} \mathrm{~km}^{3}$ (Figure $3.5 \mathrm{~b}$ ). The majority of the additional ice volume formed at the northern margin, where the UVic ESCM exhibited a cold summertime bias of up to $6^{\circ} \mathrm{C}$. Neglect of this bias was sufficient to tip the region into a net accumulation zone, allowing ice to expand to the coastlines everywhere and highlighted the fine balance between the simulated accumulation and ablation along the northern GIS margin in the model.

\section{LGM sensitivity to model bias}

The NBC LGM AIS ice volume decreased compared to the control LGM AIS volume, to $38.1 \times 10^{6} \mathrm{~km}^{3}$ (Figure $3.4 \mathrm{f}$ ). As with the late Holocene nonbias-corrected simulation, ice loss was concentrated over the central EAIS, again suggesting a temperature-bias-related control on large-scale atmospheric moisture transport.

The GIS ice volume in the NBC LGM simulation (Figure 3.5f) equilibrated at $3.66 \times 10^{6} \mathrm{~km}^{3}$, a volume almost identical to that of the biascorrected control simulation. As in that simulation, the margins reached the regressed coastline everywhere. In contrast to the late Holocene climate, neglect of the northern GIS cold bias did not affect ice volume as 
temperatures in both the control and NBC models were sufficiently low to avoid threshold melt behaviour.

\section{Eemian sensitivity to model bias}

The AIS in the NBC Eemian simulation (Figure 3.4j) responded similarly to the late Holocene NBC AIS, equilibrating at a volume of $28 \times 10 \times 10^{6} \mathrm{~km}^{3}$. Once more the ice volume loss was concentrated over the EAIS, implying a change to the atmospheric moisture transport field.

The NBC GIS (Figure 3.5j) diverged strongly from the control Eemian GIS simulation. Whereas the northern margin of the control GIS retreated, generating $3 \mathrm{~m}$ of sea level rise, the northern margin of the NBC GIS remained stable and the total volume of $3.59 \times 10^{6} \mathrm{~km}^{3}$ was maintained. As with the late Holocene NBC model, northern GIS accumulation in the Eemian NBC model exceeded ablation, which was artificially weakened due to the cold model bias, such that the GIS contribution to Eemian SLR in this simulation was negligible.

\subsubsection{Ice sheet evolution sensitivity to meltwater retention and refreezing}

Meltwater retention and refreezing is expected to be more important in regions of high melt over existing snowpack, and in general in simulations in which more melt is available to be refrozen. It is also likely to dampen the response of ice sheets to transient climate change forcing (Bougamont et al., 2007). In order to test the effect of refreezing on long-term ice sheet evolution within the coupled model we compared Eemian, LGM and late Holocene simulations with meltwater retention and refreezing neglected (here called the NMRR simulations) to the control simulations with the refreezing parameterization enabled. 


\section{Late Holocene}

The late Holocene AIS in the NMRR simulation (Figure 3.4c) displayed a small response to the removal of the refreezing process due to the lack of significant surface melting, but still exhibited perceptible changes, largely over the Antarctic Peninsula ice shelves, but also over the Ronne and to a lesser extent Ross ice shelves, where ephemeral surface runoff in the model resulted in marginally thinner shelves and correspondingly thinner sheets near the grounding lines.

In contrast, the northern and (to a lesser extent) central western GIS margins in the late Holocene NMRR simulation retreated noticeably compared to the control simulation (Figure 3.5c). This change, and associated slight inland thinning, resulted in a late Holocene NMRR GIS volume of $30.9 \times 10^{6} \mathrm{~km}^{3}$ and a smaller surface area. As expected, retreat relative to the control simulation occurred in regions where neglect of the refreezing process enhanced annual runoff of surface meltwater.

\section{LGM}

Neither the LGM AIS nor the GIS (Figs. 3.4g and 3.5g) were significantly affected when refreezing was not resolved, compared to the control LGM simulation. Given that the refreezing process is activated by melting, this result is expected, because melt extent and ablation were negligible over both ice sheets in both simulations.

\section{Eemian}

As with the late Holocene and LGM NMRR simulations, the AIS was not significantly affected due to a lack of sustained surface melting anywhere on the continent in the Eemian climate (Figure 3.4k). 
In contrast to the LGM simulations, the NMRR Eemian GIS (Figure 3.5k) differed strongly from the Eemian control simulation, underlining the importance of resolving refreezing when simulating warmer climate states. The equilibrium Eemian GIS with refreezing neglected was 31\% smaller than the control Eemian simulation with refreezing enabled, equilibrating at $1.51 \times 10^{6} \mathrm{~km}^{3}$. Additional ice loss, compared to the control run with refreezing enabled, occurred mainly along the northern margin, where the NMRR model generated substantially more runoff than the control simulation. The SLR generated from the NMRR model (relative to the late Holocene NMRR simulation) was $4.1 \mathrm{~m}$, probably an overestimate.

\subsubsection{Ice sheet evolution sensitivity to surface albedo}

Warm snow rapidly becomes less reflective, lowering the surface albedo and absorbing additional incoming radiation in an important positive icealbedo feedback loop (van de Wal and Oerlemans, 1994) that can be simulated within the coupled model. In order to test the strength of the temperature-derived surface albedo feedback within the coupled model we compared a set of simulations with cold, warm, and bare glacial ice albedos set to the cold-snow value of 0.8 (here called the "constant albedo" or CA simulations) to the control simulations in which albedo varied as a function of surface snow/ice melt. Note that as the ice retreated, the surface land albedo reverted to a value typical of tundra. This neglects the effect of boreal forest invasion of ice-free regions, which would reduce the albedo further and enhance the ice-albedo feedback. However, the runs presented here, with the possible exception of the Eemian GIS, do not retreat enough for this effect to be significant. 


\section{Late Holocene}

The AIS in the CA late Holocene simulation (Figure 3.4d) did not change volume or geometry appreciably compared to the control simulation, reflecting the fact that albedo over the AIS is rarely affected by melting conditions, minimizing the effect of the temperature-dependent ice albedo feedback. However, with consistently high albedos, the CA late Holocene GIS simulation (Figure 3.5d) grew dramatically compared to the control simulation with the variable albedo scheme, reaching a volume of $3.75 \times 10 \times 10^{6} \mathrm{~km}^{3}$ (higher than the control LGM GIS volume). This indicates that the temperature-dependent ice albedo feedback plays a strong role in determining GIS geometry in the model by enhancing melt along the coastal ablation zones and above-equilibrium-line-altitude (ELA) melt regions. The difference between the two ice sheets is indicative of the threshold nature of the temperature-dependent ice-albedo effect: when temperatures are largely below freezing (e.g., the AIS), melt and melt-derived ice exposure cannot occur, but if temperatures rise even slightly above the freezing point, the ice-albedo effect rapidly becomes a dominant factor in the overall SMB.

\section{LGM}

As with the late Holocene CA simulation, the AIS (Figure 3.4h) was not strongly affected by the imposition of constantly high snow/ice albedo compared to the control LGM simulation, due to the lack of significant ablation or melt zones. Similarly, the GIS volume (Figure 3.5h) remained the same as in the CA late Holocene simulation (in contrast to the variation in ice volume simulated in the late Holocene/LGM control simulations). 


\section{Eemian}

The CA Eemian simulation AIS (Figure 3.4l) did not respond significantly to imposition of constantly high albedos in the Eemian climate. In contrast, removal of the ice-albedo feedback over the Eemian GIS (Figure 3.51) resulted in a large change in ice volume compared to the control simulation GIS. When albedos were held constant, the resulting lack of additional ice loss was sufficient to keep the GIS at a near-late Holocene volume of $3.45 \times 10^{6} \mathrm{~km}^{3}$, contained in an area only slightly smaller than the CA late Holocene ice area $\left(1.92 \times 10^{6} \mathrm{~km}^{2}\right)$. The GIS contribution to the Eemian sea level high-stand in this simulation, compared to the late Holocene CA simulation, was $1 \mathrm{~m}$.

\subsubsection{Modern transient simulation}

In order to explore the ability of the coupled model control configuration to capture present-day SMB conditions over the GIS and AIS, we carried out a 200 year transient simulation ending at the present day, initialized from the equilibrium late Holocene simulation. The simulation was forced with transient $\mathrm{CO}_{2}$ and orbital forcings. In this simulation the bias correction procedure, variable albedo, and refreezing were all enabled.

At year $1850 \mathrm{SMB}$ over the AIS in this simulation was $22.2 \times 10^{14} \mathrm{~kg} / \mathrm{yr}$. Between years 1850 and 2010, the AIS SMB increased to $23.5 \times 10^{14} \mathrm{~kg} / \mathrm{yr}$. This SMB increase was primarily a function of increased accumulation resulting from the increased moisture-carrying capacity of warmer air as a consequence of the Clausius-Clapeyron relation (Weaver et al., 1998), a result that is common to other AIS SMB modelling studies (e.g., Krinner et al., 2007). As expected, despite increases in SAT, AIS temperatures were still generally well below $0^{\circ} \mathrm{C}$ at year 2010 , limiting the contribution of ablation to the overall SMB. The final value for modern SMB was approximately $7 \%$ lower than the 1980-2004 average SMB of van de Berg 


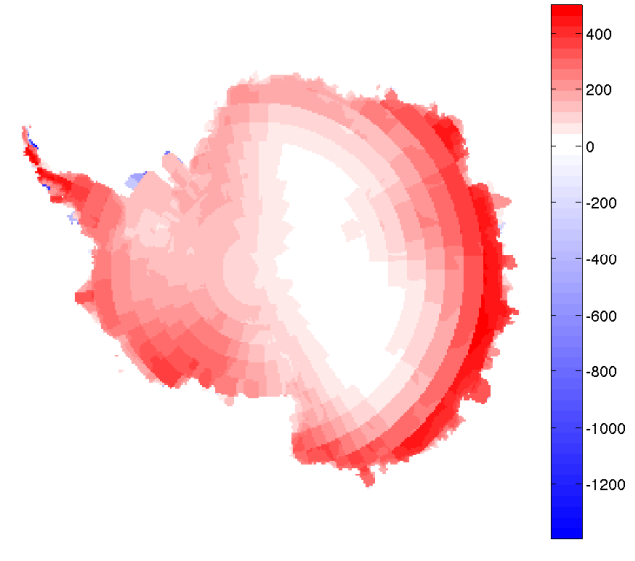

(a)

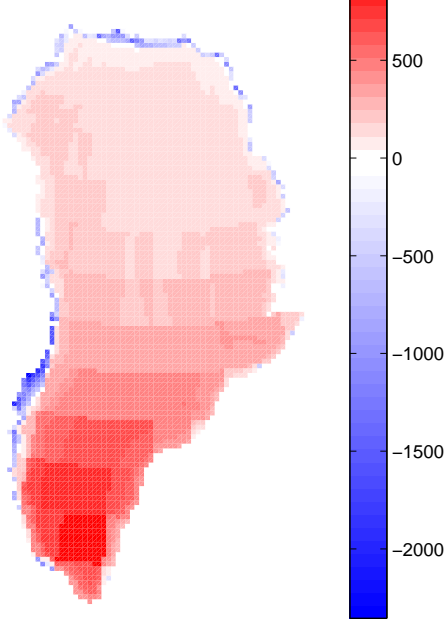

(b)

Figure 3.9: Modern SMB over the AIS and GIS $\left(\mathrm{kg} / \mathrm{m}^{2} / \mathrm{yr}\right)$, averaged from 2000 to 2010. For comparison with analagous high-resolution model results, see Figure 1.1.

et al. (2006) and 11\% higher than the 1980-2000 average AIS SMB value of Krinner et al. (2007). Additionally, the modelled AIS SMB range and spatial distribution were similar to the ranges and distributions of van de Berg et al. (2006) and Krinner et al. (2007) (Figure 3.9a). Accumulation increased from extremely low positive values over the continental EAIS to maximum values of up to $500 \mathrm{~kg} / \mathrm{m}^{2} / \mathrm{yr}$ on the coastal flanks of the EAIS and over the Antarctic Peninsula. Despite the subgridded approach to SMB calculation, relics of the overlying EMBM grid remained in the high-resolution SMB field, and due to the simplified nature of the EMBM accumulation patterns associated with local microclimates were not resolved. At year 2010 simulated ice ablation was limited to Antarctic Peninsula ice shelves and the northern extremity of the simulated Ronne Ice Shelf. Much of the simulated interior of the Ronne Ice Shelf began to experience minor surface 
melting, but this melt was almost completely refrozen. Overall AIS melt extent by year 2010 was $6.99 \times 10 \times 10^{5} \mathrm{~km}^{2}$, within the range of the $1987-$ 2008 annual average melt extent derived from Special Sensor Microwave Imager radiometer data (Tedesco, 2008). Due to the present lack of interactive ocean-ice shelf coupling, recent Antarctic mass loss attributed largely to oceanic thermal forcing of ice shelves (Payne et al., 2004; Rignot et al., 2008) was not resolved.

Late Holocene simulated SMB over the GIS was $4.70 \times 10^{14} \mathrm{~kg} / \mathrm{yr}$. Between years 1850 and 2010, accumulation over the GIS increased due to increased atmospheric moisture transport and ablation rose as temperatures warmed. These trends are common to other GIS SMB studies (Alley et al., 2007) and expected in an initially warming climate. The superposition of the competing processes led to an overall SMB that did not change appreciably throughout the simulation period, in contrast with observations and other modelling efforts, which show lower total GIS SMB values, and indicate that either modern GIS SMB is being primarily driven by decadal-scale climate variability, which the model does not resolve, or that the initial model response to imposed increases in $\mathrm{CO}_{2}$ at high latitudes is too low. Our modern SMB value was very similar to the modelled 1958-2007 SMB of Ettema et al. (2009), which is itself notably higher than previous estimates (e.g., Box et al., 2004). The broad pattern and magnitude of GIS SMB over the GIS (Figure 3.9b) corresponded to the general pattern recognized by other modelling and observational studies Ettema et al. (2009); Burgess et al. (2010). Accumulation decreased from south to north, with the highest SMB (approximately $980 \mathrm{~kg} / \mathrm{m}^{2} / \mathrm{yr}$ ) simulated on the south dome and the lowest values (in the absence of ablation) occurring in the central northern GIS. The model also simulated an increase in accumulation along the northwest coast that was captured by Ettema et al. (2009); Burgess et al. (2010), although the magnitude of the SMB gradient between the dry interior and the west coast was much less than these studies. The accumulation pattern over south-central/southeast Green- 
land was anomalously high/low and the south dome accumulation maximum displays a structure that is clearly a relic of the overlying EMBM atmosphere. These observations indicate that the atmospheric model has difficulty capturing the proper small-scale pattern of accumulation here, an issue also noted by Robinson et al. (2009). Simulated ablation accurately captured both the magnitude and distribution of observed GIS melt regions. In particular, high melt (up to $2300 \mathrm{~kg} / \mathrm{m}^{2} / \mathrm{yr}$ ) was simulated in the central western margin and along the north coast. A narrow ablation zone was also resolved along the northeast coast. Over the 2000-2010 period, simulated ablation zones covered $4.81 \%$ of the GIS ice area, lower than the $10 \%$ coverage modelled by Ettema et al. (2009). $18.4 \%$ of the GIS surface experienced surface melting. The modelled GIS melt extent area $\left(3.64 \times 10 \times 10^{5} \mathrm{~km}^{2}\right)$ was roughly $27 \%$ lower than the 1978-2007 average melt extent obtained by passive microwave data (Fettweis et al., 2007) but within the range of observed values. As with the AIS, the lack of interactive ocean forcing meant that recent dynamically-driven changes to ice volume due to ocean forcing (Holland et al., 2008a) were not resolved.

Comparison of the final state of this simulation with a control equilibrium simulation forced with constant year $2000 \mathrm{CO}_{2}$ and orbital conditions gives an indication of the simulated disequilibrium between the presentday ice sheets and present-day climate forcing. The control modern day AIS did not differ appreciably from the final state of the transient simulation. However, the GIS ice volume in the modern equilibrium simulation diminished noticeably, resulting in an equivalent SLR of approximately $1.1 \mathrm{~m}$. This result indicates that response of the modelled GIS to $\mathrm{CO}_{2}$ increases such as those associated with current trends is significant but delayed in time, relative to observations. 


\subsection{Conclusions}

A new coupled model ice sheet/climate model has been constructed, consisting of the University of Victoria Earth System Climate and the Pennsylvania State University Ice Sheet models. The two models are coupled across the ice-atmosphere interface using an energy/moisture balance model on subgrid elevation bins that can correct for model surface air temperature bias. Precipitation is delivered to the ice sheets by the overlying vertically integrated, advective/diffusive atmosphere model. Moisture and heat fluxes are routed to the atmosphere and ocean, respectively. Ice shelves shade the underlying ocean from heat and moisture fluxes. The ocean receives heat and moisture fluxes from basal shelf melting and calving. Basal melting is currently prescribed in lieu of a parameterized temperature-dependent coupling. After each timestep the ice sheets return an updated ice-sheet/ice-shelf geometry to the climate model. The overall system is designed to conserve heat and moisture to machine precision. Multiple independent ice sheet model grids within a global climate simulation are made possible through use of Fortran derived data types and pointers. The model can run in "synchronous", "asynchronous", or "synchronous accelerated" modes depending on the length and character of the simulation. The current coupled model is set up to simulate the Antarctic and Greenland Ice Sheets (AIS/GIS) at $20 \mathrm{~km}$ resolution within a global climate simulation.

The model was run to equilibrium under Eemian, LGM and late Holocene conditions to test the sensitivity of the simulated ice evolution to surface albedo feedback, refreezing, and modelled seasonal SAT biases. Sensitivity of the final equilibrium ice volumes to these aspects of model physics increased in warmer climates, as they are threshold processes that are activated when the surface temperature rises above freezing. Conversely, cold AIS and GIS climates are less sensitive to variations in treatments of surface albedo, temperature biases, and refreezing. The 
difference in the changes to ice sheet volumes under different forcing scenarios indicates that perturbations to the model physics can affect not only the equilibrium ice volume and ice geometry but the change in volume and geometry under transient forcing scenarios. This is primarily due to the strong non-linear behavior of ice sheets in the vicinity of the freezing point.

The control simulation is able to reasonably simulate the Eemian, LGM and late Holocene ice sheets, albeit with a overestimate of late Holocene ice volume. As the modern SMB distribution and total fluxes over both ice sheets generally agree well with recent detailed model studies, the overestimation of ice volume is perhaps due to incomplete representation of ice discharge through ice streams. The response of the coupled ice sheets to LGM and Eemian climates is similar to previous modelling and observations in terms of total ice volume and area, and suggests that the model responds reasonably to imposed forcings. The modelled modern AIS/GIS is/is not in equilibrium with boundary climatic forcings, and a substantial contribution to SLR from the GIS is obtained when the model is run to equilibrium with constant present-day forcings.

The lack of significant AIS change to SMB over all the climate scenarios strongly suggests that oceans are the prime control on AIS volume, and that past and future coupled model simulations of AIS response to climate require an interactive coupling between ice shelves and ocean. The model represents an ideal platform with which to test ocean-ice coupling parameterizations. More work (ideally, a transient simulation through the Eemian) is needed to constrain locations of GIS Eemian ice loss and identify the interglacial that resulted in an ice-free Dye-3 location. The magnitude of the GIS contribution to SLR generated by this study agrees with the equilibrium simulations of Cuffey and Marshall (2000) and Otto-Bliesner et al. (2006) but the location of ice loss disagrees sharply, with loss in the present study coming from the northern GIS ablation zone. 


\section{Chapter 4}

\section{Greenland in a high- $\mathrm{CO}_{2}$ world}

\subsection{Introduction}

Large continental ice sheets are sensitive to warming caused by atmospheric $\mathrm{CO}_{2}$. Recent studies have suggested that inception of the presentday Greenland and Antarctic Ice Sheets (GIS and AIS) was sensitive to levels of atmospheric $\mathrm{CO}_{2}$ (Lunt et al., 2008; DeConto et al., 2008), and that permanent expansion of both ice sheets was controlled over geologic timescales by declining Cenozoic atmospheric $\mathrm{CO}_{2}$ concentrations, with variations in the Earth's orbit providing threshold triggering for runaway continental-scale ice sheet growth (Haug et al., 2005; Pollard and DeConto, 2005). Long-term projections of anthropogenic carbon emissions are expected to elevate atmospheric $\mathrm{CO}_{2}$ levels back to the same magnitude as early Eocene concentrations, well before a stable Greenland Ice Sheet (GIS) existed (Zachos et al., 2008). Past ice sheet sensitivity to $\mathrm{CO}_{2}$-induced warming implies that predicted anthropogenic emissions of $\mathrm{CO}_{2}$ could degrade the GIS significantly in the future (Mikolajewicz et al., 2007a; Charbit et al., 2008; Vizcaíno et al., 2008, 2010; Ridley et al., 2010) and perhaps inhibit future North American glacial inception for 50-500 kyr (Berger and 
Loutre, 2002; Archer and Ganopolski, 2005). Motivated by the large uncertainty in projections of future GIS behaviour, I used the model outlined in Chapter 3 to simulate the response of the coupled global climate/GIS system to equilibrium and transient elevated $\mathrm{CO}_{2}$ scenarios under presentday orbital conditions. Furthermore, I tested the response of the modelled GIS to under these greenhouse conditions to important model parameters. This was done as a first step to quantifying the uncertainty associated with future GIS projections.

\subsection{Methods}

\subsubsection{Model Design}

The model is fully described in Chapter 3. For the purposes of this study, only one instance of the ice sheet model was utilized (over Greenland). The Antarctic ice sheet was held fixed at its present-day geometry. The ice sheet model simulates grounded ice, ice shelves, and dynamic groundingline migration. However, in these experiments the sub-shelf melt rate was set to high values to quickly remove floating ice, although use of a sub-shelf melt scheme tuned to specifically for the Antarctic Ice Sheet did not produce very different results. The simulations are unique several respects from previous modelling efforts to constrain the potential future behaviour of the GIS. Synchronous coupling between climate and ice is performed with an energy balance model, using bias-corrected air temperatures, and with a sub-grid elevation binning scheme that allows energy balance calculations to be carried out on elevation bands within climate model grid cells. This avoids interpolation-based downscaling procedures (which generally do not resolve narrow, dynamic ablation zones well) and nested regional climate modelling. Additionally, design of the system allows global energy and moisture to be conserved to within machine pre- 
cision. The climate-ice sheet model also retains computational efficiency, allowing large ensembles of multi-millennial simulations to be carried out on existing computer resources.

All simulations were initialized from an equilibrium preindustrial restart and a present-day orbital configuration. Ice sheets were run synchronously with the climate model. Justification for use of a dynamically-equilibrated GIS as an initial condition is based on transient simulations with the coupled model that indicate the GIS had ceased responding dynamically to the last deglacial episode by approximately 5 kyr BP, in line with other studies (Huybrechts and Meur, 1999). We note that the internal ice temperature field, spun up in this manner, may shorten the ice response time somewhat by neglecting internal temperature history. As noted previously (Chapter 3), the model is increasingly sensitive to other physical factors as temperatures increase. In particular, albedo and lapse rate are important parameters within the ice/climate coupling that have the ability to exert a large influence on the surface mass balance field by influencing ablation, and thus ice sheet evolution over long timescales. Reference cold snow, warm snow, and bare ice albedo values were set to $0.8,0.6$, and 0.45 respectively, while the reference surface lapse rate was set to $5^{\circ} \mathrm{C} / \mathrm{km}$, similar to melt-season lapse rates over Greenland (Fausto et al., 2009). These values were subsequently altered (by \pm 0.05 albedo units, or $\pm 0.5^{\circ} \mathrm{C} / \mathrm{km}$ for lapse rate) in a series of sensitivity experiments. Altering these values may potentially make the model slightly inconsistent with the monthly bias correction fields, which were generated using the default values and are primarily meant to correct for regional heat transport biases resulting from the simplified atmospheric model. However, I make the assumption that any inconsistency would not affect the qualitative findings of this study.

Observations (Pritchard et al., 2009) have highlighted the large role of ice dynamical processes in recent GIS ice loss (although even at current 
rates of dynamically-induced ice loss (van den Broeke et al., 2009) it would still take $\sim 28 \mathrm{kyr}$ to drain the entire ice sheet). Over the GIS, the model removes floating ice via a high prescribed basal melt rate, and therefore represents the case in which the surrounding ocean is very warm. A lack of significant drawdown in the control (preindustrial) simulation perhaps reflects the fact that the model does not capture the impact of marginal ice discharge via ice streams (an issue common to most ice sheet models). Despite ice sheet model resolution of $20 \mathrm{~km}$, input model bed topography does not capture narrow troughs that apparently steer ice discharge, extend well inland, and are below sea level. Neglect of these features may also impact ice volume evolution away from a fully-glaciated state. However, as the GIS margin retreats from a calving to a dominantly landterminated state, ocean-ice interaction and/or ice streaming would likely play a decreasing role in ice volume evolution relative to the present day.

\subsubsection{Boundary Conditions}

Equilibrium experiments, in which $\mathrm{CO}_{2}$ was elevated and held constant, have been previously used to identify thresholds on GIS stability (Ridley et al., 2005; Driesschaert et al., 2007; Vizcaíno et al., 2010). To characterize such thresholds with the present model a series of experiments were initialized with ice sheets in equilibrium under a $\mathrm{CO}_{2}$ concentration of $1 \mathrm{x}$ PAL $\mathrm{CO}_{2}$ and present day orbital conditions, then integrated forward with atmospheric $\mathrm{CO}_{2}$ varying from $1 \times \mathrm{PAL}$ to $7 \times \mathrm{PALCO}_{2}$. Runs proceeded for $35 \mathrm{kyr}$, or until GIS ice mass ceased drifting.

A suite of transient experiments forced with time-varying $\mathrm{CO}_{2}$ concentration time series (Figure 4.3) explored the transient response of the GIS to pulsed $\mathrm{CO}_{2}$ concentration profiles. Five $\mathrm{CO}_{2}$ timeseries were used, all of which were generated from prior coupled carbon simulations forced with cumulative anthropogenic carbon emission scenarios ranging from $0 \mathrm{Gt} C$ 
(i.e. complete cessation of emissions) to $5120 \mathrm{Gt} \mathrm{C} \mathrm{(burning} \mathrm{of} \mathrm{all} \mathrm{carbon}$ in the modern fossil fuel resource base) (Eby et al., 2009; Rogner, 1997). These simulations were also initialized from $1 \times \mathrm{PAL} \mathrm{CO}_{2}$ and present day orbital conditions. Importantly, the use of emissions scenarios to generate time-dependent $\mathrm{CO}_{2}$ concentration profiles allowed a quantification of maximum future emissions that avoided large-scale simulated GIS loss.

\subsection{Results and Discussion}

\subsubsection{Equilibrium Deglacial Simulations}

At 1x PAL $\mathrm{CO}_{2}$ GIS ice volume remained the same for the course of the simulation, reflecting a continued state of non-perturbed equilibrium (Figure 4.2). At 2x PAL $\mathrm{CO}_{2}$ some ice loss occurred; eventual equilibration occurred at approximately $80 \%$ of original volume. At $3 \times \mathrm{PAL} \mathrm{CO}_{2}$ the final volume decreased to $\sim 50 \%$ of the original GIS volume after $25 \mathrm{kyr}$. At $4 \mathrm{x}$ PAL $\mathrm{CO}_{2}$ the initial transient net surface mass balance became negative, crossing a theoretical limit on ice sheet stability (Gregory and Huybrechts, 2006) and indicating a theoretical threshold on GIS stability at between $3 x$ and $4 \times \mathrm{PAL} \mathrm{CO}_{2}$. Final equilibration occurred at approximately $20 \%$ of the original ice volume with remaining ice sustained by reduced accumulation areas associated with regions of high bed elevation. For simulations above $4 \times \mathrm{PAL} \mathrm{CO}_{2}$, residual ice caps decreased further in size (Figure 4.1).

Ice response times (identified by the nominal e-folding time, assuming the final state is in full equilibrium, Figure 4.2) ranged from 3-6 kyr, depending on the scenario. Initial areal loss of ice largely occurred at the northern and western GIS margins in the model, as increased ablation in this low accumulation region changed the sign of the surface mass balance from positive to negative. In contrast, over the southern portion of the 

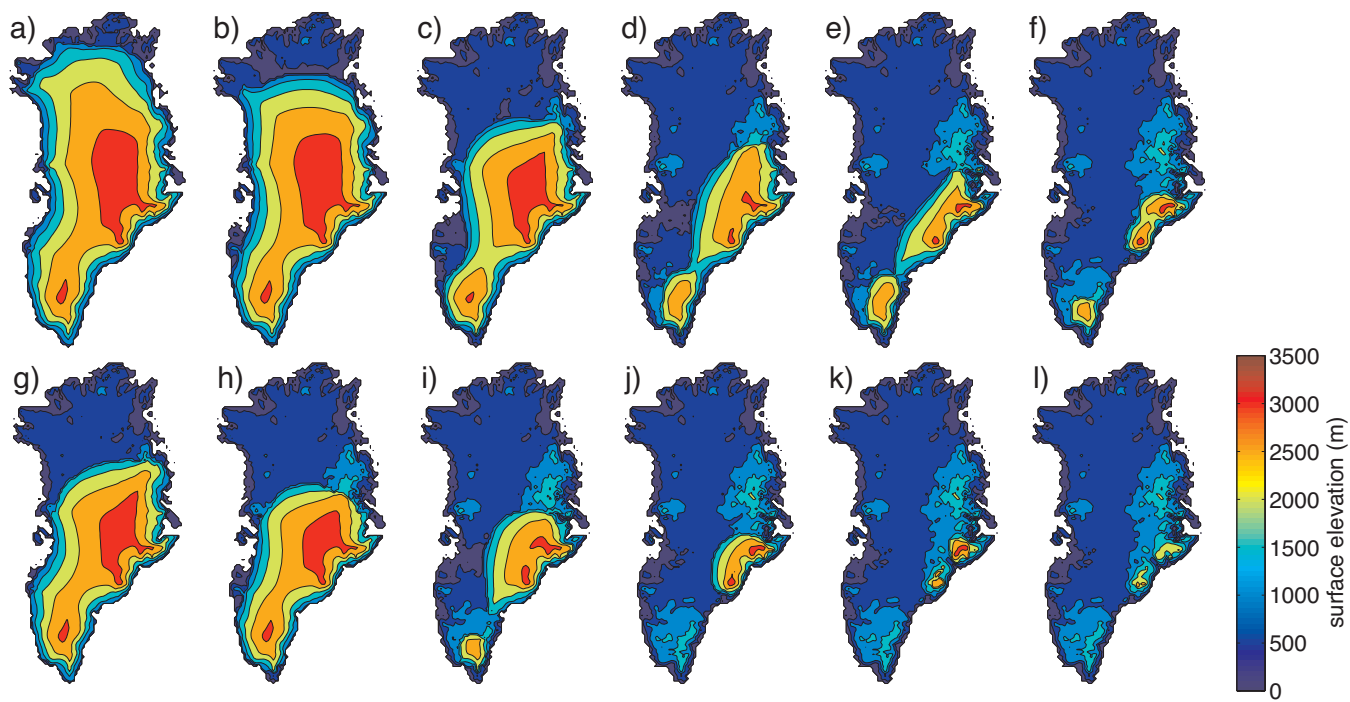

Figure 4.1: GIS ice distribution after $25 \mathrm{kyr}$ for simulations forced by constant $\mathrm{CO}_{2}$ concentrations. a-f): deglacial simulations initialized with existing ice and forced with 1-6x PAL $\mathrm{CO}_{2}$ concentrations. g-1): inception simulations initialized with ice-free conditions and forced with 1-6x PAL $\mathrm{CO}_{2}$ concentrations.

GIS, accumulation dominated ablation until the latter stages of elevated$\mathrm{CO}_{2}$ simulations, resulting in delayed marginal retreat. Key model parameters influenced these results. Additional simulations, run with cold snow, warm snow and ice albedos reduced by 0.05 units and the surface lapse rate decreased by $0.5^{\circ} \mathrm{C} / \mathrm{km}$ resulted in a reduction in the GIS stability threshold to 2-3x PAL $\mathrm{CO}_{2}$, and a decrease in the response time of equilibrated simulations by $\sim 50 \%$ (Figure 4.2 ).

The generally long response times and higher $\mathrm{CO}_{2}$ thresholds on deglaciation identified in this study are likely due to one or several factors. We simulate relatively high accumulation over the GIS (in-line with recent regional surface mass balance studies (Ettema et al., 2009)) and melt is calculated with an energy balance model, unlike degree-day 


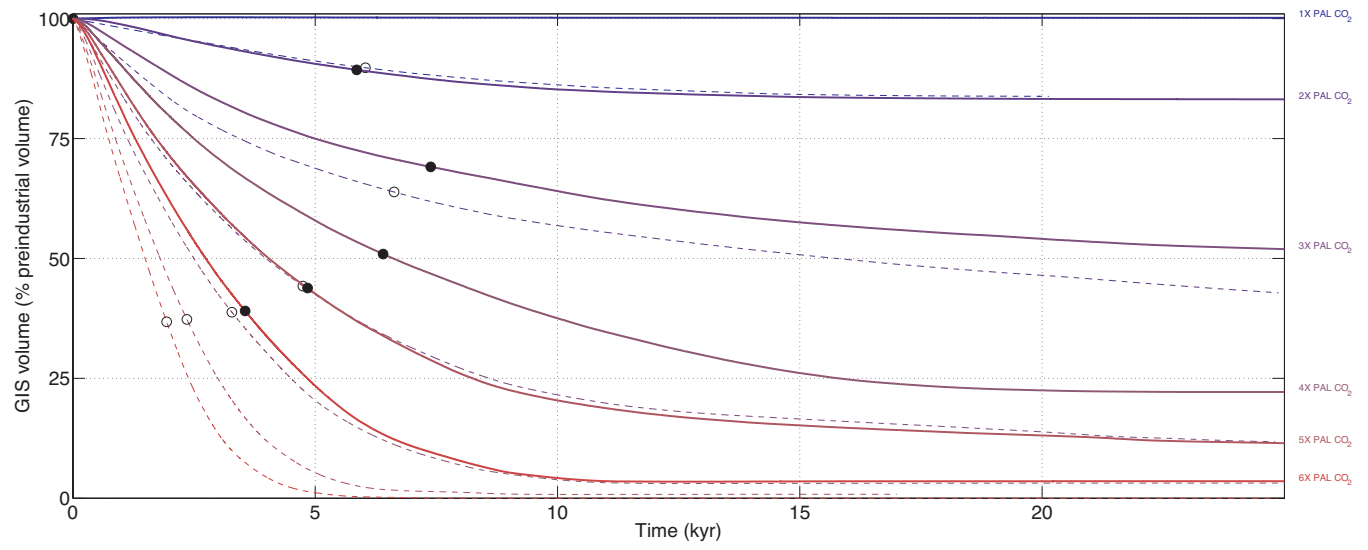

Figure 4.2: Timeseries of ice volume evolution for equilibrium deglaciation simulations. Solid lines represent default simulations, while dashed lines represent simulations with lower snow and ice albedo and surface lapse rate values. Solid and hollow black dots indicate e-folding times for ice volume loss (used as a proxy for ice sheet response times), based on initial and final ice volumes. Note that the difference between the dashed and solid lines for the simulation forced by $1 \times \mathrm{PAL} \mathrm{CO}_{2}$ represents the shift in preindustrial simulated ice volume that is strictly due to changes in model parameters. 
approaches which can overestimate ablation (Bougamont et al., 2005). Another possibility is the low polar amplification of the UVic ESCM (near the bottom of the range of polar amplifications of the models used in the IPCC AR4 (Randall et al., 2007)). Low polar amplification is likely the dominant factor, as this results in proportionately less polar warming as $\mathrm{CO}_{2}$ increases.

\subsubsection{Transient Deglacial Simulations}

Below projected emissions of $2560 \mathrm{Gt} \mathrm{C}$, final ice loss was $<25 \%$ of the initial GIS volume (Figure 4.3). At $2560 \mathrm{Gt} \mathrm{C,} \mathrm{25 \%} \mathrm{of} \mathrm{the} \mathrm{GIS} \mathrm{ice} \mathrm{volume}$ was lost, despite this simulation displaying transient $\mathrm{CO}_{2}$ concentrations well in excess of the $3 \times$ PAL CO$_{2}$ GIS stability threshold established in the equilibrium experiments. Cumulative emissions of $3840 \mathrm{Gt} C$ resulted in volume loss in excess of $50 \%$, and at $5120 \mathrm{Gt} \mathrm{C}$ over $75 \%$ of the original ice was lost. Significantly, these were the only simulations in which longterm (not peak) $\mathrm{CO}_{2}$ concentrations exceeded the $3 \times \mathrm{PAL} \mathrm{CO}_{2}$ limit. This reflects the important modelled relationship between long term (not peak) $\mathrm{CO}_{2}$ concentration and GIS response time, similar to the results of Charbit et al. (2008). The long simulated ice response times were largely responsible for sustaining the simulated GIS through transient $\mathrm{CO}_{2}$ peaks: if the GIS tracked $\mathrm{CO}_{2}$ more closely (i.e., displayed a shorter response time), volume loss would be greater than was simulated, and an increased sensitivity to peak $\mathrm{CO}_{2}$ concentrations could also arise. Importantly, model parameters also influenced the final results of the transient simulations significantly. With lower albedo and lapse rate values, ice loss $>50 \%$ occurred for cumulative emissions of $>2560 \mathrm{Gt} \mathrm{C}$, and $>75 \%$ of the original ice volume was lost at and above $3840 \mathrm{Gt} \mathrm{C}$. 


\subsubsection{Inception Simulations}

An additional set of experiments was initialized from ice-free conditions, and integrated forward under multiples of PAL $\mathrm{CO}_{2}$, to determine the effect of $\mathrm{CO}_{2}$ concentration on GIS regrowth. In all simulations above $5 \mathrm{x}$ PAL $\mathrm{CO}_{2}$ no significant Greenland ice incepted in the model. At $4 x$ and $5 x$ PAL $\mathrm{CO}_{2}$, multiple ice caps seeded in the southern and eastern Greenland mountains, but remained distinct and were largely absent from the central lowlands due to high ablation (Figure 4.4). Dynamic ice discharge at sea level on the eastern coast began at $4 \times \mathrm{PALCO}_{2}$ and $3 \%$ of the preindustrial ice volume, and discharge increased with decreasing $\mathrm{CO}_{2}$ concentrations. This result implies that geological evidence of ice flowing to sea level in the high- $\mathrm{CO}_{2}$ climate of the late Eocene (Eldrett et al., 2007) does not necessarily imply full continental ice coverage. At $3 x \mathrm{PAL} \mathrm{CO}_{2}$ further growth of the eastern ice cap resulted in partial ice occupation of the lowland plains. However, marginal ablation limited total growth to only $20 \%$ of the original ice sheet volume after $25 \mathrm{kyr}$. In contrast, at 2x-1x $\mathrm{PAL} \mathrm{CO}_{2}$ reduced marginal ablation allowed the southern and eastern ice caps to coalesce and expand to the southern lowlands. An additional simulation was performed with $\mathrm{CO}_{2}$ lowered to 180 ppmv: this simulation displayed new areas of in-situ ice formation on lower-elevation plateaux in the western and eastern mountains, an accelerated rate of ice volume increase and a notably different initial distribution of ice.

The final stage of ice sheet growth at lower $\mathrm{CO}_{2}$ concentrations (1-2x PAL $\mathrm{CO}_{2}$, and 180 ppmv $\mathrm{CO}_{2}$ ) involved expansion of the ice sheet towards the northern margin of Greenland. This proceeded slowly (similar to the 'intransitive zone' of Oerlemans (1981)). By $35 \mathrm{kyr}$ the rate of GIS volume growth for both the $2 \mathrm{x}$ and $1 \mathrm{xALCO}$ (simulations had dropped to $\leq 1 \%$ of the preindustrial volume per $1 \mathrm{kyr}$, and $50 \% / 60 \%$ of the original ice volume had regrown, respectively. The slow rate of northward ice advance likely reflects the need for ice dynamics to move ice through a low surface 
gradient and accumulation zone, into an active ablation zone. Further resistance to rapid regrowth may also arise from an interplay between the marginal ablation zone, low accumulation, and grid resolution. Berg et al. (2006) noted that at 'low' resolution in a 1D shallow ice flow model (20 $\mathrm{km}^{2}$ ), inception was inhibited in ice sheets with low accumulation, ablative margins. Conversely, inception occurred at higher resolutions $(\leq 5$ $\mathrm{km}^{2}$ ). The effect stems from artificially low surface gradients in the last few grid cells before the ice sheet margin, and may apply to the northern GIS margin, as modelled here. If this numerical artifact does not present in the model described here, and northern GIS ice regrowth indeed occurs on $10^{4}$ year timescales, it implies that the ice sheet would struggle to regain full volume between interglacials with characteristic periodicity of order $10^{4}$ years.

The $\mathrm{CO}_{2}$-based threshold on GIS inception found here (based on the first appearance of a continental-scale ice sheet at $2 \times \mathrm{PAL} \mathrm{CO}_{2}$ ) was somewhat higher than recent estimates (DeConto et al., 2008; Ridley et al., 2010). However, only small changes to key model parameters were necessary to arrive at a much closer match with these estimates: with lower albedos and lapse rates, GIS regrowth did not occur in all simulations above $1 \mathrm{x}$ PAL $\mathrm{CO}_{2}$, and at $1 \times \mathrm{PAL} \mathrm{CO}_{2}$ initial regrowth occurred at half the rate of the default simulation.

\subsubsection{Hysteresis}

To visualize hysteresis behaviour arising from $\mathrm{CO}_{2}$-driven GIS deglaciation and regrowth, GIS ice volumes generated by the default deglaciation and inception simulations were mapped onto the ice volume $/ \mathrm{CO}_{2}$ plane. The resulting curve demonstrated the existence of multiple GIS states after $35 \mathrm{kyr}$ over a range of $\mathrm{CO}_{2}$ concentrations (Figure 4.4), with final states in all cases dependent on initial GIS conditions. The spread between final 
ice sheet volumes increased as $\mathrm{CO}_{2}$ concentrations decreased, with maximum range of $35 \%$ of the preindustrial ice volume occurring at $1 \mathrm{x}$ PAL $\mathrm{CO}_{2}$. This implies that even if near-total GIS loss was followed by a long term decrease in $\mathrm{CO}_{2}$ to preindustrial levels, the GIS would only partially recover after many millennia.

The particular hysteresis generated by the default simulations is somewhat narrower, and positioned at higher $\mathrm{CO}_{2}$ concentrations, than other recent modelling results (Ridley et al., 2010; ?; Charbit et al., 2008). This implies that the GIS in this study is more robust in the sense that it is able to at least partially regrow if $\mathrm{CO}_{2}$ drops to present-day levels. However, it is clear from the sensitivity experiments carried out here that this behaviour is very model-specific: within the physically plausible parameter space tested here, the results of the above studies can be reasonably reproduced. This suggests that the hysteresis response of the GIS in model studies is highly dependent on model design, and that a robust determination of hysteresis behaviour may require a probabilistic experimental approach.

\subsubsection{Discussion and Conclusions}

The high sensitivity of modelled ice sheet volume changes to small changes to parameters that describe surface processes clearly highlights that model parameters also play a critical role in determining model hysteretic behaviour and threshold response, especially in warmer climate states (Chapter 3). For example, using slightly lower values to describe albedo and lapse rates resulted in a drop of the GIS stability threshold by $\sim 200$ ppmv $\mathrm{CO}_{2}$, and a decrease in ice sheet response times of $56 \%$ due to increased summer ablation; a similar albedo/lapse rate drop in the transient simulations resulted in a $\sim 1000$ Gt $C$ drop in the stability threshold. This finding indicates that sensitive parameters used 
in ice/climate modelling must be identified, and then well-constrained by data or used in an ensemble modelling framework, before high significance can to be attached to model output.

I echo an earlier call (Ridley et al., 2010) for other groups to carry out similar GIS threshold and hysteresis experiments, ideally within a formal inter-comparison exercise and with a large ensemble of simulations (Goelzer et al., 2010), in order to arrive at quantified statements of risk that could be utilized in a policy framework. In addition, I agree with Charbit et al. (2008) that coordinated efforts to constrain the relationship between long-term atmospheric carbon drawdown rates and ice sheet response time may be an important step in better understanding future GIS behaviour. 

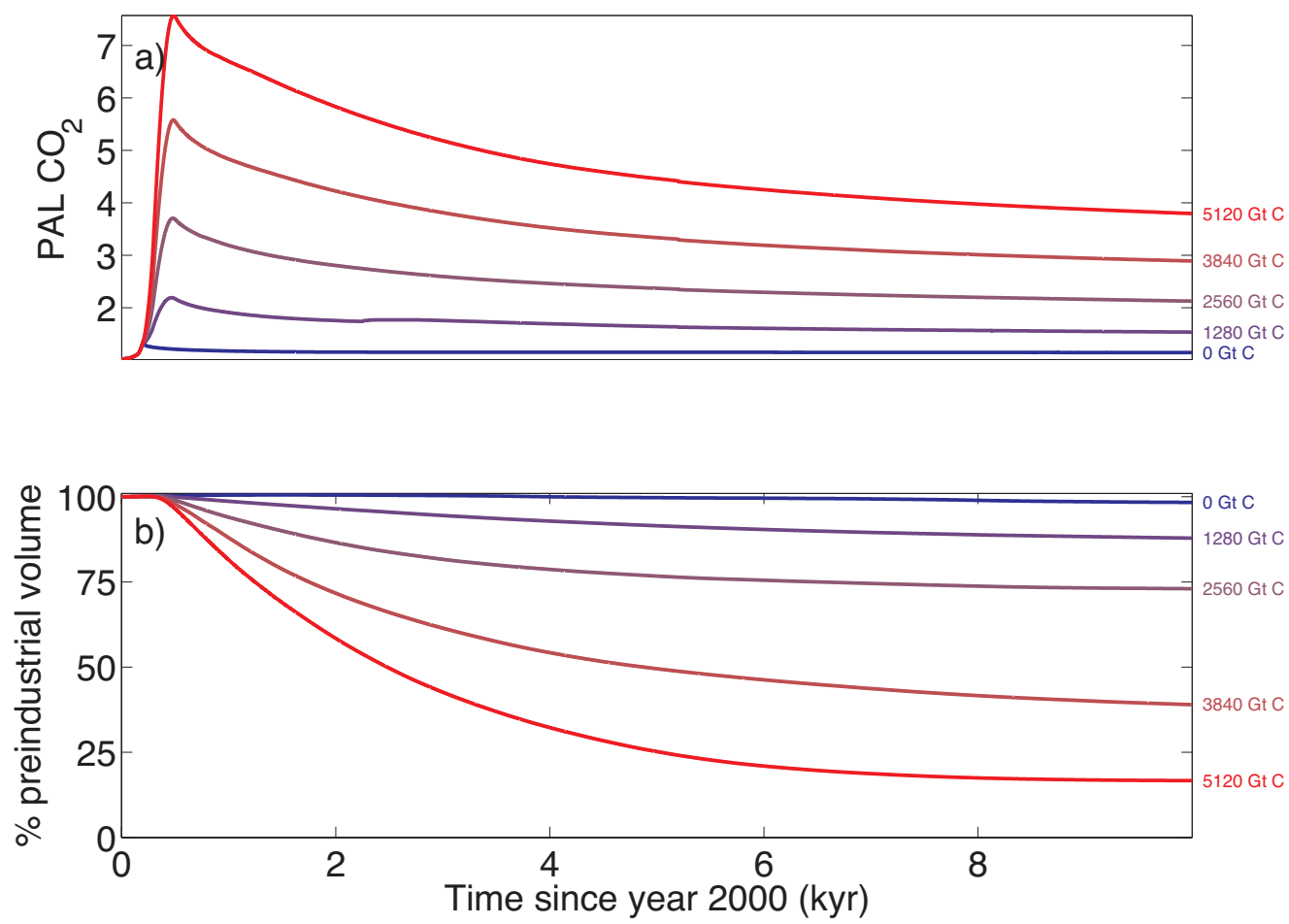

Figure 4.3: a) $\mathrm{CO}_{2}$ profiles (Eby et al., 2009) for transient $\mathrm{CO}_{2}$ simulations. b) corresponding timeseries of GIS volume. Note: similar colors denote the same experiment. 


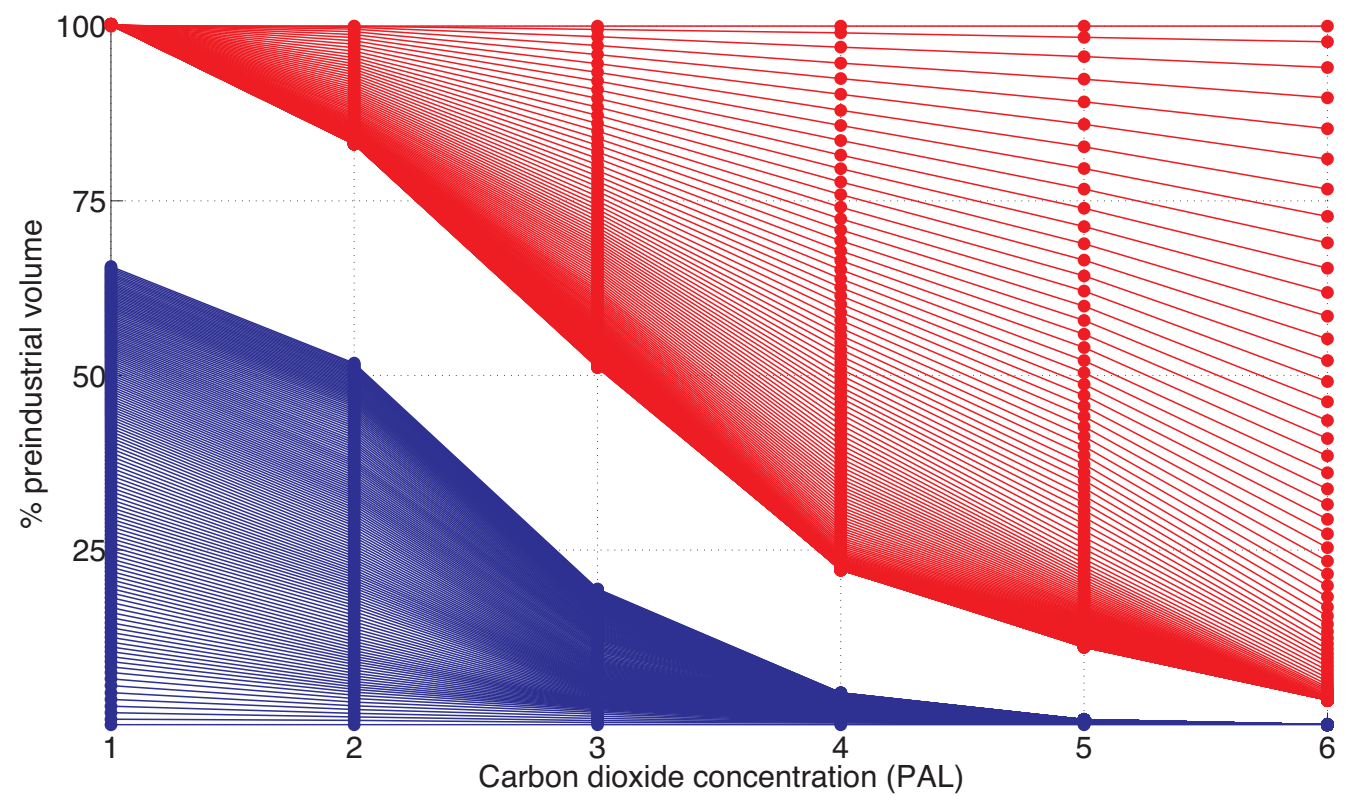

Figure 4.4: Development of ice volume hysteresis curve in ice volume $/ \mathrm{CO}_{2}$ space over $25 \mathrm{kyr}$. Red lines represent the range of ice volumes for deglacial simulations under different $\mathrm{CO}_{2}$ forcings at 200 year intervals; blue lines are the equivalent for inception simulations. The change in distance between neighbouring lines is a visual indication of the various rates of approach towards the state at $25 \mathrm{kyr}$, which is represented by the lowermost red line for deglaciation and uppermost blue line for inception. After $25 \mathrm{kyr}$, only $1 \mathrm{x}$ and $2 \mathrm{xAL} \mathrm{CO}_{2}$ inception simulations display residual drift. 


\section{Chapter 5}

\section{The oceanographic response to Antarctic ice loss: preliminary results}

\subsection{Introduction}

The West Antarctic Ice Sheet (WAIS) is a large mass of ice located in the Pacific sector of the Antarctic continent. It is largely isolated from the East Antarctic Ice Sheet (EAIS) by the Transantarctic Mountains. Based roughly on this division, the WAIS contains enough ice to raise eustatic sea level rise by $5 \mathrm{~m}$ were the entire ice mass to disappear (Lythe and Vaughan, 2001). The WAIS is unique in that much of the ice is grounded below sea level and the bed slopes downwards as one proceeds landward (Figure 5.1). Minimum bed elevations reach $2 \mathrm{~km}$ below mean sea level (bmsl); these minima are generally located near the central WAIS. Based on the modern surface convexity and bed elevations, Hughes (1973) postulated that the WAIS is currently in a natural state of ongoing collapse. Weertman (1974) built on the theme with a seminal modelling study, while Mercer 
(1978) suggested that the present-day WAIS is in fact stable, but near a tipping point that could be surpassed by anthropogenic climate change.

Instability arises because an initial thinning at the grounding line will cause it to retreat landwards. As the magnitude of the flux of ice across the grounding-line is dependent upon ice column thickness (Schoof, 2007), grounding-line retreat over a bed that slopes in the opposite direction of ice flow will drive (i) larger cross-grounding-line flux, (ii) transition zone thinning, (iii) grounding-line retreat to thicker ice, and (iv) even greater flux. Retreat will not stop, in theory, until the bed under the grounding line shallows inland (against the direction of ice flow).

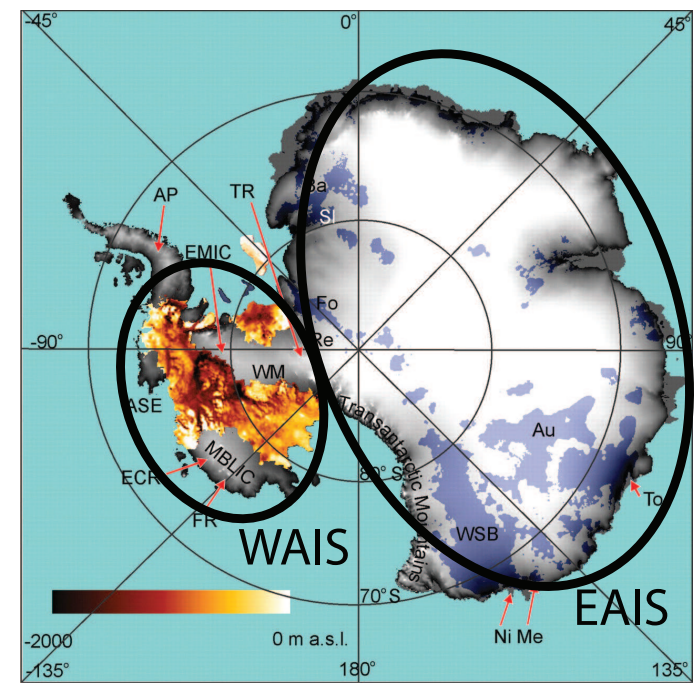

Figure 5.1: Antarctic surface topography (gray) and bed topography (yellow to brown). Where WAIS bed topography is shown, bed elevation deepens inland, defined as the opposite direction of ice flow. Blue shading represents areas of the EAIS with bed elevations $<-200$ m.a.s.l. (Bamber et al., 2009). Smaller-font abbreviations denote regions of interest in Bamber et al. (2009).

Pollard and DeConto (2009) utilized an ice sheet model (Pollard and DeConto, 2007) which included the grounding line flux parameterization 
of Schoof (2007) to simulate WAIS advance and retreat over the Pliocene and Pleistocene. The primary model run demonstrated periodic largescale retreats driven by increased prescribed sub-ice-shelf melt rates and sea level. However, the oceanic response of these modelled changes to ice volume was not described. On the other hand, Weaver et al. (2003) showed that in certain configurations the global ocean could be sensitive to fluxes of ice sheet-derived freshwater to the Southern Ocean. In particular, during a climate state in which North Atlantic Deepwater (NADW) production has collapsed, a freshwater flux applied to the Amudsen Sea (corresponding to $22 \mathrm{~m}$ of sea level rise over 500 years) was sufficient to trigger a resumption of NADW production via the bi-polar ocean density seasaw (whereby decreases in Antarctic Intermediate Water - AAIW - density drove increased salinity flux to the North Atlantic, eventually triggering deep convection). Weaver et al. (2003) suggested that this process could explain the relationship between Meltwater Pulse 1A (MWP1A ( 14 kyr BP), the Bølling-Allerød warm interval, and the Antarctic Cold Reversal (though see Trevena et al. (2008) for alternate interpretations using the same model). However, neither Weaver et al. (2003) nor Trevena et al. (2008) addressed the specific Antarctic ice dynamic processes that could have potentially generated the fresh water flux.

These studies demonstrate that i) the AIS is capable of undergoing large-scale changes in response to changing sea level and sub-ice-shelf melting and ii) the global ocean circulation is sensitive to AIS-derived fluxes of freshwater. This behaviour implies that an ice sheet/climate model may be an ideal tool with which to explore the coupled AIS/ocean system. The strengths of a coupled model approach to investigating AIS/ocean interactions (compared to Pollard and DeConto (2009) or Weaver et al. (2003)) are that i) a 3D ocean model is available to translate ice sheet model-derived fluxes into a global oceanic response; ii) time-dependent ice dynamics are explicitly represented; iii) the coastal Antarctic locations of freshwater discharge correspond to realistic ice 
drainage basins; iv) negative (latent) heat fluxes are associated with positive fluxes of iceberg-derived freshwater; and v) ice sheet-derived changes to oceanography are reflected in the AIS surface mass balance. Here I present an initial model simulation that explores the interaction of realistic time dependent AIS behaviour with the global ocean/climate system and forms the framework for further model simulations (Chapter 6).

\subsection{Methods}

The coupled ice sheet/climate model is described in Chapter 3. Initial conditions for all experiments were obtained from the final state of the spin-up simulations described in Chapter 4. A control simulation ('Control') was also extended from initial conditions. The completed run, (hereafter termed 'Sim1'), was meant primarily as a preliminary test of the ability of AIS retreat to affect the ocean/climate system and form a baseline for additional simulations. In it, a late Holocene equilibrium state (i.e. prior to significant anthropogenic emissions) was perturbed by increasing sub-shelf melt rates to the upper 'hot' values of Pollard and DeConto (2009). This magnitude of melt has been demonstrated to cause a retreat of the WAIS (Pollard and DeConto, 2009) that matched observations of past WAIS behaviour (Naish et al., 2009) back to the mid-Pliocene. Sim1 therefore explores the response of a preindustrial ocean equilibrium state to the freshwater flux derived from a realistic AIS response to increased sub-shelf melting.

Several aspects of the model design bear mentioning. Surface melt and ice discharge are binned according to present-day, large-scale ice drainage basins. Within these basins, melt and discharge is delivered to the ocean evenly along coastlines. In the case of ice shelves, sub-shelf melt (calculated using the parameterization described in Pollard and DeConto (2009)) 
is delivered to the ocean model at the ice front (not the grounding line), and is associated with equivalent fluxes of latent heat out of the ocean.

Climate boundary conditions (namely $\mathrm{CO}_{2}$ and orbital parameters) were set to preindustrial values. Because of thus, the imposition of high melt rates under the ice shelves is not mirrored by an equivalent sea ice response that would presumably occur under a consistent climate change scenario. This experimental design is required to isolate the sea ice response to ice shelf loss, but may not capture nonlinear sea ice behaviour that could manifest during combined sea ice/ice sheet response to climate change (e.g. Nichols, 1997).

\subsection{Preliminary results}

Results from Sim 1 are presented below. Analysis focuses on the ice volume response to increased basal melting, the resulting freshwater flux anomaly (based on changes to ice sheet mass), sea level, and the sea ice and oceanic response to ice-derived flux.

\subsubsection{Ice sheet response to increased basal melting}

The ice sheet response to an increase in melting was characterized by several stages. Immediately after the imposition of high sub-shelf melt (year 0, Figure 5.2), freshwater fluxes associated with changing AIS ice volume increased to $0.12 \mathrm{~Sv}$. This initial flux more than doubled the total modelled background freshwater flux from the continent, and is of the same order of magnitude as Heinrich Event fluxes (Levine and Bigg, 2008). For approximately 200 years following the increase in sub-ice-shelf melt rates, the AIS underwent rapid mass loss associated with initial retreat of both WAIS and EAIS grounding lines (Figure 5.3), such that the sea level contribution from 
each component of the AIS was approximately equal despite the large difference in EAIS and WAIS ice volumes (Figure 5.2d). The initial total AIS ice volume stored in ice shelves was $3.6 \times 10^{14} \mathrm{~m}^{3}$, or approximately $10 \%$ of the total AIS volume change after $10 \mathrm{kyr}$. As this floating ice mass contributed to the initial fresh water flux (Figure 5.2b) but not the change in sea level (Figure 5.2d), the initial rate of change of sea level did not relate linearly to the fresh water flux, suggesting that sea level-derived estimates of maximum fresh water fluxes (e.g. MWP1A) may be low if floating ice shelves contributed significantly to the flux.

From 200-800 years, the AIS retreat-derived freshwater flux anomaly stabilized at $0.035 \mathrm{~Sv}$, equating to $~ 50 \%$ of the background Antarctic contribution to the Southern Ocean freshwater input in the control simulation. This indicates that even given a gradual 'ramp-up' to high-melt conditions over several hundred years (as opposed to the step-function increase modelled in Sim1), the resulting ice-retreat-derived freshwater flux would still compose a significant fraction of the total flux derived from the AIS for centuries thereafter. Between 800-3000 years, the ice sheet-derived flux experienced a further linear decrease to approximately $0.015 \mathrm{~Sv}$, or $20 \%$ of the background control flux. After year 3000, the EAIS ceased contributing significantly to the total ice sheet-derived fresh water flux, and all remaining fresh water and SLR was sourced from the WAIS (Figure 5.2d). From year 3000 onwards WAIS-derived fresh water flux asymptotically approached 0 as the diminished WAIS stabilized and the rate of change of ice volume slowed.

\subsubsection{Sea ice and surface ocean response to ice discharge}

Figure 5.4 shows the difference in annual average sea ice after 4000 years of model simulation (where 4000 years was chosen to represent the typical sea ice and ocean configuration that persisted for the remainder of the simulation). Sea ice thickness increased in regions that experienced ice shelf 
loss, as new sea ice grew in place of permanent ice shelves. The offshore sea ice change was generally towards greater fractional sea ice coverage and thickness, consistent with the increased freshwater flux and removal of heat from the surface ocean associated with ice sheet discharge. However, this trend was not universal: a region north of the Rockefeller Plateau experienced a noticeable decrease in sea ice thickness (but not area), while the Indian Ocean sector of the Southern Ocean experienced a sea ice fraction decrease.

The modelled surface ocean salinity response integrated both a direct ice sheet-sourced signal and an indirect sea ice signal. Figure 5.6 displays the surface ocean temperature and salinity changes after 4000 years of model simulation. Of particular significance are the regions of the Ross and Weddell Seas where ice shelf cover was lost; these regions became productive sea ice factories in which new sea ice was formed and exported northwards (Figure 5.5a). This increased sea ice export effectively transported much of ice sheet-derived fresh water signal directly to the open Southern Ocean. As a result of the salinity forcing provided by sea ice export, the surface density of the regions characterized by ice shelf retreat generally increased (Figure 5.5b).

A broad band of the Southern Ocean corresponding to the modelled formation region of the AAIW (between $\sim 40^{\circ} \mathrm{S}-60^{\circ} \mathrm{S}$ ) experienced both a freshening and cooling (likely resulting from greater rates of sea ice melt there) while regions offshore of Cape Adare and the Antarctic Peninsula, both of which were immediately downstream of increased Ross/Weddell sea ice formation regions, also experienced a strong freshening trend.

\subsubsection{Deep ocean response to ice discharge}

The baseline Southern Hemisphere circulation simulated in the model is shown in Figure 5.7. Cold, saline Antarctic Bottom Water (AABW) was 
generated near the Antarctic coast and mixed with Circumpolar Deep Water (CDW), fresh Antarctic Intermediate Water (AAIW) was subducted between $\sim 45^{\circ}-60^{\circ} \mathrm{S}$, and North Atlantic Deep Water (NADW) entered the Southern Ocean between 2000-4000 mbsl. Snapshots of zonally averaged salinity differences between Sim 1 and Control simulations are shown in Figure 5.8. The ice sheet-sourced discharge generated a low-salinity signal that propagated northward at depth in the modelled AAIW before being subducted in NADW source regions. Counterintuitively, for the first 3000 years the salinity of the AABW increased due to downwelling along the Antarctic coast resulting from enhanced atmospherically-driven surface water cooling and brine rejection. Final freshening of the deep Southern Ocean was delayed until after some 4000 years of simulation, as fresher NADW-sourced deepwater slowly invaded the southern hemisphere. By year 10000, the entire zonally averaged Sim 1 salinity crosssection was fresher than the equivalent Control profile.

The impact of the ice sheet-derived freshwater flux on the North Atlantic meridional overturning stream function after 4000 years is shown in Figure 5.9 (the high-latitude Southern Ocean poleward of Drake Passage is omitted for consistency in the meridional streamfunction calculation). A persistent overall weakening and shallowing of the North Atlantic arm of the thermohaline circulation cell occurred, consistent with increased northward freshwater flux. However, the absolute value of the weakening was less than $10 \%$ of maximum North Atlantic maximum overturning value. This indicates that a southern fresh water flux associated with millennial-scale retreat of the AIS, by itself, would not have a large effect on a 'modern' North Atlantic, but would act to reinforce predicted future weakening of the NADW thermohaline cell (Meehl et al., 2007). 


\subsubsection{Ice sheet-climate feedbacks}

The retreat of the WAIS had a noticeable effect on the simulated surface mass balance (SMB) of regions of the interior ice sheet near newly-exposed sources of moisture (Figure 5.10): the surface mass balance of these regions increased by up to $15 \%$. However, as the absolute value of the surface mass balance over the ice sheet interior was small, the absolute change in SMB was also small and the effect diminished with distance from the retreated WAIS. In contrast, a strong decrease in surface mass balance was evident around the edges of the ice sheet, where ice retreat drastically decreased surface elevation. The overall SMB decreased by $22 \%$, with the majority of the decrease simply due to the $17 \%$ decrease in AIS areal extent.

The requirement of prescribed melt-rates precluded analysis of feedbacks between ocean temperature and ice shelf melt rates. However, simulated ice shelf loss and ice sheet retreat drove a temperature decrease in newly-exposed Ross and Weddell Sea regions due to exposure to the atmosphere coupled with an increase in local negative heat flux associated with sub-ice-shelf melt (Figure 5.5b). This cooling extended to depth in both seas, and would act as a negative feedback on an initial perturbation to sub-shelf melting (Hattermann and Levermann, 2009) but not instability-driven ice retreat in a fully coupled model. It should be noted that closing the coupling loop completely would require a parameterization that relates coarse-scale OGCM temperature to spatiotemporally variable distributions of sub-shelf melting and not simply whole-shelf rates of melt (Beckmann and Goosse, 2003; Holland et al., 2008b).

\subsection{Summary}

A preliminary simulation, motivated by the observation that large-scale ocean-driven AIS retreat can in turn cause significant changes to Southern 
Ocean and global ocean dynamics, was carried out using the coupled ice sheet-climate model. Sub-ice-shelf melting was prescribed according to the method of Pollard and DeConto (2009); an increase to this prescribed melt provided the only forcing that drove coupled model evolution.

Increased sub-shelf melt resulted in a retreat of the AIS (and particularly the WAIS) over the 10000 year simulation. The flux of fresh water derived from transient AIS volume loss represented a significant fraction of the background Antarctic flux for over 3000 years. The flux of fresh water (and corresponding negative flux of heat) to the Antarctic coast was accompanied by exposure of large areas of the Ross and Weddell surface seas to colder atmospheric temperatures. This exposure initiated regional sea ice production and export, which resulted in higher salinities and cold temperatures in the interior Ross and Weddell seas, and higher salinity AABW formation water. Melt of excess sea ice generated cold and fresh anomalies in the open Southern Ocean, and resulted in the export of fresh water, via the AAIW, to the North Atlantic, where the signal was subducted as NADW and returned at depth to the Southern Hemisphere after a millennial-scale lag. As a result of the increased fresh water input, the NADW arm of the global meridional overturning circulation shoaled and weakened slightly but did not collapse.

In addition to the direct effect of sub-shelf melting, retreat of the AIS was also regulated by ice-climate feedbacks. In particular, a moderate increase in SMB occurred over ice sheet regions near to newly-exposed ocean basins, lowering of marginal ice elevations decreased SMB there. A decrease in the temperature of the inland Ross and Weddell seas would have acted to decrease sub-shelf melting, were this permitted by the model.

Further investigation of the sensitivity of the global climate system to ice sheet model-derived fresh water fluxes is an important research topic, given the demonstrated ability of sub-shelf melt to instigate global-scale 
changes to oceanography. The use of coupled ice sheet-climate models constrains the potential magnitude of fresh water fluxes by explicitly representing the ice dynamics that drives coastal ice discharge; the set of proposed simulations detailed in Chapter 6 will extend the approach demonstrated here to simulations representative of the LGM and future climate. 


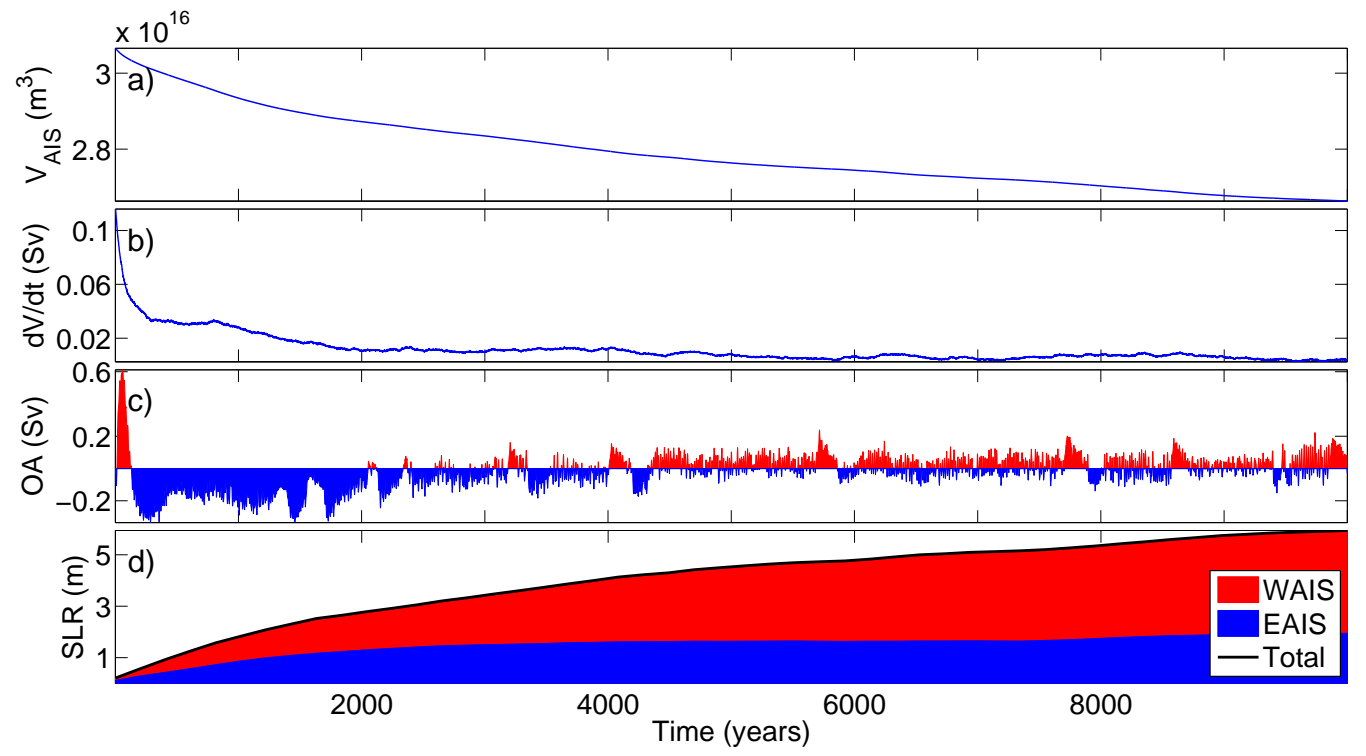

Figure 5.2: Timeseries of shelf loss experiment output. a), total AIS volume. b), freshwater flux anomaly $\left(\mathrm{dV}_{A I S} / d t\right.$, expressed in Sverdrups, $\left.10^{6} \mathrm{~m}^{3} \mathrm{~s}^{-1}\right) . \mathrm{c}$ ), maximum positive zonally averaged overturning anomaly $(\mathrm{OA})$, which is representative of the strength of the North Atlantic meridional overturning cell and is defined as the difference between the maximum zonal average overturning stream function between the Sim1 and Control simulations. d), eustatic sea level rise (SLR). Note, the sea level rise curve is smoothed relative to other curves due to use of 200-yearsnapshot ice distributions to calculate the net sea level contribution of the WAIS and EAIS. 

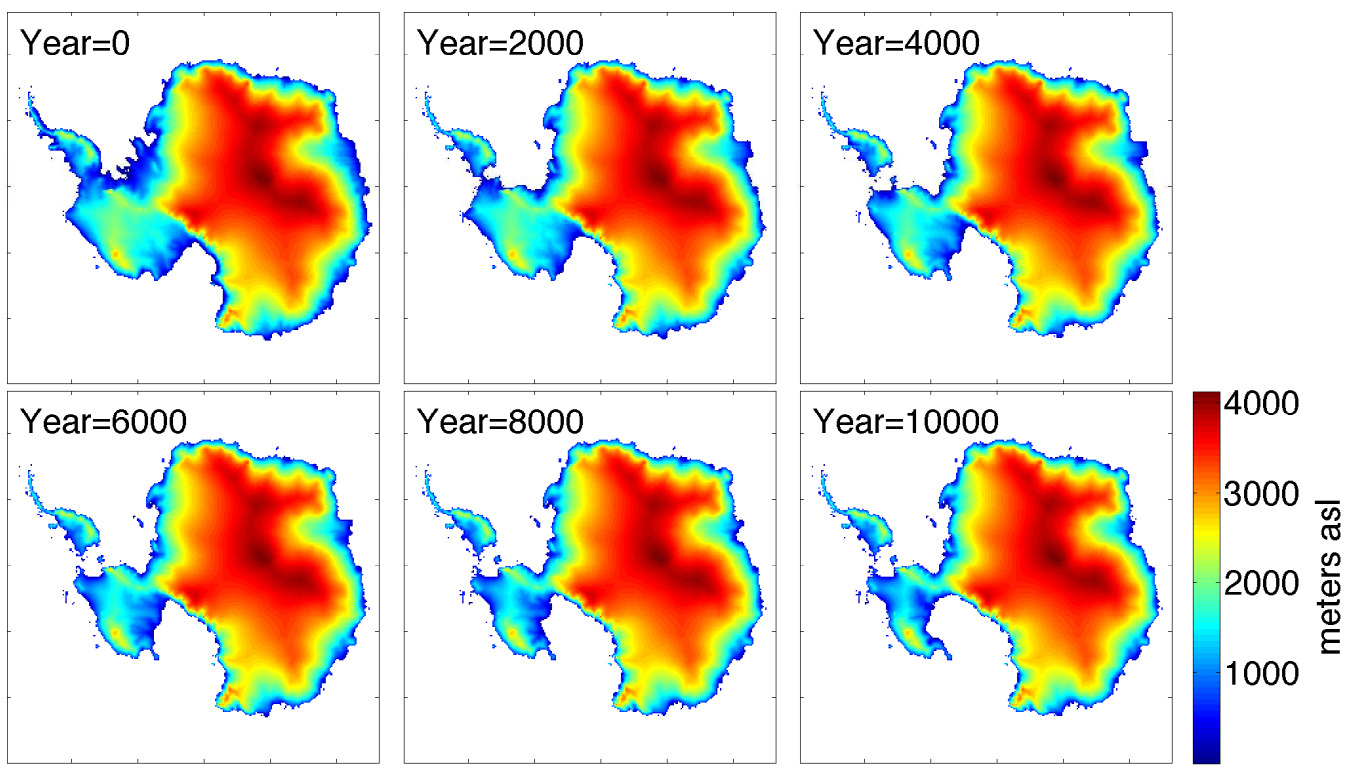

Figure 5.3: Time evolution of AIS in response to increased basal melting. Note that any floating ice is omitted in all plots for clarity. Color axis: surface height.

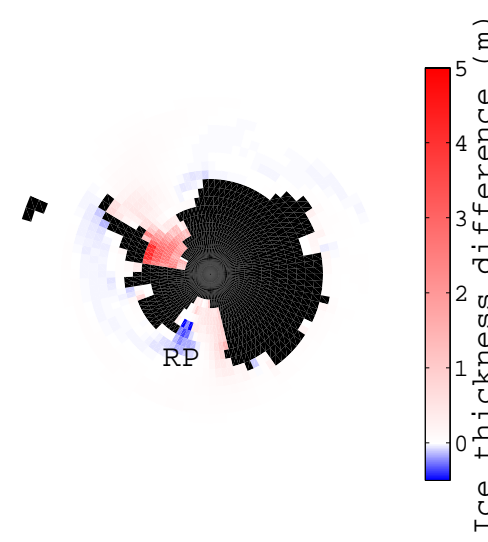

(a) Ice thickness difference

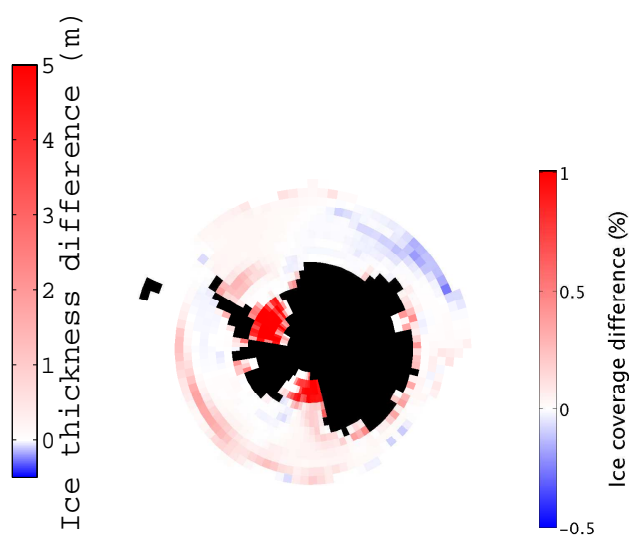

(b) Ice fraction difference

Figure 5.4: Sim1-Control sea ice difference after 4000 years (i.e. change relative to simulated preindustrial sea ice concentrations). Note that the present-day Antarctic continental mask represents the present-day grounding line. RP: Rockefeller Plateau; IO: Indian Ocean. 


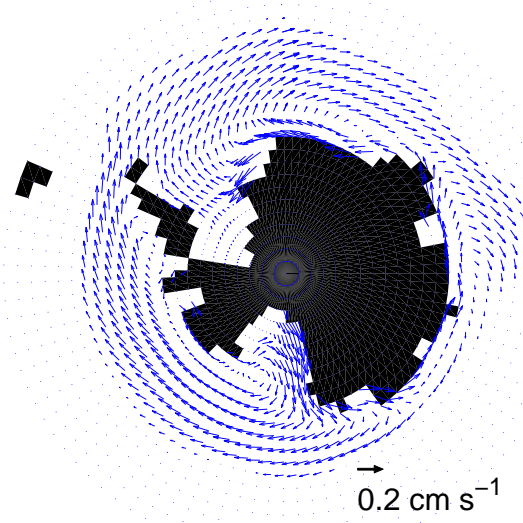

(a) Southern Ocean sea ice velocity

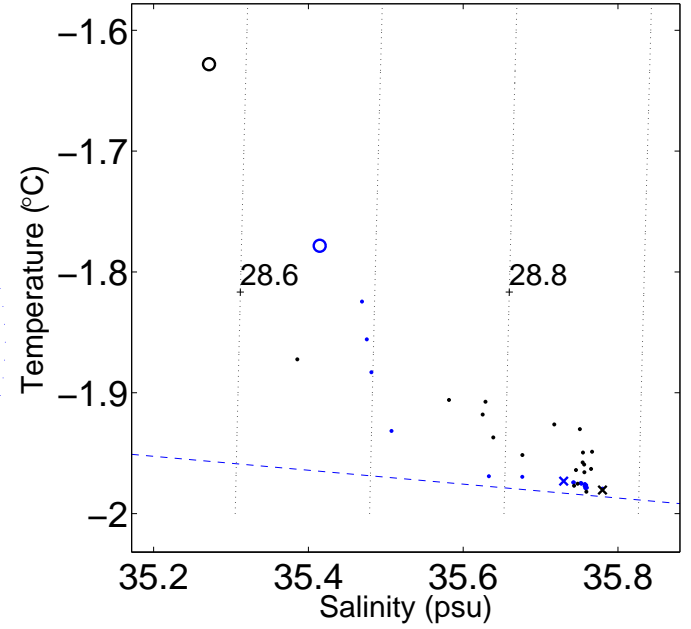

(b) Temperature-salinity diagram

Figure 5.5: a) Southern Ocean annual average ice velocity vectors after 4000 years of simulation. b) Representative T-S trajectories of grid cells within interior of the Ross (blue) and Weddell (black) Seas that underwent ice shelf removal. Open circle: initial T-S; small dots: intermediate T-S; crosses: final T-S state after 4000 years; blue dashed line: T-S-dependent freezing point; black dashed lines: $\sigma_{t}$ isopycnals.

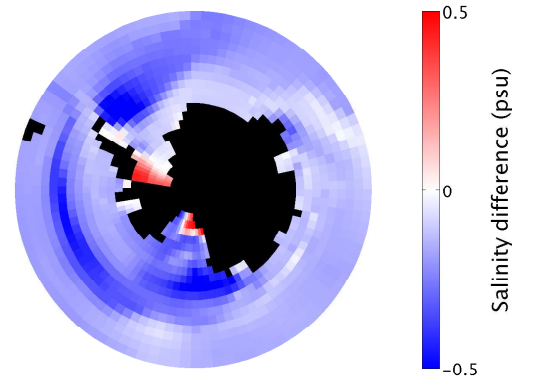

(a) Surface salinity difference (b) Surface temperature difference

Figure 5.6: Ice retreat-control simulation surface ocean salinity and temperature differences after 4000 years. 


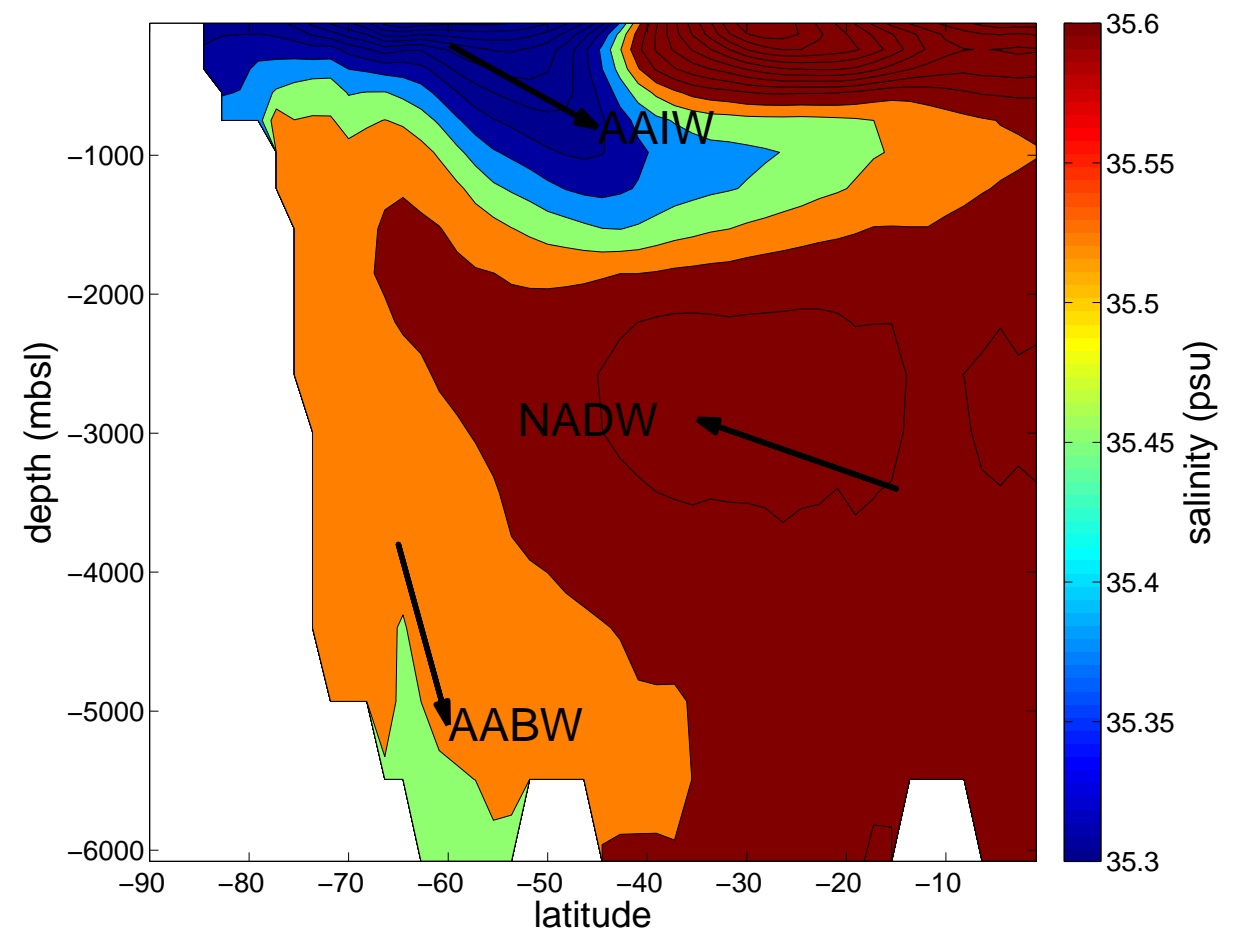

Figure 5.7: Zonally averaged southern hemisphere ocean salinity. Major simulated water masses indicated with bold arrowed lines. AAIW: Antarctic Intermediate Water; NADW: North Atlantic Deep Water; AABW: Antarctic Bottom Water; CDW: Circumpolar Deep Water. 


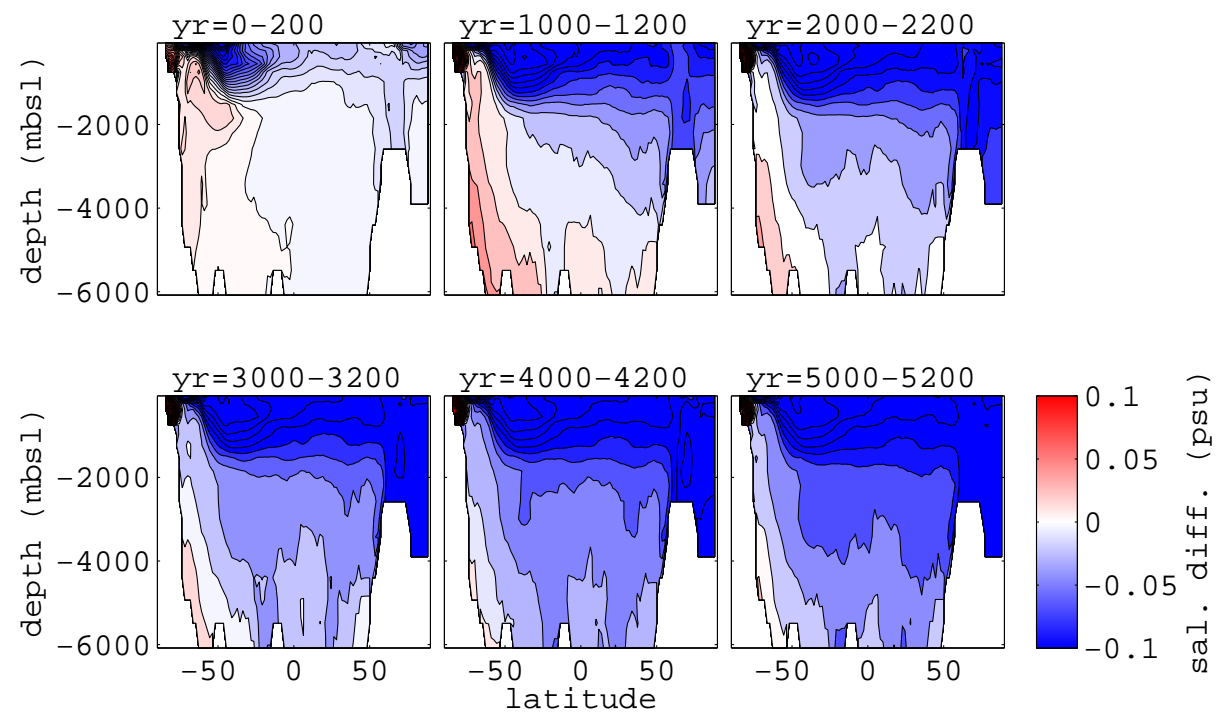

Figure 5.8: Zonally averaged salinity difference (Sim1 minus Control), for 200-year average snapshots for several intervals throughout the simulation.

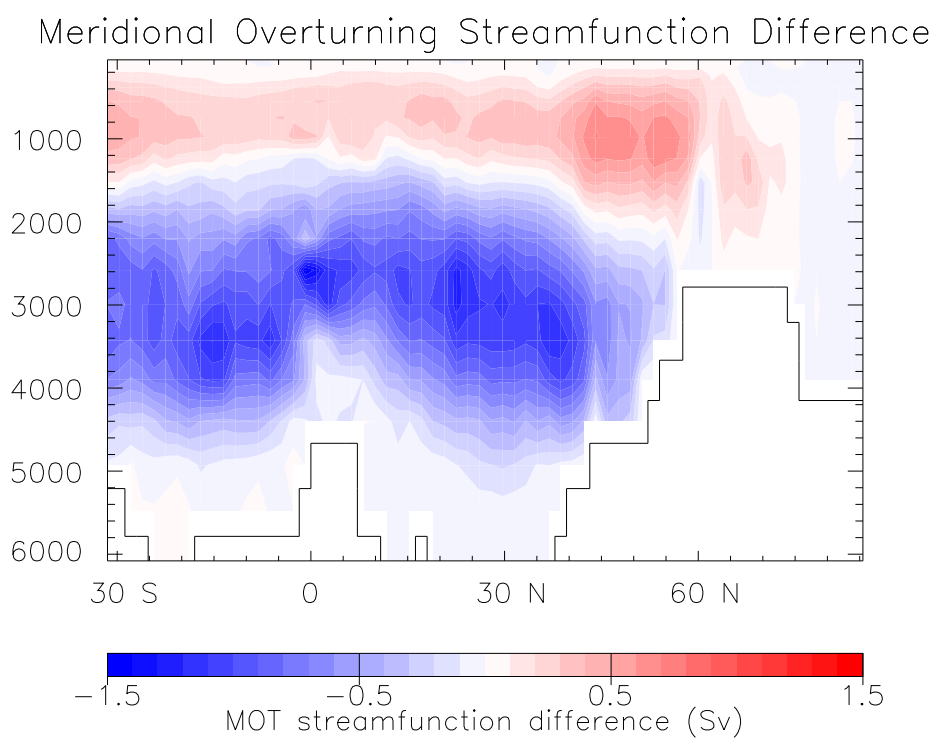

Figure 5.9: North Atlantic meridional overturning stream function difference (Sim1 minus Control). 


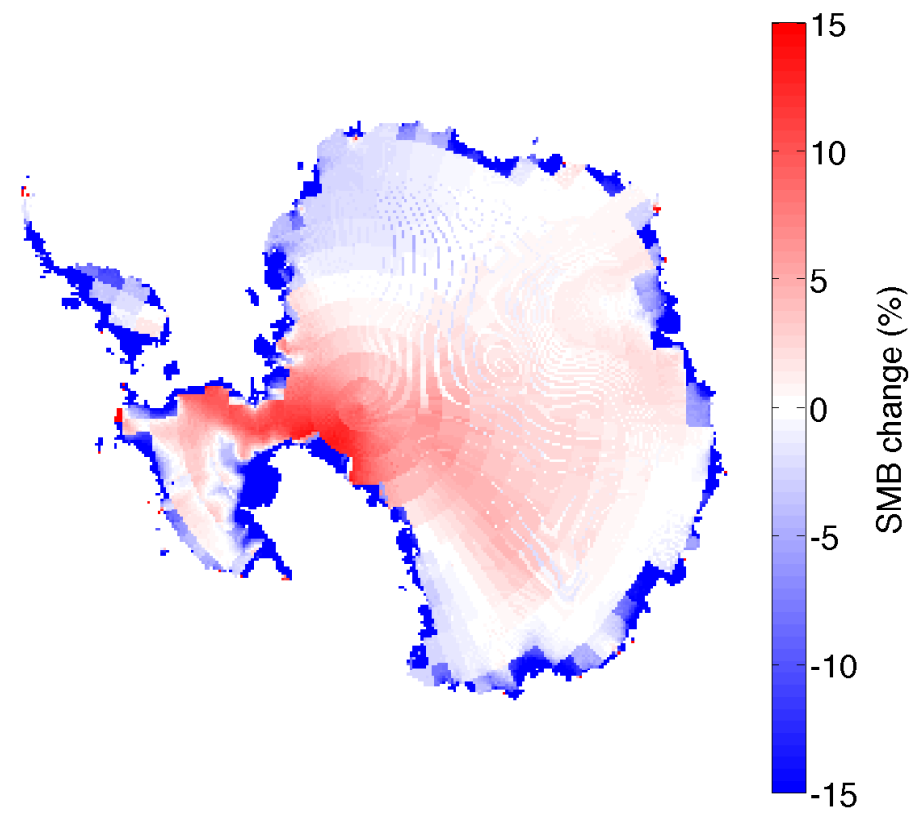

Figure 5.10: Sim1-Control surface mass balance difference, expressed as a percent change from control conditions, at year 10000. Red implies an increase in annual average surface mass balance, while blue represents a decrease. Regions that have undergone complete ice loss are omitted from the diagram. 


\section{Chapter 6}

\section{Conclusions}

\subsection{Summary}

Research presented in this thesis contributes to the scientific understanding of the global ice sheet-climate system. This research includes use of climate model simulations to explore SAT-based surface melting regimes over ice sheets and ice shelves, development and testing of a new ice sheetclimate model, which was used to explore the role of $\mathrm{CO}_{2}$ on deglaciation and inception of the GIS, and the oceanographic implications of AIS retreat. Taken collectively, this work helps to reveal the role that ice sheets play in the climate system, highlights the sensitivity of the contemporary AIS and GIS to climate change, and demonstrates the ability new coupling techniques to improve coupled ice sheet-climate simulations.

Chapter 2 details initial efforts to quantify changes to the ice sheetclimate system by exploring the ability of high-melt conditions to invade the interior of ice sheets and ice shelves under climate warming. SAT output from a series of simulations forced with emissions of $\mathrm{CO}_{2}$ was processed to obtain model-bias-corrected estimates of the number of annual positive degree days (PDDs) occurring at each grid cell. These spatially 
and temporally evolving PDD fields were then used to delineate evolving $200 \mathrm{PDD} \mathrm{yr}^{-1}$ isocontours at both poles, which a number of independent studies had previously identified as an important air temperature-based threshold on ice shelf stability. The simulations captured observed isocontour migrations and past Arctic and Antarctic ice shelf losses well considering the large scale of the model, and indicated that:

- If a maximum future emission scenario of $5120 \mathrm{Gt} C$ by year 2300 was realized, $>200 \mathrm{PDD} \mathrm{yr}^{-1}$ would occur over all large Antarctic ice shelves, and high summer melt conditions would develop over most of the grounded GIS and coastal WAIS, while the melt regime in the interior of the WAIS would resemble that of the modern-day GIS;

- If simulated $\mathrm{CO}_{2}$ concentrations were capped at present-day levels (implying immediate cessation of emissions), the Antarctic ice shelves and the WAIS would remain entirely within the $<200$ PDD $\mathrm{yr}^{-1}$ polar regime.

The simulations described above did not utilize a dynamic ice sheet coupled to the climate model. Therefore, in order to carry out full coupled simulations of AIS and GIS response to future climate change, I undertook development of a coupled ice sheet/climate model consisting of PSUI and the UVic ESCM (Chapter 3). Important aspects of the coupled model include:

- An energy balance model-derived surface mass balance (SMB) field generated with UVic ESCM climate fields;

- A sub-gridded distribution of SMB calculations that resolves narrow ablation zones while retaining computational efficiency;

- An energy-conserving surface air temperature bias correction procedure; 
- Simulations of ice shelves on both the high resolution ice sheet model and lower-resolution climate model grids;

- The ability to represent an arbitrary number of ice sheets within a global climate simulation.

Before carrying out future projection simulations with the newly-developed model, I first evaluated the role of important aspects of the model (bias correction procedure, meltwater refreezing and variable snow/ice albedo) in determining AIS and GIS geometry under Eemian, LGM, late Holocene and modern boundary conditions. I determined that:

- The uncorrected climate model SAT bias played a primary role in long-term ice sheet evolution, followed by the effect of surface albedo and refreezing of meltwater;

- Model bias, refreezing, and surface albedo all played a more important role in determining equilibrium ice sheet volumes in situations where significant surface melting occurred. For example, the AIS was relatively insensitive to changes to model parameters compared to the GIS, and the GIS became more sensitive to model parameter changes in warmer climate states such as the Eemian, as more of the ice sheet surface experienced melting conditions;

- The bias-corrected model, with refreezing and variable surface albedos enabled, was able to reasonably capture important aspects of the AIS and GIS, including modern SMB and ice distribution, as well as simulate northern and western GIS retreat under Eemian boundary conditions;

- Evaluation of the model under the climate conditions of the Eemian, LGM, and late Holocene provided an effective means of identifying optimal model configurations. By comparing results from various 
model configurations against both paleoclimate and modern observations, the procedure tested the ability of the model to reproduce both a modern 'snapshot' of the AIS and GIS, and ice sheet change in response to changing climatic boundary conditions.

Model development and evaluation were necessary first steps towards a coupled model-based scientific exploration of the ice sheet/climate system. Chapter 4 describes initial results of the model, resulting from simulations designed to explore thresholds on GIS stability and behaviour of the GIS under realistic transient $\mathrm{CO}_{2}$ scenarios. Two suites of simulations were used to quantify model-based $\mathrm{CO}_{2}$ thresholds on GIS loss and regrowth. In the first suite, the model was initialized from a late Holocene steady state climate and run forward with $\mathrm{CO}_{2}$ concentrations increased instantaneously from 1 to 2-7 PAL $\mathrm{CO}_{2}$, to explore the role of $\mathrm{CO}_{2}$ on GIS deglaciation. While a step-function change in $\mathrm{CO}_{2}$, in the absence of change in any other external climate forcings (e.g. orbital parameters), is physically unrealistic, the experiments were primarily meant to provide important 'bounding' thresholds that the transient system could cross in the course of realistic climate evolution under orbital conditions similar to the present day. In addition, the use of only one forcing parameter allowed clear isolation of the GIS response to changing $\mathrm{CO}_{2}$. Analysis of these simulations revealed that:

- Deglacial simulations resulted in crossing of a SMB-based GIS stability threshold defined by Gregory and Huybrechts (2006), between $3-4 x \mathrm{PAL} \mathrm{CO}_{2}$ (i.e. at $3 \times \mathrm{PAL} \mathrm{CO}_{2}$ the net $\mathrm{SMB}$ remained positive, while at $4 \times \mathrm{PAL} \mathrm{CO}_{2}$ the $\mathrm{SMB}$ became temporarily negative);

- Below the SMB-based stability threshold, GIS retreat occurred but the ice ultimately stabilized in a 'reduced ice sheet' configuration, while at $\mathrm{CO}_{2}>=4 \times \mathrm{PALCO}_{2}$, ice retreated to the east and southern mountains, where high elevation ultimately limited ablation and al- 
lowed a return to net neutral mass balance and GIS equilibrium at a much-reduced ice volume;

- Simulated ice retreat in elevated- $\mathrm{CO}_{2}$ simulations occurred preferentially in the north and west, where increased ablation was able to overcome low simulated accumulation.

In addition to simulations utilizing the standard ice sheet/climate model, a set of parallel simulations was carried out with lapse rate and albedo values perturbed slightly, to derive an initial estimate of GIS evolution sensitivity to these model parameters under elevated $\mathrm{CO}_{2}$. This 'perturbed physics' approach demonstrated that GIS evolution over millennial timescales was highly sensitive to small changes in important parameters: the response time of the ice sheet to a given $\mathrm{CO}_{2}$ increase was typically halved, and the GIS stability threshold decreased by $\sim 280$ ppmv to between 2-3x PAL $\mathrm{CO}_{2}$, under small changes to lapse rate and albedo values. This large change in modelled GIS behavior in response to a relatively small change in model physics clearly highlighted one of the fundamental difficulties of climate modelling, that large uncertainty in model output can, in certain cases, be derived from small uncertainties in model input. These findings suggest that well-constrained parameterizations of ice sheet surface processes will be an important component of confident qualitative millennial-scale assessments of ice sheet retreat and future sea level rise.

In a second set of simulations, the GIS domain was initialized with ice-free conditions and integrated forward under elevated $\mathrm{CO}_{2}$ levels to explore the role of $\mathrm{CO}_{2}$ in simulated GIS inception. Information gained from these simulations shed light not only on potential future GIS recovery following anthropogenically driven deglaciation, but also on original GIS inception in potentially higher- $\mathrm{CO}_{2}$ atmospheres of the Cenozoic. In addition, these simulations resolved the spatial character of GIS growth, 
and as such provided insight into the dynamics of ice sheet inception in the coupled model. Key conclusions from these experiments are:

- At and above 4x PAL $\mathrm{CO}_{2}$, ice growth was limited to small ice caps on the southern and eastern mountains. At $4 x \mathrm{PAL} \mathrm{CO}_{2}$ ice was able to reach the eastern Greenland coastline despite existence of only small regional ice caps, suggesting that late Eocene IRD deposits in the Greenland and Irminger Seas do not necessarily imply full GIS coverage;

- Between 2-3x PAL $\mathrm{CO}_{2}$ separate ice caps in the southern and eastern mountains coalesced and exported ice onto the lowland plains, which were too warm to support in-situ ice growth in all scenarios $<=1 \times \mathrm{PAL} \mathrm{CO}_{2}$. However, large-scale ice sheet growth was limited until 1-2x PAL $\mathrm{CO}_{2}$, at which point the ice advanced slowly northwards as regional accumulation was able to overcome marginal ablation;

- As with the deglaciation simulations, modification of precribed lapse rate and albedo values was able to strongly influence GIS inception. With lower lapse rates and albedos, inception of a (reduced-area) GIS was limited to $1 \times \mathrm{PAL} \mathrm{CO}_{2}$, and inception proceeded at approximately half the rate as the default simulation. This indicates that ice sheet inception studies, like deglaciation studies, are strongly dependent on model parameters;

- The ability of large low-elevation ice masses to be effectively seeded from spatially-limited high mountain regions highlights the need for high resolution topography in simulations of ice sheet inception.

A third and final set of simulations utilized $\mathrm{CO}_{2}$ trajectories from earlier coupled-carbon simulations (Eby et al., 2009) to explore the response of the GIS to transient $\mathrm{CO}_{2}$-induced warming. The trajectories corresponded 
to cumulative future emissions of carbon ranging from $0 \mathrm{Gt} C$ (i.e. an immediate and complete cessation of emissions at the present day) to $5120 \mathrm{Gt}$ $\mathrm{C}$ (corresponding roughly to the present-day economic fossil fuel resource base). In these simulations:

- GIS ice loss increased with rising $\mathrm{CO}_{2}$ emissions, such that $75 \%$ of the ice was lost at $5120 \mathrm{Gt}$ C;

- The GIS was able to briefly overshoot the $3 x \mathrm{PAL} \mathrm{CO}_{2}$ stability threshold (defined by the equilibrium deglacial experiments) in medium-emission simulations without experiencing drastic ice retreat, due to the long response time of the simulated GIS relative to the timescale of the thermal perturbation;

- Only in simulations with long term $\mathrm{CO}_{2}$ concentrations at or above the stability threshold did the GIS retreat dramatically, indicating that, in this model at least, the GIS was relatively insensitive to temporally realistic $\mathrm{CO}_{2}$ pulses arising from multi-century $\mathrm{CO}_{2}$ emissions;

- Transient model results were dependent on the dynamics of the ice sheet and SMB models and also the global coupled carbon cycle model. The similarity in timescales between draw-down of ongoing and future anthropogenic carbon pulses and ice sheet dynamics implies that future GIS evolution may depend importantly on the rate of uptake of carbon by the deep ocean.

Finally, in Chapter 5, I use the coupled ice/climate model to analyse the ocean and climate response to sub-ice-shelf melt driven retreat of the AIS. In these simulations, the model was forced from a late Holocene equilibrium climate with prescribed sub-shelf melting, which was translated into dynamic AIS change and a time-dependent flux of freshwater and heat to/from the Southern Ocean. This method represented a step towards full ice shelf-ocean coupling, and generated the following findings: 
- The AIS retreat resulting from increased sub-shelf melt combined dynamic and thermodynamic ice sheet responses, and produced freshwater and heat fluxes to/from the Southern Ocean that were of the same magnitude (and initially greater) than the background continental flux of $0.07 \mathrm{~Sv}$. Ice discharge corresponding to $>=20 \%$ of the background flux continued for 3000 years after the initial shift to high-melt conditions;

- The Ross and Weddell Seas experienced widespread ice shelf loss, and became productive sea ice export regions. Export of this sea ice resulted in higher salinities in these seas (despite the regional freshwater flux from retreating ice sheets) and very low ocean temperatures that would counteract further ice shelf melt;

- Enhanced sea ice export and melt in the open Southern Ocean contributed to changes in surface ocean properties and deep ocean circulation that was visible in the North Atlantic as a slight shallowing and weakening of the NADW circulation cell, which would reinforce predicted trends expected as a result of anthropogenic emissions;

- Over the course of the 10000 year simulation, eustatic sea level rose by $\sim 6 \mathrm{~m}$, with $2 \mathrm{~m}$ derived from the EAIS and the remainder sourced from simulated WAIS retreat.

\subsection{Concluding Perspectives}

The work carried out here advances model-based understanding of the coupled ice sheet/climate system.

Of primary importance is the development of a new coupled ice sheet/climate model (Chapter 3). This new model has been demonstrated capable of simulating modern and past AIS and GIS 
conditions, and exploring model sensitivity to important model processes and parameters. Explorations of model parameter space (albedo, lapse rate, model bias, refreezing) are of direct relevance to other ice sheet/climate models currently under development, particularly those which use physically-based energy balance-based surface mass balance models. Ultimately, exploration of parameter space will aid estimation of uncertainty in future projections of ice sheet behaviour, as demonstrated in Chapter 4 for the GIS.

Further significant work detailed in this thesis relates to interactions between ice shelves and the surrounding climate. Chapter 2 details projections of surface melt conditions over the major ice shelves of the AIS (in addition to the grounded ice sheet), while Chapter 5 describes an initial investigation of the oceanographic signature of increased sub-shelf meltderived dynamic ice sheet/shelf evolution. Taken together, these studies offer substantial insight into the role of ice shelf-climate interactions in the past and future and indicate that physical coupling of the simulated ice shelf/climate system is will be a critical component of models that aim to predict future AIS behaviour.

\subsection{Proposed future work}

\subsubsection{Development and model analysis}

Future efforts related to coupled ice sheet-climate model development and testing will focus on model intercomparison, increased constraint of model uncertainties, and development of improved coupling between ice sheets and the atmospheric, terrestrial, and oceanic components of the climate model. 


\section{Model intercomparison}

Work to reconcile results presented here with results of similar recent simulations undertaken by other ice sheet-climate models will be a valuable constraint on model behaviour. Particular attention will be paid to understanding why differences in response times and $\mathrm{CO}_{2}$ thresholds on ice sheet stability arise. This work would essentially be an model intercomparison, which could identify features of the model used in this thesis that require further development as well as robust trends among models. Such an intercomparison was recently proposed by Ridley et al. (2010). Given the large differences between extant ice sheet-climate models, this model comparison would likely be a valuable exercise that has not been rigorously attempted yet.

\section{Constraining model uncertainty}

Results in this thesis highlight the ability of small and reasonable variations in important parameters (here, surface albedo and lapse rate values) to significantly influence millennial-scale GIS evolution (Chapter 2). Additional sensitive parameters potentially exist within the climate-ice interface, the dynamic component of the ice sheet model, and more generally as regions in multi-parameter phase space that display greater response to imposed model perturbations. The large number of parameters within the ice sheet-climate model, combined with the time taken for coupled simulations to reach equilibrium, make it near-impossible to fully sample the sensitivity model parameter space for all potential parameters. For these reasons, automated sampling of phase space to identify regions of high sensitivity (Goelzer et al., 2010) or full adjoint modelling (Heimbach and Bugnion, 2009) are preferable to traditional forward modelling sensitivity studies for tackling the difficult problem of constraining model uncertainty. To date, adjoint modelling has been limited to stand-alone ice sheet 
models or OGCMs / AGCMs. An adjoint model of the full ice sheet-climate model presented in this thesis would provide fascinating insight into the ice sheet sensitivity to climate processes, but would be a very large undertaking.

\section{Model development}

Further expansion of the coupled model developed in this thesis will focus on two tasks:

- Inclusion of an atmospheric model component that is capable of dynamically adjusting to changes in ice sheet geometry via changes to prognostically-calculated wind fields;

- Development of a coupling method between the coarse-resolution model ocean and the high resolution ice shelves.

The former task ultimately requires replacing the existing atmospheric heat and moisture transport model within the UVic ESCM with a full AGCM. However, the computational expense of the coupled AGCM needs to be weighed against the efficiency of the present model, which allows suites of millennial-scale simulations that are not feasible with presentgeneration AOGCMs. Addition of an atmospheric model would also entail re-tuning and re-coding of the entire UVic ESCM (a major task) and would potentially introduce significant wind biases.

Ice shelf-ocean coupling requires either a nested regional ocean model, or a simpler dynamic parameterization for ice shelf-ocean coupling. A regional model would be required to support lateral, upper and lower boundary migration (corresponding to grounding line migration, ice shelf draft change, and isostatic adjustment), and utilize resolution on the order 
$10^{0} \mathrm{~m}$. Such models are not yet openly available, and are likely to significantly slow global model simulations. The alternate (and less computationally expensive) approach is a parameterization that translates openocean temperatures to a distribution of sub-shelf melt. Existing parameterizations (e.g. Beckmann and Goosse, 2003; Holland et al., 2008b) typically consider the overlying ice shelf as fixed in space. This is problematic for long simulations of large-scale ice shelf change (e.g. Chapter 5), because the distribution of sub-ice-shelf melt must dynamically adjust with changing shelf geometry. In the absence of a full regional ocean model, a dynamic ice shelf-ocean parameterization scheme would represent an important step in coupling ice sheets to the global oceans. The UVic ESCM-PSUI represents an obvious platform for designing and testing such a scheme.

\subsubsection{Science}

Outstanding science questions to be addressed by the coupled model are centered on resolving mechanisms behind past ice sheet changes, and prediction of future changes to the GIS and AIS.

\section{Oceanographic effect of AIS retreat}

Additional simulations exploring the effect of AIS ice shelf and ice sheet retreat on global ocean circulation are intended to follow up the work presented in Chapter 5. In particular, a series of sub-shelf-melt and sea leveldriven experiments are planned to test the ability of the ice sheet model to produce freshwater flux events similar to MWP1A, and gauge the effect of these ice sheet model-derived fluxes on the global ocean in NADW-on and NADW-off modes. 
The impact of Drake Passage opening on global oceanography and the carbon cycle

The interplay between AIS inception, the global carbon cycle, and the opening of the Drake and Tasman passages represents a scarsely-explored example of coupled Earth system evolution. Previous modelling of the Drake Passage prescribed atmospheric $\mathrm{CO}_{2}$ concentrations, either at constant levels (Sijp et al., 2009) or in a slowly decreasing trend that mirrors paleoclimate proxy records (Pollard and DeConto, 2003). The latter study concluded that Drake Passage opening was secondary to falling $\mathrm{CO}_{2}$ in triggering AIS inception. However, the role of Drake Passage opening on oceanic carbon storage has not been addressed in modelling studies, despite indications that a large reorganization of the global carbon cycle occurred contemporaneously with ACC initiation (Tripati et al., 2005). In order to explore the combined effect of Drake Passage opening on the physical distribution of heat and the partitioning of carbon between land, ocean, and atmosphere, a suite of coupled-carbon simulations with the UVic ESCM is currently being spun up under elevated $\mathrm{CO}_{2}$ conditions and with all permutations of Drake Passage and the Central American Seaway open and closed. These simulations will initially exclude a dynamic AIS. However, if initial results warrant further investigation, a computationally intensive series of full coupled carbon-ice-sheet-climate simulations will be carried out to explore AIS inception within the fully carbon-coupled model.

\section{Future evolution of the GIS and AIS}

This thesis presents an initial analysis of the modelled GIS response to elevated $\mathrm{CO}_{2}$ (Chapter 4). Future work will integrate the dynamic vegetation model into the ice sheet model domain, to include the role of vegetation in regulating GIS evolution through albedo and surface roughness 
effects. Additionally, the role of surface melt on long-term Antarctic dynamic response in future scenarios where substantial surface melting occurs over the WAIS interior (Chapter 2) will be evaluated. Proposed work described above, to integrate a robust ocean-ice shelf coupling procedure, will be critical in simulating the whole ice-sheet response to projected anthropogenic warming. 


\section{Appendix A}

\section{A simple 1D glacier model}

As part of a group project during the 2009 Portland Ice Sheet Models for the 21st Century Summer School, a simple 1D shallow ice flow dynamic core was coded following the general numerical method outlined in, for example, Section 5.6 of Oerlemans (2001) and Chapter 4 of Huybrechts (1992). Summarized briefly here, the horizontal ice flux under the shallow ice approximation in a 1D model (neglecting surface mass balance) can be cast in the form of a diffusion equation:

$$
F=D \nabla h
$$

where $F$ is the vertically averaged horizontal ice flux, $\nabla h$ is the gradient of the ice surface (slope), and D is the spatiotemporally varying diffusion, calculated as:

$$
D=2 \rho g^{n} A{\frac{\delta h^{(n-1)}}{\delta x}}^{n+2} H^{n+2}
$$

$$
\begin{aligned}
& \rho=\text { ice density } \\
& g=\text { gravitational acceleration }
\end{aligned}
$$

$A$ and $n=$ flow law parameters, and $H$ is ice thickness. In the model, equation A.1 is solved on a $1 \mathrm{~km}$ resolution finite difference grid using a 
basic forward-in-time timestepping scheme and a staggered spatial scheme whereby diffusion values and fluxes are calculated between ice thickness gridpoints. Diffusion values from the ice geometry of the previous timestep are used for efficiency.

Following construction of the dynamical ice flow core, I coupled this dynamic core to a simple climate driver. Accumulation was prescribed and a simple PDD model was used to calculate ablation based on elevated surface air temperature:

$$
M(x)=-\max \left(0, F \cdot\left(T_{s l}-L \cdot E(x)\right)\right.
$$

$M(x)=$ melt rate $(\mathrm{m} / \mathrm{y}$, negative $M(x)$ implies melt-induced mass loss)

$F=$ positive degree day factor $\left(\mathrm{m} / \mathrm{y} /{ }^{\circ} \mathrm{C}\right)$

$T_{s l}=$ sea level temperature $\left({ }^{\circ} \mathrm{C}\right)$

$L=$ lapse rate $\left({ }^{\circ} \mathrm{C} / \mathrm{m}\right)$

$E(x)=$ elevation $(\mathrm{m})$

A number of simulations were carried out using reasonable parameter values to explore the response of idealized glaciers/ice sheets to variations in bed geometry, accumulation, ablation, simple isostatic adjustment, grid resolution and time steps. These experiments are not described further. The model was used to explore basic ice sheet/climate feedbacks (Figure 1.4) and the effect of seasonality on equilibrium ice sheet extent. A final simulation was carried out to recreate in simple form the experiments of Pollard and DeConto (2003) (Figure 1.6). This simulation was initialized with ice-free conditions over an idealized plateau and lowland bed topography (crudely representative of the AIS), and then forced with a longterm linear decrease in $\mathrm{T}_{s l}$ over which idealized Milankovitch and seasonal cycle signals were imposed. The model clearly displayed non-linear 
threshold behavior in response to the prescribed $T_{s l}$ forcing time series, including ice volume changes that qualitatively reproduced the inferred early behaviour of the AIS. 


\section{Appendix B}

\section{Statement of author contributions}

The published research reproduced in this thesis was conceptualized, designed and carried out primarily by Jeremy Fyke. In all cases the contributions from other co-authors in the published work are relatively minor $(\approx 10 \%)$ and do not preclude inclusion of the manuscripts in this thesis. 
Appendix C

Journal of Climate article: Surface melting over ice shelves and ice sheets as assessed from modelled surface air temperatures 


\title{
NOTES AND CORRESPONDENCE
}

\section{Surface Melting over Ice Shelves and Ice Sheets as Assessed from Modeled Surface Air Temperatures}

\author{
JEREMY G. FyKe, LIONEL CARTER, AND ANDREW MACKINTOSH \\ Victoria University of Wellington, Wellington, New Zealand \\ ANDREW J. WEAVER AND KATRIN J. MEISSNER \\ School of Earth and Ocean Sciences, University of Victoria, Victoria, British Columbia, Canada
}

(Manuscript received 6 March 2009, in final form 13 November 2009)

\begin{abstract}
Summer surface melting plays an important role in the evolution of ice shelves and their progenitor ice sheets. To explore the magnitude of surface melt occurring over modern ice shelves and ice sheets in a climate scenario forced by anthropogenic emissions of carbon dioxide $\left(\mathrm{CO}_{2}\right)$, a coupled climate model was used to simulate the distribution of summer melt at high latitudes and project the future evolution of high-melt regions in both hemispheres. Forcing of the climate model with $\mathrm{CO}_{2}$ emissions resulting from combustion of the present-day fossil-fuel resource base resulted in expansion of high-melt regions, as defined by the contour marking 200 positive degree-days per year, in the Northern Hemisphere and the Antarctic Peninsula and the introduction of high summer melt over the Ross, Ronne-Filchner, and Amery ice shelves as well as a large portion of the West Antarctic Ice Sheet (WAIS) and most of the Greenland Ice Sheet (GIS) by the year 2500. Capping $\mathrm{CO}_{2}$ concentrations at present-day levels avoided significant summer melt over the large Antarctic shelves, the WAIS, and much of the GIS.
\end{abstract}

\section{Introduction}

Ice shelves and ice sheets evolve in response to changes in oceanic and atmospheric boundary conditions. Recent dramatic losses of long-lived ice shelves in both hemispheres highlight the uniqueness of recent climate change and have focused attention on causal factors that promote ice shelf retreat. Ice shelves respond dynamically and thermodynamically to changes in underlying ocean temperature (Holland et al. 2008a) and surface air temperature (SAT). Several authors (e.g., Mercer 1978; Vaughan and Doake 1996) have linked the observed poleward migration of annual or monthly SAT isotherms to episodes of ice shelf retreat, indicating a strong correlation between SAT and the sudden breakup of existing ice shelves. While the Larsen

Corresponding author address: Jeremy G. Fyke, Antarctic Research Centre, Victoria University of Wellington, P.O. Box 600, Wellington 6140, New Zealand.

E-mail: fykejere@student.vuw.ac.nz
B ice shelf was preweakened by at least a decade of thinning largely resulting from ocean-induced basal melting (Shepherd et al. 2003) prior to the final collapse [an event that Domack et al. (2005) suggested was unprecedented for Larsen B during the Holocene], the final sudden disintegration event (along with that of Larsen A) has been attributed to warming SAT, which led to development of surface melt ponds and ice fracturing of existing crevasses (van den Broeke 2005; Scambos et al. 2000, 2003). The Wilkins ice shelf, which currently undergoes extensive summer melting, also experienced a breakup event associated with the 2008 melt season that Scambos et al. (2009) suggested was triggered by meltwaterinduced crevasse deepening. This breakup differs from large wintertime breakup loss events over the Wilkins ice shelf, which Braun et al. (2009) attributed to basal melt-induced bending stresses. In the Northern Hemisphere, ice shelf breakup events associated with the generation of significant summer surface melt have been observed on northern Ellesmere Island, where the Ward Hunt and Ayles ice shelves retreated (2002-09 and 2005, 
respectively) (Mueller et al. 2003; Copland et al. 2007). These examples indicate that increased SAT over an ice shelf that is structurally vulnerable because of internal glacial discontinuities provides one important mechanism for rapid ice shelf retreat or loss.

The stability of remaining Antarctic ice shelves has implications for West Antarctic Ice Sheet (WAIS) stability, sea level rise, and bottom-water production. The loss of the Larsen B ice shelf resulted in an increased flow velocity of several grounded inland source glaciers (Scambos et al. 2004). Similarly, present-day thinning of the grounded Pine Island Glacier has been attributed to changes in the rate of ice shelf basal melting (Payne et al. 2004). It has been suggested that loss of the Ross and/or Ronne-Filchner ice shelves would also accelerate flow of the marine-based WAIS (Mercer 1978), potentially resulting in large-scale WAIS retreat. Naish et al. (2009) and Pollard and DeConto (2009) interpreted sediment core results and an associated ice sheet-modeling simulation to suggest that periodic loss of the Ross ice shelf occurred during the warm, early Pliocene $\sim 5-3 \times 10^{6} \mathrm{yr}$ before present, indicating that it is sensitive to changes in environmental conditions that are similar to those projected for the coming centuries. Arctic ice shelves, in contrast to their southern counterparts, do not buttress significant grounded ice.

Recent Arctic and Antarctic air temperature changes have been attributed directly to human influence (Gillett et al. 2008). Continuing evolution of high-latitude climate in response to anthropogenic forcing may significantly affect the stability of remaining ice shelves in both hemispheres. We utilized a climate model forced by anthropogenic emissions of carbon dioxide $\left(\mathrm{CO}_{2}\right)$ to simulate large-scale surface warming trends. Model output was analyzed for periods of extended summer warmth to infer the potential for melting of the magnitude that is currently associated with observed ice shelf retreat. Although we focused on regions of the earth where ice shelves occur, the global model domain also allowed us to analyze melting trends over present-day grounded ice sheets.

The model output was first compared with observed SAT, an ensemble of atmosphere-ocean general circulation model (AOGCM) simulations of the twenty-first century and the timing of major ice shelf retreats and was then integrated for several hundred years into the future to explore the potential for increased melting over ice surfaces in both hemispheres.

\section{Model and methods}

Version 2.8 of the University of Victoria Earth System Climate Model (UVic ESCM) was used. This intermediate-complexity climate model couples atmospheric, oceanic, and land surface components, a thermodynamic/dynamic sea ice model, and a closed and coupled carbon cycle that includes carbon transfer between inorganic and organic carbon reservoirs. The ocean component is a full 3D ocean general circulation model [Modular Ocean Model, version 2 (MOM2); Pacanowski 1995]. The atmospheric component consists of a vertically integrated energy-moisture balance model in which the radiative forcing associated with atmospheric $\mathrm{CO}_{2}$ is applied through a decrease in outgoing longwave radiation, parameterized as

$$
F=F_{0} \ln [C(t) / 350]
$$

where $C(t)$ is the atmospheric $\mathrm{CO}_{2}$ concentration (ppmv) at time $t$ and $F_{0}=5.35 \mathrm{~W} \mathrm{~m}^{-2}$ corresponds to a specified radiative forcing of $3.7 \mathrm{~W} \mathrm{~m}^{-2}$ for a doubling of atmospheric $\mathrm{CO}_{2}$ (Houghton et al. 2001). Surface air temperature is prognostically calculated as a function of the surface energy balance and elevation (via a constant lapse rate). Ice sheets are static, noninteractive components of the model and are reflected in global elevation and albedo fields. Surface albedo fields are a function of surface type such as plant functional type, ice, and snow cover. While potential melt ponding plays an important role in the energy balance over ice (via a lowered surface albedo), we could not resolve this effect because of a lack of a detailed surface hydrological scheme. This made our subsequent determination of SAT change conservative by removing a positive feedback on SAT.

Heat and moisture fluxes between the ice shelves and the ocean were neglected in this version of the model. Heat flux from the ocean to ice shelves is proportional to the temperature difference between the pressuredependent melt temperature of ice and the in situ temperature of seawater at the ice-ocean interface and is expected to increase in a quadratic fashion as the ocean warms (Holland et al. 2008b). However, UVic ESCM simulations indicated that the contribution of this flux to the total Southern Ocean heat budget is still small relative to heat fluxes to (from) the ocean resulting from sea ice formation (melting) and open-ocean heat exchange with the atmosphere. We therefore assume that ice shelf-to-ocean heat flux plays a small role in the large-scale SAT, which is the field in which we are primarily interested. The resolution of all of the components within the model is $3.6^{\circ}$ longitude by $1.8^{\circ}$ latitude.

The UVic ESCM reproduces the observed climate, including the zonal-mean amplitude of seasonal SAT change (Randall et al. 2007), and falls within the midrange of the Intergovernmental Panel on Climate Change (IPCC) Fourth Assessment Report model ensemble predictions 
of the twenty-first century (Meehl et al. 2007). Because of computational efficiency, the model is able to simulate climate over millennial time scales, making it ideal for exploring long-term effects of anthropogenic emissions that cannot be addressed using full AOGCMs. A detailed description of the model and its validation is described in Weaver et al. (2001).

Two simulations were done. Both were initialized from a preindustrial equilibrium at year 1850 in which atmospheric $\mathrm{CO}_{2}$ was stable at approximately 280 ppmv. They were then integrated forward for $1000 \mathrm{yr}$ until year 2850 . In the first simulation, termed the "high-emission scenario," observed emissions were applied until year 2000 (Marland et al. 2008). From 2000 to 2100, emissions followed the IPCC A2 scenario (Meehl et al. 2007). From 2100 to 2300 , emissions decreased linearly back to zero. This emission profile added $5134 \mathrm{Gt}$ of carbon to the climate system and corresponds closely to combustion of all of the present-day oil, natural gas, and coal resource bases [including nonconventional sources such as tar sands (Rogner 1997)]. The second simulation, in which $\mathrm{CO}_{2}$ was capped at 390 ppmv from 2010 onward, was undertaken to simulate warming to which the climate system is already committed, because Weaver et al. (2007) found that reduction below present-day $\mathrm{CO}_{2}$ concentrations within the next millenium is unrealistic if emissions are reduced by anything less than $90 \%$ of present-day levels by 2050 . This simulation is termed the "commitment scenario."

An anomaly approach was used to obtain SAT fields. This method superimposed the temperature trend simulated by the UVic ESCM on the National Centers for Environmental Prediction-National Center for Atmospheric Research (NCEP-NCAR) climatology (Kalnay et al. 1996). This removed potential systematic SAT biases within the raw simulated UVic ESCM SAT field. Daily average SAT for the period of 1970-2001 was generated for NCEP-NCAR data and the UVic ESCM simulation. The final SAT was then calculated as

$$
\mathrm{SAT}=\mathrm{SAT}_{\text {raw }}-\mathrm{SAT}_{\mathrm{UVic}}+\mathrm{SAT}_{\mathrm{NCEP}},
$$

where $\mathrm{SAT}_{\text {raw }}$ is the raw simulated time-dependent SAT and SAT $_{\text {UVic }}$ and SAT $_{\text {NCEP }}$ are the 1970-2001 daily average UVic ESCM and NCEP-NCAR SAT fields, respectively. The 30-yr-average period removed high-frequency variability from the NCEP-NCAR and UVic ESCM climate that would otherwise obscure the long-term evolution of SAT trends. Bromwich et al. (2007) analyzed NCEP-NCAR data over high-latitude locations. They found large biases in presatellite NCEP-NCAR data over the winter periods at high latitudes, particularly over Antarctica. However, biases were much reduced during the summer when melting occurs.
To infer regions that experience summer melt periods of the same magnitude as those observed in conjunction with observed ice shelf retreat, the annual sum of positive degree-days (PDD), which is assumed to be proportional to the annual melt, was recorded throughout the simulation for each grid cell following the method of Vaughan (2006). Based on observations, Copland et al. (2007) estimated that the contour marking 200 PDD $\mathrm{yr}^{-1}$ defines the limit of ice shelf stability for the northern Ellesmere Island ice shelves. Vaughan (2006) analyzed the distribution of PDDs over the Antarctic Peninsula. The 200 PDD $\mathrm{yr}^{-1}$ contour of his analysis lies across the Larsen A/B ice shelves in 2000, which approximates the period during which both shelves underwent persistent large-scale surface melt and retreat. A limit of

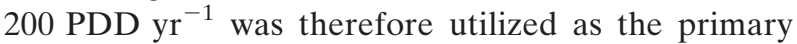
threshold, with a reasonable range of values explored to determine the sensitivity of the ice shelf stability zone to this value.

\section{Results}

The simulated preindustrial steady-state climate exhibited two broad regions in each hemisphere in which less than $200 \mathrm{PDD} \mathrm{yr}^{-1}$ occurred. In the Arctic, this zone encompassed northern Ellesmere Island (the location of the Ward Hunt and Ayles ice shelves), the Greenland Ice Sheet (GIS), and a region of the offshore Arctic Ocean (Fig. 1). In the Antarctic, the entire continent and nearby Southern Ocean fell within the low summer melt zone. This agrees with established ice shelves here prior to significant human-derived emissions.

In the Arctic, by 2011-21, the criterion of $200 \mathrm{PDD} \mathrm{yr}^{-1}$ was surpassed in the ocean off Ellesmere Island (Fig. 2). When the threshold was reduced to $160 \mathrm{PDD} \mathrm{yr}^{-1}$ the ocean off Ellesmere Island surpassed the threshold in 2001-11. This result bracketed the timing of ongoing ice shelf loss in this region remarkably well within the framework of a 1000-yr simulation and reinforced the 200-PDD limit estimate of Copland et al. (2007).

On the Antarctic Peninsula, high summer melting (based on the 200 PDD $\mathrm{yr}^{-1}$ criterion) migrated over the Larsen A/B ice shelf region in the 2061-71 period in the high-emission scenario. This lies in contrast to observations, which indicate an excess of $200 \mathrm{PDD} \mathrm{yr}^{-1}$ on the Antarctic Peninsula next to the Larsen A/B shelves by year 2000. This discrepancy was due to an underestimation of the observed northern Antarctic Peninsula warming trend in 1960-2000 (Chapman and Walsh 2007) by the UVic ESCM. Elsewhere, the PDD trend bias was smaller. Grid cells immediately next to the Wilkins ice shelf experienced warmth in excess of $200 \mathrm{PDD} \mathrm{yr}^{-1}$ in 2011-21. Tedesco (2008) determined an average annual Antarctic 


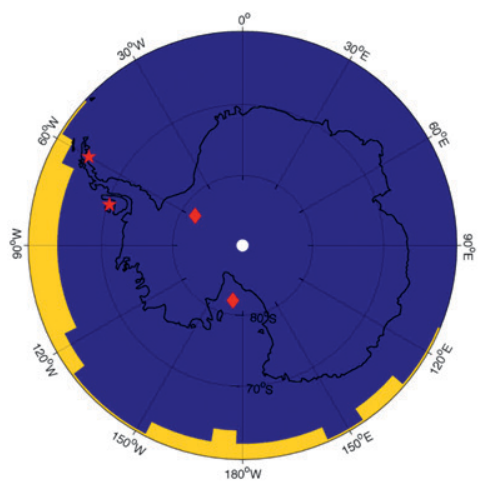

1850
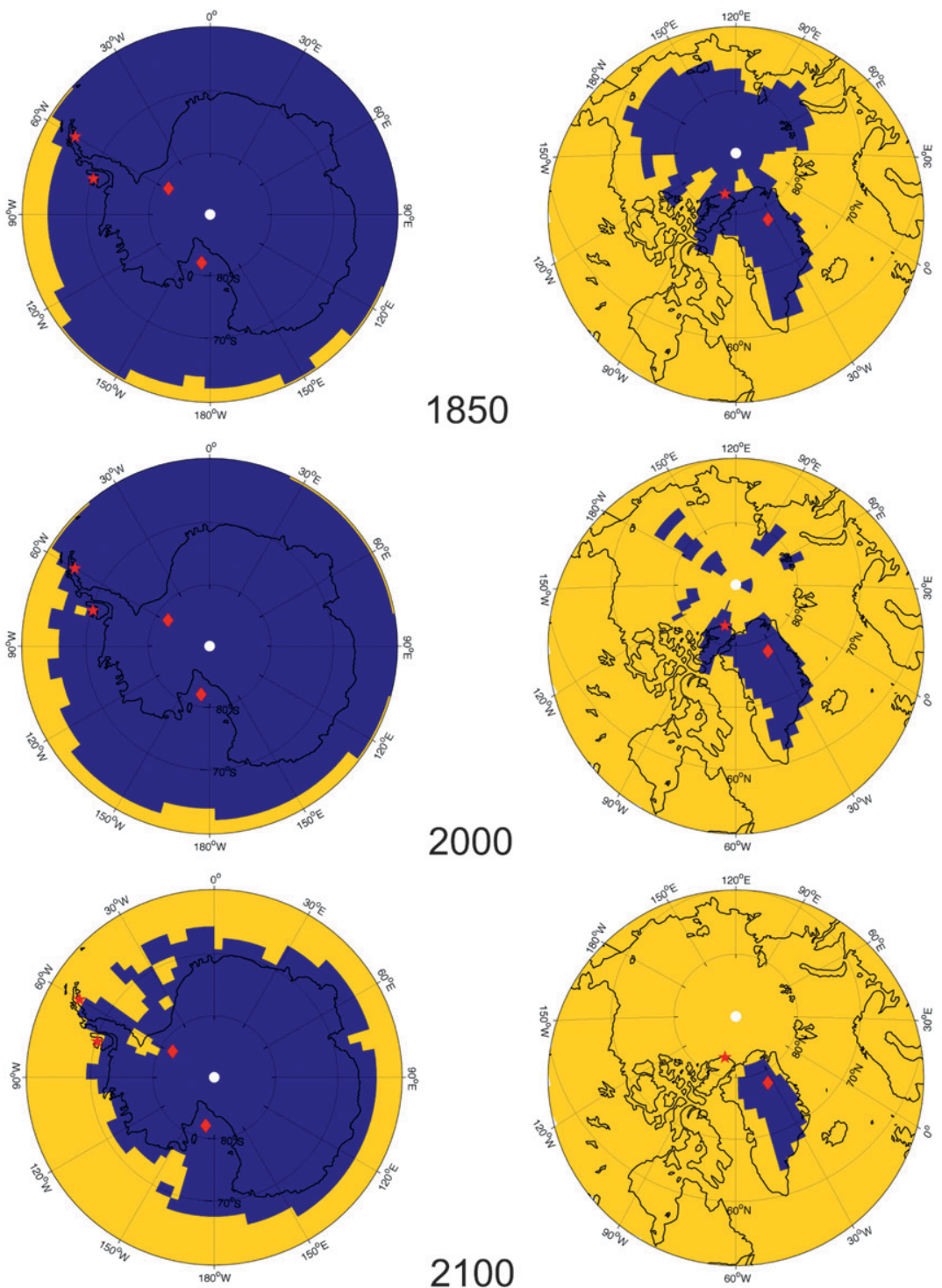

2000
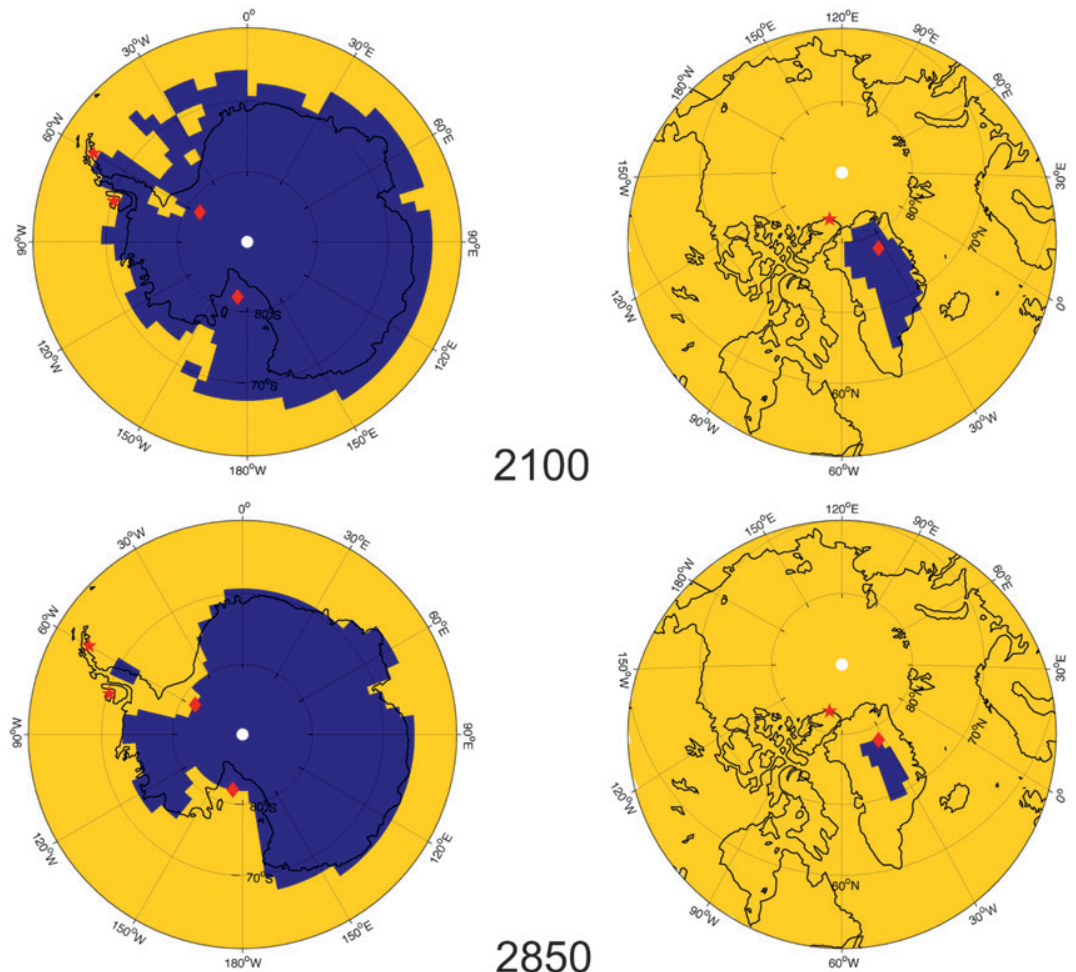

2100

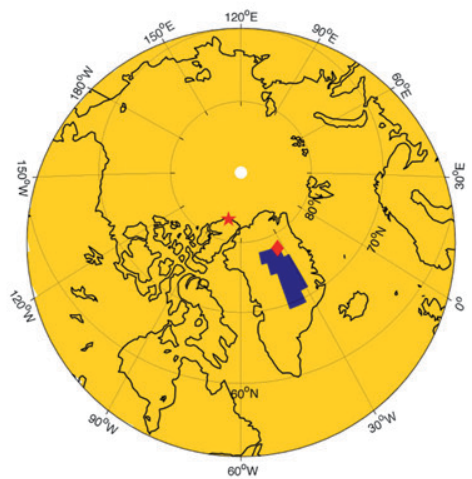

FIG. 1. Simulated evolution of (left) Antarctic and (right) Greenland summer melting caused by combustion of the entire present-day fossil-fuel resource base. Yellow denotes regions that experience more than $200 \mathrm{PDD} \mathrm{yr}^{-1}$, and blue is for regions that experience

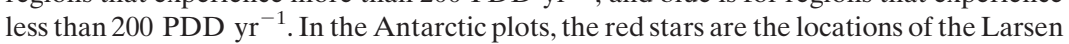
$\mathrm{A} / \mathrm{B}$ and Wilkins ice shelf PDD time series and the red diamonds show the locations of the Ross and Ronne-Filchner ice shelf PDD evolution time series. In the Greenland plots, the red star is the location of the Ward Hunt/Ayles PDD time series and the red diamond is the location of the GIS PDD evolution time series (Figs. 2 and 3). 


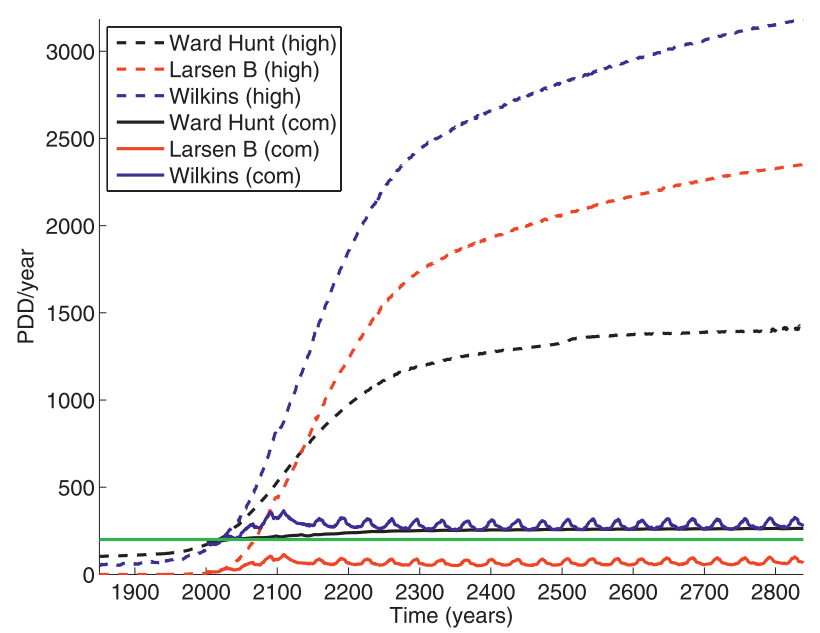

FIG. 2. Simulated PDD evolution time series of Larsen B, Wilkins, and Ayles/Ward Hunt ice shelves (Fig. 1). Dashed lines show the high-emission scenario (labeled as high), and solid lines denote the commitment scenario (labeled as com). The green line is the 200 PDD $\mathrm{yr}^{-1}$ level. Note that the high-emissions and commitment scenarios begin to diverge from each other after year 2010 as a result of a change in $\mathrm{CO}_{2}$ concentrations after this time. The oscillations in the Larsen B and Wilkins ice shelf PDD time series are mirrored in small interannual fluctuations in simulated Southern Hemisphere sea ice distribution and are prominent in the PDD time series because these locations lie near to the $0^{\circ} \mathrm{C}$ annual isotherm in this simulation.

melt extent of $8.6 \times 10^{5} \mathrm{~km}^{2}$ for $1987-2008$. This melt extent was not surpassed in the high-emission scenario simulation until 2063 (although by 1997, the simulated melt extent of $3.0 \times 10^{5} \mathrm{~km}^{2}$ was within the measured range of melt extents). This delay was largely attributable to the underestimated warming over the Antarctic Peninsula, although an additional important cause of the low simulated melt extent was the coarseness of the UVic ESCM grid, which simply did not resolve narrow coastal regions of melt that contributed to the melt extent of Tedesco (2008). A comparison of simulated rates of PDD increase to observed rates is given on Table 1.

To gauge further the accuracy of high-latitude warming simulated by the UVic ESCM in the near future, the rate of warming for 2000-2100 under the high-emission scenario was compared with a five-model ensemble of AOGCMs [Canadian Centre for Climate Modelling and Analysis (CCCma) Coupled General Circulation Model, version 3 (CGCM3), Geophysical Fluid Dynamics Laboratory Climate Model, version 2 (GDFL CM2), ECHAM5-Max Planck Institute Ocean Model (MPI-OM), Community Climate System Model, version 3 (CCSM3), and third climate configuration of the Met Office Unified Model (HadCM3)] that was also forced with the IPCC A2 scenario for the 2000-2100 period (Meehl et al. 2007). The UVic ESCM rate of warming over the Antarctic Peninsula and the Antarctic coastal warming trend corresponded well to the ensemble average, but the rate of warming over the interior of Antarctica (including the WAIS) and the GIS was slightly lower $\left[\sim 0.1^{\circ} \mathrm{C}(10 \mathrm{yr})^{-1}\right]$ than the ensemble average. This indicated that polar amplification of warming in the UVic ESCM, while present, was less pronounced than in the IPCC ensemble.

Overall, the simulations captured both preindustrial regions of ice shelf stability and the introduction of significant summer melting over regions characterized by recent ice shelf losses (with a particular delay in southward migration of the high-melt zone based on the 200 PDD $\mathrm{yr}^{-1}$ criterion across the western Antarctic Peninsula). The underestimated rate of warming over the Antarctic Peninsula, combined with the slightly lower average rate of warming at each pole (relative to the IPCC ensemble), suggested that melt extent and PDD-per-year values obtained by the UVic ESCM simulations represented lower bounds on the rate of poleward migration of high-melt zones over the coming centuries.

Further integration of the high-emission scenario to 2850 resulted in a global annual average SAT increase of $\sim 7^{\circ} \mathrm{C}$. Temperatures were still slowly increasing at the end of the simulation, despite a total cessation of emissions at 2300. Polar amplification of SAT changes resulted in Arctic temperature increases of up to $12^{\circ} \mathrm{C}$, whereas in the Antarctic several coastal regions warmed by up to $10^{\circ} \mathrm{C}$. In the Arctic, warming occurred rapidly; in the Antarctic, major warming was delayed until approximately 2100-2300.

In the Arctic, by 2100, widespread surface melting was simulated over all regions that presently contain ice shelves (Fig. 1). Further expansion of the high-melt zone resulted in marked summer melt over most of the GIS by 2850 , with only a small central core remaining below the 200 PDD $\mathrm{yr}^{-1}$ threshold. In Antarctica, by 2100, several isolated regions of the Antarctic Peninsula began to experience summer melting above the 200 PDD $\mathrm{yr}^{-1}$ criterion, while the WAIS and EAIS remained below the $200 \mathrm{PDD} \mathrm{yr}^{-1}$ threshold. However, between $\sim 2050$ and $\sim 2500$, regions encompassing the Ronne-Filchner, Ross, and Amery ice shelves experienced a rise in PDDs, such that large portions of these regions surpassed the $200 \mathrm{PDD} \mathrm{yr}^{-1}$ threshold by year 2500 (for representative example locations, see Fig. 3). By the year 2850 the entire Ronne-Filchner and Ross ice shelves and the northern Amery ice shelf were all well above the 200 PDD $\mathrm{yr}^{-1}$ threshold (Fig. 1). In addition, significant parts of the WAIS poleward of the Ronne-Filchner and Ross ice shelves and the Antarctic Peninsula moved into the highmelt region (Fig. 1). In contrast, the EAIS did not experience significant summer melting of the ice sheet interior, 
TABLE 1. Comparison of available observed PDD-per-year trends to UVic ESCM-simulated trends. Also shown for comparison are the simulated 2006-46 PDD-per-year trends. In all cases the PDD-per-year trend accelerates relative to the observational period. For observed PDD-per-year trend sources, an asterisk indicates Vaughan (2006) and two asterisks is for Copland et al. (2007).

\begin{tabular}{lccr}
\hline \hline PDD trend obs location & $\begin{array}{c}\text { Avg obs PDD-per-year } \\
\text { increase (time series length) }\end{array}$ & $\begin{array}{c}\text { Simulated PDD-per-year } \\
\text { trend over obs period }\end{array}$ & $\begin{array}{c}\text { Simulated 2006-46 } \\
\text { PDD-per-year trend }\end{array}$ \\
\hline Faraday & $1.4 \pm 0.7(1947-2005)^{*}$ & 0.8 & 3.2 \\
Bellingshausen & $2.7 \pm 1.3(1967-2005)^{*}$ & 1.9 & 4.6 \\
Rothera & $1.8 \pm 1.7(1979-2005)^{*}$ & 0.00 & 0.1 \\
Ayles & $2.6(1965-2005)$ & 1.4 & 2.8 \\
& $0.18(1947-2005)^{* *}$ & & \\
\hline
\end{tabular}

with the exception of sporadic coastal cells and a small area around Prydz Bay. The total simulated extent of Antarctic melt had expanded by roughly a factor of 10 from the simulated and observed present-day extent, to $3.6 \times 10^{6} \mathrm{~km}^{2}$.

In contrast to the high-emission scenario, the commitment scenario simulation exhibited less encroachment of melting at high latitudes. By 2500, global average SAT had equilibrated at $\sim 0.6^{\circ} \mathrm{C}$ above 2010 levels. Although the Arctic Ocean and surrounding regions still migrated almost completely into the high-summer-melt zone for all criteria, the major Antarctic ice shelves and the WAIS, all of which experienced melting in excess of $200 \mathrm{PDD} \mathrm{yr}^{-1}$ in the high-emission scenario, now remained well below the 200 PDD $\mathrm{yr}^{-1}$ criterion (Figs. 2-4) for the commitment scenario. Although the Wilkins region experienced

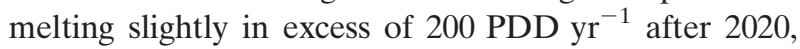
simulated PDD values over the Larsen region remained low. This indicated that warming in this region was too modest for the commitment scenario simulation and was consistent with the anomalously late warming experienced in the high-emission scenario: under modest $\mathrm{CO}_{2}$ increases, the UVic ESCM (along with the IPCC ensemble) underestimated the warming over the western Antarctic Peninsula.

\section{Discussion}

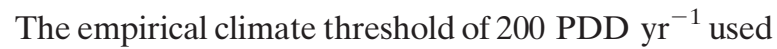
here to delineate regions of high summer melting was chosen to reflect SAT conditions closely associated with observed melt-induced fracturing of ice shelves and was meant to extrapolate the SAT-ice shelf loss correlation of Vaughan and Doake (1996) into the future using climate model output instead of observations. However, it is important to note that oceanic heat flux is an alternate or additional thermodynamic mechanism for driving ice shelf loss (Holland et al. 2008b). Several ice shelf retreats have been attributed at least in part to subshelf melting. Furthermore, future Antarctic ice shelf loss resulting from undershelf warming and/or increased injection of warm Circumpolar Deep Water could result in ice shelf loss that was not captured by the SAT-derived ice shelf stability inference used here.

Several first-order trends in the simulated future evolution of summer melt zones at each pole, as represented

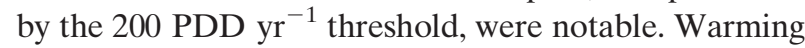
trends resulted in high-summer-melt periods over the entire Arctic Ocean by 2100 , even if $\mathrm{CO}_{2}$ concentrations were capped at 2010 levels. In addition, when the model was forced by emissions equivalent to all of the presentday fossil-fuel resource base, most of the GIS experienced periods of extended summer surface melting by 2500 , in agreement with other modeling studies (Ridley et al. 2005; Charbit et al. 2008). Ongoing work incorporating an integrated mass balance/dynamic ice sheet model into the coupled climate model indicates that this intensity of melting results in annually averaged net ice loss from the GIS. Increased flow of meltwater into the

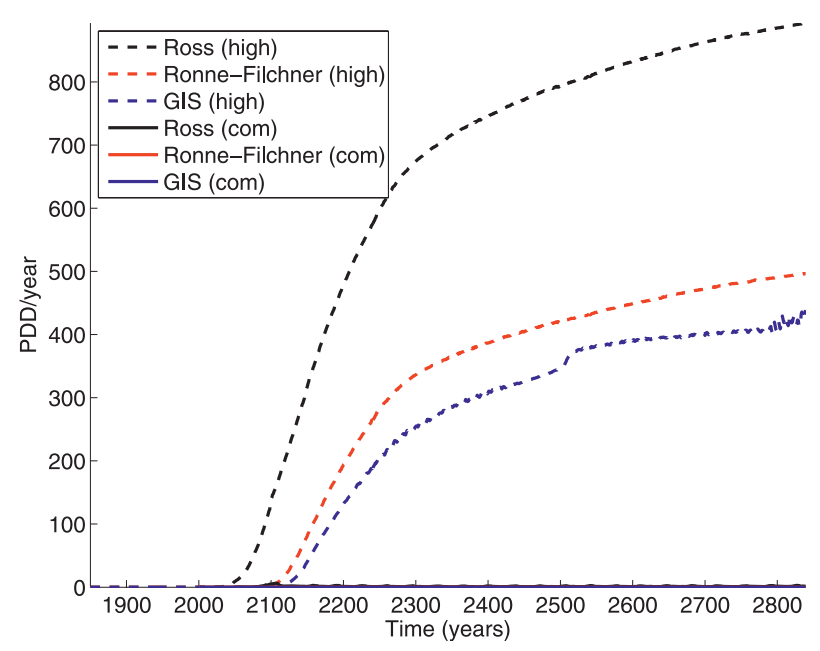

FIG. 3. Simulated PDD evolution time series of representative Ross and Ronne ice shelf and GIS locations (Fig. 1) that transit from

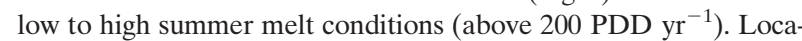
tions were chosen to represent PDD-per-year evolution at the farthest inland extent of high-melt regions by 2850 . Dashed lines show the high-emission scenario (labeled as high), and solid lines denote the commitment scenario (labeled as com). Note that because all locations exhibit a negligible PDD-per-year count in the commitmentscenario simulation, all of the solid lines lie along the $x$ axis. 

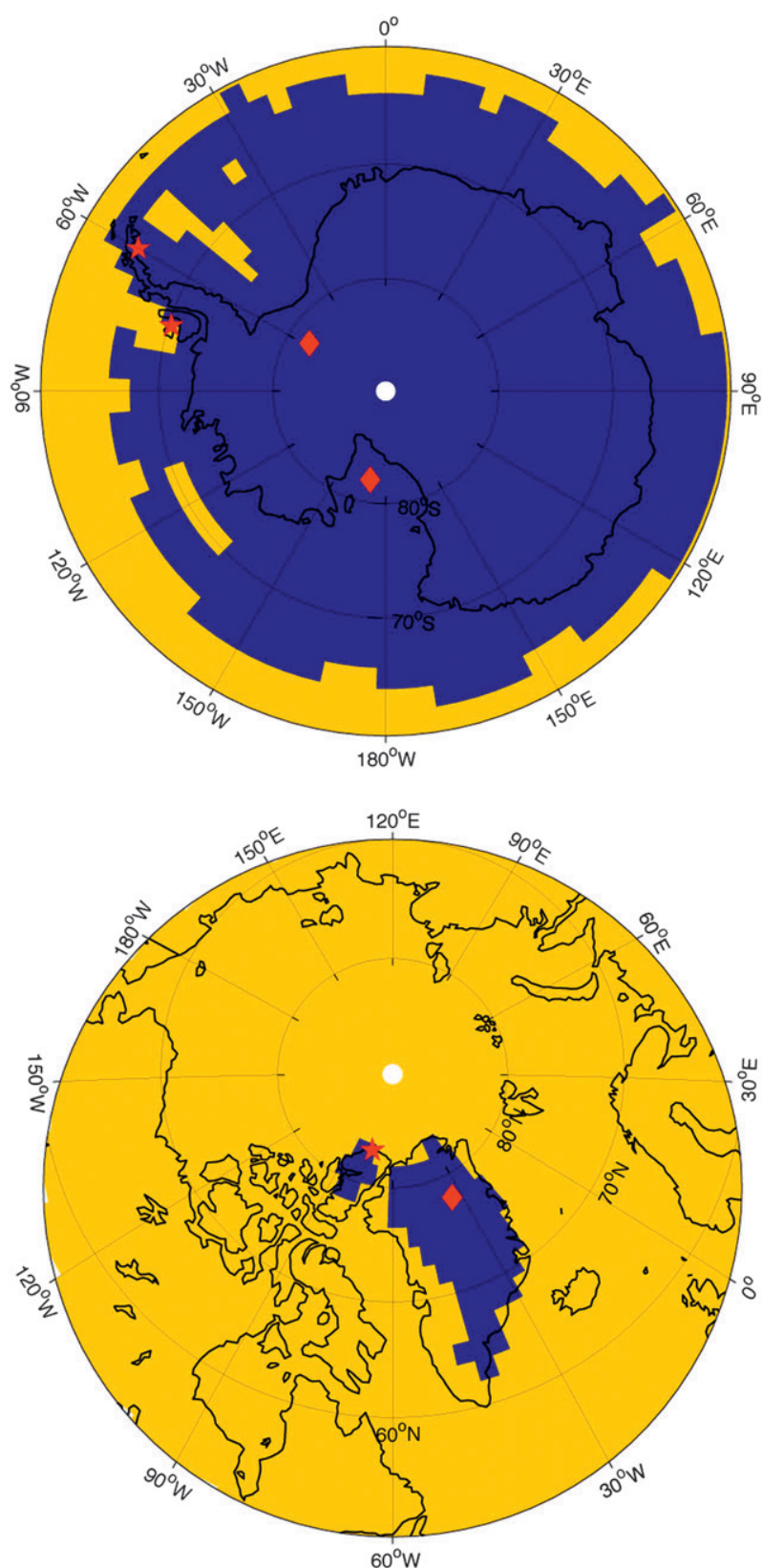

FIG. 4. Final equilibrium state (year 2850) of (top) Antarctica and (bottom) Greenland summer melting extent as a result of a $\mathrm{CO}_{2}$ concentration cap at year 2010 levels. Colors are as for previous figures.

GIS via moulins would warm interior ice through both advection of heat and latent heat release during refreezing and would contribute toward lubrication of the ice sheet bed. However, explicit analysis of this effect was beyond the scope of this study.

The high-emission scenario resulted in extended summer surface melt periods over the Ross, Ronne-Filchner, and Amery ice shelves (as well as lower-elevation por- tions of the WAIS) by year 2850, with extensive summer melt beginning at $\sim 2100-2300$. This result suggested that, in the absence of a mechanism that reinforces ice shelf stability (i.e., reduced subshelf melting), summer melting could begin to degrade the integrity of these large shelves where zones of existing surface glacial discontinuities exist. It is unlikely that ocean temperatures under the ice shelves will decrease, thereby counteracting the potential effect of melt-induced weakening. On the contrary, the simulated ocean immediately offshore of the Ross and Ronne-Filchner ice shelves between 300- and 1400-m water depth warmed by $2.2^{\circ}$ and $2.6^{\circ} \mathrm{C}$, respectively, over the course of the high-emission scenario simulation, providing an additional source of heat for basal shelf melting. Introduction of significant simulated summer melting over the WAIS implied that in the future the WAIS surface may resemble that of the GIS, with a similar accumulation of summer melt ponds, moulins, and associated meltwater transfer to the ice sheet bed.

Recent analysis of sediment cores obtained from beneath the Ross ice shelf combined with ice sheet modeling (Pollard and DeConto 2009) revealed cyclical retreats or even collapses of the Ross ice shelf and the WAIS during the warm early Pliocene, resulting in an open Ross Sea (Naish et al. 2009), despite $\mathrm{CO}_{2}$ concentrations of only $\sim 400$ ppmv. This implies that the WAIS was sensitive to retreat under climatic conditions that are expected to occur in coming decades. Vaughan and Doake (1996) suggested that a SAT warming of $10^{\circ} \mathrm{C}$ above presentday temperatures could threaten the Ross and RonneFilchner ice shelves. This magnitude of warming was simulated in response to combustion of all of the present day fossil-fuel resource base but was notably absent over the large Antarctic ice shelves and the WAIS if $\mathrm{CO}_{2}$ was capped at 2010 concentrations. This indicates that at least two important climatic thresholds-that of largescale Antarctic ice shelf degradation and significant WAIS surface melting - could be crossed if humanderived $\mathrm{CO}_{2}$ emissions are not reduced.

Acknowledgments. We thank Dr. Alun Hubbard for valuable discussions, Michael Eby and Ed Wiebe for technical support, and Luke Copland for supplying calculated Arctic PDD data. Travel related to this work was funded by the FRST-supported ANZICE program and the VUW Endowed Development Fund. JGF is supported with a VUW Ph.D. scholarship.

\section{REFERENCES}

Braun, M., A. Humbert, and A. Moll, 2009: Changes in the Wilkins ice shelf over the past 15 years and inferences on its stability. Cryosphere, 3, 41-56. 
Bromwich, D. H., R. L. Fogt, K. I. Hodges, and J. E. Walsh, 2007: A tropospheric assessment of the ERA-40, NCEP, and JRA-25 global reanalyses in the polar regions. J. Geophys. Res., 112, D10111, doi:10.1029/2006JD007859.

Chapman, W. L., and J. E. Walsh, 2007: A synthesis of Antarctic temperatures. J. Climate, 20, 609-632.

Charbit, S., D. Paillard, and G. Ramstein, 2008: Amount of CO2 emissions irreversibly leading to the total melting of Greenland. Geophys. Res. Lett., 35, L12503, doi:10.1029/2008GL033472.

Copland, L., D. R. Mueller, and L. Weir, 2007: Rapid loss of the Ayles ice shelf, Ellesmere Island, Canada. Geophys. Res. Lett., 34, L21501, doi:10.1029/2007GL031809.

Domack, E., and Coauthors, 2005: Stability of the Larsen B ice shelf on the Antarctic Peninsula during the Holocene epoch. Nature, 436, 681-685, doi:10.1038/nature03908.

Gillett, N. P., D. A. Stone, P. A. Stott, T. Nozawa, A. Yu. Karpechko, G. C. Hegerl, M. F. Wehner, and P. D. Jones, 2008: Attribution of polar warming to human influence. Nat. Geosci., 1, 750-754, doi:10.1038/ngeo338.

Holland, D. M., R. H. Thomas, B. Young, M. H. Ribergaard, and B. Lybert, 2008a: Acceleration of Jakobshavn Isbr triggered by warm subsurface ocean waters. Nat. Geosci., 1, 659-664, doi:10.1038/ngeo316.

Holland, P. R., A. Jenkins, and D. M. Holland, 2008b: Response of ice shelf basal melting to variations in ocean temperature. J. Climate, 21, 2558-2572.

Houghton, J. T., Y. Ding, D. J. Griggs, M. Noguer, P. J. van der Linden, X. Dai, K. Maskell, and C. A. Johnson, Eds., 2001: Climate Change 2001: The Scientific Basis. Cambridge University Press, 996 pp.

Kalnay, E., and Coauthors, 1996: The NCEP/NCAR 40-Year Reanalysis Project. Bull. Amer. Meteor. Soc., 77, 437-471.

Marland, G., T. Boden, and R. Andres, 2008: Global, regional, and national $\mathrm{CO}_{2}$ emissions. Trends: A Compendium of Data on Global Change, Carbon Dioxide Information Analysis Center, Oak Ridge National Laboratory, U.S. Department of Energy. [Available online at http://cdiac.ornl.gov/trends/emis/ em_cont.html.]

Meehl, G., and Coauthors, 2007: Global climate projections. Climate Change 2007: The Physical Science Basis, S. Solomon et al., Eds., Cambridge University Press, 747-845.

Mercer, J., 1978: West Antarctic ice sheet and $\mathrm{CO}_{2}$ greenhouse effect: A threat of disaster. Nature, 271, 321-325, doi:10.1038/ $271321 \mathrm{a} 0$.

Mueller, D. R., W. F. Vincent, and M. O. Jeffries, 2003: Break-up of the largest Arctic ice shelf and associated loss of an epishelf lake. Geophys. Res. Lett., 30, 2031, doi:10.1029/2003GL017931.

Naish, T., and Coauthors, 2009: Obliquity-paced Pliocene West Antarctic ice sheet oscillations. Nature, 458, 322-329, doi:10.1038/ nature 07867.

Pacanowski, R. C., 1995: MOM 2 documentation user's guide and reference manual. GFDL Ocean Tech. Rep. 3.2, 350 pp.
[Available online at http://www.gfdl.noaa.gov/cms-filesystemaction/model_development/ocean/manual2.2.pdf.]

Payne, A. J., A. Vieli, A. P. Shepherd, D. J. Wingham, and E. Rignot, 2004: Recent dramatic thinning of largest West Antarctic ice stream triggered by oceans. Geophys. Res. Lett., 31, L23401, doi:10.1029/2004GL021284.

Pollard, D., and R. M. DeConto, 2009: Modelling West Antarctic ice sheet growth and collapse through the past five million years. Nature, 458, 329-332, doi:10.1038/nature07809.

Randall, D., and Coauthors, 2007: Climate models and their evaluation. Climate Change 2007: The Physical Science Basis, S. Solomon et al., Eds., Cambridge University Press, 590-661.

Ridley, J. K., P. Huybrechts, J. M. Gregory, and J. A. Lowe, 2005: Elimination of the Greenland Ice Sheet in a high $\mathrm{CO}_{2}$ climate. J. Climate, 18, 3409-3427.

Rogner, H., 1997: An assessment of world hydrocarbon resources. Annu. Rev. Energy Environ., 22, 217-262.

Scambos, T., C. Hulbe, M. Fahnestock, and J. Bohlander, 2000: The link between climate warming and break-up of ice shelves in the Antarctic Peninsula. J. Glaciol., 46, 516-530.

,-- , and — 2003: Climate-induced ice shelf disintegration in the Antarctic Peninsula. Antarct. Res. Ser., 79, 79-92.

_ J. A. Bohlander, C. A. Shuman, and P. Skvarca, 2004: Glacier acceleration and thinning after ice shelf collapse in the Larsen B embayment, Antarctica. Geophys. Res. Lett., 31, L18402, doi:10.1029/2004GL020670.

, H. A. Fricker, C.-C. Liu, J. Bohlander, J. Fastook, A. Sargent, R. Massom, and A.-M. Wu, 2009: Ice shelf disintegration by plate bending and hydro-fracture: Satellite observations and model results for the 2008 Wilkins ice shelf break-ups. Earth Planet. Sci. Lett., 280, 51-60, doi:10.1016/j.epsl.2008.12.027.

Shepherd, A., D. Wingham, T. Payne, and P. Skvarca, 2003: Larsen ice shelf has progressively thinned. Science, 302, 856-859, doi:10.1126/science.1089768.

Tedesco, M., 2008: Updated 2008 surface snowmelt trends in Antarctica. Eos, Trans. Amer. Geophys. Union, 89, doi:10.1029/ 2008EO130002.

van den Broeke, M., 2005: Strong surface melting preceded collapse of Antarctic Peninsula ice shelf. Geophys. Res. Lett., 32, L12815, doi:10.1029/2005GL023247.

Vaughan, D., 2006: Recent trends in melting conditions on the Antarctic Peninsula and their implications for ice-sheet mass balance and sea level. Arct. Antarct. Alp. Res., 38, 147-152.

_ treat of ice shelves on the Antarctic Peninsula. Nature, 379, $328-331$.

Weaver, A. J., and Coauthors, 2001: The UVic Earth System Climate Model: Model description, climatology and application to past, present and future climates. Atmos.-Ocean, 39, 361-428.

— K. Zickfeld, A. Montenegro, and M. Eby, 2007: Long term climate implications of 2050 emission reduction targets. Geophys. Res. Lett., 34, L19703, doi:10.1029/2007GL031018. 
Appendix D

Geoscientific Model Development article: A new coupled ice sheet/climate model: description and sensitivity to model physics under Eemian, Last Glacial Maximum, late Holocene and modern climate conditions 


\title{
A new coupled ice sheet/climate model: description and sensitivity to model physics under Eemian, Last Glacial Maximum, late Holocene and modern climate conditions
}

\author{
J. G. Fyke ${ }^{1}$, A. J. Weaver ${ }^{2}$, D. Pollard ${ }^{3}$, M. Eby ${ }^{2}$, L. Carter ${ }^{1}$, and A. Mackintosh ${ }^{1}$ \\ ${ }^{1}$ Antarctic Research Centre, School of Geography, Environment and Earth Sciences, Victoria University of Wellington, \\ Wellington, New Zealand \\ ${ }^{2}$ Climate Modelling Group, School of Earth and Ocean Sciences, University of Victoria, Victoria BC, Canada \\ ${ }^{3}$ Earth and Environmental Systems Institute, College of Earth and Mineral Sciences, Pennsylvania State University, \\ State College, PA, USA
}

Received: 14 July 2010 - Published in Geosci. Model Dev. Discuss.: 13 August 2010

Revised: 9 February 2011 - Accepted: 16 February 2011 - Published: 1 March 2011

\begin{abstract}
The need to better understand long-term climate/ice sheet feedback loops is motivating efforts to couple ice sheet models into Earth System models which are capable of long-timescale simulations. In this paper we describe a coupled model that consists of the University of Victoria Earth System Climate Model (UVic ESCM) and the Pennsylvania State University Ice model (PSUI). The climate model generates a surface mass balance (SMB) field via a sub-gridded surface energy/moisture balance model that resolves narrow ice sheet ablation zones. The ice model returns revised elevation, surface albedo and ice area fields, plus coastal fluxes of heat and moisture. An arbitrary number of ice sheets can be simulated, each on their own highresolution grid and each capable of synchronous or asynchronous coupling with the overlying climate model. The model is designed to conserve global heat and moisture. In the process of improving model performance we developed a procedure to account for modelled surface air temperature (SAT) biases within the energy/moisture balance surface model and improved the UVic ESCM snow surface scheme through addition of variable albedos and refreezing over the ice sheet.

A number of simulations for late Holocene, Last Glacial Maximum (LGM), and Eemian climate boundary conditions were carried out to explore the sensitivity of the coupled model and identify model configurations that best represented these climate states. The modelled SAT bias was
\end{abstract}

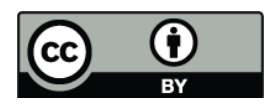

Correspondence to: J. G. Fyke

(fykejere@myvuw.ac.nz) found to play a significant role in long-term ice sheet evolution, as was the effect of refreezing meltwater and surface albedo. The bias-corrected model was able to reasonably capture important aspects of the Antarctic and Greenland ice sheets, including modern SMB and ice distribution. The simulated northern Greenland ice sheet was found to be prone to ice margin retreat at radiative forcings corresponding closely to those of the Eemian or the present-day.

\section{Introduction}

Ice sheets are important components of the climate system, but are among the least understood (Lemke et al., 2007). Dramatic changes to the global climate in the past are likely due in part to the evolution of large ice sheets in response to changing external forcing and internal ice sheet dynamics. Ice sheets may also exert a large influence on the climate system in the coming millennia, a time when large changes to the planet are expected in response to human forcing of climate. Recent research indicates that present and projected anthropogenic carbon emissions and corresponding temperature will be retained by the surface-Earth carbon system over millennial timescales (Montenegro et al., 2007; Eby et al., 2009). Such timescales are relevant to ice sheet dynamics and evolution. It is therefore important that the effect of such emissions on the cryosphere be explored, before thresholds on ice sheet stability, based on increases to atmospheric or ocean temperatures, are surpassed and the Earth becomes irreversibly committed to near-permanent ice sheet decay or loss and associated sea level rise (Ridley et al., 2010).

Published by Copernicus Publications on behalf of the European Geosciences Union. 
A coupled Earth system modelling approach is a powerful way to explore interactions between ice sheets and climate. Coupled Earth system models incorporate realistic subcomponent models (e.g., atmosphere, ocean, or land surface) and interactive communication of fluxes between subcomponents in such a way that allows feedbacks within the climate system to be resolved. To date only a few fully coupled Earth system models with the ability to realistically simulate climate change over millennial timescales have been synchronously coupled to high resolution, dynamic ice sheets (e.g., Kageyama et al., 2004; Ridley et al., 2005; Driesschaert et al., 2007; Vizcaíno et al., 2008; Charbit et al., 2008; Vizcaíno et al., 2010; Pritchard et al., 2008a). Furthermore, to date no coupled ice-climate models have explicitly represented the large Antarctic ice shelves.

A new ice-sheet/ice-shelf/climate model consisting of the University of Victoria Earth System Climate Model (UVic ESCM) and the Pennsylvania State University ice sheet model (PSUI) is presented here. It is designed to efficiently simulate the ice sheet/climate system over $1-10 \mathrm{kyr}$ timescales. First, the model and its components are described. Then, the performance of the model under equilibrium Eemian (ca. $129 \mathrm{kyr} \mathrm{BP}$ ), LGM (ca. $21 \mathrm{kyr}$ BP), late Holocene (ca. 0.2 kyr BP), and transient modern climate conditions is evaluated in response to simple perturbations to model physics, including the treatment of climate model surface air temperature (SAT) bias, surface albedo, and refreezing. Finally, a transient simulation that models present-day SMB conditions is described.

\section{Model description}

Several major design requirements dictated the choice of both climate and ice sheet models, as well as the design of the coupling software, and motivated the choice of the UVic ESCM, version 2.9 and PSUI as suitable candidates for coupling. An earlier version of the UVic model had previously been coupled to an ice sheet model (Marshall and Clarke, 1997) and used to study the role of ice sheets during deglacial periods (Yoshimori et al., 2001; Schmittner et al., 2002). However, the representation of ice in these studies was simplified, in part due to very low ice sheet resolution, isothermal ice and an inability to resolve floating ice shelves. Given the recent advances in ice sheet modeling we felt it prudent to update the ice sheet component of the UVic ESCM to the full PSUI model.

\subsection{UVic ESCM}

UVic ESCM is an Earth System model of intermediate complexity that includes fully coupled atmospheric, oceanic and land surface components, a thermodynamic/dynamic sea ice model and a closed and coupled complex carbon cycle model. The ocean component is the full 3-D ocean general circulation model MOM2 (Pacanowski, 1995). The atmospheric component consists of a vertically integrated energymoisture balance model in which the radiative forcing associated with an increase in atmospheric $\mathrm{CO}_{2}$ is applied as a decrease in outgoing long wave radiation. Heat and moisture are diffused and advected throughout the atmosphere, with winds being provided by present-day NCEP climatological long-term monthly means (Kalnay et al., 1996). Dynamic modification to the prescribed wind fields is obtained by a routine which generates anomalies to the monthly mean winds as a function of surface air temperature (Weaver et al., 2001). The land surface component of the model includes the MOSES-TRIFFID global vegetation model (Meissner et al., 2003). The model has been extensively used for a large number of studies of paleoclimate and future climate projections and is currently under active development and use. The UVic ESCM was recently run at ocean eddy-resolving resolution (Spence et al., 2008). While regional differences exist between this version of the UVic ESCM and the standard lower resolution version, the overall response is similar between the two. We therefore retain the standard UVic ESCM resolution of $3.6^{\circ}$ in longitude by $1.8^{\circ}$, as this allows millennial-scale simulations to be performed on existing computers.

\subsection{PSUI}

PSUI is a hybrid ice-sheet/ice-shelf model that simulates grounded and floating ice. Over inland ice on stiff bedrock, the shallow-ice approximation applies. Over ice with reduced basal traction (for example, ice shelves and regions of the West Antarctic Ice Sheet), the shallow shelf equations are employed. The transition between the two is dealt with heuristically by iteratively blending the velocities of both solutions. Additionally, a grounding-line ice velocity is imposed, and shelf back-stress is included, based on the analytic treatment of Schoof (2007). Three-dimensional advection and vertical diffusion of heat, and lithospheric flexure/local bedrock isostasy are calculated. Detailed descriptions of the model are in the Supplementary Material of Pollard and DeConto (2009), and Pollard and DeConto (2007).

\subsection{Ice-atmosphere coupling}

\subsubsection{Energy-moisture balance model (EMBM)}

The ice sheet surface mass balance (SMB), consisting of melt, runoff, sublimation and accumulation, is calculated using a modified version of the existing UVic ESCM vertically integrated energy-moisture balance atmosphere model (EMBM) and simple snow model. We were motivated to use the existing EMBM, instead of a positive-degree-day (PDD) model, to calculate the SMB for reasons that have been recently described (e.g., Bougamont et al., 2005). PDD approaches rely solely on surface air temperature (SAT) to derive snow or ice melt rates. The PDD factor must therefore 
be tuned to capture the effect of changing albedo and related non-sensible surface energy fluxes. However, this implicit adjustment may break down in scenarios where, for example, insolation remains constant but SAT increases due to higher concentrations of atmospheric greenhouse gases, or ice sheet elevation changes dramatically.

Inputs to the energy balance calculation are incoming shortwave radiation, specific humidity, wind speed, surface skin temperature, albedo and roughness, and surface air temperature (elevated from sea level using a constant lapse rate, nominally $5.0^{\circ} \mathrm{C} \mathrm{km}^{-1}$ ). This lapse rate is comparable to the summer lapse rate over the Greenland Ice Sheet (GIS) (Fausto et al., 2009), and like Stone et al. (2010) we suggest that this low lapse rate is a reasonable choice, as it reproduces summer ablation reasonably without significantly affecting wintertime accumulation. The snow temperature is found by solving the energy balance equation:

$Q_{\mathrm{dswr}}+Q_{\mathrm{dlwr}}=Q_{\mathrm{lt}}(T)+Q_{\mathrm{s}}(T)+Q_{\mathrm{ulwr}}(T)$

for temperature, using Newton's method. $T$ is temperature, and $Q_{\mathrm{dswr}}, Q_{\mathrm{dlwr}}, Q_{\mathrm{lt}}, Q_{\mathrm{s}}$ and $Q_{\mathrm{ulwr}}$ are incoming shortwave, incoming longwave (both supplied by the UVic ESCM), outgoing latent, outgoing sensible and outgoing longwave heat fluxes, respectively. Snow and ice emissivity is set to 0.94 . During the iteration, the surface equilibrium vapor pressure is determined and compared to the ambient specific humidity. If the equilibrium specific humidity is greater, solid-tovapor wind-enhanced sublimation occurs to equalize vapor pressures and the outgoing latent heat and moisture fluxes are determined. If the surface temperature is at the melting point after the iteration and a net flux of energy into the surface exists, it is entirely used to melt snow/ice. Sublimation of scoured, airborne snow (Box et al., 2006; Lenaerts et al., 2010) is not explicitly modelled, although wind speed is used in the calculation of the sublimation-derived moisture flux and therefore has a direct effect on surface sublimation rates.

Representation of snow and runoff used here is relatively simple, in line with the intermediate-complexity character of the UVic ESCM. An arbitrary maximum snow thickness of $10 \mathrm{~m}$ is prescribed, above which any additional accumulation is added to the ice sheet as a positive SMB. Conversely, the entire $10 \mathrm{~m}$ snowpack must melt before ice ablation can occur. The snow model is greatly simplified by assuming that snow/ice heat capacity $c_{p}=0$ (i.e., the snowpack temperature is always equal to the surface temperature) for the sake of energy balance calculations. This assumption leverages the fact that heat fluxes used to change snow and ice temperatures are an order of magnitude less than the the heat fluxes required for phase changes and can be neglected. This simplification is mirrored in the approach of Robinson et al. (2009).

Pfeffer et al. (1991), Bougamont et al. (2007) and others have recognized the importance of refreezing in limiting runoff from ice sheets. In order to capture the effect of refreezing within the relatively simple snow model, the parameterization described in Pfeffer et al. (1991) for representing refreezing of meltwater is adopted. An annual snow thickness (i.e., between last fall melt and first spring melt) is first accumulated. When melt is first detected, the thickness of meltwater that is stored in the snowpack is calculated based on the requirements that the annual snowpack average temperature be raised to freezing point and all the available pore space within the snowpack be filled. The scheme effectively assumes that an impermeable layer exists between annual layers in the snowpack and that the annual snow layer has a constant density (set to $330 \mathrm{~kg} \mathrm{~m}^{-3}$ ).

Over ice sheets, surface albedo varies as a function of snow/ice thickness and snow/ice temperature. Default albedo values for cold/melting snow albedo are $0.8 / 0.6$, with a linear interpolation between cold and warm snow values occurring between $-5^{\circ} \mathrm{C}$ and $0^{\circ} \mathrm{C}$. Glacial ice albedo is set to 0.45 . At snow thicknesses below $10 \mathrm{~cm}$, snow and ice albedos are linearly blended. These values are very similar to those of Robinson et al. (2009), though they were obtained independently by setting albedo values to approximate the glacier zone-specific values of Nolin and Payne (2007). The current model does not yet account for age-related changes in snow albedo (e.g., van de Wal and Oerlemans, 1994).

Moisture is delivered to the ice sheets via advective/diffusive transport within the atmospheric model. Precipitation occurs when the relative humidity at the surface surpasses 0.85 . This relative humidity is calculated as a function of the subgridded elevation-dependent SAT and the specific humidity of the overlying atmospheric grid cell. Precipitation falls as rain/snow when the sub-gridded temperature is above/below a threshold temperature, set over ice sheets to $-2{ }^{\circ} \mathrm{C}$ which is approximately the midrange of the observationally-derived snow-to-rain temperature parameterization of Robinson et al. (2009).

\subsubsection{Subgridded elevation-binned mass balance calculations}

Realistic transfer of climate-model-derived SMB to high resolution ice sheet grids is a non-trivial exercise due to spatial and temporal differences in scale between ice sheet and climate models (Pollard, 2010). Ice sheet models require grids on the order of $10^{0}-10^{1} \mathrm{~km}$ to appropriately resolve ice flow and gradients in SMB (particularly ablation). However, due to the slow flow of ice, time steps can be long, on the order of months to years. Climate models, on the other hand, typically operate on grids with spatial scales on the order $10^{2} \mathrm{~km}$ and temporal scales of minutes to days. In order to accommodate the variation in scales while maintaining computational efficiency and conservation of mass and energy, a routine was developed to calculate SMB based on the distribution of elevation within each climate grid cell. Instead of one EMBM calculation per climate grid cell, the scheme allocates $N$ EMBM calculations: 


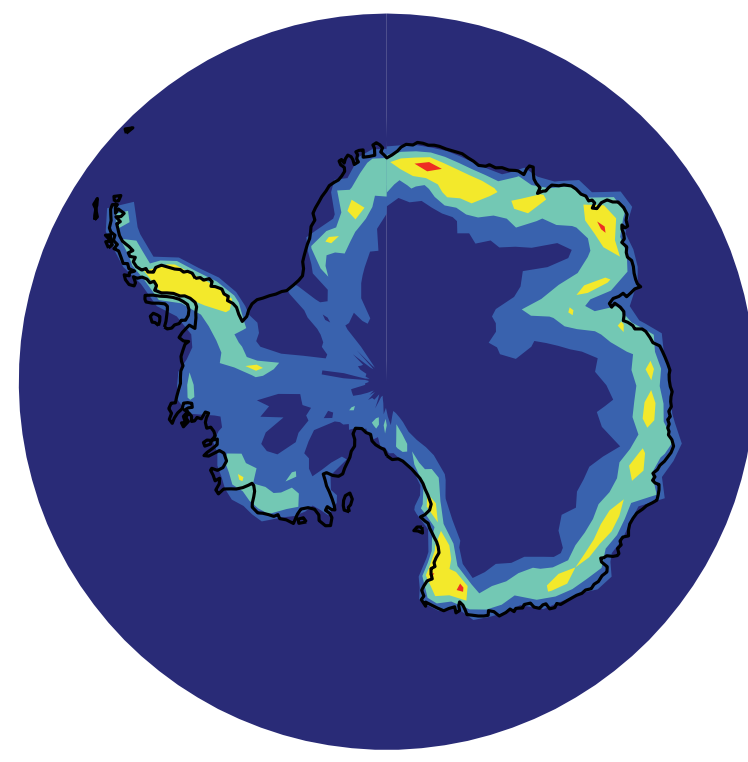

(a) AIS relief
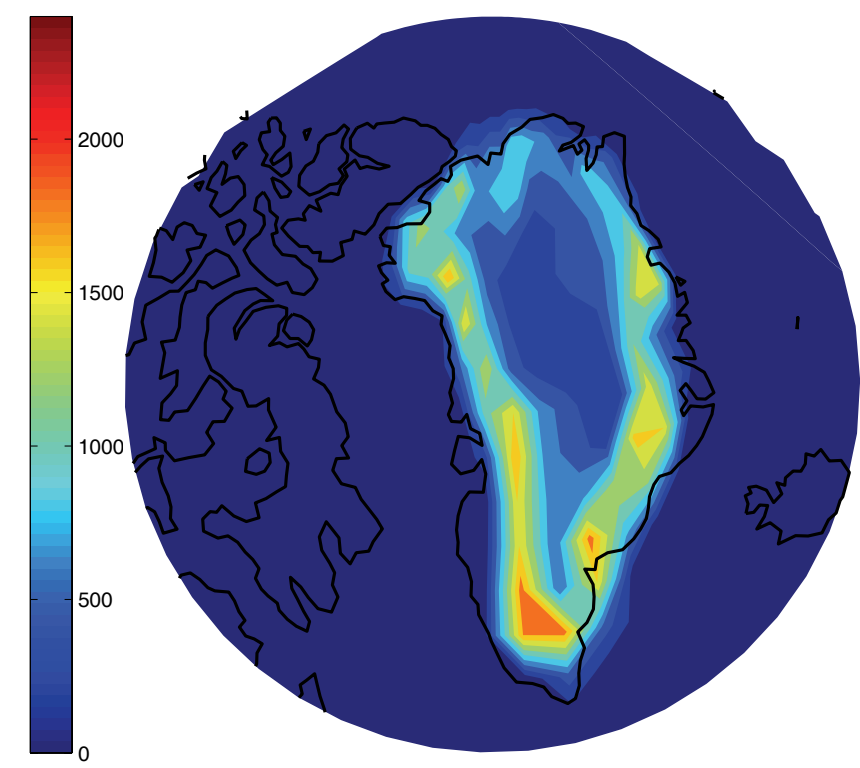

(b) GIS relief

Fig. 1. Total relief used to determine number of elevation bins in each climate model grid cell (m) for the Antarctic Ice Sheet (AIS) and Greenland Ice Sheet (GIS), where total relief is the maximum elevation minus the minimum elevation existing in the ice sheet grid cells contained within the boundaries of a UVic ESCM grid cell.

$N=\operatorname{int}(R / D)+1$

where $R$ is the total relief (defined as the difference between the maximum and minimum ice sheet surface elevations falling within the larger UVic ESCM grid cell, Fig. 1) and $D$ is the binning threshold of the elevations bins, set to $100 \mathrm{~m}$. Within each bin, the elevation is set to the average area-weighted elevation of the ice sheet grid cells that fall within the bin elevation range, and for each bin the EMBM algorithm evolves independent albedos, $Q_{1 \mathrm{t}}(T)$, $Q_{\mathrm{s}}(T), Q_{\mathrm{ulwr}}(T)$, snow thicknesses, and SMB values. When remapped back onto the ice sheet grid, the resolution of ablation zones and accumulation over short-wavelength, highrelief topography is greatly improved, in agreement with the similar approach and results of Wild et al. (2003). Over topography with wavelengths greater than the overlying climate model grid resolution (e.g., the continental East Antarctic Ice Sheet, EAIS) the subgrid scheme-derived accumulation field rapidly approaches the equivalent non-subgridded distribution.

Prior to each atmospheric time step, fluxes from all subgrid ice sheet bins within a climate model cell are accumulated, after area-weighting, and passed to the atmospheric model. This implies that the atmosphere is well mixed within each climate model cell, which was the implicit assumption before subgrid binning was introduced. At initialization and after each ice sheet timestep, the elevation bins are re-calculated according to the updated ice sheet geometry and the existing snowpack is redistributed into the new elevation bins. Where the ice dynamically retreats or melts over land or ocean any residual snow, if it exists, is sent to the ocean. Where the ice sheet dynamically expands, snow from the overridden bare land is transferred to the ice sheet surface. Finally, the updated fractional ice coverage is relayed to the overlying climate model grid. Model simulations with and without the sub-gridded elevation binning scheme indicate that the subgrid-enabled scheme is much better suited to resolve narrow ablation zones (limited in width only by the underlying ice sheet grid resolution) and orographically driven precipitation over short wavelength topography than interpolationbased SMB downscaling procedures. Furthermore, it retains computational efficiency by automatically focussing computing resources over high-relief regions, not unlike the manual procedure of van de Wal and Oerlemans (1994). For the modern ice sheet distribution, the number of EMBM calculations is reduced by a factor of 14 , compared to the same number of equivalent calculations over each high-resolution ice sheet grid-point. The resulting system is designed to conserve mass and energy to within machine precision, in accordance with the rest of the UVic ESCM.

\subsubsection{SAT bias correction}

Surface mass balance and evolution of ice sheet geometry are highly sensitive to variations in SAT that are of the same magnitude as SAT biases in present-generation climate models (van de Wal and Oerlemans, 1994; Pollard, 2000). For this reason, previous coupled ice sheet-climate model studies 
(e.g., Ridley et al., 2005, 2010) have utilized approaches in which modelled temperature anomalies, obtained by subtracting a perturbed model state from the control value, are added to observational climatologies prior to processing by PDD models. This method reduces spurious SMB values resulting from persistent and intrinsic modelled temperature biases but is handicapped by drawbacks of the PDD model approach (Sect. 2.3.1). Other studies (Bonelli et al., 2009; Pritchard et al., 2008a; Charbit et al., 2008) also utilized the PDD approach, but with "uncorrected" climate model SAT that still retained a climate model SAT bias. Recently, Calov et al. (2009) and Vizcaíno et al. (2010) employed surface energy balance models to calculate SMB over the Northern Hemisphere and Greenland, respectively, without SAT corrections. They suggested that their annual present-day modelled climatology was sufficiently similar to observations to justify use of raw model output to supply their SMB model. However, visual inspection of Fig. 1 in Vizcaíno et al. (2010) suggests that differences of $\sim 5-10^{\circ} \mathrm{C}$ still exist in their annually averaged surface air temperature and Calov et al. (2009) do not provide an analagous difference figure of SAT.

In order to use a surface energy balance model to generate $\mathrm{SMB}$, but also analyze and optionally correct the effect of climate model-derived SAT biases on ice sheet evolution, all without losing global conservation of energy, the following bias correction procedure for use in the EMBM was developed.

1. A UVic ESCM simulation forced with late Holocene orbital and $\mathrm{CO}_{2}$ conditions was run to equilibrium. Ice sheet model elevations were held constant at presentday values. Equilibrium late Holocene monthly-mean raw model SAT fields were extracted.

2. The model was then forced with transient $\mathrm{CO}_{2}$ concentrations to year 2000 , and the monthly-mean temperature difference between year 2000 and the late Holocene steady state was obtained.

3. This difference was subtracted from the 1971-2000 ERA40 (Uppala et al., 2006) monthly-mean SAT to derive an observed SAT, extrapolated to late Holocene conditions.

4. Another late Holocene UVic ESCM simulation was carried out, in which the model-derived SAT values were replaced with the late Holocene "observed" SAT values used in the EMBM calculations over the ice sheets (the SAT used in non-ice-sheet EMBM calculations remained the value provided by the atmospheric component of the UVic ESCM). This procedure effectively forced the energy balance model over ice sheet domains to respond to SAT anomalies and generated a regionally altered pattern of atmospheric heat transport. This altered transport field perturbed the global modelled SAT field in bias-corrected simulations, but the magnitude of

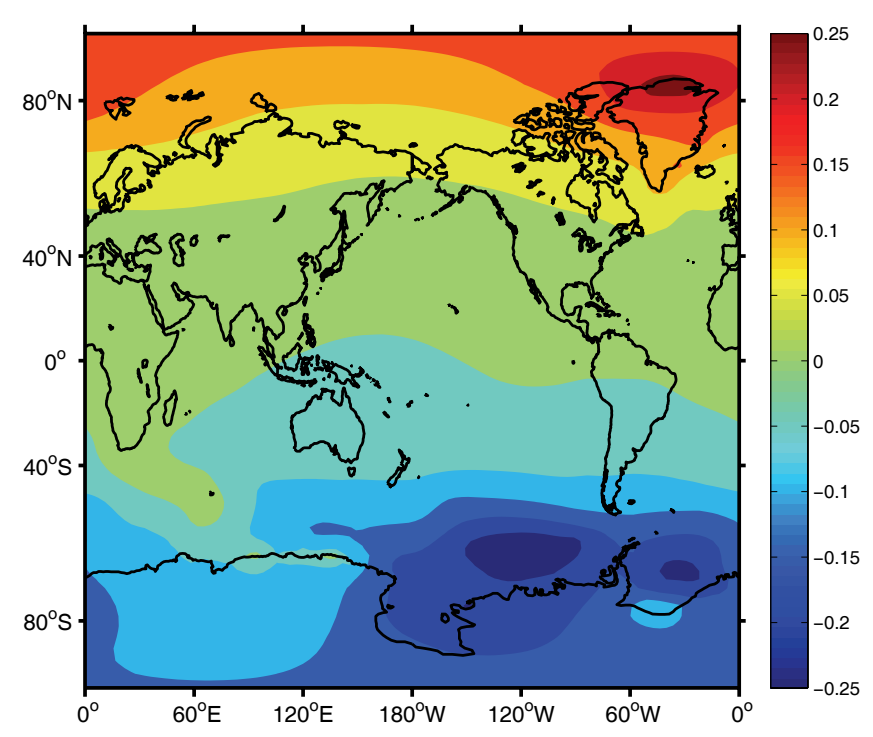

Fig. 2. The difference $\left({ }^{\circ} \mathrm{C}\right)$ between annual mean UVic ESCM atmospheric SAT fields of late Holocene simulations with/without the bias correction applied over the ice sheets. The effect of the bias correction procedure is largest over the AIS and GIS and diminishes with distance from the correction regions. The global effect of the bias correction over both ice sheets is to redistribute heat from the Southern Hemisphere to the Northern Hemisphere. However, the resulting temperature change is less than $0.25^{\circ} \mathrm{C}$ everywhere and does not significantly affect the non-ice-sheet components of the system.

the perturbation was less than $0.25^{\circ} \mathrm{C}$ anywhere (Fig. 2) and lessened with distance from the ice sheets.

5. The monthly-mean SAT difference between the two simulations was obtained. These monthly-mean bias maps were added as a correction factor to the UVic ESCM atmospheric temperature used in the calculation of the surface energy balance and the rain/snow decision.

Results of the bias-corrected models are described in Sect. 3.2.

\subsection{Ice-land coupling}

As the simulated grounded ice sheets advance or retreat they cover or expose bare land. The dynamic vegetation model MOSES-TRIFFID is currently excluded from any potential ice sheet region (i.e., the island of Greenland and the Antarctic continent) in the present version of the model. Instead, the albedo and roughness lengths of bare land areas in Greenland and Antarctica are set to values typical of tundra (when free of snow). For GIS and AIS simulations initialized with existing ice that do not undergo drastic retreat this is likely a reasonable approach.

Surface meltwater is routed instantaneously via large-scale drainage basins to the ocean model. The AIS drainage basin 


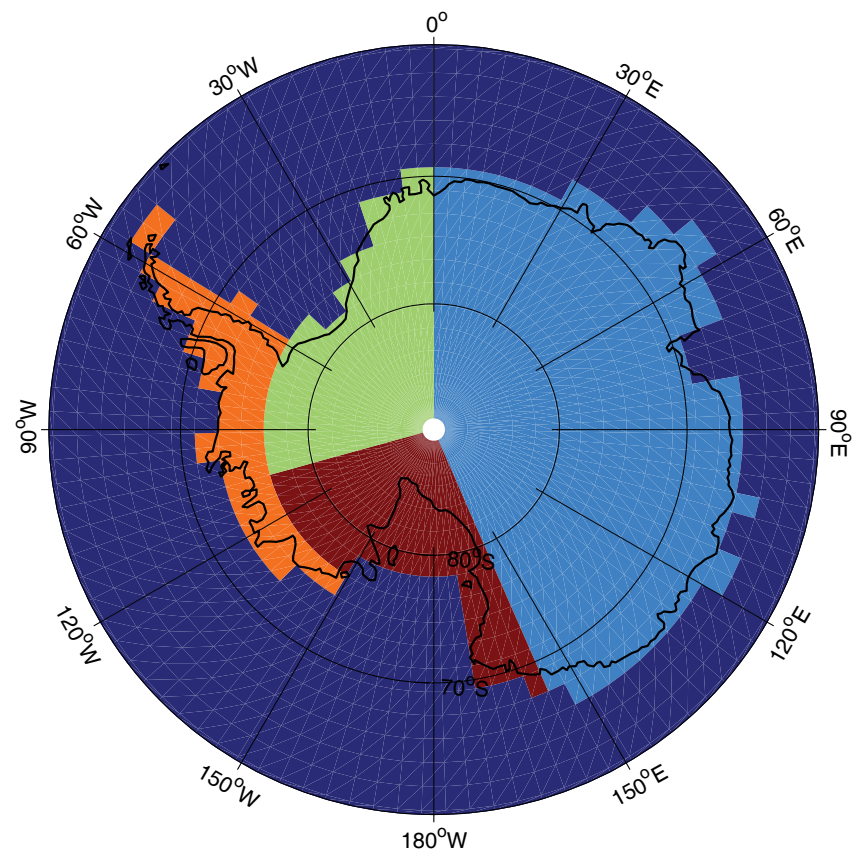

Fig. 3. Antarctic drainage basins. Moisture and heat fluxes associated with ice discharge are evenly distributed to coastlines within each drainage basin.

distribution (Fig. 3) is based roughly on present-day ice surface topography and would become unrealistic only under a drastic change to ice geometry or significant continentalscale deviation in subglacial drainage from the surface topography. The GIS was assigned one drainage basin, resulting in an even distribution of meltwater flux around the GIS coast.

The elevation field of climate model grid cells that overlay ice sheet model instances evolve according to the gridaveraged ice sheet or exposed bedrock elevations calculated by the ice sheet lithosphere model. Elevations remain static over climate grid cells that do not overlay ice sheet grids.

\subsection{Ice-ocean coupling}

PSUI explicitly simulates ice shelves and a dynamic grounding line. Ice shelves are represented in the UVic ESCM by fractional surface coverage of ocean grid cells. Increasing fractional ice shelf coverage progressively "shades" underlying ocean and sea ice grid cells from atmospheric heat and moisture fluxes until the climate grid cell is fully covered, at which point the ocean and sea ice models are completely insulated from all atmospheric heat and moisture fluxes. The treatment of momentum fluxes is slightly different. If atmospheric momentum fluxes are simply shaded, calculation of sea ice dynamics within the dynamic/thermodynamic sea ice component of the UVic ESCM results in artificial convergence and divergence of sea ice in partially-covered ocean cells. Therefore, sea ice is allowed to advect freely in partially-covered ocean cells (although the thermodynam- ically derived rate of change of sea ice thickness is reduced due to decreased heat and moisture fluxes).

Simulated bathymetry in the ocean model MOM2 was improved over the default UVic ESCM bathymetry to better represent modern under-shelf conditions (Lythe and Vaughan, 2001). The ocean is therefore free to circulate to the equivalent of the modern-day AIS grounding line. MOM2 is not capable of capturing the effect of a depressed upper boundary geometry. For this reason, as well as the the coarse scale of the ocean model, oceanic effects associated with ice shelf draft are currently neglected.

Modelling and observations indicate that oceanic melting of ice shelves plays an important role in ice sheet evolution (Pollard and DeConto, 2009; Payne et al., 2004). Modelling results that attempt to simulate the interaction between ice shelves and subshelf ocean circulation (Holland et al., 2008a; Olbers and Hellmer, 2009) suggest that an ocean temperature increase of only a few degrees Celcius results in a quadratic increase in ice shelf melt rates. The obvious relationship between ocean temperature and ice shelf melt rates calls for a parameterization that links ice shelf melt rates to coarse modelled ocean temperatures. However, this version of the coupled model does not currently include such a parameterization as a default option. Instead, melt rates and calving are prescribed according to the method described in the Methods section of Pollard and DeConto (2009) for either modern or LGM conditions for the AIS. This parameterization, which generates a time-and-space-evolving distribution of sub-ice-shelf melt, is based on a triplet of melt values $\left(M_{\mathrm{p}}<M_{\mathrm{d}}<M_{\mathrm{e}}\right)$ for protected, deep-ocean and exposedshelf conditions, respectively. This triplet of melt values is combined based on gridpoint-specific bathymetry, access to open ocean, and distance to the current shelf edge, to generate point-specific sub-shelf melt rates. In lieu of a universal calving law, calving is parameterized as high sub-shelf melt, which increases with decreasing straight-line distance to the shelf edge, as described above. The overall parameterization was tuned by Pollard and DeConto (2009) in order to obtain realistic late Holocene and LGM ice shelf extents when combined with realistic sea level. The associated triplet values are given in Table 1. Fluxes of moisture and heat derived from AIS sub-shelf melting are delivered to the ocean along the ice shelf edge. In contrast to the AIS, sub-shelf melt is simply set to high values for the GIS (although the model does not generate spurious GIS shelves in the present-day with the standard Pollard and DeConto (2009) parameterization values).

The ice sheet model has the ability to simulate large-scale grounding line migration (Pollard and DeConto, 2009) similar to that found in West Antarctic Ice Sheet (WAIS) paleoclimate records (Naish et al., 2009). However, the current UVic ESCM ocean component does not support lower and lateral boundary geometry (i.e., bathymetry and coastline) adjustment. For this reason, any potential climatic effects of large-scale (order $10^{2} \mathrm{~km}$ and above) grounding line 
Table 1. Sub-shelf melt triplet values used in the ice shelf melting parameterization that is employed here. $M_{\mathrm{p}}$ =protected shelf melt values, $M_{\mathrm{d}}=$ deepwater shelf melt values, $M_{\mathrm{e}}=$ exposed shelf melt values. For more information, see Pollard and DeConto (2009).

\begin{tabular}{lccc}
\hline Sub-shelf melt triplet values $\left(\mathrm{m} \mathrm{yr}^{-1}\right.$ ice $)$ & $M_{\mathrm{p}}$ & $M_{\mathrm{d}}$ & $M_{\mathrm{e}}$ \\
\hline late Holocene & 0.1 & 5 & 5 \\
LGM & 0 & 0 & 2 \\
\hline
\end{tabular}

migration, such as that implied by the endmember no-WAIS case of Bougamont et al. (2007), are not captured. Here we effectively assume that large-scale oceanographic effects resulting from grounding-line-migration-induced changes to ocean basin geometry are small and recognize that the ability to make ocean boundaries track dynamic grounding lines is an obvious avenue for future ocean model development. In general, we believe the existing model provides an excellent foundation for development of a complete ocean-ice coupling procedure.

\subsection{Multiple ice sheet capability, initialization, ice acceleration and $\mathrm{I} / \mathrm{O}$}

One global, high-resolution ice sheet grid within the global coupled model is not feasible for geometric and computational reasons (Rutt et al., 2009). Therefore, following Rutt et al., the model was designed to accommodate multiple ice sheet "instances", which contain variables describing the entire state of each independent ice sheet in separate derived data type (DDT) variables. The ice sheet instances are accessible via corresponding Fortran 90 pointers (Metcalf and Reid, 1999). This method permits independent regional ice sheet model instances (each with different resolutions, grid sizes, time steps, and ice sheet physics parameters) to exist within a single coupled climate/ice sheet model simulation.

Ice sheets are among the slowest of the exogenic Earth system components to respond to applied climatic forcings. For this reason we have included the ability to accelerate ice sheet evolution relative to the climate. For equilibrium simulations, annual SMB is accumulated, and then used to force the ice sheets for multiple years. Resulting moisture and heat fluxes from ice sheets to the surrounding climate are scaled proportionally (Yoshimori et al., 2001) resulting in a loss of global conservation of heat and moisture. Ice acceleration is limited to no more than 20 times (i.e., one year of climate forcing drives no more than 20 years of ice sheet evolution) for equilibrium simulations. Given the efficiency of the UVic ESCM, this still allows $100 \mathrm{kyr}$ simulations to be carried out within a reasonable timeframe. Long-term (i.e., over $10 \mathrm{kyr}$ ) transient simulations can be carried out using a technique in which the orbital and $\mathrm{CO}_{2}$ forcings are accelerated at the same rate as the ice sheet. Following Calov et al.
(2009) we limit the acceleration in these cases to no more than 10 times due to the long dynamic and thermal response times of the ice sheet, as well as the abyssal oceans. Interannual variability is not simulated by the UVic ESCM, so we are not concerned with extraction of a longterm climatology for use in forcing the ice sheet model, despite suggestions that millennial-scale ice sheet evolution may in fact be sensitive to ENSO-timescale climate variability (Pritchard et al., 2008b).

The current model configuration contains two ice sheet instances that represent the GIS and AIS. Both operate on $20 \mathrm{~km}$ resolution stereographic grids with grid dimensions of 76 by 140 and 282 by 282 grid cells, respectively. At yearly intervals each ice sheet is targeted and run through the ice sheet subroutines for $A_{i} / d t_{\text {ice }}$ timesteps, where $d t_{\text {ice }}$ is the ice sheet timestep (years) and $A_{i}$ is the acceleration factor. In the following experiments each ice sheet utilizes $d t_{\text {ice }}=0.25 \mathrm{yr}$.

Both the ice sheet model and climate model have the capability to initialize from observations or the saved states of previous model simulations. Initial ice sheet observations are obtained from Bamber et al. (2001) for the GIS and Lythe and Vaughan (2001) for the AIS. As the dimension of subgridded elevation bin arrays changes interactively with ice sheet model size and geometry, restarts are checked at initialization to ensure they are consistent. If not, new subgridded arrays are constructed and the existing snowpack is redistributed.

\section{Results and discussion}

A suite of sensitivity tests was carried out in order to explore the response of the simulated AIS and GIS to model physics, and to approach the model design that produced optimal equilibrium ice sheet states for Eemian, LGM, and late Holocene climate forcings. Equilibrium ice sheet simulations imply non-changing climate forcings, which is not the case in reality. However, since the equilibrium experiments were primarily meant to isolate the effect of model physics on GIS/AIS ice sheet evolution, transient climate forcings (e.g., $\mathrm{CO}_{2}$, orbitally-induced changes to insolation and sea level) were intentionally set to constant values in these equilibrium simulations. To assess the simulated effect of recent climate forcings, we carried out a transient simulation to evaluate simulated SMB trends over modern AIS and GIS geometry and the approximate state of disequilibrium of the present-day ice sheets with respect to anthropogenicallyperturbed radiative forcing.

For each equilibrium experiment the model was forced with relevant orbital and $\mathrm{CO}_{2}$ forcings. The paleoclimate equilibrium $\mathrm{CO}_{2}$ concentrations were obtained from a composite of the Vostok (Petit et al., 1999), Taylor Dome (Indermühle et al., 2002), and Law Dome (Meure et al., 2006) ice core records. In all equilibrium simulations the ice sheets were initialized from ice-present conditions (glacial 


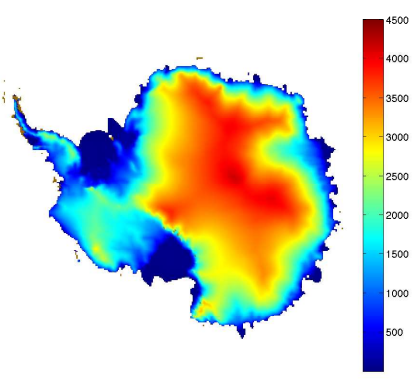

(a) late Holocene control

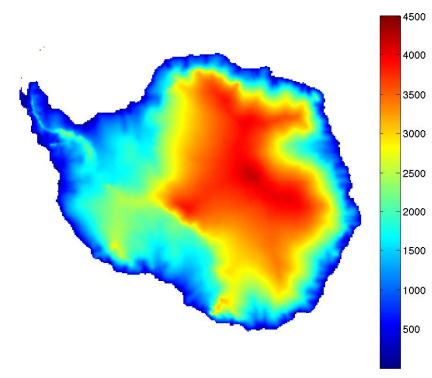

(e) LGM control

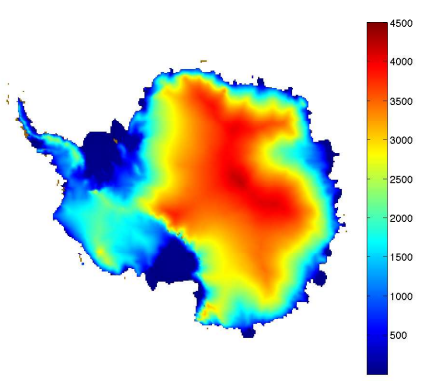

(i) Eemian control

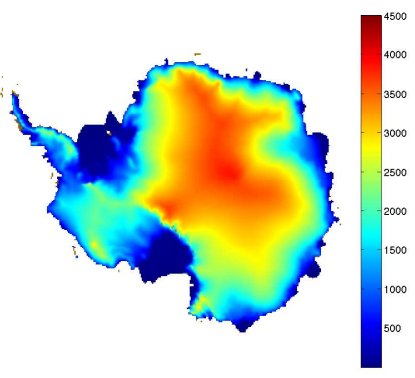

(b) late Holocene NBC

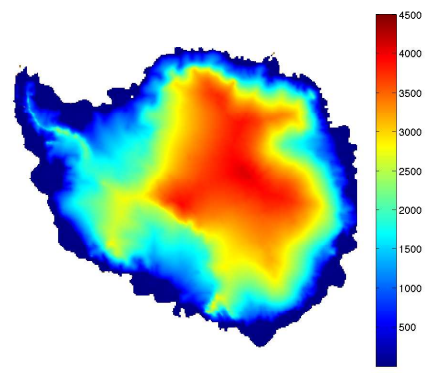

(f) LGM NBC

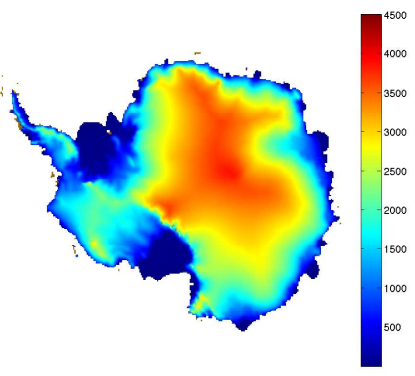

(j) Eemian NBC

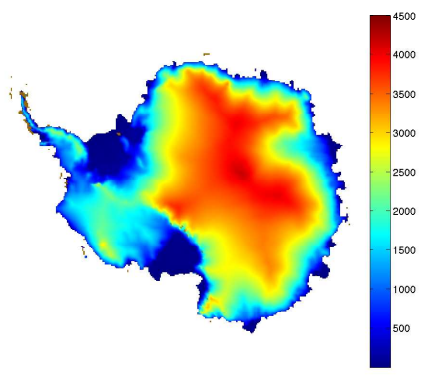

(c) late Holocene NMRR

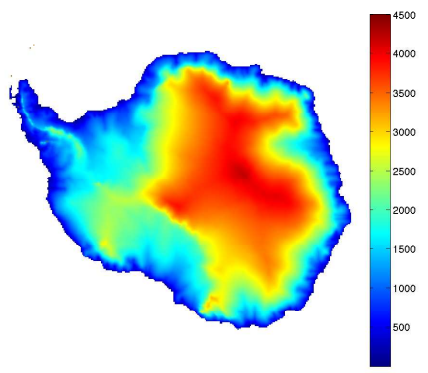

(g) LGM NMRR

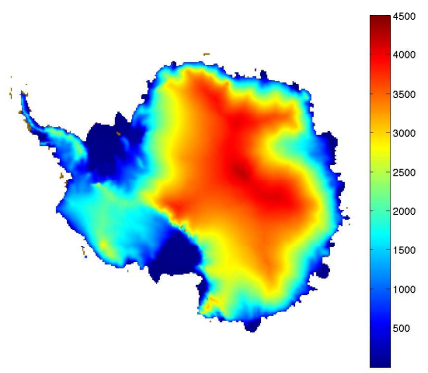

(k) Eemian NMRR

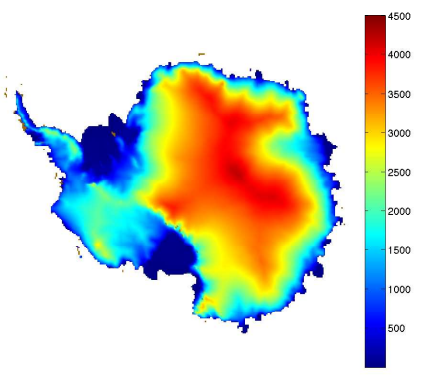

(d) late Holocene CA

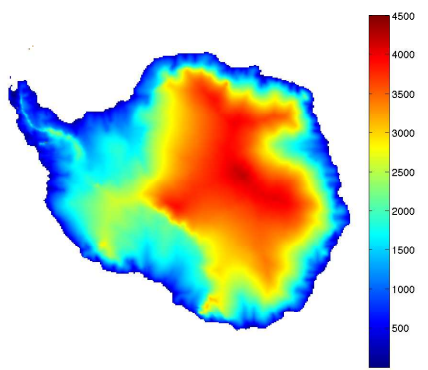

(h) LGM CA

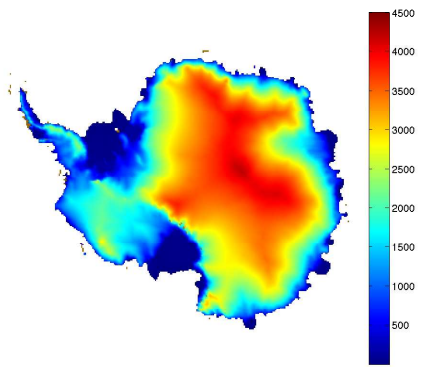

(1) Eemian CA

Fig. 4. AIS surface ice elevation (m) from control and perturbed physics experiments. NBC=non-bias-corrected, NMRR = non-meltwaterretention or refreezing, $\mathrm{CA}=$ constant albedo.

inception was not simulated). The ice sheets were accelerated with respect to the climate by a factor of 20 to hasten the approach to equilibrium. The results described below focus on the effects of climate-model-generated SAT biases, albedo, and parameterized refreezing for each climate state. Simulations with corrected SAT biases, refreezing of meltwater, and variable surface albedo were treated as control simulations. The effect of perturbing the model physics was then analysed by comparing runs without SAT bias correction, refreezing, or surface albedo against the control runs. AIS and GIS ice volumes and areas are summarized in Tables 2 and 3, respectively.

\subsection{Control simulations}

\subsubsection{Late Holocene}

In order to simulate equilibrium ice sheet conditions representative of the late Holocene, orbital and $\mathrm{CO}_{2}$ concentrations were set to $0.2 \mathrm{kyr}$ BP. The control AIS late Holocene volume (Fig. 4a) grew to $30.9 \times 10^{6} \mathrm{~km}^{3}$, from the initial (present-day observed) volume of approximately $26 \times$ $10^{6} \mathrm{~km}^{3}$. This overestimation was not due to the neglect of transient forcings or spurious SMB. Rather, since excess ice grew primarily in regions that are presently observed to discharge ice through prominent ice streams (the Ross Sea sector of the WAIS, the Pine Island Glacier ice drainage basin, the Transantarctic Mountains, and the Amery/Prydz Bay region) it is very likely that the overestimation was due to the 


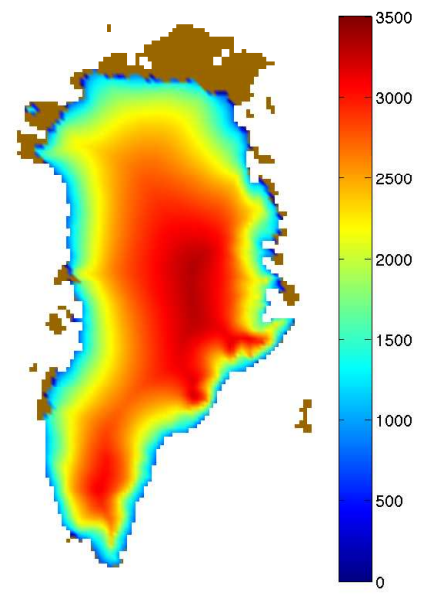

(a) late Holocene control

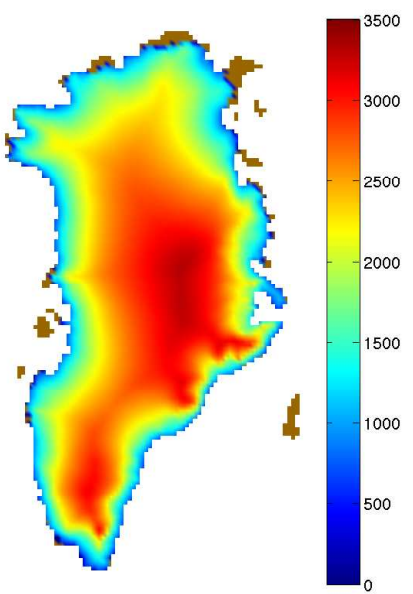

(e) LGM control

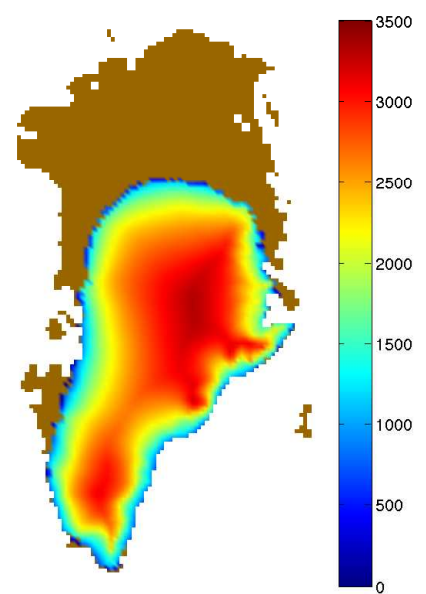

(i) Eemian control

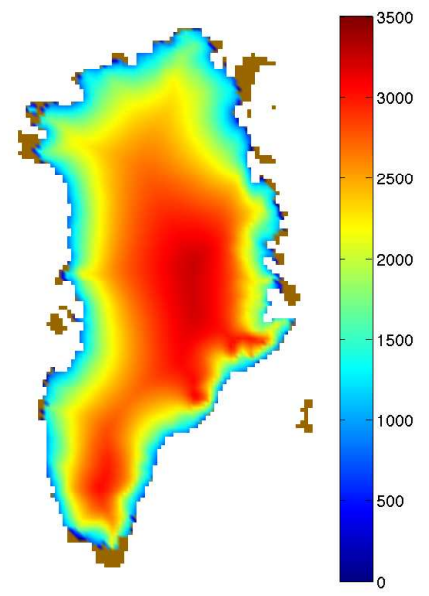

(b) late Holocene NBC

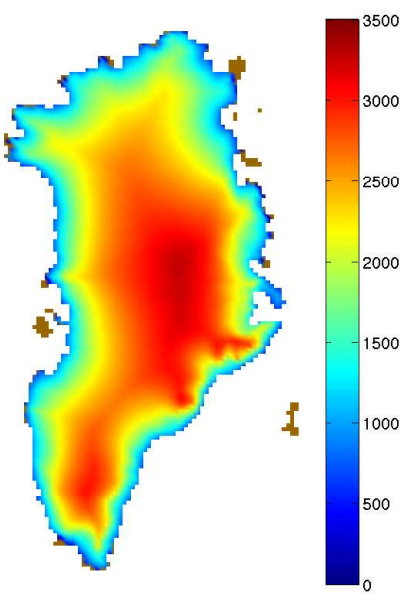

(f) LGM NBC

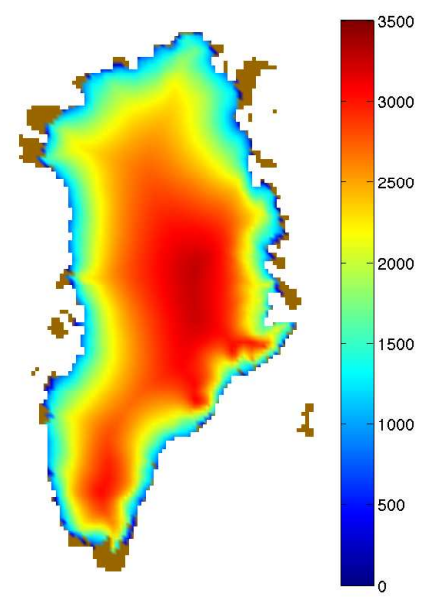

(j) Eemian NBC

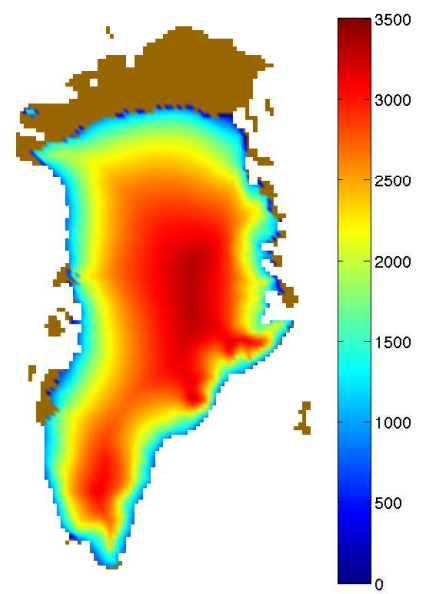

(c) late Holocene NMRR

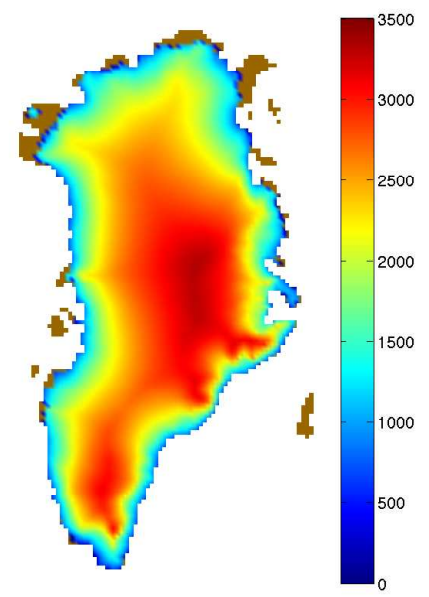

(g) LGM NMRR

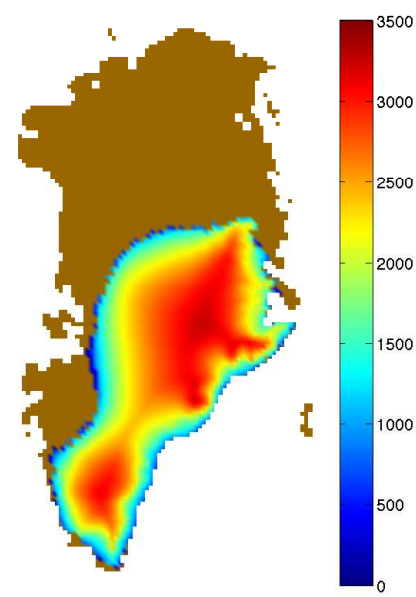

(k) Eemian NMRR

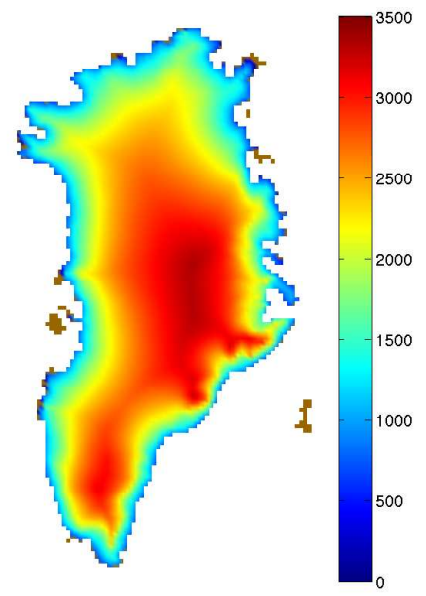

(d) late Holocene CA

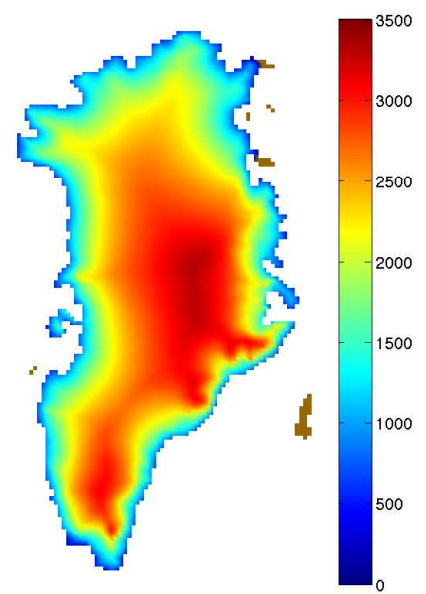

(h) LGM CA

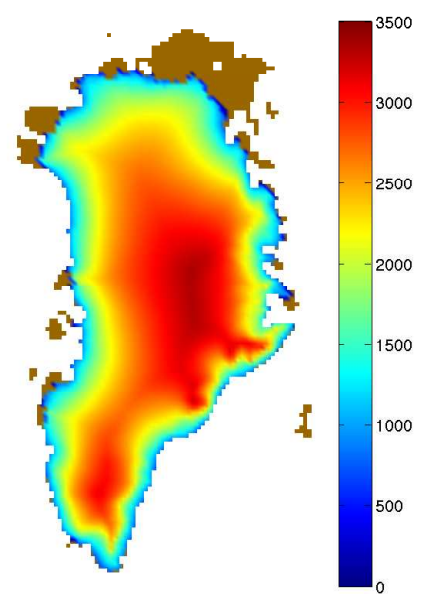

(1) Eemian CA

Fig. 5. GIS surface ice elevation $(\mathrm{m})$ from control and perturbed physics experiments. $\mathrm{NBC}=$ non-bias-corrected, NMRR $=$ non-meltwaterretention or refreezing, $\mathrm{CA}=$ constant albedo. 
Table 2. Final AIS ice volumes $\left(/ 10^{6} \mathrm{~km}^{3}\right)$ and areas $\left(/ 10^{6} \mathrm{~km}^{2}\right)$ for all equilibrium experiments. $\mathrm{NMRR}=$ no melting/refreezing; $\mathrm{NBC}=$ no bias correction; $\mathrm{CA}=$ constant albedo.

\begin{tabular}{lcccc}
\hline AIS ice volumes & Control & NMRR & NBC & CA \\
\hline Eemian & 31.2 & 31.2 & 28.1 & 31.3 \\
LGM & 40.4 & 40.1 & 38.1 & 40.5 \\
Late Holocene & 30.9 & 30.9 & 28.2 & 31.2 \\
\hline AIS ice areas & & & & \\
\hline Eemian & 14.2 & 14.1 & 14.2 & 14.2 \\
LGM & 18.7 & 18.7 & 18.5 & 18.7 \\
Late Holocene & 14.1 & 14 & 14.2 & 14.1 \\
\hline
\end{tabular}

inability of the model to fully represent ice stream features. This is a common problem among recent modelling studies (Stone et al., 2010; Vizcaíno et al., 2010) that requires a fuller representation of outlet glaciers in whole ice sheet models to alleviate. However, the elevation of the central dome of the EAIS was captured to within $100 \mathrm{~m}$, and the total ice extent, including ice shelves, equilibrated at $14.1 \times 10^{6} \mathrm{~km}^{2}$, close to the initial ice area.

The control GIS late Holocene volume (Fig. 5a) grew to $3.47 \times 10^{6} \mathrm{~km}^{3}$ from an initial observed volume of approximately $2.9 \times 10^{6} \mathrm{~km}^{3}$. Excess GIS ice formed primarily along the coasts. In particular, ice expanded westwards along the southwest and central eastern margins, covering exposed land surface. Elsewhere around the margins, existing ice thickened. It is likely that here, too, incomplete representation of ice streams allowed the excess ice to build up instead of dynamically discharging. Much of the elevations of the central and eastern interior and the interior of the south dome were within $100 \mathrm{~m}$ of their initial observed elevations. The northern margin retreated slightly due to the sensitive balance between low accumulation and summer ablation. The combination of slight northern margin retreat and intermittent central and southern margin expansion resulted in a total areal ice extent of $1.91 \times 10^{6} \mathrm{~km}^{2}$, very similar to the initial observed ice area.

Further detailed discussion of SMB is in Sect. 3.5, where we examine the effect of possible anthropogenic influences on recent measured/modelled surface conditions, which have not yet had time to impact large-scale ice geometry.

\subsubsection{Last glacial maximum}

In the LGM control simulation, the model was forced with orbital and $\mathrm{CO}_{2}$ conditions corresponding to $21 \mathrm{kyr} \mathrm{BP}$. The control LGM AIS total ice volume (Fig. 4e) grew significantly to $40.4 \times 10^{6} \mathrm{~km}^{3}$ compared to the late Holocene simulation, largely due to an imposed $125 \mathrm{~m}$ sea level drop, which allowed thick grounded ice to advance into the Ross and Filchner-Ronne basins. The prescribed basal melt rates
Table 3. Final GIS ice volumes $\left(/ 10^{6} \mathrm{~km}^{3}\right)$ and areas $\left(/ 10^{6} \mathrm{~km}^{2}\right)$ for all equilibrium experiments. $\mathrm{NMRR}=$ no melting/refreezing; $\mathrm{NBC}=$ no bias correction; $\mathrm{CA}=$ constant albedo

\begin{tabular}{lcccc}
\hline GIS ice volumes & Control & NMRR & NBC & CA \\
\hline Eemian & 2.19 & 1.51 & 3.59 & 3.45 \\
LGM & 3.68 & 3.64 & 3.66 & 3.75 \\
Late Holocene & 3.47 & 3.14 & 3.61 & 3.75 \\
\hline GIS ice areas & & & & \\
\hline Eemian & 1.29 & 1.01 & 2 & 1.92 \\
LGM & 2.12 & 2.07 & 2.14 & 2.22 \\
Late Holocene & 1.91 & 1.76 & 2.04 & 2.14 \\
\hline
\end{tabular}

were also reduced, but as found in Pollard and DeConto (2009) sea level was the predominant control on AIS grounding lines, which advanced to the shelf edge. Interior sectors of the WAIS, particularly those that feed the present-day Ross and Filchner-Ronne ice shelves also thickened, by up to $600 \mathrm{~m}$, in response to the increase in seaward ice thickness. The EAIS response was less drastic, with ice thicknesses increasing by $0-200 \mathrm{~m}$ over much of the interior of the ice sheet. Slight thinning $(<100 \mathrm{~m})$ occurred along the coastal EAIS. The Lambert Glacier sector also thinned slightly compared to the late Holocene simulation, due to the spurious lack of ice retreat there in the Holocene simulation. The overall difference in ice elevations was in broad agreement with the reconstruction of Denton and Hughes (2002), with the exception of the Lambert Glacier region.

The control LGM GIS (Fig. 5e) also grew in comparison to the late Holocene control simulation, to $3.68 \times 10^{6} \mathrm{~km}^{3}$. The area also increased, to $2.12 \times 10^{6} \mathrm{~km}^{2}$, as ablation zones largely vanished and sea level allowed the ice to expand. Despite this growth in ice area, the total SMB decreased slightly as a result of decreased atmospheric moisture transport. The lower SMB resulted in a slight decrease in the elevation of the central ice sheet.

\subsubsection{Eemian}

For the Eemian control simulation, the model was forced with orbital and $\mathrm{CO}_{2}$ conditions corresponding approximately to the midst of the Eemian interglacial, -129 kyr BP. Middle-Eemian $\mathrm{CO}_{2}$ concentrations were very similar to late Holocene levels, leaving insolation anomalies as the only significant change in forcings between late Holocene and Eemian periods. The Northern Hemisphere experienced a strong positive spring-summer insolation anomaly of up to $80 \mathrm{~W} \mathrm{~m}^{-2}$ at $70^{\circ} \mathrm{N}$ compared to the present day, while the Southern Hemisphere insolation remained similar or slightly less than present (Overpeck et al., 2006).

The control Eemian AIS (Fig. 4i) did not respond strongly to the change in forcing and equilibrated at a volume of 
$31.2 \times 10^{6} \mathrm{~km}^{3}$, almost identical to the late Holocene control run. This agrees with the modelling results of Overpeck et al. (2006), who found a slight AIS surface cooling under Eemian conditions that would not change the AIS volume significantly.

The control Eemian GIS, in contrast, retreated significantly along the northern margin, and to a lesser extent the western margin, as the increased Northern Hemisphere spring-summer insolation resulted in greater ablation. The final equilibrated GIS ice area (Fig. 5i) decreased by $32 \%$ compared to the late Holocene control, to $1.29 \times 10^{6} \mathrm{~km}^{2}$. Total simulated GIS ice loss was equivalent to $3.1 \mathrm{~m}$ of sea level rise (compared to the equivalent late Holocene simulation), very similar to the mean model-based estimate of OttoBliesner et al. (2006) of 1.9-3.0 m of global mean sea level rise (SLR), but the pattern of ice loss between the two simulations differed noticeably. Otto-Bliesner et al. (2006) lost ice primarily from the south, resulting in an ice-free corridor that developed across the location of the Dye-3 ice core. In support of our modelling result, the validity of an icefree Eemian Dye-3 location was challenged by recent work (Willerslev et al., 2007) which tentatively limited the age of Dye-3 basal ice to no younger than 450 kyr. The sensitivity of the northern margin to retreat is also reflected in other recent GIS simulations (Stone et al., 2010; Greve et al., 2011). However, the extent of northern retreat contradicts evidence of Eemian ice at the base of the Camp Century and NEEM ice cores, suggesting either model overestimation of northern margin retreat or a real GIS that did not reach full equilibration with transient orbital and $\mathrm{CO}_{2}$ forcings during the Eemian. Simulated ice distribution also contradicts evidence of significant vegetation over southern Greenland during the Eemian (de Vernal and Hillaire-Marcel, 2008).

These results warrant further examination that is beyond the scope of this evaluation. However, two points are worth noting: teleconnections that could transport excess heat from north to south (or vice versa) are not significant in the control Eemian simulation, resulting in AIS surface temperatures and SMB that remained relatively unchanged despite the large positive Northern Hemisphere insolation anomaly. An associated simulation in which the Eemian AIS was also forced with the GIS-derived SLR resulted in negligible AIS volume change, ruling out that as a teleconnection, and leaving local oceanic thermal forcing, which was not resolved here as a coupled connection between ice and ocean, as the remaining mechanism available for driving Eemian AIS response. The depth-averaged Southern Ocean water temperature difference (at depths roughly typical of Antarctic ice shelf drafts) between late Holocene and Eemian simulations (Fig. 6) is not typically large, but does reach $+0.2{ }^{\circ} \mathrm{C}$ in the Ross Sea, suggesting that moderate increases in simulated basal melting of the ice shelf could occur there.

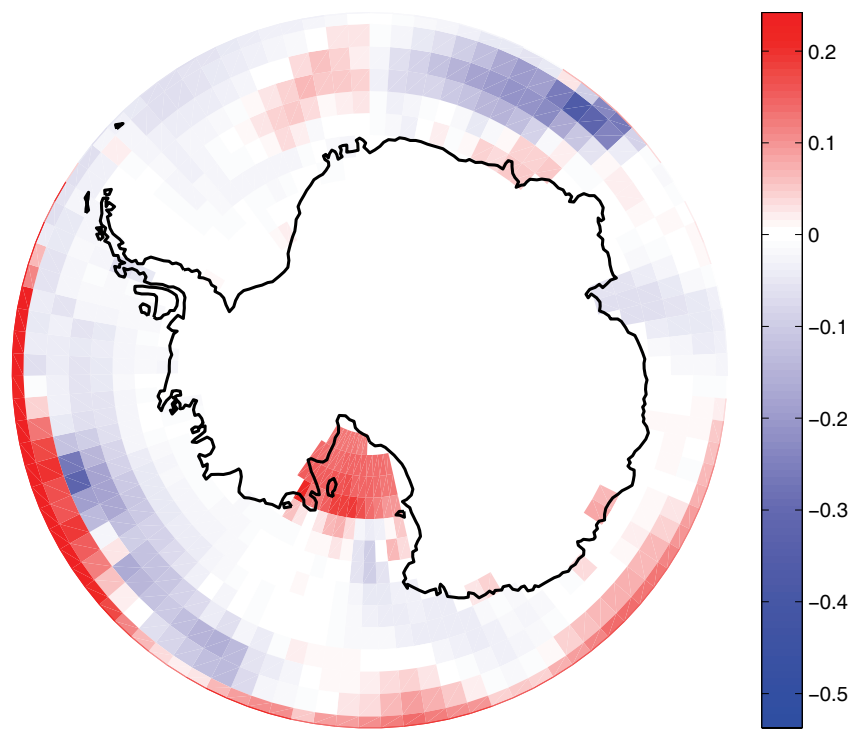

Fig. 6. Eemian minus late Holocene depth averaged ocean temperatures $\left({ }^{\circ} \mathrm{C}\right)$, from $130 \mathrm{~m}$ to $750 \mathrm{~m}$ depth. Red: warmer Eemian, blue: warmer modern. Note the asymmetry of the color bar towards colder values (white is centered on $0^{\circ} \mathrm{C}$ ).

\subsection{Ice sheet evolution sensitivity to climate model surface air temperature bias}

To gauge the effect of seasonally-resolved modelled temperature biases on SMB and long term ice sheet evolution in the model, we first compared the 1970-2001 UVic ESCM SAT with the equivalent ERA40 SAT field to determine the extent of the model SAT bias, then compared the Eemian, LGM and late Holocene control (bias-corrected) simulations to similar simulations forced with raw UVic ESCM SAT (here called non-bias-corrected "NBC" simulations). Use of a constant bias corrector field assumes that the modelled SAT bias is independent of the climate or ice sheet state; this is a common assumption among modelling studies but is difficult to confirm given the lack of reliable and comprehensive gridded paleoclimate SAT records.

The simulated 1970-2001 annual average SAT over the ice sheets is compared with ERA40 in Figs. 7 and 8. The simulated annual average AIS SAT exhibited a warm bias in the cold interior of Wilkes Land and a cold bias over the interior of the WAIS. Around the coast, however, the absolute bias value was typically less than $5^{\circ} \mathrm{C}$. The annual average SAT over the GIS agreed well with ERA40, with absolute values below $6{ }^{\circ} \mathrm{C}$ everywhere except two local regions in the southeast.

Annual SAT maps do not resolve seasonal SAT biases, which are of greater relevance to ice sheet SMB. Figures 7 and 8 also show summer and winter SAT compared to equivalent ERA40 values. In winter, locations on the WAIS are up to $15^{\circ} \mathrm{C}$ too cold, while Wilkes Land is up to $15^{\circ} \mathrm{C}$ too warm. The wintertime GIS suffers from much less pronounced SAT 


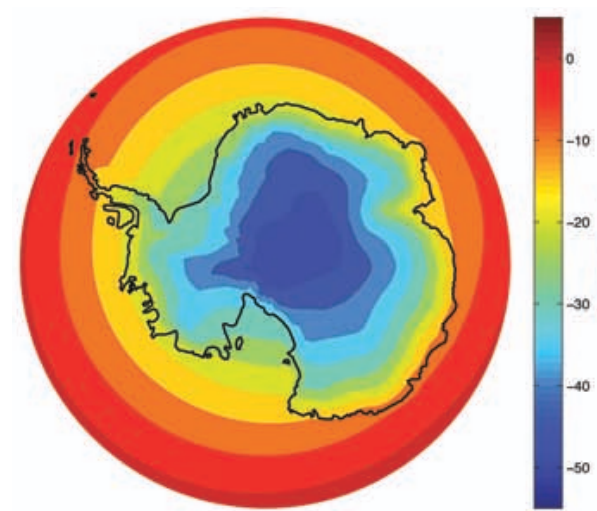

(a) Simulated AIS annual SAT

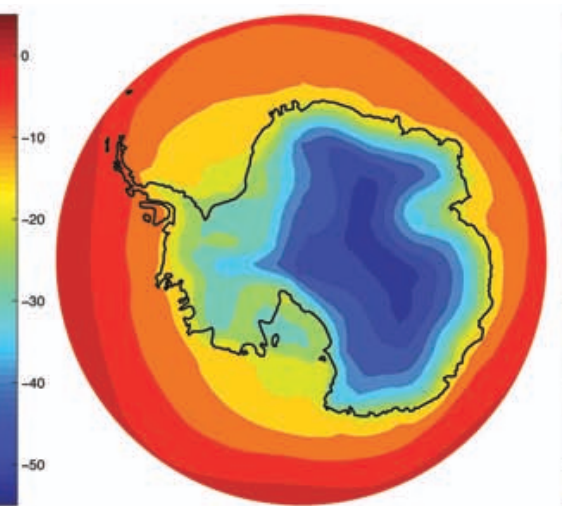

(b) ERA40 AIS annual SAT

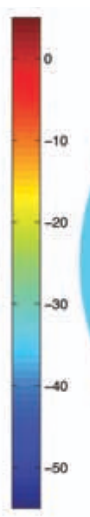

(1)

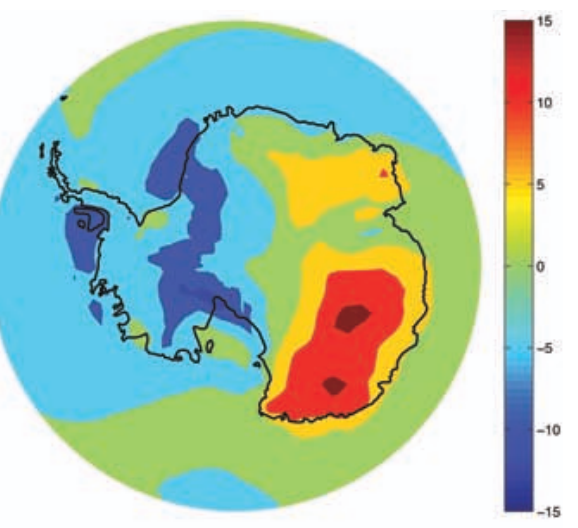

(c) Model-ERA40 GIS annual SAT

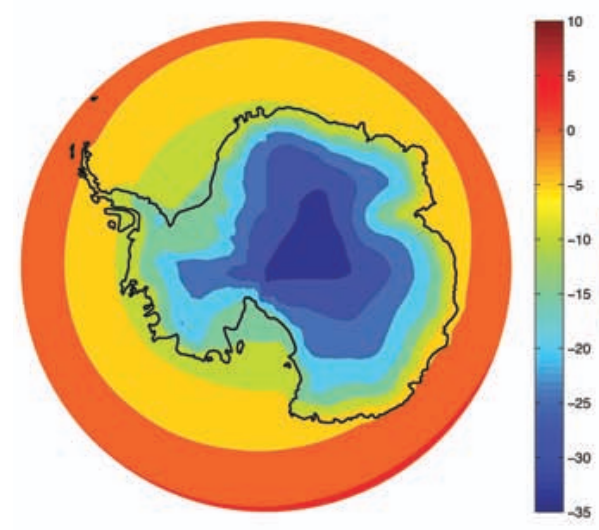

(d) Simulated AIS DJF SAT

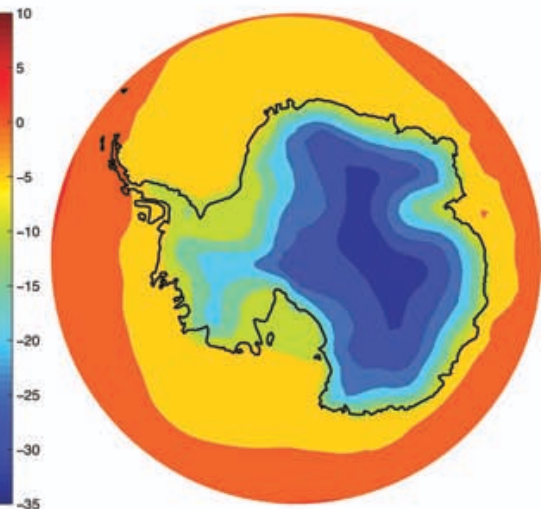

(e) ERA40 AIS DJF SAT

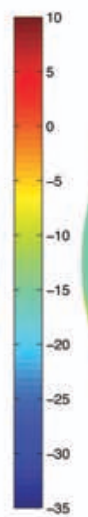

(f)

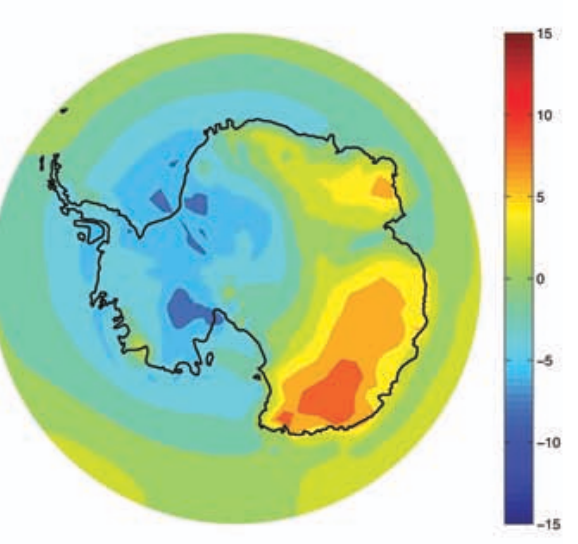

(f) Model-ERA40 AIS DJF SAT

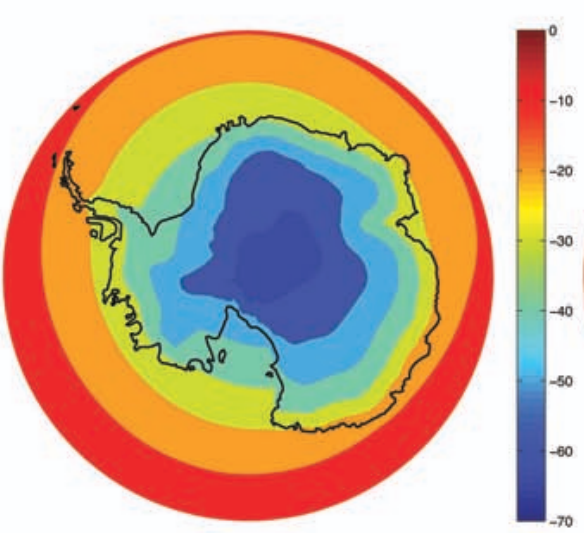

(g) Simulated AIS JJA SAT

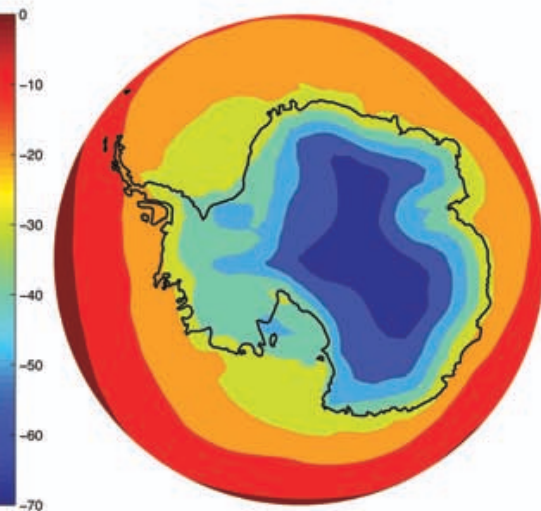

(h) ERA40 AIS JJA SAT

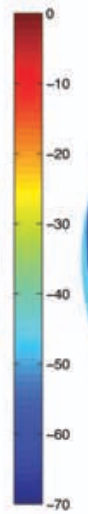

(i) Model-ERA40 AIS JJA SAT

Fig. 7. Simulated/ERA40 1970-2001 annual, June-July-August (JJA, Austral winter) and December-January-February (DJF, Austral summer) average SAT over the Antarctic Ice Sheet $\left({ }^{\circ} \mathrm{C}\right)$. Note the different color scales for each seasonal average.

biases, but still experiences warm biases of up to $10^{\circ} \mathrm{C}$ locally on the southeast coast. However, despite their magnitude, the wintertime biases over the AIS and GIS are unlikely to play a significant role in the SMB (Stone et al., 2010) as they are not large enough to drive the modelled SAT to the melt point. In contrast, summer-time biases have the ability to affect melt season length, melt magnitude (through both direct sensible heat flux and the impact of SAT on albedo) and the determination of whether precipitation falls as rain or snow. The general distribution of summer biases over the AIS is similar to the winter but with a much reduced range, from $-6^{\circ} \mathrm{C}$ over the WAIS to locally $+8^{\circ}$ in Wilkes Land. 


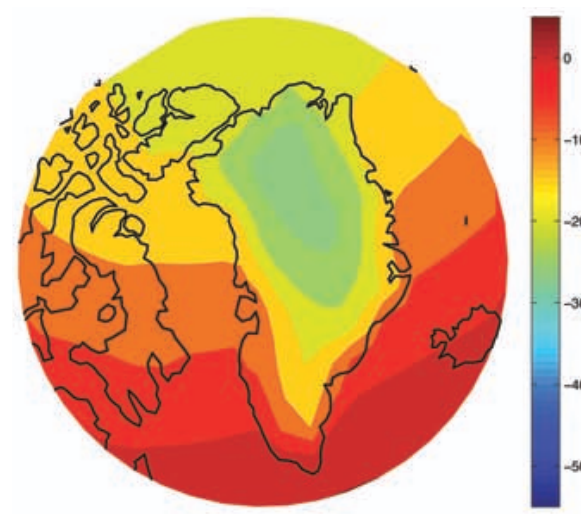

(a) Simulated GIS annual SAT

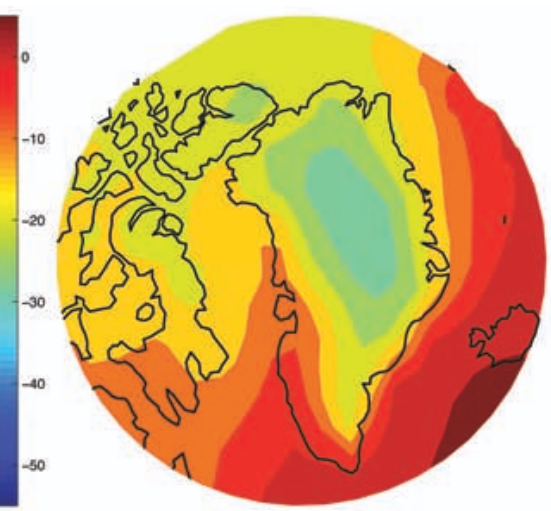

(b) ERA40 GIS SAT

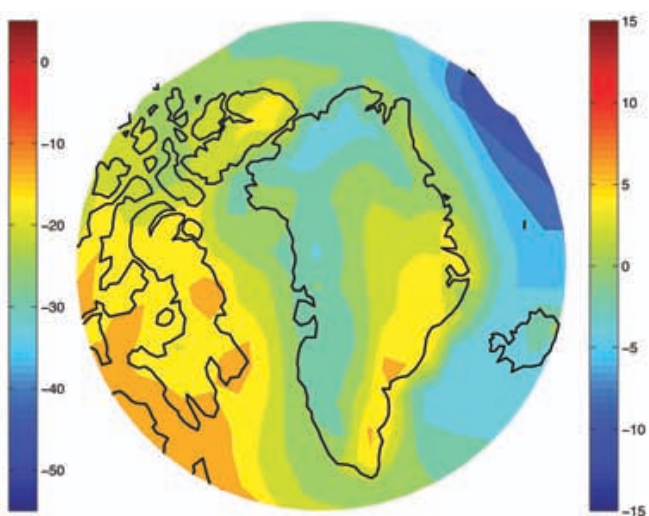

(c) Model-ERA40 GIS annual SAT

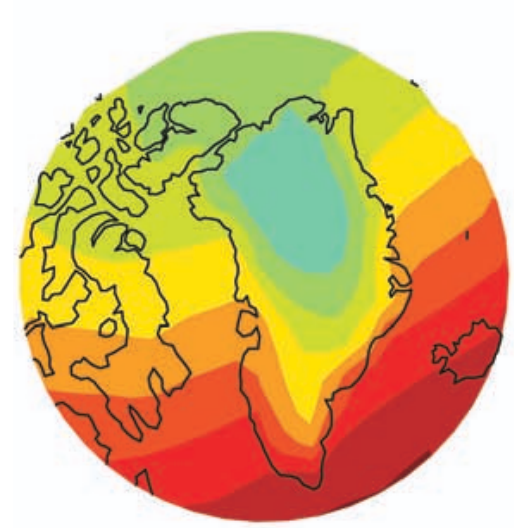

(d) Simulated GIS DJF SAT

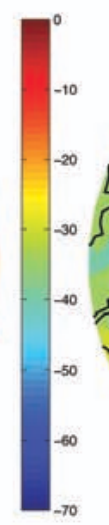

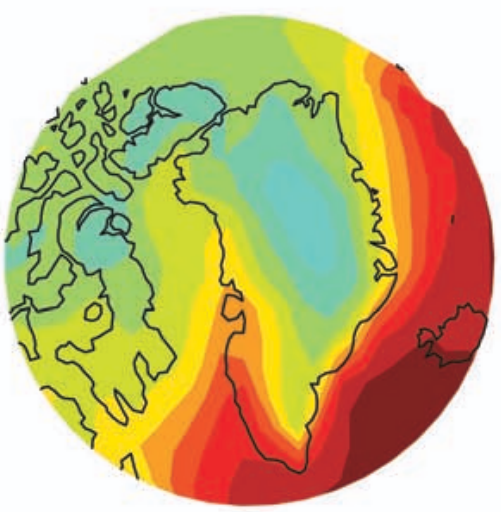

(e) ERA40 GIS DJF SAT

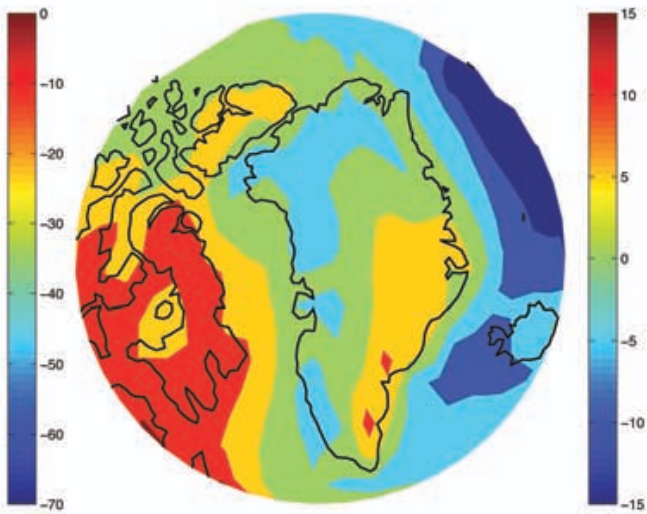

(f) Model-ERA40 GIS DJF SAT

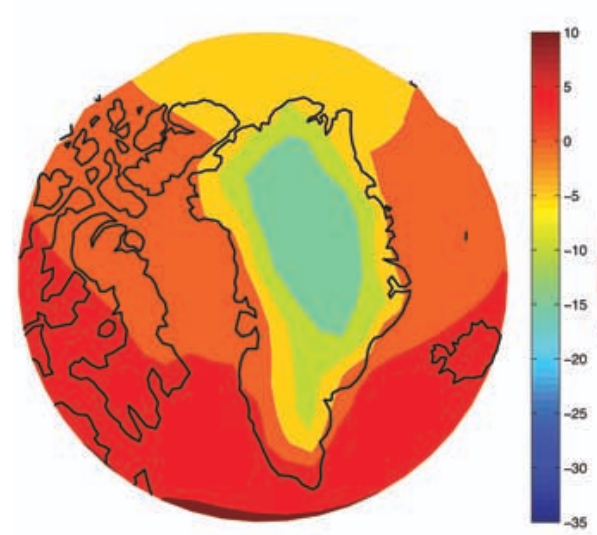

(g) Simulated GIS JJA SAT

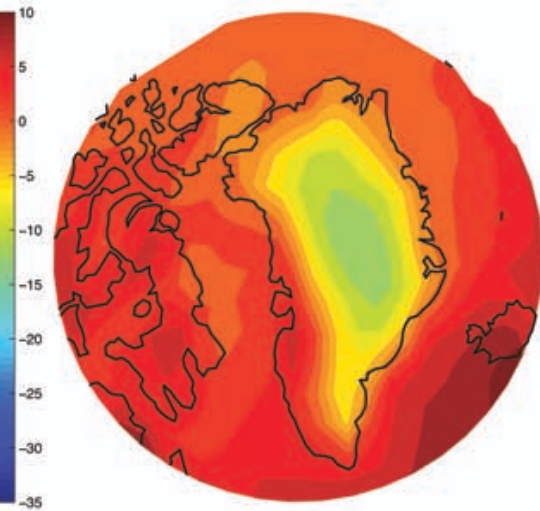

(h) ERA40 GIS JJA SAT

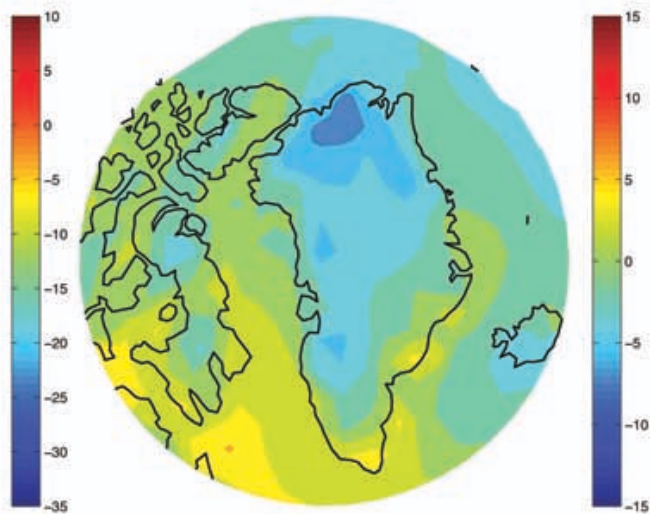

(i) Model-ERA40 GIS JJA SAT

Fig. 8. Simulated/ERA40 1970-2001 annual, June-July-August (JJA) and December-January-February (DJF) average SAT over the Greenland Ice Sheet $\left({ }^{\circ} \mathrm{C}\right)$. Note the different color scales for each seasonal average.

SAT biases over the GIS exhibit a general increasing northwest trend with maximum biases of up to $-6^{\circ} \mathrm{C}$ over the central northern ice sheet and along the west coast.

The following sections describe the results of the NBC simulations, in comparison with the control simulations.

\subsubsection{Late Holocene sensitivity to model bias}

The total ice volume of the AIS in the late Holocene NBC simulation (Fig. 4b) decreased to $28.2 \times 10^{6} \mathrm{~km}^{3}$, closer to the observed AIS volume. Despite lack of a bias correction, no additional ablation zones appeared, as the biases over the 
AIS were too small to push the SAT over the freezing point in the late Holocene climate. The majority of the ice was lost over the central EAIS, indicating that the large scale atmospheric moisture transport was affected by the temperaturebased bias correction over the AIS.

In contrast to the AIS, the total ice volume of the NBC late Holocene GIS increased relative to the control late Holocene ice sheet, stabilizing at $3.59 \times 10^{6} \mathrm{~km}^{3}$ (Fig. 5b). The majority of the additional ice volume formed at the northern margin, where the UVic ESCM exhibited a cold summertime bias of up to $6^{\circ} \mathrm{C}$. Neglect of this bias was sufficient to tip the region into a net accumulation zone, allowing ice to expand to the coastlines everywhere and highlighted the fine balance between the simulated accumulation and ablation along the northern GIS margin in the model.

\subsubsection{LGM sensitivity to model bias}

The NBC LGM AIS ice volume decreased compared to the control LGM AIS volume, to $38.1 \times 10^{6} \mathrm{~km}^{3}$ (Fig. 4f). As with the late Holocene non-bias-corrected simulation, ice loss was concentrated over the central EAIS, again suggesting a temperature-bias-related control on large-scale atmospheric moisture transport.

The GIS ice volume in the NBC LGM simulation (Fig. 5f) equilibrated at $3.66 \times 10^{6} \mathrm{~km}^{3}$, a volume almost identical to that of the bias-corrected control simulation. As in that simulation, the margins reached the regressed coastline everywhere. In contrast to the late Holocene climate, neglect of the northern GIS cold bias did not affect ice volume as temperatures in both the control and NBC models were sufficiently low to avoid threshold melt behaviour.

\subsubsection{Eemian sensitivity to model bias}

The AIS in the NBC Eemian simulation (Fig. 4j) responded similarly to the late Holocene NBC AIS, equilibrating at a volume of $28 \times 10 \times 10^{6} \mathrm{~km}^{3}$. Once more the ice volume loss was concentrated over the EAIS, implying a change to the atmospheric moisture transport field.

The NBC GIS (Fig. 5j) diverged strongly from the control Eemian GIS simulation. Whereas the northern margin of the control GIS retreated, generating $3 \mathrm{~m}$ of sea level rise, the northern margin of the NBC GIS remained stable and the total volume of $3.59 \times 10^{6} \mathrm{~km}^{3}$ was maintained. As with the late Holocene NBC model, northern GIS accumulation in the Eemian NBC model exceeded ablation, which was artificially weakened due to the cold model bias, such that the GIS contribution to Eemian SLR in this simulation was negligible.

\subsection{Ice sheet evolution sensitivity to meltwater retention and refreezing}

Meltwater retention and refreezing is expected to be more important in regions of high melt over existing snowpack, and in general in simulations in which more melt is available to be refrozen. It is also likely to dampen the response of ice sheets to transient climate change forcing (Bougamont et al., 2007). In order to test the effect of refreezing on long-term ice sheet evolution within the coupled model we compared Eemian, LGM and late Holocene simulations with meltwater retention and refreezing neglected (here called the NMRR simulations) to the control simulations with the refreezing parameterization enabled.

\subsubsection{Late Holocene}

The late Holocene AIS in the NMRR simulation (Fig. 4c) displayed a small response to the removal of the refreezing process due to the lack of significant surface melting, but still exhibited perceptible changes, largely over the Antarctic Peninsula ice shelves, but also over the Ronne and to a lesser extent Ross ice shelves, where ephemeral surface runoff in the model resulted in marginally thinner shelves and correspondingly thinner sheets near the grounding lines.

In contrast, the northern and (to a lesser extent) central western GIS margins in the late Holocene NMRR simulation retreated noticeably compared to the control simulation (Fig. 5c). This change, and associated slight inland thinning, resulted in a late Holocene NMRR GIS volume of $30.9 \times 10^{6} \mathrm{~km}^{3}$ and a smaller surface area. As expected, retreat relative to the control simulation occurred in regions where neglect of the refreezing process enhanced annual runoff of surface meltwater.

\subsubsection{LGM}

Neither the LGM AIS nor the GIS (Figs. 4g and 5g) were significantly affected when refreezing was not resolved, compared to the control LGM simulation. Given that the refreezing process is activated by melting, this result is expected, because melt extent and ablation were negligible over both ice sheets in both simulations.

\subsubsection{Eemian}

As with the late Holocene and LGM NMRR simulations, the AIS was not significantly affected due to a lack of sustained surface melting anywhere on the continent in the Eemian climate (Fig. 4k).

In contrast to the LGM simulations, the NMRR Eemian GIS (Fig. 5k) differed strongly from the Eemian control simulation, underlining the importance of resolving refreezing when simulating warmer climate states. The equilibrium Eemian GIS with refreezing neglected was $31 \%$ smaller than the control Eemian simulation with refreezing enabled, equilibrating at $1.51 \times 10^{6} \mathrm{~km}^{3}$. Additional ice loss, compared to the control run with refreezing enabled, occurred mainly along the northern margin, where the NMRR model generated substantially more runoff than the control simulation. The SLR generated from the NMRR model (relative to the 
late Holocene NMRR simulation) was $4.1 \mathrm{~m}$, probably an overestimate.

\subsection{Ice sheet evolution sensitivity to surface albedo}

Warm snow rapidly becomes less reflective, lowering the surface albedo and absorbing additional incoming radiation in an important positive ice-albedo feedback loop (van de Wal and Oerlemans, 1994) that can be simulated within the coupled model. In order to test the strength of the temperaturederived surface albedo feedback within the coupled model we compared a set of simulations with cold, warm, and bare glacial ice albedos set to the cold-snow value of 0.8 (here called the "constant albedo" or CA simulations) to the control simulations in which albedo varied as a function of surface snow/ice melt. Note that as the ice retreated, the surface land albedo reverted to a value typical of tundra. This neglects the effect of boreal forest invasion of ice-free regions, which would reduce the albedo further and enhance the icealbedo feedback. However, the runs presented here, with the possible exception of the Eemian GIS, do not retreat enough for this effect to be significant.

\subsubsection{Late Holocene}

The AIS in the CA late Holocene simulation (Fig. 4d) did not change volume or geometry appreciably compared to the control simulation, reflecting the fact that albedo over the AIS is rarely affected by melting conditions, minimizing the effect of the temperature-dependent ice albedo feedback. However, with consistently high albedos, the CA late Holocene GIS simulation (Fig. 5d) grew dramatically compared to the control simulation with the variable albedo scheme, reaching a volume of $3.75 \times 10 \times 10^{6} \mathrm{~km}^{3}$ (higher than the control LGM GIS volume). This indicates that the temperature-dependent ice albedo feedback plays a strong role in determining GIS geometry in the model by enhancing melt along the coastal ablation zones and above-equilibriumline-altitude (ELA) melt regions. The difference between the two ice sheets is indicative of the threshold nature of the temperature-dependent ice-albedo effect: when temperatures are largely below freezing (e.g., the AIS), melt and melt-derived ice exposure cannot occur, but if temperatures rise even slightly above the freezing point, the ice-albedo effect rapidly becomes a dominant factor in the overall SMB.

\subsubsection{LGM}

As with the late Holocene CA simulation, the AIS (Fig. 4h) was not strongly affected by the imposition of constantly high snow/ice albedo compared to the control LGM simulation, due to the lack of significant ablation or melt zones. Similarly, the GIS volume (Fig. 5h) remained the same as in the CA late Holocene simulation (in contrast to the variation in ice volume simulated in the late Holocene/LGM control simulations).

\subsubsection{Eemian}

The CA Eemian simulation AIS (Fig. 41) did not respond significantly to imposition of constantly high albedos in the Eemian climate. In contrast, removal of the ice-albedo feedback over the Eemian GIS (Fig. 51) resulted in a large change in ice volume compared to the control simulation GIS. When albedos were held constant, the resulting lack of additional ice loss was sufficient to keep the GIS at a near-late Holocene volume of $3.45 \times 10^{6} \mathrm{~km}^{3}$, contained in an area only slightly smaller than the CA late Holocene ice area $\left(1.92 \times 10^{6} \mathrm{~km}^{2}\right)$. The GIS contribution to the Eemian sea level high-stand in this simulation, compared to the late Holocene CA simulation, was $1 \mathrm{~m}$.

\subsection{Modern transient simulation}

In order to explore the ability of the coupled model control configuration to capture present-day SMB conditions over the GIS and AIS, we carried out a 200 year transient simulation ending at the present day, initialized from the equilibrium late Holocene simulation. The simulation was forced with transient $\mathrm{CO}_{2}$ and orbital forcings. In this simulation the bias correction procedure, variable albedo, and refreezing were all enabled.

At year 1850 SMB over the AIS in this simulation was $22.2 \times 10^{14} \mathrm{~kg} \mathrm{yr}^{-1}$. Between years 1850 and 2010 , the AIS SMB increased to $23.5 \times 10^{14} \mathrm{~kg} \mathrm{yr}^{-1}$. This SMB increase was primarily a function of increased accumulation resulting from the increased moisture-carrying capacity of warmer air as a consequence of the Clausius-Clapeyron relation (Weaver et al., 1998), a result that is common to other AIS SMB modelling studies (e.g., Krinner et al., 2007). As expected, despite increases in SAT, AIS temperatures were still generally well below $0{ }^{\circ} \mathrm{C}$ at year 2010 , limiting the contribution of ablation to the overall SMB. The final value for modern SMB was approximately 7\% lower than the 1980-2004 average SMB of van de Berg et al. (2006) and $11 \%$ higher than the 1980-2000 average AIS SMB value of Krinner et al. (2007). Additionally, the modelled AIS SMB range and spatial distribution were similar to the ranges and distributions of van de Berg et al. (2006) and Krinner et al. (2007) (Fig. 9a). Accumulation increased from extremely low positive values over the continental EAIS to maximum values of up to $500 \mathrm{~kg} \mathrm{~m}^{-2} \mathrm{yr}^{-1}$ on the coastal flanks of the EAIS and over the Antarctic Peninsula. Despite the subgridded approach to SMB calculation, relics of the overlying EMBM grid remained in the high-resolution SMB field, and due to the simplified nature of the EMBM accumulation patterns associated with local microclimates were not resolved. At year 2010 simulated ice ablation was limited to Antarctic Peninsula ice shelves and the northern extremity of the simulated Ronne Ice Shelf. Much of the simulated interior of the Ronne Ice Shelf began to experience minor surface melting, but this melt was almost completely refrozen. Overall AIS 


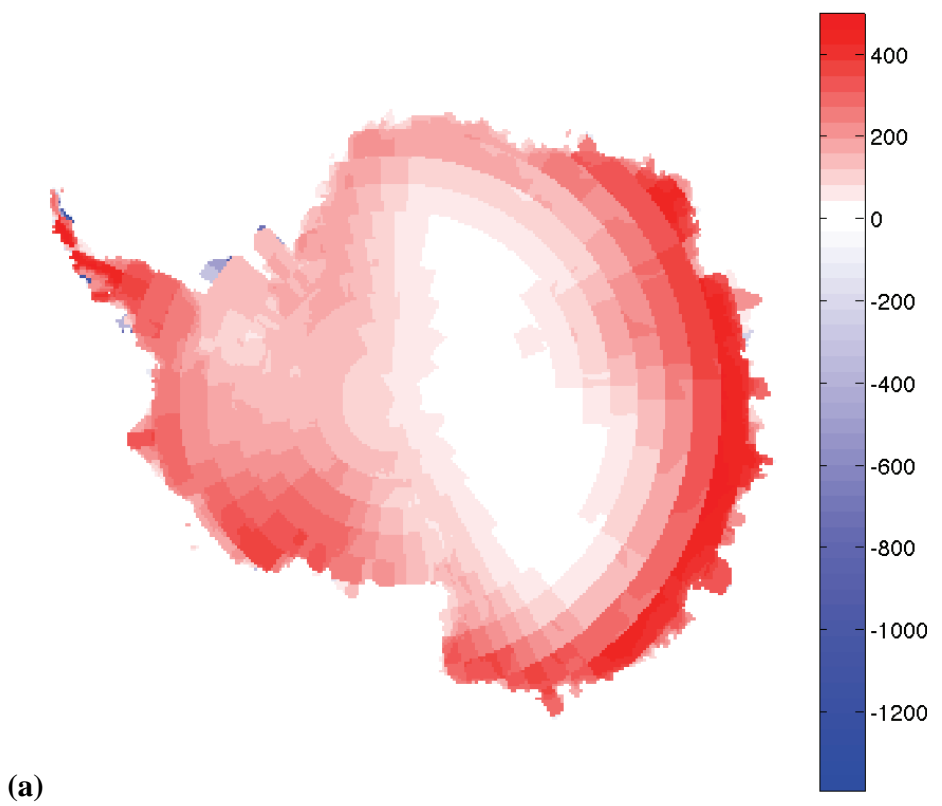

(b)

Fig. 9. Modern SMB over the AIS and GIS ( $\mathrm{kg} \mathrm{m}^{-2} \mathrm{yr}^{-1}$ ), averaged from 2000 to 2010. Black line represents equilibrium line.

melt extent by year 2010 was $6.99 \times 10 \times 10^{5} \mathrm{~km}^{2}$, within the range of the 1987-2008 annual average melt extent derived from Special Sensor Microwave Imager radiometer data (Tedesco, 2008). Due to the present lack of interactive ocean-ice shelf coupling, recent Antarctic mass loss attributed largely to oceanic thermal forcing of ice shelves (Payne et al., 2004; Rignot et al., 2008) was not resolved.

Late Holocene simulated SMB over the GIS was $4.70 \times$ $10^{14} \mathrm{~kg} \mathrm{yr}^{-1}$. Between years 1850 and 2010, accumulation over the GIS increased due to increased atmospheric moisture transport and ablation rose as temperatures warmed. These trends are common to other GIS SMB studies (Alley et al., 2007) and expected in an initially warming climate. The superposition of the competing processes led to an overall SMB that did not change appreciably throughout the simulation period, in contrast with observations and other modelling efforts, which show lower total GIS SMB values, and indicate that either modern GIS SMB is being primarily driven by decadal-scale climate variability, which the model does not resolve, or that the initial model response to imposed increases in $\mathrm{CO}_{2}$ at high latitudes is too low. Our modern SMB value was very similar to the modelled 1958-2007 SMB of Ettema et al. (2009), which is itself notably higher than previous estimates (e.g., Box et al., 2004). The broad pattern and magnitude of GIS SMB over the GIS (Fig. 9b) corresponded to the general pattern recognized by other modelling and observational studies Ettema et al. (2009); Burgess et al. (2010). Accumulation decreased from south to north, with the highest SMB (approximately $980 \mathrm{~kg} \mathrm{~m}^{-2} \mathrm{yr}^{-1}$ ) simulated on the south dome and the lowest values (in the absence of ablation) occurring in the central northern GIS. The model also simulated an in- crease in accumulation along the northwest coast that was captured by Ettema et al. (2009); Burgess et al. (2010), although the magnitude of the SMB gradient between the dry interior and the west coast was much less than these studies. The accumulation pattern over south-central/southeast Greenland was anomalously high/low and the south dome accumulation maximum displays a structure that is clearly a relic of the overlying EMBM atmosphere. These observations indicate that the atmospheric model has difficulty capturing the proper small-scale pattern of accumulation here, an issue also noted by Robinson et al. (2009). Simulated ablation accurately captured both the magnitude and distribution of observed GIS melt regions. In particular, high melt (up to $2300 \mathrm{~kg} \mathrm{~m}^{-2} \mathrm{yr}^{-1}$ ) was simulated in the central western margin and along the north coast. A narrow ablation zone was also resolved along the northeast coast. Over the 2000-2010 period, simulated ablation zones covered $4.81 \%$ of the GIS ice area, lower than the $10 \%$ coverage modelled by Ettema et al. (2009). 18.4\% of the GIS surface experienced surface melting. The modelled GIS melt extent area $\left(3.64 \times 10 \times 10^{5} \mathrm{~km}^{2}\right)$ was roughly $27 \%$ lower than the $1978-$ 2007 average melt extent obtained by passive microwave data (Fettweis et al., 2007) but within the range of observed values. As with the AIS, the lack of interactive ocean forcing meant that recent dynamically-driven changes to ice volume due to ocean forcing (Holland et al., 2008b) were not resolved.

Comparison of the final state of this simulation with a control equilibrium simulation forced with constant year 2000 $\mathrm{CO}_{2}$ and orbital conditions gives an indication of the simulated disequilibrium between the present-day ice sheets and present-day climate forcing. The control modern day AIS 
did not differ appreciably from the final state of the transient simulation. However, the GIS ice volume in the modern equilibrium simulation diminished noticeably, resulting in an equivalent SLR of approximately $1.1 \mathrm{~m}$. This result indicates that response of the modelled GIS to $\mathrm{CO}_{2}$ increases such as those associated with current trends is significant but delayed in time, relative to observations.

\section{Conclusions}

A new coupled model ice sheet/climate model has been constructed, consisting of the University of Victoria Earth System Climate and the Pennsylvania State University Ice Sheet models. The two models are coupled across the ice-atmosphere interface using an energy/moisture balance model on subgrid elevation bins that can correct for model surface air temperature bias. Precipitation is delivered to the ice sheets by the overlying vertically integrated, advective/diffusive atmosphere model. Moisture and heat fluxes are routed to the atmosphere and ocean, respectively. Ice shelves shade the underlying ocean from heat and moisture fluxes. The ocean receives heat and moisture fluxes from basal shelf melting and calving. Basal melting is currently prescribed in lieu of a parameterized temperature-dependent coupling. After each timestep the ice sheets return an updated ice-sheet/ice-shelf geometry to the climate model. The overall system is designed to conserve heat and moisture to machine precision. Multiple independent ice sheet model grids within a global climate simulation are made possible through use of Fortran derived data types and pointers. The model can run in "synchronous", "asynchronous", or "synchronous accelerated" modes depending on the length and character of the simulation. The current coupled model is set up to simulate the Antarctic and Greenland Ice Sheets (AIS/GIS) at $20 \mathrm{~km}$ resolution within a global climate simulation.

The model was run to equilibrium under Eemian, LGM and late Holocene conditions to test the sensitivity of the simulated ice evolution to surface albedo feedback, refreezing, and modelled seasonal SAT biases. Sensitivity of the final equilibrium ice volumes to these aspects of model physics increased in warmer climates, as they are threshold processes that are activated when the surface temperature rises above freezing. Conversely, cold AIS and GIS climates are less sensitive to variations in treatments of surface albedo, temperature biases, and refreezing. The difference in the changes to ice sheet volumes under different forcing scenarios indicates that perturbations to the model physics can affect not only the equilibrium ice volume and ice geometry but the change in volume and geometry under transient forcing scenarios. This is primarily due to the strong non-linear behavior of ice sheets in the vicinity of the freezing point.

The control simulation is able to reasonably simulate the Eemian, LGM and late Holocene ice sheets, albeit with a overestimate of late Holocene ice volume. As the modern SMB distribution and total fluxes over both ice sheets generally agree well with recent detailed model studies, the overestimation of ice volume is perhaps due to incomplete representation of ice discharge through ice streams. The response of the coupled ice sheets to LGM and Eemian climates is similar to previous modelling and observations in terms of total ice volume and area, and suggests that the model responds reasonably to imposed forcings. The modelled modern AIS/GIS is/is not in equilibrium with boundary climatic forcings, and a substantial contribution to SLR from the GIS is obtained when the model is run to equilibrium with constant present-day forcings.

The lack of significant AIS change to SMB over all the climate scenarios strongly suggests that oceans are the prime control on AIS volume, and that past and future coupled model simulations of AIS response to climate require an interactive coupling between ice shelves and ocean. The model represents an ideal platform with which to test ocean-ice coupling parameterizations. More work (ideally, a transient simulation through the Eemian) is needed to constrain locations of GIS Eemian ice loss and identify the interglacial that resulted in an ice-free Dye-3 location. The magnitude of the GIS contribution to SLR generated by this study agrees with the equilibrium simulations of Cuffey and Marshall (2000) and Otto-Bliesner et al. (2006) but the location of ice loss disagrees sharply, with loss in the present study coming from the northern GIS ablation zone.

Acknowledgements. JF wishes to thank Edward Wiebe for extensive technical support, Bill Lipscomb for valuable coupling advice and discussions, and Janneke Ettema and David Vaughan for supplying SMB datasets for comparison.

Edited by: B. L. Otto-Bliesner

\section{References}

Alley, R., Spencer, M., and Anandakrishnan, S.: Ice-sheet mass balance: assessment, attribution and prognosis, Ann. Glaciol., 46, 1-7, 2007.

Bamber, J. L., Layberry, R. L., and Gogineni, S.: A new ice thickness and bed data set for the Greenland Ice Sheet 1: Measurement, data reduction, and errors, J. Geophys. Res., 106, 3377333780, 2001.

Bonelli, S., Charbit, S., Kageyama, M., Woillez, M.-N., Ramstein, G., Dumas, C., and Quiquet, A.: Investigating the evolution of major Northern Hemisphere ice sheets during the last glacialinterglacial cycle, Clim. Past, 5, 329-345, doi:10.5194/cp-5-3292009, 2009.

Bougamont, M., Bamber, J., and Greuell, W.: A surface mass balance model for the Greenland Ice Sheet, J. Geophys. Res., 110, F04018, doi:10.1029/2005JF000348, 2005.

Bougamont, M., Hunke, E., and Tulaczyk, S.: Sensitivity of ocean circulation and sea-ice conditions to loss of West Antarctic ice shelves and ice sheet, J. Glaciol., 53, 490-498, 2007. 
Box, J., Bromwich, D., and Bai, L.-S.: Greenland Ice Sheet surface mass balance 1991-2000: application of Polar MM5 mesoscale model and in situ data, J. Geophys. Res., 109, D16105, doi:10.1029/2003JD004451, 2004.

Box, J., Bromwich, D., Veenhuis, B., Bai, L.-S., Wang, S.-H., Stroeve, J., Haran, T., Rogers, J., and Steffen, K.: Greenland Ice Sheet surface mass balance variability (1988-2004) from calibrated polar MM5 output, J. Climate, 19, 2783-2800, doi:10.1175/JCLI3738.1, 2006.

Burgess, E., Forster, R., Box, J., Mosley-Thompson, E., Bromwich, D., Bales, R., and Smith, L.: A spatially calibrated model of annual accumulation rate on the Greenland Ice Sheet (1958-2007), J. Geophys. Res., 115, F02004, doi:10.1029/2009JF001293, 2010.

Calov, R., Ganopolski, A., Kubatzki, C., and Claussen, M.: Mechanisms and time scales of glacial inception simulated with an Earth system model of intermediate complexity, Clim. Past, 5, 245-258, doi:10.5194/cp-5-245-2009, 2009.

Charbit, S., Paillard, D., and Ramstein, G.: Amount of $\mathrm{CO}_{2}$ emissions irreversibly leading to the total melting of Greenland, Geophys. Res. Lett., 35, L12503, doi:10.1029/2008GL033472, 2008.

Cuffey, K. and Marshall, S.: Substantial contribution to sea-level rise during the last interglacial from the Greenland Ice Sheet, Nature, 404, 591-594, doi:10.1038/35007053, 2000.

Denton, G. and Hughes, T.: Reconstructing the Antarctic Ice Sheet at the Last Glacial Maximum, Quaternary Sci. Rev., 21, 193202, doi:10.1016/S0277-3791(01)00090-7, 2002.

de Vernal, A. and Hillaire-Marcel, C.: Natural variability of Greenland climate, vegetation, and ice volume during the past million years, Science, 320, 1622-1625, doi:10.1126/science.1153929, 2008.

Driesschaert, E., Fichefet, T., Goosse, H., Huybrechts, P., Janssens, I., Mouchet, A., Munhoven, G., Brovkin, V., and Weber, S. L.: Modeling the influence of Greenland Ice Sheet melting on the Atlantic meridional overturning circulation during the next millennia, Geophys. Res. Lett., 34, L10707, doi:10.1029/2007GL029516, 2007.

Eby, M., Zickfeld, M., Montenegro, A., Archer, D., Meissner, K., and Weaver, A.: Lifetime of anthropogenic climate change: Millennial timescales of potential $\mathrm{CO}_{2}$ and surface temperature perturbations, J. Climate, 22, 2501-2511, 2009.

Ettema, J., van den Broeke, M., van Meijgaard, E., van de Berg, W. J., Bamber, J., Box, J., and Bales, R.: Higher surface mass balance of the Greenland Ice Sheet revealed by highresolution climate modeling, Geophys. Res. Lett., 36, L12501, doi:10.1029/2009GL038110, 2009.

Fausto, R., Ahlstrøm, A., As, D. V., Bøggild, C., and Johnsen, S.: A new present-day temperature parameterization for Greenland, J. Glaciol., 55, 95-105, doi:10.3189/002214309788608985, 2009.

Fettweis, X., van Ypersele, J.-P., Gallée, H., Lefebre, F., and Lefebvre, W.: The 1979-2005 Greenland Ice Sheet melt extent from passive microwave data using an improved version of the melt retrieval XPGR algorithm, Geophys. Res. Lett., 34, L05502, doi:10.1029/2006GL028787, 2007.

Greve, R., Saito, F., and Abe-Ouchi, A.: Initial results of the SeaRISE numerical experiments with the models SICOPOLIS and IcIES for the Greenland ice sheet, Ann. Glaciol., 52, 23-30, 2011.
Holland, P., Jenkins, A., and Holland, D.: The nonlinear response of ice-shelf basal melting to variation in ocean temperature, J. Climate, 1151, 2558-2572, doi:10.1175/2007JCLI1909.1, 2008a.

Holland, D., Thomas, R., Young, B., Ribergaard, M., and Lybert, B.: Acceleration of Jakobshavn Isbrae triggered by warm subsurface ocean waters, Nat. Geosci., 1, 659-664, doi:10.1038/ngeo316, 2008b.

Indermühle, A., Monnin, E., Stauffer, B., Stocker, T., and Wahlen, M.: Atmospheric $\mathrm{CO}_{2}$ concentration from 60 to $20 \mathrm{kyr}$ BP from the Taylor Dome Ice Core, Antarctica, Geophys. Res. Lett., 27, 735-738, doi:10.1029/1999GL010960, 2002.

Kageyama, M., Charbit, S., Ritz, C., and Khodri, M.: Quantifying ice-sheet feedbacks during the last glacial inception, Geophys. Res. Lett., 31, L24203, doi:10.1029/2004GL021339, 2004.

Kalnay, E., Kanamitsu, M., Kistler, R., Collins, W., Deaven, D., Gandin, L., Iredell, M., Saha, S., White, G., Woollen, J., Zhu, Y., Leetmaa, A., Reynolds, B., Chelliah, M., Ebisuzaki, W., Higgins, W., Janowiak, J., Mo, K., Ropelewski, C., Wang, J., Jenne, R.,and Joseph, D.: The NCEP/NCAR 40-year reanalysis project, B. Am. Meteorol. Soc., 77, 437-471, 1996.

Krinner, G., Magand, O., Simmonds, I., Genthon, C., and Dufresne, J.-L.: Simulated Antarctic precipitation and surface mass balance at the end of the twentieth and twenty-first centuries, Clim. Dynam., 46, 215-230, doi:10.1007/s00382-0060177-x, 2007.

Lemke, P., Ren, J., Alley, R., Allison, I., Carrasco, J., Flato, G., Fujii, Y., Kaser, G., Mote, P., Thomas, R., and Zhang, T.: Observations: changes in snow, ice and frozen ground, in: Climate Change 2007: the Physical Science Basis. Contribution of Working Group I to the Fourth Assessment Report of the Intergovernmental Panel on Climate Change, edited by: Solomon, S., Qin, D., Manning, M., Chen, Z., Marquis, M., Avery, K., Tignor, M., and Miller, H., 337-383, Cambridge University Press, Cambridge, UK, 2007.

Lenaerts, J. T. M., van den Broeke, M. R., Déry, S. J., KönigLanglo, G., Ettema, J., and Munneke, P. K.: Modelling snowdrift sublimation on an Antarctic ice shelf, The Cryosphere, 4, 179-190, doi:10.5194/tc-4-179-2010, 2010.

Lythe, M. and Vaughan, D.: A new ice thickness and subglacial topographic model of Antarctica, J. Geophys. Res., 106, 1133511351, 2001.

Marshall, S. and Clarke, G.: A continuum mixture model of ice stream thermomechanics in the Laurentide Ice Sheet 1. Theory, J. Geophys. Res., 102, 20599-20613, 1997.

Meissner, K., Weaver, A., Matthews, H., and Cox, P.: The role of land surface dynamics in glacial inception: a study with the UVic Earth System Model, Clim. Dynam., 21, 515-537, doi:10.1007/s00382-003-0352-2, 2003.

Metcalf, M. and Reid, J.: FORTRAN 90/95 Explained, Oxford Univ. Press, Oxford, UK, 1999.

Meure, C., Etheridge, D., Trudinger, C., Steele, P., Langenfelds, R., van Ommen, T., Smith, A., and Elkins, J.: Law Dome $\mathrm{CO}_{2}, \mathrm{CH}_{4}$ and $\mathrm{N}_{2} \mathrm{O}$ ice core records extended to 2000 years BP, Geophys. Res. Lett., 33, L14810, doi:10.1029/2006GL026152, 2006.

Montenegro, A., Brovkin, V., Eby, M., Archer, D., and Weaver, A.: Long term fate of anthropogenic carbon, Geophys. Res. Lett., 34 , L19707, doi:10.1029/2007GL030905, 2007.

Naish, T., Powell, R., Levy, R., Wilson, G., Scherer, R., Talarico, F., Krissek, L., Niessen, F., Pompilio, M., Wilson, T., Carter, L., 
DeConto, R., Huybers, P., McKay, R., Pollard, D., Ross, J., Winter, D., Barrett, P., Browne, G., Cody, R., Cowan, E., Crampton, J., Dunbar, G., Dunbar, N., Florindo, F., Gebhardt, C., Graham, I., Hannah, M., Hansaraj, D., Harwood, D., Helling, D., Henrys, S., Hinnov, L., Kuhn, G., Kyle, P., Läufer, A., Maffioli, P., Magens, D., Mandernack, K., McIntosh, W., Millan, C., Morin, R., Ohneiser, C., Paulsen, T., Persico, D., Raine, I., Reed, J., Riesselman, C., Sagnotti, L., Schmitt, D., Sjunneskog, C., Strong, P., Taviani, M., Vogel, S., Wilch, T., and Williams, T.: Obliquity-paced Pliocene West Antarctic ice sheet oscillations, Nature, 458, 322-329, 10.1038/nature07867, 2009.

Nolin, A. and Payne, M.: Classification of glacier zones in western Greenland using albedo and surface roughness from the Multiangle Imaging SpectroRadiometer (MISR), Remote Sens. Environ., 107, 264-275, doi:10.1016/j.rse.2006.11.004, 2007.

Olbers, D. and Hellmer, H.: A box model of circulation and melting in ice shelf caverns, Ocean Dynam., 60, 141-153, doi:10.1007/s10236-009-0252-z, 2009.

Otto-Bliesner, B., Marshall, S., Overpeck, J., Miller, G., Hu, A., and CAPE Last Interglacial Project members: Simulating Arctic climate warmth and icefield retreat in the last interglaciation, Science, 311, 1751-1753, doi:10.1126/science.1120808, 2006.

Overpeck, J., Otto-Bliesner, B., Miller, G., Muhs, D., Alley, R., and Kiehl, J.: Paleoclimatic evidence for future ice-sheet instability and rapid sea-level rise, Science, 311, 1747-1750, doi:10.1126/science.1115159, 2006.

Pacanowski, R.: MOM 2 Documentation User's Guide and Reference Manual, GFDL Ocean Group Technical Report, NOAA/GFDL, Princeton, 1995.

Payne, A., Vieli, A., Shepherd, A., Wingham, D., and Rignot, E.: Recent dramatic thinning of largest West Antarctic ice stream triggered by oceans, Geophys. Res. Lett., 31, L23401, doi:10.1029/2004GL021284, 2004.

Petit, J., Jouzel, J., Raynaud, D., Barkov, N., Barnola, J.-M., Basile, I., Benders, M., Chappellaz, J., Davis, M., Delague, G., Delmotte, M., Kotlyakov, V., Legrand, M., Lipenkov, V., Lorius, C., Pépin, L., Ritz, C., Saltzman, E., and Stievenard, M.: Climate and atmospheric history of the past 420000 years from the Vostok ice core, Antarctica, Nature, 399, 429-436, doi:10.1038/20859, 1999.

Pfeffer, W., Meier, M., and Illangasekar, T.: Retention of Greenland runoff by refreezing: implications for projected future sea level change, J. Geophys. Res., 96, 22117-22124, 1991.

Pollard, D.: Comparisons of ice-sheet surface mass budgets from Paleoclimate Modeling Intercomparison Project (PMIP) simulations, Global Planet. Change, 24, 79-106, doi:10.1016/S09218181(99)00071-5, 2000.

Pollard, D.: A retrospective look at coupled ice sheet - climate modeling, Climatic Change, 100, 173-194, doi:10.1007/s10584-0109830-9, 2010.

Pollard, D. and DeConto, R.: A coupled ice-sheet/iceshelf/sediment model applied to a marine-margin flowline: forced and unforced variations, in: Glacial Sedimentary Processes and Products, edited by: Hambrey, M., Christoffersen, P., Glasser, N., and Hubbard, B., Wiley-Blackwell, New Jersey, 37-52, 2007.

Pollard, D. and DeConto, R.: Modelling West Antarctic Ice Sheet growth and collapse through the past five million years, Nature, 458, 329-332, doi:10.1038/nature07809, 2009.
Pritchard, M., Bush, A., and Marshall, S.: Neglecting iceatmosphere interactions underestimates ice sheet melt in millennial-scale deglaciation simulations, Geophys. Res. Lett., 35, L01503, doi:10.1029/2007GL031738, 2008a.

Pritchard, M., Bush, B., and Marshall, S.: Interannual atmospheric variability affects continental ice sheet simulations on millennial time scales, J. Climate, 21, 5976-5992, doi:10.1175/2008JCLI2327.1, 2008b.

Ridley, J., Huybrechts, P., Gregory, J., and Lowe, J.: Elimination of the Greenland Ice Sheet in a high $\mathrm{CO}_{2}$ climate, J. Climate, 18, 3409-3427, doi:10.1175/JCLI3482.1, 2005.

Ridley, J., Gregory, J., Huybrechts, P., and Lowe, J.: Thresholds for irreversible decline of the Greenland Ice Sheet, Clim. Dynam., 35, 1065-1073, doi:10.1007/s00382-009-0646-0, 2010.

Rignot, E., Bamber, J., van den Broeke, M., Davis, C., Li, Y., van de Berg, W., and van Meijgaard, E.: Recent Antarctic ice mass loss from radar interferometry and regional climate modelling, Nat. Geosci., 1, 106-110, doi:10.1038/ngeo102, 2008.

Robinson, A., Calov, R., and Ganopolski, A.: An efficient regional energy-moisture balance model for simulation of the Greenland Ice Sheet response to climate change, The Cryosphere, 4, 129144, doi:10.5194/tc-4-129-2010, 2010.

Rutt, I., Hagdorn, M., Hulton, N., and Payne, A.: The Glimmer community ice sheet model, J. Geophys. Res., 114, F02004, doi:10.1029/2008JF001015, 2009.

Schmittner, A., Yoshimori, M., and Weaver, A.: Instability of glacial climate in a model of the ocean-atmosphere-cryosphere system, Science, 295, 1489-1493, doi:10.1126/science.1066174, 2002.

Schoof, C.: Ice sheet grounding line dynamics: Steady states, stability, and hysteresis, J. Geophys. Res., 112, F03S28, doi:10.1029/2006JF000664, 2007.

Spence, J., Eby, M., and Weaver, A.: The sensitivity of the Atlantic meridional overturning circulation to freshwater forcing at eddy-permitting resolutions, J. Climate, 21, 2697-2710, doi:10.1175/2007JCLI2103.1, 2008.

Stone, E. J., Lunt, D. J., Rutt, I. C., and Hanna, E.: Investigating the sensitivity of numerical model simulations of the modern state of the Greenland ice-sheet and its future response to climate change, The Cryosphere, 4, 397-417, doi:10.5194/tc-4-397-2010, 2010.

Tedesco, M.: Updated 2008 surface snowmelt trends in Antarctica, EOS, Transactions, 89, 126, 2008.

Uppala, S., Kållberg, P., Simmons, A., Andrae, U., Bechtold, V. D. C., Fiorino, M., Gibson, J., Haseler, J., Hernandez, A., Kelly, G., Li, X., Onogi, K., Saarinen, S., Sokka, N., Allan, R., Andersson, E., Arpe, K., Balmaseda, M., Beljaars, A., Berg, L. V. D., Bidlot, J., Bormann, N., Caires, S., Chevallier, F., Dethof, A., Dragosavac, M., Fisher, M., Fuentes, M., Hagemann, S., Holm, E., Hoskins, B., Isaksen, L., Janssen, P., Jenne, R., Mcnally, A., Mahfouf, J.-F., Morcrette, J.-J., Rayner, N., Saunders, R., Simon, P., Sterl, A., Trenberth, K., Untch, A., Vasiljevic, D., Viterbo, P., and Woollen, J.: The ERA-40 re-analysis, Q. J. Roy. Meteor. Soc., 131, 2961-3012, 10.1256/qj.04.176, 2006. van de Berg, W., van den Broeke, M., Reijmer, C., and van Meijgaard, E.: Reassessment of the Antarctic surface mass balance using calibrated output of a regional atmospheric climate model, J. Geophys. Res., 111, D11104, doi:10.1029/2005JD006495, 2006.

van de Wal, R. and Oerlemans, J.: An energy balance model for the 
Greenland Ice Sheet, Global Planet. Change, 9, 115-131, 1994. Vizcaíno, M., Mikolajewicz, U., Gröger, M., Maier-Reimer, E., Schurgers, G., and Winguth, A.: Long-term ice sheet/climate interactions under anthropogenic greenhouse forcing simulated with a complex Earth System Model, Clim. Dynam., 31, 665690, doi:10.1007/s00382-008-0369-7, 2008.

Vizcaíno, M., Mikolajewicz, U., Jungclaus, J., and Schurgers, G.: Climate modification by future ice sheet changes and consequences for ice sheet mass balance, Clim. Dynam., 43, 301-324, doi:10.1007/s00382-009-0591-y, 2010.

Weaver, A., Eby, M., Fanning, A., and Wiebe, E.: Simulated influence of carbon dioxide, orbital forcing and ice sheets on the climate of the last glacial maximum, Nature, 394, 847-853, doi:10.1038/29695, 1998.

Weaver, A., Eby, M., Weibe, E., Bitz, C., Duffy, P., Ewen, T., Fanning, A., Holland, M., MacFadyen, A., Matthews, H., Meissner, K., Saenko, O., Schmittner, A., Wang, H., and Yoshimori, M.: The UVic Earth System Climate Model: Model description, climatology and application to past, present and future climates, Atmos. Ocean, 39, 361-428, 2001.
Wild, M., Calanca, P., Scherrer, S., and Ohmura, A.: Effects of polar ice sheets on global sea level in highresolution greenhouse scenarios, J. Geophys. Res., 108, D54165, doi:10.1029/2002JD002451, 2003.

Willerslev, E., Cappellini, E., Boomsma, W., Nielsen, R., Hebsgaard, M., Brand, T., Hofreiter, M., Bunce, M., Poinar, H., DahlJensen, D., Johnsen, S., Steffensen, J., Bennike, O., Schwenninger, J.-L., Nathan, R., Armitage, S., de Hoog, C.-J., Alfimov, V., Christl, M., Beer, J., Muscheler, R., Barker, J., Sharp, M., Penkman, K., Haile, J., Taberlet, P., Gilbert, M., Casoli, A., Campani, E., and Collins, M.: Ancient biomolecules from deep ice cores reveal a forested southern Greenland, Science, 317, 111-114, 10.1126/science.1141758, 2007.

Yoshimori, M., Weaver, A., Marshall, S., and Clarke, G.: Glacial termination: sensitivity to orbital and $\mathrm{CO}_{2}$ forcing in a coupled climate system model, Clim. Dynam., 17, 571-588, doi:10.1007/s003820000134, 2001. 


\section{References}

Agassiz, L.: Études sur les glaciers, Neuchatel, 1840.

Alley, R., Spencer, M., and Anandakrishnan, S.: Ice-sheet mass balance: assessment, attribution and prognosis, Annals of Glaciology, 46, 1-7, 2007.

Alley, R., Andrews, J., Brigham-Grette, J., Clarke, G., Cuffey, K., Fitzpatrick, J., Funder, S., Marshall, S., Miller, G., Mitrovica, J., Muhs, D., Otto-Bliesner, B., Polyak, L., and White, J.: History of the Greenland Ice Sheet: paleoclimatic insights, Quaternary Science Reviews, 29, 17281756, doi:10.1016/j.quascirev.2010.02.007, 2010.

Archer, D. and Ganopolski, A.: A movable trigger: Fossil fuel $\mathrm{CO}_{2}$ and the onset of the next glaciation, Geochemistry Geophysics Geosystems, 6, doi:10.1029/2004GC000891, 2005.

Bamber, J., Riva, R., Vermeersen, B., and LeBrocq, A.: Reassessment of the potential sea-level rise from a collapse of the West Antarctic Ice Sheet, Science, 324, 901-903, doi:10.1126/science.1169335, 2009.

Bamber, J. L., Layberry, R. L., and Gogineni, S.: A new ice thickness and bed data set for the Greenland ice sheet 1: Measurement, data reduction, and errors, Journal of Geophysical Research, 106, 33 773-33 780, 2001.

Beckmann, A. and Goosse, H.: A parameterization of ice shelf/ocean in- 
teraction for climate models, Ocean Modelling, 5, 157-170, doi:10.1016/ S1463-5003(02)00019-7, 2003.

Berg, J. V. D., de Wal, R. V., and Oerlemans, J.: Effects of spatial discretization in ice-sheet modelling using the shallow-ice approximation, Journal of Glaciology, 52, 89-98, doi:10.3189/172756506781828935, 2006.

Berger, A. and Loutre, M.: Insolation values for the climate of the last 10 million years, Quaternary Science Reviews, 10, 97-317, 1991.

Berger, A. and Loutre, M.: An exceptionally long interglacial ahead?, Science, 297, 1287-1288, doi:10.1126/science.1076120, 2002.

Bo, S., Siegert, M., Mudd, S., Sugden, D., Fujita, S., Xiangbin, C., Yunyun, J., Xueyuan, T., and Yuansheng, L.: The Gamburtsev mountains and the origin and early evolution of the Antarctic Ice Sheet, Nature, 459, 690693, doi:10.1038/nature08024, 2009.

Bonelli, S., Charbit, S., Kageyama, M., Woillez, M.-N., Ramstein, G., Dumas, C., and Quiquet, A.: Investigating the evolution of major Northern Hemisphere ice sheets during the last glacial-interglacial cycle, Climate of the Past, 5, 329-345, doi:10.5194/cp-5-329-2009, 2009.

Bougamont, M., Bamber, J., and Greuell, W.: A surface mass balance model for the Greenland Ice Sheet, Journal of Geophysical Research, 110, F04 018, doi:10.1029/2005JF000348, 2005.

Bougamont, M., Hunke, E., and Tulaczyk, S.: Sensitivity of ocean circulation and sea-ice conditions to loss of West Antarctic ice shelves and ice sheet, Journal of Glaciology, 53, 490-498, 2007.

Box, J., Bromwich, D., and Bai, L.-S.: Greenland ice sheet surface mass balance 1991-2000: application of Polar MM5 mesoscale model and in situ data, Journal of Geophysical Research, 109, D16105, doi:10.1029/ 2003JD004451, 2004. 
Box, J., Bromwich, D., Veenhuis, B., Bai, L.-S., Wang, S.-H., Stroeve, J., Haran, T., Rogers, J., and Steffen, K.: Greenland ice sheet surface mass balance variability (1988-2004) from calibrated polar MM5 output, Journal of Climate, 19, 2783-2800, doi:10.1175/JCLI3738.1, 2006.

Braun, M., Humbert, A., and Moll, A.: Changes in the Wilkins Ice Shelf over the past 15 years and inferences on its stability, The Cryosphere, 3 , 41-56, 2009.

Broecker, W.: Massive iceberg discharges as triggers for global climate change, Nature, 372, 421-424, 1994.

Bromwich, D., Toracinta, E., Wei, H., Fastook, J., and Hughes, T.: Polar MM5 Simulations of the Winter Climate of the Laurentide Ice Sheet at the LGM, Journal of Climate, 17, 3415-3433, 2004.

Bromwich, D., Fogt, R., Hodges, K., and Walsh, J.: A tropospheric assessment of the ERA-40, NCEP, and JRA-25 global reanalyses in the polar regions, Journal of Geophysical Research, 112, D10111, doi:10.1029/ 2006JD007859, 2007.

Budyko, M.: The effect of solar radiation variations on the climate of the Earth, Tellus XXI, 5, 611-619, 1969.

Burgess, E., Forster, R., Box, J., Mosley-Thompson, E., Bromwich, D., Bales, R., and Smith, L.: A spatially calibrated model of annual accumulation rate on the Greenland Ice Sheet (19582007), Journal of Geophysical Research, 115, F02 004, doi:10.1029/2009JF001293, 2010.

Calov, R., Ganopolski, A., Kubatzki, C., and Claussen, M.: Mechanisms and time scales of glacial inception simulated with an Earth system model of intermediate complexity, Climate of the Past, 5, 245-258, 2009.

Carter, L., Carter, R., and McCave, I.: Evolution of the sedimentary system beneath the deep Pacific inflow off eastern New Zealand, Marine Geology, 205, 9-27, doi:10.1016/S0025-3227(04)00016-7, 2004. 
Cassano, J., Box, J., Bromwich, D., Li, L., and Steffen, K.: Evaluation of Polar MM5 simulations of Greenland's atmospheric circulation, Journal of Geophysical Research, 106, 33 867-33 890, doi:10.1029/2001JD900044, 2001.

Chapman, W. and Walsh, J.: A synthesis of Antarctic temperatures, Journal of Climate, 20, 609-632, 2007.

Charbit, S., Kageyama, M., Roche, D., Ritz, C., and Ramstein, G.: Investigating the mechanisms leading to the deglaciation of past continental northern hemisphere ice sheets with the CLIMBER-GREMLINS coupled model, Global and Planetary Change, 48, 253-273, doi:10.1016/j. gloplacha.2005.01.002, 2005.

Charbit, S., Paillard, D., and Ramstein, G.: Amount of $\mathrm{CO}_{2}$ emissions irreversibly leading to the total melting of Greenland, Geophysical Research Letters, 35, L12 503, doi:10.1029/2008GL033472., 2008.

Clark, P., Alley, R., and Pollard, D.: Northern hemisphere ice-sheet influences on global climate change, Science, 286, 1104-1111, doi:10.1126/ science.286.5442.1104, 1999.

Clark, P., Dyke, A., Shakun, J., Carlson, A., J.Clark, Wohlfarth, B., Mitrovica, J., Hostetler, S., and McCabe, A. M.: The Last Glacial Maximum, Science, 325,,710-714, doi:10.1126/science.1172873, 2009.

Collins, W., Rasch, P., Boville, B., Hack, J., McCaa, J., Williamson, D., Briegleb, B., Bitz, C., Lin, S., and Zhang, M.: The formulation and atmospheric simulation of the Community Atmosphere Model version 3 (CAM3), Journal of Climate, 19, 2144-2161, doi:10.1175/JCLI3760.1, 2006.

Copland, L., Mueller, D., and Weir, L.: Rapid loss of the Ayles Ice Shelf, Ellesmere Island, Canada, Geophysical Research Letters, p. L21501, doi: 0094-8276/07/2007GL031809, 2007. 
Crowley, T. and Hyde, W.: Transient nature of late Pleistocene climate variability, Nature, 456, 226-230, doi:10.1038/nature07365, 2008.

Cuffey, K. and Marshall, S.: Substantial contribution to sea-level rise during the last interglacial from the Greenland ice sheet, Nature, 404, 591594, doi:10.1038/35007053, 2000.

Daly, R.: Pleistocene Glaciation and the Coral Reef Problem, American Journal of Science, 30, 297-308, 1910.

de Vernal, A. and Hillaire-Marcel, C.: Natural variability of Greenland climate, vegetation, and ice volume during the past million years, Science, 320, 1622-1625, doi:10.1126/science.1153929, 2008.

DeConto, R.: Personal communication, 2010.

DeConto, R. and Pollard, D.: Rapid Cenozoic glaciation of Antarctica induced by declining atmospheric $\mathrm{CO}_{2}$, Nature, 421, 245-249, doi: 10.1038/nature01290, 2003.

DeConto, R., Pollard, D., Wilson, P., Pölike, H., Lear, C., and Pagani, M.: Thresholds for Cenozoic bipolar glaciation, Nature, 455, 652-656, doi: 10.1038/nature07337, 2008.

Denton, G. and Hughes, T.: Reconstructing the Antarctic Ice Sheet at the Last Glacial Maximum, Quaternary Science Reviews, 21, 193-202, doi: 10.1016/S0277-3791(01)00090-7, 2002.

Domack, E., Duran, D., Leventer, A., Ishman, S., Doane, S., McCallum, S., Amblas, D., Ring, J., Gilbert, R., and Prentice, M.: Stability of the Larsen B ice shelf on the Antarctic Peninsula during the Holocene epoch, Nature, 436, 681-685, doi:10.1038/nature03908, 2005.

Driesschaert, E., Fichefet, T., Goosse, H., Huybrechts, P., Janssens, I., Mouchet, A., Munhoven, G., Brovkin, V., and Weber, S. L.: Model- 
ing the influence of Greenland ice sheet melting on the Atlantic meridional overturning circulation during the next millennia, Geophysical Research Letters, 34, L10 707, doi:10.1029/2007GL029516, 2007.

Eby, M., Zickfeld, M., Montenegro, A., Archer, D., Meissner, K., and Weaver, A.: Lifetime of anthropogenic climate change: Millennial timescales of potential $\mathrm{CO}_{2}$ and surface temperature perturbations, Journal of Climate, 22, 2501-2511, doi:10.1175/2008JCLI2554.1, 2009.

Eldrett, J., Harding, I., Wilson, P., Butler, E., and Roberts, A.: Continental ice in Greenland during the Eocene and Oligocene, Nature, 446, 176179, doi:10.1038/nature05591, 2007.

Ettema, J., van den Broeke, M., van Meijgaard, E., van de Berg, W. J., Bamber, J., Box, J., and Bales, R.: Higher surface mass balance of the Greenland ice sheet revealed by high-resolution climate modeling, Geophysical Research Letters, 36, L12 501, doi:10.1029/2009GL038110, 2009.

Eyles, N.: Earth's glacial record and its tectonic setting, Earth-Science Reviews, 35, 1-248, 1993.

Fairchild, I. and Kennedy, M.: Neoproterozoic glaciation in the Earth System, Journal of the Geological Society, 164, 895-921, 2007.

Fanning, A. and Weaver, A.: An atmospheric energy-moisture balance model: climatology, interpentadal climate change, and coupling to an ocean general circulation model, Journal of Geophysical Research, 101, 15111-15128, 1996.

Fausto, R., Ahlstrøm, A., As, D. V., Bøggild, C., and Johnsen, S.: A new present-day temperature parameterization for Greenland, Journal of Glaciology, 55, 95-105, doi:10.3189/002214309788608985, 2009.

Fettweis, X., van Ypersele, J.-P., Gallée, H., Lefebre, F., and Lefebvre, W.: The 1979-2005 Greenland ice sheet melt extent from passive microwave 
data using an improved version of the melt retrieval XPGR algorithm, Geophysical Research Letters, 34, L05502, doi:10.1029/2006GL028787, 2007.

Fyke, J. and Weaver, A.: The effect of potential future climate change on the marine methane hydrate stability zone, Journal of Climate, 19, 59035917, doi:10.1175/JCLI3894.1, 2006.

Gillett, N., Stone, D., Stott, P., Nozawa, T., Karpechko, A., Hegerl, G., Wehner, M., and Jones, P.: Attribution of polar warming to human influence, Nature Geoscience, 1, 750-754, doi:10.1038/ngeo338, 2008.

Goelzer, H., Huybrechts, P., Loutre, M., Goosse, H., Fichefet, T., and Mouchet, A.: Impact of Greenland and Antarctic ice sheet interactions on climate sensitivity, Climate Dynamics, doi:10.1007/ s00382-010-0885-0, 2010.

Gregory, J. and Huybrechts, P.: Ice-sheet contributions to future sea-level change, Philosophical Transactions of the Royal Society, 364, 1709-1731, doi:10.1098/rsta.2006.1796, 2006.

Greve, R.: Application of a polythermal three-dimensional ice sheet model to the Greenland Ice Sheet: response to steady-state and transient climate scenarios, Journal of Climate, 10, 901-918, doi:10.1175/

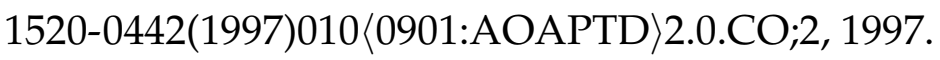

Greve, R., Saito, F., and Abe-Ouchi, A.: Initial results of the SeaRISE numerical experiments with the models SICOPOLIS and IcIES for the Greenland ice sheet, Annals of Glaciology, 52, 23-30, 2011.

Guo, Z., Bromwich, D., and Cassano, J.: Evaluation of Polar MM5 Simulations of Antarctic Atmospheric Circulation, Monthly Weather Review, 131, 384-411, 2003. 
Hattermann, T. and Levermann, A.: Response of Southern Ocean circulation to global warming may enhance basal ice shelf melting around Antarctica, Climate Dynamics, 35, 741-756, doi:10.1007/ s00382-009-0643-3, 2009.

Haug, G., Ganopolski, A., Sigman, D., Rosell-Mele, A., Swann, G., Tiedemann, R., Jaccard, S., Bollmann, J., Maslin, M., Leng, M., and Eglinton, G.: North Pacific seasonality and the glaciation of North America 2.7 million years ago, Nature, 433, 821-825, doi:10.1038/nature03332, 2005.

Hay, W., DeConto, R., and Wold, C.: Climate: Is the past the key to the future?, Geologiche Rundschau, 86, 471-491, 1997.

Hays, J., Imbrie, J., and Shackleton, N.: Variations in the Earth's orbit: pacemaker of the ice ages, Science, 194, 1121-1132, 1976.

Heimbach, P. and Bugnion, V.: Greenland ice-sheet volume sensitivity to basal, surface and initial conditions derived from an adjoint model, Annals of Glaciology, 50, 67-80, 2009.

Heinrich, H.: Origin and consequences of cyclic ice rafting in the Northeast Atlantic Ocean during the past 130,000 years, Quaternary Research, 2, 142-152, 1988.

Hoffman, P., Kaufman, A., Halverson, G., and Schrag, D.: A Neoproterozoic Snowball Earth, Science, 281, 1342-1346, doi:10.1126/science.281. 5381.1342, 1998.

Holland, D., Thomas, R., Young, B., Ribergaard, M., and Lybert, B.: Acceleration of Jakobshavn Isbrae triggered by warm subsurface ocean waters, Nature Geoscience, 1, 659-664, doi:10.1038/ngeo316, 2008a.

Holland, P., Jenkins, A., and Holland, D.: The nonlinear response of iceshelf basal melting to variation in ocean temperature, Journal of Climate, 1151, 2558-2572, doi:10.1175/2007JCLI1909.1, 2008b. 
Houghton, J., Ding, Y., Griggs, D., Noguer, M., der Linden, P. V., Dai, X., Maskell, K., and Johnson, C., eds.: Climate change 2001: the scientific basis. IPCC Third Assessment Report, Cambridge University Press, Cambridge, UK, 2001.

Hu, A., Meehl, G., Otto-Bliesner, B., Waelbroeck, C., Han, W., Loutre, M.F., Lambeck, K., Mitrovica, J., and Rosenbloom, N.: Influence of Bering Strait flow and North Atlantic circulation on glacial sea-level changes, Nature Geoscience, 3, 118-121, doi:10.1038/ngeo729, 2010.

Hughes, T.: Is the West Antarctic Ice Sheet disintegrating?, Journal of Geophysical Research, 78, 7884-7910, 1973.

Huybers, P.: Pleistocene glacial variability as a chaotic response to obliquity forcing, Climate of the Past, 5, 481-488, 2009.

Huybers, P. and Tziperman, E.: Integrated summer insolation forcing and 40,000-year glacial cycles: The perspective from an icesheet/energy-balance model, Paleoceanography, 23, PA1208, doi:10. 1029/2007PA001463, 2008.

Huybrechts, P.: The Antarctic ice sheet and environmental change: a threedimensional modelling study, Ph.D. thesis, Vrije Universiteit Brussel, 1992.

Huybrechts, P.: Sea-level changes at the LGM from ice-dynamic reconstructions of the Greenland and Antarctic ice sheets during the glacial cycles, Quaternary Science Reviews, 21, 203-231, doi:10.1016/ S0277-3791(01)00082-8, 2002.

Huybrechts, P. and de Wolde, J.: The dynamic response of the Greenland and Antarctic Ice Sheets to multiple-century climatic warming, Journal of Climate, 12, 2169-2188, doi:10.1175/1520-0442(1999)012〈2169: TDROTG $>2.0 . C O ; 2,1999$. 
Huybrechts, P. and Meur, E. L.: Predicted present-day evolution patterns of ice thickness and bedrock elevation over Greenland and Antarctica, Polar Research, 18, 299-306, 1999.

Hyde, W., Crowley, T., Baum, S., and Peltier, W.: Neoproterozoic 'snowball Earth' simulations with a coupled climate/ice-sheet model, Nature, 405, 425-429, doi:10.1038/35013005, 2000.

Indermühle, A., Monnin, E., Stauffer, B., Stocker, T., and Wahlen, M.: Atmospheric $\mathrm{CO} 2$ concentration from 60 to $20 \mathrm{kyr} \mathrm{BP}$ from the Taylor Dome Ice Core, Antarctica, Geophysical Research Letters, 27, 735-738, doi:10.1029/1999GL010960, 2002.

Jenkins, A., Dutrieux, P., Jacobs, S., McPhail, S., Perrett, J., Webb, A., and White, D.: Observations beneath Pine Island Glacier in West Antarctica and implications for its retreat, Nature, 3, 468-472, doi:10.1038/ngeo890, 2010.

Kageyama, M., Charbit, S., Ritz, C., and Khodri, M.: Quantifying ice-sheet feedbacks during the last glacial inception, Geophysical Research Letters, 31, L24 203, doi:10.1029/2004GL021339, 2004.

Kalnay, E., Kanamitsu, M., Kistler, R., Collins, W., Deaven, D., Gandin, L., Iredell, M., Saha, S., White, G., Woollen, J., Zhu, Y., Leetmaa, A., Reynolds, B., Chelliah, M., Ebisuzaki, W., Higgins, W., Janowiak, J., Mo, K., Ropelewski, C., Wang, J., Jenne, R., and Joseph, D.: The NCEP/NCAR 40-year reanalysis project, Bulletin of the American Meteorological Society, 77, 437-471, 1996.

Kasting, J.: Faint young Sun redux, Nature, 464, 687-688, doi:10.1038/ 464687a, 2010.

Kendall, R., Mitrovica, J., and Milne, G.: On post-glacial sea level II. Numerical formulation and comparative results on spherically sym- 
metric models, Geophysical Journal International, 161, 679-706, doi: 10.1111/j.1365-246X.2005.02553.x, 2005.

Kennett, J.: Cenozoic evolution of Antarctic glaciation, the circumAntarctic ocean, and their impact on global paleoceanography, Journal of Geophysical Research, 82, 3483-3860, doi:10.1029/JC082i027p03843, 1977.

Kennett, J. and Exon, N.: Paleoceanographic evolution of the Tasmanian seaway and its climatic implications, in: The Cenozoic Southern Ocean: Tectonics, Sedimentation and Climate Change Between Australia and Antarctica, Geophysical Monograph 151, edited by Exon, N., Kennett, J., and Malone, M., pp. 345-367, AGU, San Francisco, 2004.

Kiehl, J.: Overview of climate modelling, in: Frontiers of Climate Modelling, edited by Kiehl, J. and Ramanathan, V., Cambridge University Press, Cambridge, UK, 2006.

Konzlemann, T. and Braithwaite, R.: Variations of alblation, albedo and energy balance at the margin of the Greenland ice sheet, Kronpins Christian Land, eastern north Greenland, Journal of Glaciology, 41, 174-182, 1995.

Krinner, G., Magand, O., Simmonds, I., Genthon, C., and Dufresne, J.-L.: Simulated Antarctic precipitation and surface mass balance at the end of the twentieth and twenty-first centuries, Climate Dynamics, 46, 215230, doi:10.1007/s00382-006-0177-x, 2007.

Lagabrielle, Y., Goddéris, Y., Donnadieu, Y., Malavieille, J., and Suarez, M.: The tectonic history of Drake Passage and its possible impacts on global climate, Earth and Planetary Science Letters, 279, 197-211, doi: 10.1016/j.epsl.2008.12.037, 2009.

Lemke, P., Ren, J., Alley, R., Allison, I., J.Carrasco, Flato, G., Fujii, Y., Kaser, G., Mote, P., Thomas, R., and Zhang, T.: Observations: Changes in 
Snow, Ice and Frozen Ground, in: Climate Change 2007: the Physical Science Basis. Contribution of Working Group I to the Fourth Assessment Report of the Intergovernmental Panel on Climate Change, edited by Solomon, S., Qin, D., Manning, M., Chen, Z., Marquis, M., Avery, K., Tignor, M., and Miller, H., pp. 337-383, Cambridge University Press, Cambridge, United Kingdom, 2007.

Lenaerts, J., van den Broeke, M., Déry, S., Kø̈nig-Langlo, G., Ettema, J., and Munneke, P.: Modelling snowdrift sublimation on an Antarctic ice shelf, The Cryosphere, 4, 179-190, doi:10.5194/tc-4-179-2010, 2010.

Levine, R. and Bigg, G.: Sensitivity of the glacial ocean to Heinrich events from different iceberg sources, as modeled by a coupled atmosphere-iceberg-ocean model, Paleoceanography, 23, PA4213, doi: 10.1029/2008PA001613, 2008.

Lewis, J., Weaver, A., Johnston, S., and Eby, M.: Neoproterozoic "snowball Earth": Dynamic sea ice over a quiescent ocean, Paleoceanography, 18, 1092, doi:10.1029/2003P000926, 2003.

Lisiecki, L. and Raymo, M.: A Pliocene-Pleistocene stack of 57 globally distributed benthic $\mathrm{d}^{18} \mathrm{O}$ records, Paleoceanography, 20, PA1003, doi: 10.1029/2004PA001071, 2005.

Lunt, D., Foster, G., Haywood, A., and Stone, E.: Late Pliocene Greenland glaciation controlled by a decline in atmospheric $\mathrm{CO}_{2}$ levels, Nature, 454, 1102-1105, doi:10.1038/nature07223, 2008.

Lüthi, D., Floch, M. L., Bereiter, B., Blunier, T., Barnola, J.-M., Siegenthaler, U., Raynaud, D., Jouzel, J., Fischer, H., Kawamura, K., and Stocker, T.: High-resolution carbon dioxide concentration record 650,000800,000 years before present, Nature, 453, 379-382, doi:10.1038/nature06949, 2008. 
Lythe, M. and Vaughan, D.: A new ice thickness and subglacial topographic model of Antarctica, Journal of Geophysical Research, 106, 11335-11351, 2001.

MacAyeal, D.: Binge-purge oscillations of the Laurentide Ice Sheet as a cause of the North Atlantics Heinrich events, Paleoceanography, 8, 775784, 1993.

MacAyeal, D., Okal, E., Aster, R., Bassis, J., Brunt, K., Cathles, L., Drucker, R., Fricker, H., Kim, Y.-J., Martin, S., Okal, M., Sergienko, O., and Sponsler, M.: Transoceanic wave propagation links iceberg calving margins of Antarctica with storms in tropics and Northern Hemisphere, Geophysical Research Letters, 33, L17502, doi:10.1029/2006GL027235, 2006.

Manabe, S. and Broccoli, A.: The influence of continental ice sheets on the climate of an ice age, Journal of Geophysical Research, 90, 2167-2190, 1985.

Mandryk, C., Josenhans, H., Fedje, D., and Mathewes, R.: Late Quaternary paleoenvironments of Northwestern North America: implications for inland versus coastal migration routes, Quaternary Science Reviews, 20, 301-314, doi:10.1016/S0277-3791(00)00115-3, 2001.

Marland, G., Boden, T., and Andres, R.: Global, regional, and national $\mathrm{CO}_{2}$ emissions, in: Trends: A Compendium of Data on Global Change, Carbon Dioxide Information Analysis Center, Oak Ridge National Laboratory, U.S. Department of Energy, Oak Ridge, Tenn., U.S.A., 2008.

Marshall, S. and Clarke, G.: A continuum mixture model of ice stream thermomechanics in the Laurentide Ice Sheet 1. Theory, Journal of Geophysical Research, 102, 20599-20613, 1997.

Meehl, G., Stocker, T., Collins, W., Friedlingstein, P., Gaye, A., Gregory, J., Kitoh, A., Knutti, R., Murphy, J., Noda, A., Raper, S., Watterson, 
I., Weaver, A., and Zhao, Z.-C.: Global Climate Projections, in: Climate Change 2007: the Physical Science Basis. Contribution of Working Group I to the Fourth Assessment Report of the Intergovernmental Panel on Climate Change, pp. 747-845, Cambridge University Press, Cambridge, United Kingdom, 2007.

Meissner, K., Weaver, A., Matthews, H., and Cox, P.: The role of land surface dynamics in glacial inception: a study with the UVic Earth System Model, Climate Dynamics, 21, 515-537, doi:10.1007/s00382-003-0352-2, 2003.

Mercer, J.: West Antarctic ice sheet and $\mathrm{CO}_{2}$ greenhouse effect: the threat of disaster, Nature, 271, 321-325, doi:10.1038/271321a0, 1978.

Metcalf, M. and Reid, J.: FORTRAN 90/95 Explained, Oxford Univ. Press, Oxford, U. K, 1999.

Meure, C., Etheridge, D., Trudinger, C., Steele, P., Langenfelds, R., van Ommen, T., Smith, A., and Elkins, J.: Law Dome $\mathrm{CO}_{2}, \mathrm{CH}_{4}$ and $\mathrm{N}_{2} \mathrm{O}$ ice core records extended to 2000 years BP, Geophysical Research Letters, 33, L14 810, doi:10.1029/2006GL026152, 2006.

Mikolajewicz, U., Gröger, M., Maier-Reimer, E., Schurgers, G., Vizcaíno, M., and Winguth, A.: Long-term effects of anthropogenic $\mathrm{CO}_{2}$ emissions simulated with a complex earth system model, Climate Dynamics, 28, 599 633, doi:10.1007/s00382-006-0204-y, 2007a.

Mikolajewicz, U., Vizcaíno, M., Jungclaus, J., and Schurgers, G.: Effect of ice sheet interactions in anthropogenic climate change simulations, Geophysical Research Letters, 34, L18 706, doi:10.1029/2007GL031173, 2007b.

Molnia, B.: Glossary of glacier terminology - USGS Publications Repository, URL http://pubs.usgs.gov/of/2004/1216/text.html, 2007. 
Montenegro, A., Eby, M., Kaplan, J., Meissner, K., and Weaver, A.: Carbon storage on exposed continental shelves during the glacialinterglacial transition, Geophysical Research Letters, 33, L08703, doi: 10.1029/2005GL025480, 2006.

Montenegro, A., Brovkin, V., Eby, M., Archer, D., and Weaver, A.: Long term fate of anthropogenic carbon, Geophysical Research Letters, 34, L19707, doi:10.1029/2007GL030905, 2007.

Moran, K., Backman, J., Brinkhuis, H., Clemens, S., Cronin, T., Dickens, G., Eynaud, F., Gattacceca, J., Jakobsson, M., Jordan, R., Kaminski, M., King, J., Koc, N., Krylov, A., Martinez, N., Matthiessen, J., McInroy, D., Moore, T., Onodera, J., O'Regan, M., Pälike, H., Rea, B., Rio, D., Sakamoto, T., Smith, D., Stein, R., John, K. S., Suto, I., Suzuki, N., Takahashi, K., Watanabe, M., Yamamoto, M., Farrell, J., Frank, M., Kubik, P., Jokat, W., and Kristoffersen, Y.: The Cenozoic palaeoenvironment of the Arctic Ocean, Nature, 441, 601-605, doi:10.1038/nature04800, 2006.

Mosley-Thompson, E., Readinger, C., Craigmile, P., Thompson, L., and Calder, C.: Regional sensitivity of Greenland precipitation to NAO variability, Geophysical Research Letters, 32, L24707, doi:10.1029/ 2005GL024776, 2005.

Mueller, D., Vincent, W., and Jeffries, M.: Break-up of the largest Arctic ice shelf and associated loss of an epishelf lake, Geophysical Research Letters, 30, 2031, doi:10.1029/2003GL017931, 2003.

Naish, T., Powell, R., Levy, R., Wilson, G., Scherer, R., Talarico, F., Krissek, L., Niessen, F., Pompilio, M., Wilson, T., Carter, L., DeConto, R., Huybers, P., McKay, R., Pollard, D., Ross, J., Winter, D., Barrett, P., Browne, G., Cody, R., Cowan, E., Crampton, J., Dunbar, G., Dunbar, N., Florindo, F., Gebhardt, C., Graham, I., Hannah, M., Hansaraj, D., Harwood, D., Helling, D., Henrys, S., Hinnov, L., Kuhn, G., Kyle, P., Läufer, A., Maffioli, P., Magens, D., Mandernack, K., McIntosh, W., Millan, C., Morin, R., 
Ohneiser, C., Paulsen, T., Persico, D., Raine, I., Reed, J., Riesselman, C., Sagnotti, L., Schmitt, D., Sjunneskog, C., Strong, P., Taviani, M., Vogel, S., Wilch, T., and Williams, T.: Obliquity-paced Pliocene West Antarctic ice sheet oscillations, Nature, 458, 322-329, doi:10.1038/nature07867, 2009.

Nichols, K.: Predicted reduction in basal melt rates of an Antarctic ice shelf in a warmer climate, Nature, 388, 460-462, 1997.

NOAA: Data Announcement 88-MGG-02, Digital relief of the Surface of the Earth, in: Technical report, National Geophysical Data Centre, NOAA, U.S. Dept. of Commerce, Boulder, CO, 1988.

Nolin, A. and Payne, M.: Classification of glacier zones in western Greenland using albedo and surface roughness from the Multi-angle Imaging SpectroRadiometer (MISR), Remote Sensing of Environment, 107, 264275, doi:10.1016/j.rse.2006.11.004, 2007.

North, G., Cahalan, R., and Coakley, J.: Energy balance climate models, Reviews of Geophysics and Space Physics, 19, 91-121, 1981.

Oerlemans, J.: Some basic experiments with a vertically-integrated ice sheet model, Tellus, 33, 1-11, 1981.

Oerlemans, J.: A model of the Antarctic Ice Sheet, Nature, 297, 550-553, 1982.

Oerlemans, J.: The mass balance of the Greenland ice sheet: sensitivity to climate change as revealed by energy-balance modelling, The Holocene, 1, 40-49, doi:10.1177/095968369100100106, 1991.

Oerlemans, J.: Glaciers and climate change, Taylor and Francis, Oxford UK, 2001. 
Olbers, D. and Hellmer, H.: A box model of circulation and melting in ice shelf caverns, Ocean Dynamics, 60, 141-153, doi:10.1007/ s10236-009-0252-z, 2009.

Otieno, F. and Bromwich, D.: Contribution of atmospheric circulation to inception of the Laurentide Ice Sheet at $116 \mathrm{kyr}$ BP, Journal of Climate, 22, 39-57, doi:10.1175/2008JCLI2211.1, 2009.

Otto-Bliesner, B., Marshall, S., Overpeck, J., Miller, G., Hu, A., and CAPE Last Interglacial Project members: Simulating Arctic climate warmth and icefield retreat in the last interglaciation, Science, 311, 1751-1753, doi:10.1126/science.1120808, 2006.

Overpeck, J., Otto-Bliesner, B., Miller, G., Muhs, D., Alley, R., and Kiehl, J.: Paleoclimatic evidence for future ice-sheet instability and rapid sealevel rise, Science, 311, 1747-1750, doi:10.1126/science.1115159, 2006.

Pacanowski, R.: MOM 2 Documentation User's Guide and Reference Manual, GFDL Ocean Group Technical Report, NOAA/GFDL, Princeton, 1995.

Pagani, M., Zachos, J., Freeman, K., Tipple, B., and Bohaty, S.: Marked decline in atmospheric carbon dioxide concentrations during the Paleogene, Science, 309, 600-603, doi:10.1126/science.1110063, 2005.

Pagani, M., Liu, Z., LaRiviere, J., and Ravelo, A.: High Earth-system climate sensitivity determined from Pliocene carbon dioxide concentrations, Nature Geoscience, 3, 27-30, doi:10.1038/NGEO724, 2010.

Paterson, W.: The Physics of Glaciers, Pergamon, New York, New York, 1994.

Payne, A., Vieli, A., Shepherd, A., Wingham, D., and Rignot, E.: Recent dramatic thinning of largest West Antarctic ice stream triggered 
by oceans, Geophysical Research Letters, 31, L23 401, doi:10.1029/ 2004GL021284, 2004.

Peltier, W.: Global glacial isostasy and the surface of the ice-age Earth: the ICE-5G (VM2) Model and GRACE, Annual Reviews of Earth and Planetary Science, 32, 111-149, doi:10.1146/annurev.earth.32.082503.144359, 2004.

Peters, S., Carlson, A., Kelly, D., and Gingerich, P.: Large-scale glaciation and deglaciation of Antarctica during the Late Eocene, Geology, 38, 723726, doi:10.1130/G31068.1, 2010.

Petit, J., Jouzel, J., Raynaud, D., Barkov, N., Barnola, J.-M., Basile, I., Benders, M., Chappellaz, J., Davis, M., Delague, G., Delmotte, M., Kotlyakov, V., Legrand, M., Lipenkov, V., Lorius, C., Pépin, L., Ritz, C., Saltzman, E., and Stievenard, M.: Climate and atmospheric history of the past 420,000 years from the Vostok ice core, Antarctica, Nature, 399, 429-436, doi:10.1038/20859, 1999.

Pfeffer, W., Meier, M., and Illangasekar, T.: Retention of Greenland runoff by refreezing: implications for projected future sea level change, Journal of Geophysical Research, 96, 22 117-22 124, 1991.

Philippon, G., Ramstein, G., Charbit, S., Kageyama, M., Ritz, C., and Dumas, C.: Evolution of the Antarctic ice sheet throughout the last deglaciation: A study with a new coupled climate/north and south hemisphere ice sheet model, Earth and Planetary Science Letters, 30, 750-758, doi:10.1016/j.epsl.2006.06.017, 2006.

Pierrehumbert, R.: Climate dynamics of a hard snowball Earth, Journal of Geophysical Research, 110, D01 111, doi:10.1029/2004JD005162, 2005.

Pollard, D.: Comparisons of ice-sheet surface mass budgets from Paleoclimate Modeling Intercomparison Project (PMIP) simulations, Global and Planetary Change, 24, 79-106, doi:10.1016/S0921-8181(99)00071-5, 2000. 
Pollard, D.: A retrospective look at coupled ice sheet-climate modeling, Climatic Change, 100, 173-194, doi:10.1007/s10584-010-9830-9, 2010.

Pollard, D. and DeConto, R.: Antarctic ice and sediment flux in the Oligocene simulated by a climate-ice sheet-sediment model, Palaeogeography, Palaeoclimatology, Palaeoecology, 198, 53-67, doi:10.1016/ S0031-0182(03)00394-8, 2003.

Pollard, D. and DeConto, R.: Hysteresis in Cenozoic Antarctic icesheet variations, Global and Planetary Change, 45, 9-21, doi:10.1016/ j.gloplacha.2004.09.011, 2005.

Pollard, D. and DeConto, R.: A coupled ice-sheet/ice-shelf/sediment model applied to a marine-margin flowline: forced and unforced variations, in: Glacial Sedimentary Processes and Products, edited by Hambrey, M., Christoffersen, P., Glasser, N., and Hubbard, B., pp. 37-52, Wiley-Blackwell, New Jersey, 2007.

Pollard, D. and DeConto, R.: Modelling West Antarctic ice sheet growth and collapse through the past five million years, Nature, 458, 329-332, doi:10.1038/nature07809, 2009.

Pritchard, H., Arthern, R., Vaughan, D., and Edwards, L.: Extensive dynamic thinning on the margins of the Greenland and Antarctic ice sheets, Nature, 461, 971-975, doi:10.1038/nature08471, 2009.

Pritchard, M., Bush, A., and Marshall, S.: Neglecting ice-atmosphere interactions underestimates ice sheet melt in millennial-scale deglaciation simulations, Geophysical Research Letters, 35, L01503, doi:10.1029/ 2007GL031738, 2008a.

Pritchard, M., Bush, B., and Marshall, S.: Interannual atmospheric variability affects continental ice sheet simulations on millennial time scales, Journal of Climate, 21, 5976-5992, doi:10.1175/2008JCLI2327.1, 2008b. 
Randall, D. et al.: Climate Models and their Evaluation, in: Climate Change 2007: the Physical Science Basis. Contribution of Working Group I to the Fourth Assessment Report of the Intergovernmental Panel on Climate Change, edited by Solomon, S. et al., pp. 590-661, Cambridge University Press, Cambridge, United Kingdom, 2007.

Ridley, J., Huybrechts, P., Gregory, J., and Lowe, J.: Elimination of the Greenland Ice Sheet in a high $\mathrm{CO}_{2}$ climate, Journal of Climate, 18, 34093427, doi:10.1175/JCLI3482.1, 2005.

Ridley, J., Gregory, J., Huybrechts, P., and Lowe, J.: Thresholds for irreversible decline of the Greenland ice sheet, Climate Dynamics, 35, 10651073, doi:10.1007/s00382-009-0646-0, 2010.

Rignot, E., Bamber, J., van den Broeke, M., Davis, C., Li, Y., van de Berg, W., and van Meijgaard, E.: Recent Antarctic ice mass loss from radar interferometry and regional climate modelling, Nature Geoscience, 1, 106-110, doi:10.1038/ngeo102, 2008.

Rippeth, T., Scourse, J., Uehara, K., and McKeown, S.: Impact of sealevel rise over the last deglacial transition on the strength of the continental shelf CO2 pump, Geophysical Research Letters, 35, L24 604, doi: 10.1029/2008GL035880, 2008.

Ritz, C., Rommelaere, V., and Dumas, C.: Modeling the evolution of Antarctic ice sheet over the last 420,000 years: Implications for altitude changes in the Vostok region, Journal of Geophysical Research, 106, 31 943-31964, 2001.

Robinson, A., Calov, R., and Ganopolski, A.: An efficient regional energymoisture balance model for simulation of the Greenland ice sheet response to climate change, The Cryosphere Discussions, 3, 729-764, 2009.

Rogner, H.: An assessment of world hydrocarbon resources, Annual Review of Energy and the Environment, 22, 217-262, 1997. 
Rutt, I., Hagdorn, M., Hulton, N., and Payne, A.: The Glimmer community ice sheet model, Journal of Geophysical Research, 114, doi: 10.1029/2008JF001015, 2009.

Saenko, O., Weaver, A., Robitaille, D., and Flato, G.: Warming of the subpolar Atlantic triggered by freshwater discharge at the continental boundary, Geophysical Research Letters, 34, L15 604,, doi:10.1029/ 2007GL030674, 2007.

Scambos, T., Hulbe, C., Fahnestock, M., and Bohlander, J.: The link between climate warming and break-up of ice shelves in the Antarctic Peninsula, Journal of Glaciology, 46, 516-530, 2000.

Scambos, T., Hulbe, C., and Fahnestock, M.: Climate-induced ice shelf disintegration in the Antarctic Peninsula, Antarctic Research Series, 79, 79-92, 2003.

Scambos, T., Bohlander, J., Shuman, C., and Skvarca, P.: Glacier acceleration and thinning after ice shelf collapse in the Larsen B embayment, Antarctica, Geophysical Research Letters, 31, L18402, doi: 10.1029/2004GL020670, 2004.

Scambos, T., Fricker, H., Liu, C., Bohlander, J., Fastook, J., Sargent, A., Massom, R., and $\mathrm{Wu}, \mathrm{A}$. Ice shelf disintegration by plate bending and hydro-fracture: satellite observations and model results for the 2008 Wilkins ice shelf break-ups, Earth and Planetary Science Letters, pp. 5160, doi:10.1016/j.epsl.2008.12.027, 2009.

Scher, H. and Martin, E.: Timing and climatic consequences of the opening of Drake Passage, Science, 312, 428-430, doi:10.1126/science.1120044, 2006.

Schmittner, A., Meissner, K. J., Eby, M., and Weaver, A. J.: Forcing of the deep ocean circulation in simulations of the Last Glacial Maximum, Paleoceanography, 17, doi:10.1029/2001PA000633, 2002a. 
Schmittner, A., Yoshimori, M., and Weaver, A.: Instability of glacial climate in a model of the ocean-atmosphere-cryosphere system, Science, 295, 1489-1493, doi:10.1126/science.1066174, 2002b.

Schoof, C.: Ice sheet grounding line dynamics: Steady states, stability, and hysteresis, Journal of Geophysical Research, 112, F03S28, doi:10.1029/ 2006JF000664, 2007.

Scorer, R.: Sunny Greenland, Quarterly Journal of the Royal Meteorological Society, 14, 3-29, 1988.

Shepherd, A., Wingham, D., Payne, T., and Skvarca, P.: Larsen Ice Shelf has progressively thinned, Science, 302, 856-859, doi:10.1126/science. 1089768, 2003.

Sijp, W. and England, M.: Effect of the Drake Passage throughflow on global climate, Journal of Physical Oceanography, 34, 1254-1266, doi: 10.1175/1520-0485(2004)034〈1254:EOTDPT〉2.0.CO;2, 2004.

Sijp, W., England, M., and Toggweiler, J.: Effect of ocean gateway changes under greenhouse warmth, Journal of Climate, 22, 6639-6652, doi:10. 1175/2009JCLI3003.1, 2009.

Spence, J., Eby, M., and Weaver, A.: The sensitivity of the Atlantic meridional overturning circulation to freshwater forcing at eddypermitting resolutions, Journal of Climate, 21, 2697-2710, doi:10.1175/ 2007JCLI2103.1, 2008.

Stone, E. J., Lunt, D. J., Rutt, I. C., , and Hanna, E.: The effect of more realistic forcings and boundary conditions on the modelled geometry and sensitivity of the Greenland ice-sheet, The Cryosphere Discussions, 4, 233-285, 2010.

Tedesco, M.: Updated 2008 surface snowmelt trends in Antarctica, EOS, Transactions, 89, 126, 2008. 
Teller, J., Leverington, D., and Mann, J.: Freshwater outbursts to the oceans from glacial Lake Agassiz and their role in climate change during the last deglaciation, Quaternary Science Reviews, 21, 879-887, doi:10.1016/ S0277-3791(01)00145-7, 2002.

Thompson, S. and Pollard, D.: Ice-sheet mass balance at the Last Glacial Maximum from the GENESIS version 2 global climate model, Annals of Glaciology, 25, 250-258, 1997.

Toggweiler, J. and Samuels, B.: Effect of Drake Passage on the global thermohaline circulation, Deep-Sea Research I., 42, 477-500, 1995.

Trevena, J., Sijp, W., and England, M.: North Atlantic Deep Water collapse triggered by a Southern Ocean meltwater pulse in a glacial climate state, Geophysical Research Letters, 35, L09704, doi:10.1029/2008GL033236, 2008.

Tripati, A., Backman, J., Elderfield, H., and Ferretti, P.: Eocene bipolar glaciation associated with global carbon cycle changes, Nature, 436, 341-346, doi:10.1038/nature03874, 2005.

Tripati, A., Eagle, R., Morton, A., Dowdeswell, J., Atkinson, K., Bahé, Y., Dawber, C., Khadun, E., Shaw, R., Shorttle, O., and Thanabalasundaram, L.: Evidence for glaciation in the Northern Hemisphere back to $44 \mathrm{Ma}$ from ice-rafted debris in the Greenland Sea, Earth and Planetary Science Letters, 265, 112-122, doi:10.1016/j.epsl.2007.09.045, 2008.

Uppala, S., KÅllberg, P., Simmons, A., Andrae, U., Bechtold, V. D. C., Fiorino, M., Gibson, J., Haseler, J., Hernandez, A., Kelly, G., Li, X., Onogi, K., Saarinen, S., Sokka, N., Allan, R., Andersson, E., Arpe, K., Balmaseda, M., Beljaars, A., Berg, L. V. D., Bidlot, J., Bormann, N., Caires, S., Chevallier, F., Dethof, A., Dragosavac, M., Fisher, M., Fuentes, M., Hagemann, S., Holm, E., Hoskins, B., Isaksen, L., Janssen, P., Jenne, R., Mcnally, A., Mahfouf, J.-F., Morcrette, J.-J., Rayner, N., Saunders, R., Simon, P., Sterl, 
A., Trenberth, K., Untch, A., Vasiljevic, D., Viterbo, P., and Woollen, J.: The ERA-40 re-analysis, Quarterly Journal of the Royal Meteorological Society, 131, 2961-3012, doi:10.1256/qj.04.176, 2006.

van de Berg, W., van den Broeke, M., Reijmer, C., and van Meijgaard, E.: Reassessment of the Antarctic surface mass balance using calibrated output of a regional atmospheric climate model, Journal of Geophysical Research, 111, D11 104, doi:10.1029/2005JD006495, 2006.

van de Wal, R. and Oerlemans, J.: An energy balance model for the Greenland ice sheet, Global and Planetary Change, 9, 115-131, 1994.

van den Broeke, M.: Strong surface melting preceded collapse of Antarctic Peninsula ice shelf, Geophysical Research Letters, 32, doi:10.1029/ 2005GL023247, 2005.

van den Broeke, M., Bamber, J., Ettema, J., Rignot, E., Schrama, E., van de Berg, W., van Meijgaard, E., Velicogna, I., and Wouters, B.: Partitioning recent Greenland mass loss, Science, 326, 984-986, doi:10.1126/science. 1178176, 2009.

Vaughan, A.: Climate and geology - a Phanerozoic perspective, in: Deeptime perspectives on climate change: marrying the signal from computer models and biological proxies, edited by Williams, M., Haywood, A. M., and Gregory, J., pp. 5-59, The Geological Society, London, 2007.

Vaughan, D.: Recent trends in melting conditions on the Antarctic Peninsula and their implications for ice-sheet mass balance and sea level, Arctic, Antarctic, and Alpine Research, 38, 147-152, 2006.

Vaughan, D. and Doake, C.: Recent atmospheric warming and retreat of ice shelves on the Antarctic Peninsula, Nature, 379, 328-331, 1996.

Vizcaíno, M.: Long-term interactions between ice sheets and climate under anthropogenic greenhouse forcing: simulations with two complex 
Earth System Models, Ph.D. thesis, Max Planck Institute for Meteorology, 2006.

Vizcaíno, M., Mikolajewicz, U., Gröger, M., Maier-Reimer, E., Schurgers, G., and Winguth, A.: Long-term ice sheet/climate interactions under anthropogenic greenhouse forcing simulated with a complex Earth System Model, Climate Dynamics, 31, 665-690, doi:10.1007/s00382-008-0369-7, 2008.

Vizcaíno, M., Mikolajewicz, U., Jungclaus, J., and Schurgers, G.: Climate modification by future ice sheet changes and consequences for ice sheet mass balance, Climate Dynamics, 43, 301-324, doi:10.1007/ s00382-009-0591-y, 2010.

Weaver, A., Eby, M., Fanning, A., and Wiebe, E.: Simulated influence of carbon dioxide, orbital forcing and ice sheets on the climate of the last glacial maximum, Nature, 394, 847-853, doi:10.1038/29695, 1998.

Weaver, A., Eby, M., Weibe, E., Bitz, C., Duffy, P., Ewen, T., Fanning, A., Holland, M., MacFadyen, A., Matthews, H., Meissner, K., Saenko, O., Schmittner, A., Wang, H., and Yoshimori, M.: The UVic Earth System Climate Model: Model description, climatology and application to past, present and future climates, Atmosphere Ocean, 39, 361-428, 2001.

Weaver, A., Saenko, O., Clark, P., and Mitrovica, J.: Meltwater pulse 1A from Antarctica as a trigger of the Bølling-Allerød warm interval, Science, 299, 1709-1713, doi:10.1126/science.1081002, 2003.

Weaver, A., Zickfeld, K., Montenegro, A., and Eby, M.: Long term climate implications of 2050 emission reduction targets, Geophysical Research Letters, 34, L19703, doi:10.1029/2007GL031018, 2008.

Weertman, J.: Stability of the junction of an ice sheet and an ice shelf, Journal of Glaciology, 13, 3-11, 1974. 
Weertman, J.: Milankovitch solar radiation variations and ice age ice sheet sizes, Nature, 261, 17-20, 1976.

Wild, M., Calanca, P., Scherrer, S., and Ohmura, A.: Effects of polar ice sheets on global sea level in high-resolution greenhouse scenarios, Journal of Geophysical Research, 108, D54 165, doi:10.1029/2002JD002451, 2003.

Willerslev, E., Cappellini, E., Boomsma, W., Nielsen, R., Hebsgaard, M., Brand, T., Hofreiter, M., Bunce, M., Poinar, H., Dahl-Jensen, D., Johnsen, S., Steffensen, J., Bennike, O., Schwenninger, J.-L., Nathan, R., Armitage, S., de Hoog, C.-J., Alfimov, V., Christl, M., Beer, J., Muscheler, R., Barker, J., Sharp, M., Penkman, K., Haile, J., Taberlet, P., Gilbert, M., Casoli, A., Campani, E., and Collins, M.: Ancient biomolecules from deep ice cores reveal a forested southern Greenland, Science, 317, 111-114, doi: 10.1126/science.1141758, 2007.

Winguth, A., Mikolajewicz, U., Gröger, M., Maier-Reimer, E., Schurgers, G., and Vizcaíno, M.: Centennial-scale interactions between the carbon cycle and anthropogenic climate change using a dynamic Earth system model, Geophysical Research Letters, 32, L23 714, doi:10.1029/ 2005GL023681, 2005.

Yoshimori, M., Weaver, A., Marshall, S., and Clarke, G.: Glacial termination: sensitivity to orbital and $\mathrm{CO}_{2}$ forcing in a coupled climate system model, Climate Dynamics, 17, 571-588, doi:10.1007/s003820000134, 2001.

Zachos, J., Breza, J., and Wise, S.: Early Oligocene ice-sheet expansion on Antarctica: Stable isotope and sedimentological evidence from Kerguelen Plateau, southern Indian Ocean, Geology, 20, 569-573, 1992.

Zachos, J., Pagani, M., Sloan, L., Thomas, E., and Billups, K.: Trends, 
rhythms, and aberrations in global climate $65 \mathrm{Ma}$ to present, Science, 292, 686-693, doi:10.1126/science.1059412, 2001.

Zachos, J., Dickens, G., and Zeebe, R.: An early Cenozoic perspective on greenhouse warming and carbon-cycle dynamics, Nature, 451, 279-283, doi:10.1038/nature06588, 2008. 